Polytechnique University of Valencia, Doctoral School in Biotechnology

PhD Thesis

\title{
Human milk microbiota and its relationship with milk components in health and during lactational mastitis
}

Alba Boix Amorós

Directors: Dr. Alejandro Mira Obrador and Dr. Maria Carmen Collado

July 2019 


\section{Table of contents}

Original Publications 3

List of Abbreviations $\quad 4$

Summary 5

Resumen- Castellano $\quad 5$

$\begin{array}{lr}\text { Resum- Valencià } & 6\end{array}$

$\begin{array}{ll}\text { General Introduction } & 10\end{array}$

Aims of this Thesis 30

$\begin{array}{ll}\text { Chapter } 1 & 31\end{array}$

Relationship between Milk Microbiota, Bacterial Load, Macronutrients, and Human

Cells during Lactation 31

$\begin{array}{ll}\text { Chapter } 2 & 46\end{array}$

Multiple Approaches Detect the Presence of Fungi in Human Breast milk Samples from

Healthy Mothers 46

$\begin{array}{ll}\text { Chapter } 3 & 68\end{array}$

Mycobiome Profiles in Breast Milk from Healthy Women Depend on Mode of Delivery, Geographic Location and Interaction With Bacteria 68

$\begin{array}{ll}\text { Chapter } 4 & 88\end{array}$

Etiology of Sub-acute Lactational Mastitis as Inferred by Breast Milk Bacterial

Composition and Activity. $\quad 88$

$\begin{array}{ll}\text { General Discussion } & 108\end{array}$

$\begin{array}{ll}\text { Main conclusions } & 129\end{array}$

$\begin{array}{ll}\text { References } & 131\end{array}$

$\begin{array}{ll}\text { Annexes } & 151\end{array}$ 


\section{Original Publications}

This doctoral thesis is based on the following research articles (here included as the authors last version, with the permission from the publisher):

Alba Boix-Amorós, Maria Carmen Collado, Alex Mira. 2016. Relationship between Milk Microbiota, Bacterial Load, Macronutrients and Human Cells during Lactation. Frontiers in Microbiology, 7:492.

Alba Boix-Amorós, Cecilia Martinez-Costa, Amparo Querol, Maria Carmen Collado, Alex Mira. 2017. Multiple Approaches Detect the Presence of Fungi in Human Breastmilk Samples from Healthy Mothers. Scientific Reports, 7(1): 13016.

Link to the license: $\mathrm{http}: / /$ creativecommons.org/licenses/by/4.0/

Alba Boix-Amorós, Fernando Puente-Sánchez, Elloise du Toit, Kaisa Linderborg, Yumei Zhang, Baoru Yang, Seppo Salminen, Erika Isolauri, Javier Tamames, Alex Mira, Maria Carmen Collado. 2019. Mycobiome profiles in breast milk from healthy women depend on mode of delivery, geographic location and interactions with bacteria. Applied and Environmental Microbiology, 85(9).

Parts of the General Introduction section have been borrowed from the following review articles:

Daniel Munblit, Diego G. Peroni, Alba Boix-Amorós, Peter S. Hsu, Belinda Van't Land, Melvin C.L. Gay, Anastasia Kolotilina, Chrysanthi Skevaki, Robert J. Boyle, Maria Carmen Collado, Johan Garssen, Donna T. Geddes, Ralph Nanan, Carolyn Slupsky, Ganesa Wegienka, Anita L. Kozyrskyj, John O. Warner. 2017. Human Milk and Allergic Diseases: An Unsolved Puzzle. Nutrients, 9(8).

Majda Dzidic*, Alba Boix-Amorós*, Marta Selma-Royo*, Alex Mira, Maria Carmen Collado. 2018. Gut Microbiota and Mucosal Immunity in the Neonate. Medical Sciences, $17 ; 6(3)$.

${ }^{*}$ Equal contribution

Alba Boix-Amorós, Maria Carmen Collado, Belinda Van't Land, Anna Calvert, Kristy Le Doare, Johan Garssen, Heather Hanna, Ekaterina Khaleva, Diego G. Peroni, Donna T. Geddes, Anita L. Kozyrskyj, John O. Warner, Daniel Munblit. 2019. Reviewing the evidence on breast milk composition and immunological outcomes. Nutrition Reviews, 77(8):541-56. 


\section{List of Abbreviations}

Secretory immunoglobulin A - sIgA

Secretory immunoglobulin G - sIgG

Secretory immunoglobulin $\mathrm{M}$ - sIgM

Necrotizing enterocolitis - NEC

Human milk oligosaccharides - HMOs

Epidermal growth factor - EGF

Mucin 1 - MUC1

Polyunsaturated fatty acids - PUFA

Omega-3 docosahexaenoic acid - DHA

Omega-6 arachidonic acid - AA

Transforming growth factor beta - TGF- $\beta$

Epidermal growth factor - EGF

Insulin-like growth factor - IGF

Vascular endothelial growth factor - VEGF

Extracellular vesicles - EVs

Micro-RNAs - miRNAs

Soluble CD14 - sCD14

Denaturing gradient gel electrophoresis - DGGE

Temperature gradient gel electrophoresis - TGGE

Next generation sequencing - NGS

Quantitative polymerase chain reaction - qPCR

Coagulase negative staphylococci - CNS

Acute mastitis - AM

Sub-acute mastitis - SAM 


\section{Summary}

Background: Human milk is nature's ideal food for the nurture and protection of the new-born and growing infant. Recent evidence reported the presence of bacteria in human milk under normal, healthy conditions, which are thought to confer beneficial properties to the infant. However, little is known about the relationship between bacteria and milk macronutrients and human cells, and there is no optimal protocol to estimate bacterial numbers in the samples. Also, the potential presence of fungi in human milk has not been explored to date, despite the fact that fungi has been previously detected in dairy animal's milk and in the neonatal gut. In addition, the aetiology of sub-acute mastitis is not well understood, and information about the composition of the milk microbiota during this process by means of next-generation sequencing and its potential implications in the disease is scarce. This thesis is aimed to improve our understanding of human milk microbiota, its composition and diversity as well as the interactions with other milk components and microorganisms, in health and during sub-acute mastitis. We also explore the potential effect of environmental factors, such as mode of delivery and geographic location, and the lactation stage on human milk microbiota composition. Methods: Next-generation sequencing technologies targeting the bacterial 16S rRNA gene, and the fungal 28S rRNA gene and ITS1 genetic region, in combination with classic microbiological analyses, were used in order to assess the bacterial and fungal composition in milk of healthy mothers, and in mothers suffering sub-acute mastitis. Bacterial and fungal loads in human milk were obtained by qPCR methodology calibrated with flow cytometry.

Results: Bacterial composition in human milk has a high inter-individual variability, and also over time, and is predominantly comprised of bacteria from the Staphylococacceae family. A bacterial and fungal "core" were found in the human milk of Spanish donors. Some correlations were observed between bacteria with milk macronutrients and human somatic cells, indicating an active relationship between milk microbiota and the environment. Bacterial density appeared to be higher than previously estimated based on culture methods, at a mean of $10^{6} \mathrm{cells} / \mathrm{ml}$, and bacteria were found both in a freeliving state and associated to human cells. No correlations were observed between bacterial load with number of somatic cells nor bacterial richness and diversity, indicating that higher bacterial densities under healthy conditions do not trigger an immune response in the mammary gland, nor alter the microbial community. In addition, our results revealed the existence of certain diversity of fungi in human milk that was further confirmed by culture-dependent methods and microscopy. $89 \%$ of the Spanish samples analysed had detectable levels of fungal DNA, at a median load of approximately $10^{5}$ cells $/ \mathrm{ml}$. Malassezia, Candida and Saccharomyces prevailed in the samples, and fungi interacted with milk components in different ways. The presence of fungi in milk was further confirmed in samples from distant geographic origins, and it was observed that maternal and delivery factors can impact milk microbial communities. After describing milk microbiota in healthy conditions, we performed an 
observational, prospective case-control study, where DNA and RNA from human milk microbiota from healthy and sub-acute mastitis-suffering mothers were studied before and after the treatment. Bacterial loads increased during the disease, diversity decreased and alterations in bacterial composition likely reflected a dysbiotic process in the mammary gland. This supports that sub-acute mastitis is a microbial-driven disease. Future investigations should go beyond characterization of human milk microbiota composition and investigate functional mechanisms between human milk microorganisms and infant health, including immune and microbiota development. In addition, further research is needed in order to understand how to maintain a healthy status in the mammary gland. To this end, human milk biomolecules and cells should be investigated for their potential use as biomarkers of mammary dysbiosis, such as that occurring during sub-acute mastitis.

\section{Resumen- Castellano}

Antecedentes: La leche humana es el alimento natural ideal para el desarrollo y la protección del recién nacido y el niño en crecimiento. Estudios recientes han demostrado la presencia de bacterias en la leche humana en condiciones de salud, y se cree que podrían conferir propiedades beneficiosas para el bebé. Sin embargo, poco se sabe sobre la relación entre las bacterias y los macronutrientes de la leche y las células humanas, y no existe un protocolo óptimo para estimar el número de bacterias en las muestras. Además, hasta la fecha no se ha explorado la posible presencia de hongos en la leche humana, a pesar de que previamente éstos se han encontrado en la leche de otros animales y en el intestino neonatal. Por otro lado, la etiología de la mastitis sub-aguda no está bien descrita, y esfuerzos para describir la composición de la microbiota de la leche durante este proceso por medio de tecnologías de secuenciación próxima, y su potencial implicación en la enfermedad son escasos. Esta tesis está dirigida a mejorar nuestra comprensión de la microbiota de la leche humana, su composición y diversidad, así como las interacciones con otros componentes de la leche y microorganismos en condiciones de salud y durante la mastitis sub-aguda. También exploramos el efecto potencial de factores ambientales, como el tipo de parto y el origen geográfico, y el periodo de la lactancia en la composición de la microbiota de la leche humana.

Métodos: Se utilizaron tecnologías de secuenciación de próxima generación dirigidas al gen bacteriano $16 \mathrm{~S}$ rRNA y a los genes fúngicos 28S rRNA y la región ITS1, en combinación con análisis microbiológicos clásicos, para evaluar la composición bacteriana y fúngica en la leche de madres sanas, y de madres con mastitis sub-aguda. Las cargas bacterianas y fúngicas en la leche humana se obtuvieron mediante la metodología qPCR calibrada con citometría de flujo.

Resultados: La composición bacteriana en la leche humana tiene una alta variabilidad interindividual, y también a lo largo del tiempo, y está compuesta predominantemente por bacterias de la familia Staphylococacceae. Se encontró un "núcleo" de bacterias y 
hongos en la leche humana de donantes españolas. Se observaron algunas correlaciones entre bacterias con los macronutrientes de la leche y células somáticas humanas, lo que indica una relación activa entre la microbiota de la leche y el medio ambiente. La densidad bacteriana resultó ser más alta que lo estimado previamente según los métodos de cultivo, a una media de $10^{6}$ células $/ \mathrm{ml}$, presentes tanto en estado libre como asociadas a células humanas. No se observaron correlaciones entre carga bacteriana, el número de células somáticas, y la riqueza y diversidad bacteriana, lo que podría indicar que un aumento en la densidad bacteriana en condiciones de salud no activa una respuesta inmune en la glándula mamaria, ni altera la comunidad microbiana. Además, nuestros resultados de secuenciación revelaron la existencia de hongos en la leche humana que se confirmó mediante métodos de cultivo y microscopía. El 89\% de las muestras españolas analizadas tenían niveles detectables de ADN fúngico, con una carga aproximada de $10^{5}$ células/ml. Malassezia, Candida y Saccharomyces eran prevalentes en las muestras, y se observaron diferentes interacciones fúngicas con los componentes de la leche. La presencia de hongos en la leche se confirmó posteriormente en muestras de orígenes geográficos distantes, y se observó que factores maternos y tipo de parto pueden afectar a las comunidades microbianas de la leche. Después de describir la microbiota de la leche en condiciones de salud, realizamos un estudio observacional prospectivo de casos/controles, donde se estudió el ADN y el ARN de la microbiota de la leche de madres sanas y madres con mastitis sub-aguda, antes y después del tratamiento. La carga bacteriana aumentó durante la enfermedad, la diversidad disminuyó y las alteraciones en la composición bacteriana probablemente reflejen un proceso disbiótico en la glándula mamaria. Esto apoya que la mastitis sub-aguda es una enfermedad de origen microbiano. Investigaciones futuras deberían ir más allá de la caracterización de la composición de la microbiota de la leche humana e investigar mecanismos funcionales entre los microorganismos y la salud infantil, incluyendo el desarrollo inmunitario y la microbiota. Además, se necesitan más estudios para comprender cómo mantener el estado de salud en la glándula mamaria. Con este fin, las biomoléculas y células de la leche humana deberían investigarse por su posible uso como biomarcadores de la disbiosis mamaria, como el que ocurre durante la mastitis sub-aguda. 


\section{Resum- Valencià}

Antecedents: La llet humana és l'aliment natural ideal per al desenvolupament i la protecció del nadó i el nen en creixement. Estudis recents han demostrat la presència de bacteris a la llet humana en condicions normals de salut, i es creu que podrien conferir propietats beneficioses per al nadó. No obstant això, poc se sap sobre la relació entre els bacteris i els macronutrients de la llet i les cèl-lules humanes, i no hi ha un protocol òptim per estimar el nombre de bacteris en les aquestes mostres. A més, fins a la data no s'ha explorat la possible presència de fongs en la llet humana, tot i que prèviament s'havien trobat en la llet d'animals i en l'intestí neonatal. D'altra banda, l'etiologia de la mastitis sub-aguda no està ben descrita, i esforços per descriure la composició de la microbiota de la llet durant aquest procés per mitjà de tecnologies de seqüenciació propera, i la seua potencial implicació en la malaltia són escassos. Aquesta tesi està dirigida a millorar la nostra comprensió de la microbiota de la llet humana, la seva composició i diversitat, així com les interaccions amb altres components de la llet i microorganismes, en condicions de salut i durant la mastitis sub-aguda. També explorem l'efecte potencial de factors ambientals, com el tipus de part i l'origen geogràfic, i el període de la lactància en la composició de la microbiota de la llet humana.

Mètodes: Es van utilitzar tecnologies de seqüenciació de pròxima generació dirigides al gen bacterià 16S rRNA i als gens fúngics 28S rRNA i la regió ITS1, en combinació amb anàlisis microbiològiques clàssics, per avaluar la composició bacteriana i fúngica en la llet de mares sanes i de mares amb mastitis sub-aguda. Les quantitats bacterianes i fúngiques en la llet humana es van obtenir mitjançant la metodologia qPCR calibrada amb citometria de flux.

Resultats: La composició bacteriana en la llet humana té una alta variabilitat interindividual, i també al llarg del temps, i està composta predominantment per bacteris de la família Staphylococacceae. Es va trobar un "nucli" de bacteris i fongs a la llet humana de donants espanyoles. Es van observar algunes correlacions entre bacteris amb els macronutrients de la llet i cèllules somàtiques humanes, el que indica una relació activa entre la microbiota de la llet i el medi ambient. La densitat bacteriana va resultar ser més alta que l'estimat prèviament segons els mètodes de cultiu clàssics, a una mitjana de $10^{6}$ cèl·lules $/ \mathrm{ml}$, presents tant en estat lliure com associades a cèl·lules humanes. No es van observar correlacions entre càrrega bacteriana, el nombre de cèl-lules somàtiques, i la riquesa i diversitat bacteriana, la qual cosa podria indicar que un augment en la densitat bacteriana en condicions de salut no activa una resposta immune en la glàndula mamària, ni alteren la comunitat microbiana. A més, els nostres resultats de seqüenciació van revelar l'existència de certa diversitat de fongs a la llet humana que es va confirmar mitjançant mètodes de cultiu i microscòpia. El 89\% de les mostres espanyoles analitzades tenien nivells detectables d'ADN fúngic, amb una càrrega mitjana d'aproximadament $10^{5}$ cèl-lules/ml. Malassezia, Candida i Saccharomyces eren prevalents en les mostres, i es van observar interaccions fúngiques amb els components de la llet de diferents maneres. La presència de fongs a la llet es va confirmar posteriorment en mostres d'orígens 
geogràfics distants, i es va observar que els factors materns i de part poden afectar les comunitats microbianes de la llet. Després de descriure la microbiota de la llet en condicions de salut, vam realitzar un estudi observacional prospectiu de casos/controls, on es va estudiar l'ADN i l'ARN de la microbiota de la llet humana de mares sanes i mares amb mastitis sub-aguda, abans i després del tractament. La càrrega bacteriana va augmentar durant la malaltia, la diversitat va disminuir i les alteracions en la composició bacteriana probablement reflecteixin un procés disbiotic en la glàndula mamària. Això recolza que la mastitis sub-aguda és una malaltia d'origen microbià. Investigacions futures haurien d'anar més enllà de la caracterització de la composició de la microbiota de la llet humana i investigar mecanismes funcionals entre els microorganismes i la salut infantil, inclòs el desenvolupament immunitari i la microbiota. A més, es necessita més investigació per comprendre com mantenir un estat saludable en la glàndula mamària. Amb aquesta finalitat, les biomolècules i cèl-lules de la llet humana s'haurien d'investigar pel seu possible ús com a biomarcadors de la disbiosi mamària, com el que passa durant la mastitis sub-aguda. 


\section{General Introduction}


Milk is a complex and functional fluid, result of millions of years of evolution, which represents a unique mammalian adaptation for providing nutrients and protection to the offspring. In humans, milk (in the present thesis, referred to as breast milk or human milk, indistinctly) is the first source of nutrition to the new-born and supports infant nourishment during the initial months of life (Ballard \& Morrow 2013; Garwolińska et al. 2018). In fact, human milk is universally recognized as the "gold-standard" for infant nutrition. International organisms such as the World Health Organization and the American Academy of Paediatrics recommend exclusive breastfeeding for at least six months, followed by continued breastfeeding as complementary foods are introduced, for 1 year or longer (American Academy of Pediatrics 2012; World Health Organization \& UNICEF 2003). Besides nutrition, feeding the new-born and growing infant with human milk provides them with an extraordinary mixture of immunological and bioactive elements (Dzidic et al. 2018a; Goldman 1993; Labbok et al. 2004). These components support infant growth and offer protection against infections, are crucial for immune system development, metabolic and neuronal programming, and promote microbial colonization in the infant. In addition, breastfeeding further exerts unique benefits for both mother and infant, which go from biological to affective and psychosocial aspects.

In the past 15 years the health benefits of breastfeeding have been reinforced, and its practice has been extensively promoted. Despite it is widespread accepted that breastfeeding provides important health benefits to the infant, that continue into early childhood and potentially beyond, most countries fall short of the WHO recommendations (International Food Policy Research Institute 2015; Lutter \& Morrow 2013). Globally, only $40 \%$ of babies are exclusively breastfed for the first 6 months of age, and most preoccupying, breastfeeding practices are especially poor in countries with the highest child mortality rates. Among the developed countries, in 2005, around $40 \%$ of Spanish infants were exclusively breastfed at 3 months of age, and less than $20 \%$ at 6 months of age. UK and Mexico presented the lowest breastfeeding rates, while Hungary, Iceland or Sweden presented the highest rates (Greenslade 2018). Depriving infants from human milk (or in other words, feeding them with formula) is associated with higher incidence of infectious diseases, diabetes and obesity, sudden infant death syndrome, and in premature infants, higher risk of necrotizing enterocolitis (NEC) (Stuebe 2009). In the mother, failure to breastfeed is associated with an increased risk of suffering breast and ovarian cancer, obesity and cardiovascular diseases, among others.

\section{Human Milk and Infant Health: Reduced Mortality and Morbidity}

Human milk, through its dual function, nutritive and protective, supports an optimal growth and development of the new-born. While lipids, carbohydrates and proteins (mostly caseins) cover the nutritional needs of the growing infant, the countless variety of bioactive and immune compounds orchestrate to provide a unique defense against 
infections and other diseases, killing pathogens while also promoting intestinal barrier function development and balancing immune responses. The benefits associated to breastfeeding have been noted for centuries, and accumulating evidence supports both short-term and long-term effects on the new-born and child (American Academy of Pediatrics 2012; Boix-Amorós et al. 2019a; Newburg \& Walker 2007).

Primarily, breastfeeding is known to reduce infant death. In 1934, Grulee and colleagues showed that formula-fed infants presented higher morbidity and mortality rates when compared with breastfeeding, in a study comprising more than twenty thousand infants (Grulee et al. 1934). They also observed that exclusive breastfeeding offered the highest protection against death risk, and even partial breastfeeding provided considerable immunity. In developing countries where the majority of the world's childhood deaths occur, exclusive breastfeeding for 6 months and continued after 1 year is the most effective intervention to reduce mortality risk, having the potential of preventing more than 1 million infant deaths annually (Jones et al. 2003). Although breastfeeding benefits are more evident in low-income countries, epidemiological and biological findings over the last decade expand the benefits of breastfeeding for mothers and infants, whether they come from low- or medium-income countries (American Academy of Pediatrics 2012).

As a result of human milk's anti-pathogenic activity, the incidence of any infections is lower in breastfed infants than in formula fed infants. Exclusive breastfeeding reduces the risk and severity of lower respiratory tract infections, ear infections and urinary tract infections. If exclusive breastfeeding is prolonged for more than 6 months, the risk of pneumonia, serious colds, and ear and throat infections are considerably reduced (American Academy of Pediatrics 2012; Beaudry et al. 1995; Grulee et al. 1934). At the intestinal level, human milk promotes maturation of the gastrointestinal tract and reduces the risk of diarrhea and gastrointestinal diseases. It also influences the metabolic and neuroendocrine development, and appears to offer certain protection against obesity in childhood (American Academy of Pediatrics 2012; Coppa et al. 2006; Morrow et al. 2004; Scariati et al. 1997). Furthermore, human milk favors brain development, which has been linked to an increased intelligence quotient in infants that breastfeed (Isaacs et al. 2010; Kramer et al. 2008; Lucas et al. 1992). Other functions associated to breastfeeding include decreased risk of cardiovascular disease, diabetes type I and II, common autoimmune diseases such as celiac disease, and enhanced psychological wellbeing of the mother and infant (Akobeng et al. 2005; Das 2007; Rosenbauer et al. 2008; Singhal et al. 2001; Victora et al. 2016a). Breastfeeding has also been suggested to prevent asthma development, and to a lesser extent eczema and allergic rhinitis, while results on the protective effect against other allergies seem to be contradictory, and further studies are needed in order to establish a direct cause-effect link (Lodge et al. 2015; Munblit et al. 2017). 
Infant prematurity is associated with higher mortality and higher risk of developing gastrointestinal disorders. In an evolved adaptation to provide the premature infant an optimal protection, preterm milk alters its composition, showing increased levels of secretory immunoglobulin A (sIgA), that offers immunity against exogenous pathogens, increased growth factors that favor infants' development, higher polyamines that are associated with gut maturation, etc. (Dvorak et al. 2003; Gross et al. 1981; Plaza-Zamora et al. 2013). Breastfeeding has been suggested to be a critical factor in reducing the risk of NEC, which is most prevalent among preterm infants, especially those fed with artificial formula. In particular, epidermal growth factor (EGF), which is an important mediator of gut homeostasis, has been extensively investigated for its ability to reduce the severity in infants developing NEC. EGF has shown promoted repair of the intestinal epithelium after intravenous administration in infants presenting NEC-like symptoms, supporting its key role in the prevention and treatment of the disease (Shin et al. 2000; Sullivan et al. 2007). Animal model studies reinforce this protective effect, as administration of human milk, and administration of only EFG or transforming growth factor beta (TGF- $\beta$ ), can reduce both NEC incidence and severity (Dvorak et al. 2002; Halpern et al. 2003; Lucas \& Cole 1990; Shin et al. 2000). It appears to be consistent that the health benefits associated to breastfeeding are dependent of milk in a "dose" manner (exclusive breastfeeding versus partial breastfeeding or formula feeding), with exclusively breastfeeding showing the best health outcomes as compared to formula feeding. However, most studies concur that partial breastfeeding still provides considerable protection when compared to artificial formula (American Academy of Pediatrics 2012).

\section{Human Milk Composition}

Human milk contains all the required components to support infant growth, together with a myriad of bioactive and protective compounds that facilitate their adaptation to the extra-uterine environment. According to the lactation period, human milk can be classified in colostrum, which is produced in the mammary gland usually between 0-5 days post-partum, transitional milk, between 6-15 days post-partum, and mature milk, after 15 days post-partum. A dynamic and live fluid, breast milk adapts its composition to satisfy the rapidly growing infant's needs along lactation. Colostrum is produced in low volumes, and is rich in immunologic and developmental factors, with low content of fat as compared to mature milk, reflecting colostrum's protective role rather than nutritional. As milk matures, lactose, fat and soluble vitamins levels increase, in parallel with an increased milk volume production in order to support the development of the growing infant, while concentrations of most immune compounds decline (Coppa et al. 1993; Garwolińska et al. 2018; Goldman et al. 1982; Mitoulas et al. 2002). Not only breast milk changes its composition along lactation, but also varies daily, between feedings (the 
longer time elapsed between feedings, the lower the fat content), depending on maternal diet, maternal age, ethnicity, etc. (Garwolińska et al. 2018).

\section{Nutritional content of human milk}

During the initial period of an infant's life, the first and only food source able to satisfy all the nutritional requirements is human milk. Besides a high water content, human milk contains macronutrients, including fat, lactose, and proteins; and micronutrients, mostly vitamins and minerals, with energy estimates ranging from 65 to $70 \mathrm{kcal} / \mathrm{dL}$. Human milk components are summarized in Figure 1.

\section{Water}

Human milk is more than $80 \%$ water, with low concentration of solutes and neutral $\mathrm{pH}$. For this reason, water in milk is enough to cover the baby's needs during the first 6 months of life. In fact, giving water to an exclusive breastfed full-term baby within that period of life is contraindicated (World Health Organization 2017), as potential adverse effects in the infant have been suggested, such as reduced breastfeeding time.

\section{Lactose}

Lactose is synthesized in the mammary gland and represents the main carbohydrate of human milk, with concentrations ranging from 6.7 to $7.8 \mathrm{~g} / \mathrm{dL}$ in mature milk. Besides its nutritional role, lactose favours calcium absorbance and promotes the growth of lactic acid bacteria (Coppa et al. 1993; Venema 2012).

\section{Lipids}

Fat in human milk represents the most important energy source for the infant, contributing to $40-55 \%$ of the infant daily energy requirements, ranging from approximately 3.2 to $3.6 \mathrm{~g} / \mathrm{dL}$ in mature milk (Garwolińska et al. 2018). Fat is the most variable macronutrient of human milk, changing in concentration throughout the day, and even during the same feeding, with lowest concentrations in foremilk (the first milk of a feed) and highest in hind milk (the last milk of a feed). Lipids are secreted in milk in the form of milk fat globules. In its majority, milk lipids are composed of triacylglycerides, made up of a broad spectrum of fatty acids, with palmitic acid representing the most abundant saturated fatty acid, whereas oleic and linoleic acids are the most abundant unsaturated fatty acids.

\section{Proteins}

Human milk protein fraction is mainly constituted of casein (approximately 13\% of total proteins) present in the form of casein micelles, and whey proteins, being the most abundant $\alpha$-lactalbumin, lactoferrin, sIgA, serum albumin and lysozyme. Casein and $\alpha$ lactalbumin have important nutritional value, while other whey proteins exert important immune functions in the infant. Protein content is highest in colostrum as 
compared to transitional and mature milk, with total milk protein estimated to range between 0.8 to $1.6 \mathrm{~g} / \mathrm{dL}$ (Lönnerdal 2003).

\section{Micronutrients}

Micronutrients are only needed in minuscule amounts, but are essential for the body to produce enzymes, hormones and other key elements necessary for proper growth and development, and deficiencies can lead to severe health outcomes (Bates \& Prentice 1994; Valentine \& Wagner 2013). Human milk contains vitamins, including A, B1, B2, B6, B12, $\mathrm{C}, \mathrm{D}, \mathrm{E}, \mathrm{K}$ and iodine. Vitamins are essential for calcium absorption in the intestine, which is necessary for the infant's growth and bone mineralization. Minerals in milk, including calcium, sodium, potassium, magnesium, iron, copper, zinc, manganese, selenium and chromium, perform numerous functions in the body. Concentrations of some vitamins and minerals in milk depend on maternal diet, which is not always optimal, and therefore multi-vitamin intake during lactation is usually recommended (Greer 2001).

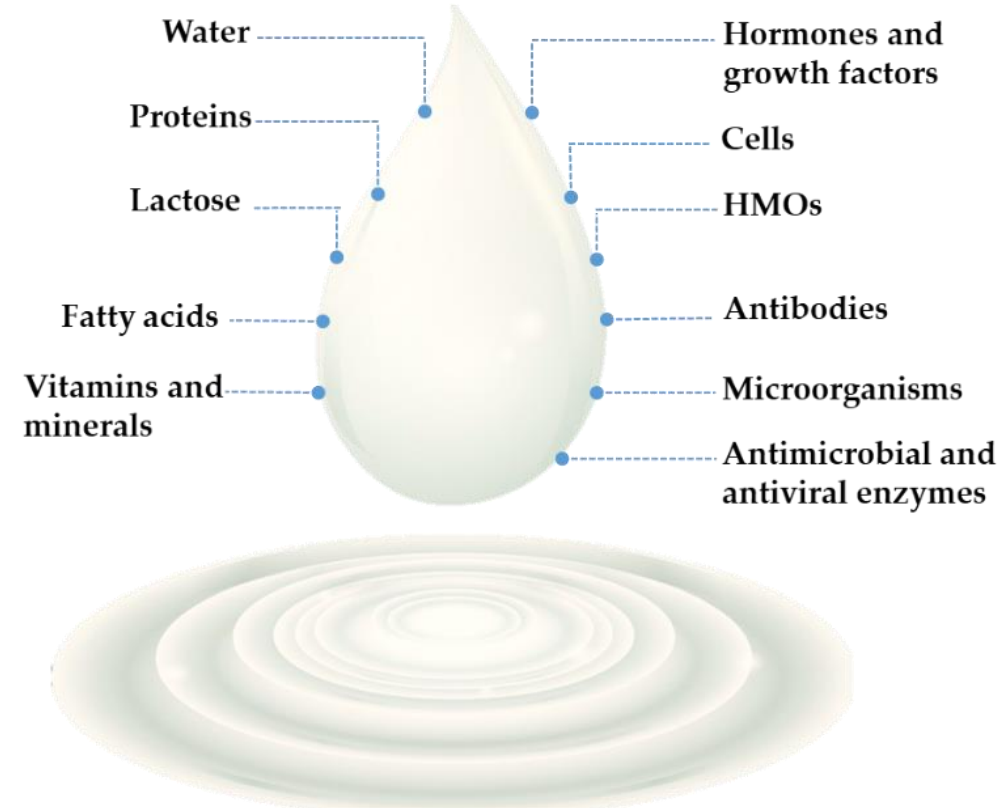

Figure 1. Principal nutrients and bioactive components of human milk.

\section{Bioactive molecules}

Beyond nutrition, human milk provides protection to the infant through transference of countless bioactive compounds (Figure 2). Dietary bioactive compounds are defined as "food components that can affect biological processes or substrates and hence have an impact on body function or condition and ultimately health"(Schrezenmeir et al. 2000). The bioactivity of human milk encompasses a wide variety of antimicrobial, anti-inflammatory, and immunomodulatory compounds (Boix-Amorós et al. 2019a; Dzidic et al. 2018a; Goldman 
1993; Labbok et al. 2004). After delivery, when the infant host defences are vulnerable, human milk protective factors passively confront infections, while also promote immunocompetence in the infant. In addition, breast milk contains prebiotic compounds, as well as its own microbiota, both supplying microorganisms and supporting microbial colonization in the infant gut.

\section{Antibodies}

Immunoglobulins are present in significant abundances in human milk. sIgA is the most predominant form, representing over $90 \%$ of total immunoglobulins, and to a lesser extent, sIgG and sIgM. sIgA levels are highest in colostrum (12 g/l), and gradually decrease to its lowest levels in mature milk (0.5 g/l) (Hanson 1961; Telemo \& Hanson 1996). During the first weeks of life, when the infant's immune system is still immature, protection against infections heavily relies on human milk antibodies. $\operatorname{sg} \mathrm{A}$ is the key anti-infective component in human milk, protecting mucosal sites by blocking pathogen adherence to epithelial cells and neutralizing toxins. sIgA transference to the infant's gut compensates the delayed innate sIgA production in the new-born, and its concentration declines in transition and mature milk as the immune system matures, when it is able to produce sIgA endogenous levels. When the maternal intestinal or respiratory mucosa are exposed to a pathogen, antigen-specific B lymphocytes migrate to the mammary gland, where they differentiate into plasma cells and produce large amounts of IgA (Fishaut et al. 1981; Kleinman \& Walker 1979). IgA attaches to the polymeric Ig receptor, after which the complex is cleaved and sIgA is secreted in milk and transferred to the baby through breastfeeding, resisting the acidity of gastric acids and reaching the infant's gut. Once there, sIgA provides a unique immunological protection towards pathogens, including bacteria, fungi, viruses, and parasites the maternal immune system has encountered during the perinatal period, and therefore, which are likely to be encountered by the infant (Van de Perre 2003).

HMOs

Human milk oligosaccharides (HMOs) are a family of diverse unconjugated glycans, which represent the third most abundant component in human milk, and approximately $20 \%$ of total carbohydrates. HMOs cannot be digested in the infant gut, which lacks specific glycosidases, sugar transporters and other proteins dedicated to HMO utilization. Nevertheless, HMOs play unique and essential functions for the correct development of the infant. HMOs are widely known for their prebiotic effect, encouraging the growth of beneficial bacteria in the lower part of the intestinal tract, such as Bifidobacterium and Bacteroides spp. (Bode 2012; Marcobal et al. 2010; Smilowitz et al. 2014). Thus, HMOs have been suggested to play a role in shaping the infant microbiome, and may be responsible for the differences observed in gut bacteria between breast-fed and formula-fed infants (Sela \& Mills 2010). Importantly, specific $\mathrm{HMO}$ can serve as homologous to gut cell receptors, blocking binding of pathogens to the intestinal epithelium, or directly inhibiting their growth (Coppa et al. 2006; Lin et al. 
2017). HMOs have also been suggested to participate in the modulation of immune cell responses, improve brain development and cognition associated to sialic acid, reduced risk for NEC and diarrhea, etc. (Doherty et al. 2018; Morrow et al. 2004). The structural complexity of HMOs makes it difficult to chemically synthesize them, although some efforts have been made to produce artificial alternatives with the purpose of adding them to formula milk (Akkerman et al. 2018).

\section{Antimicrobial proteins}

Lactoferrin, lysozyme, and $\alpha$-lactalbumin are, together with immunoglobulins, major whey proteins with immunity-enhancing properties. Lactoferrin exerts antimicrobial and immunomodulatory properties. It chelates free iron, a necessary nutritional requirement for most bacterial pathogens, inhibiting their growth; stimulates pathogen phagocytosis by macrophages; downregulates inflammatory cytokines production, stimulates leukocytes maturation and correlates with beneficial bacteria colonization in infants feces (Håversen et al. 2002; Lima \& Kierszenbaum 1985; Mastromarino et al. 2014; Weinberg 1994). In addition, pepsine digestion of lactoferrin in the stomach leads to lactoferricin, a peptide with potent broad activity against bacteria, fungi, and viruses (Fernandes \& Carter 2017; van der Strate et al. 2001). Lysozyme, although present in lower concentrations, can break peptidoglycan bonds of pathogenic Gram-positive bacteria cell walls, and can act synergistically with lactoferrin to kill Gram-negative bacteria (Ellison et al. 1991). $\alpha$-Lactalbumin is the major whey protein in human milk, and some of its proteolytic fragments have shown prebiotic properties in vitro by stimulating the growth of beneficial bifidobacteria (Lönnerdal 2010). Interestingly, $\alpha$ lactalbumin can conjugate with oleic acid present in milk and form "HAMLET", a cancer-killing molecule that has shown to be effective against different types of cancer without harming healthy cells (Ho et al. 2017). Other glycosylated proteins, such as Mucin-1 (MUC1) and $\kappa$-Casein, are present in the surface of fat globules and can also interfere with bacterial and viral adherence to the gut epithelium (Yolken et al. 1992).

\section{Bioactive lipids}

Besides the energetic properties of milk fat, some specific lipids play key functions for the growing infant. Polyunsaturated fatty acids (PUFA), such as omega-3 docosahexaenoic acid (DHA) and omega-6 arachidonic acid (AA), are essential for normal growth and development, being part of cell membranes, such as the brain and retina. Digestion of milk lipids by lipases in milk and infant lingual and gastric secretions, leads to free fatty acids and monoglycerides, which are known to be highly toxic to many human pathogens, especially enveloped viruses and some parasites (Hernell et al. 1986; Thormar et al. 1987).

\section{Human cells}

In addition to biochemical compounds, human milk contains live maternal cells, including epithelial and immune cells. Their concentrations highly vary along lactation 
stages, within mothers or in response to feeding, with estimated concentrations between $10^{4}$ and $10^{6}$ cells $/ \mathrm{ml}$. Epithelial cells predominate in human milk, and include lactocytes (responsible for milk secretion) and myoepithelial cells from the alveoli and ducts of the mammary gland. On the other hand, colostrum is rich in blood-derived leukocytes, which greatly vary between approximately $2-70 \%$ of total milk cells, and include macrophages, polymorphonuclear neutrophils and lymphocytes (mostly $\mathrm{T}$ cells, and in a lower extent, B cells) (Hassiotou et al. 2013a). However, leukocytes in healthy mature milk only account for $<2.5 \%$ of total cells (Hassiotou et al. 2013b). Milk leukocytes provide active immunity, protecting the infant against pathogenic infections directly via phagocytosis, while also stimulating the infant immune system's development through production of bioactive components, such as antimicrobial proteins and peptides, cytokines and immunoglobulins, and antigen presentation. Leukocyte levels in human milk increase in response to maternal and infant infections, reflecting a dynamic interaction and regulated response that confers an optimal protection (Bryan et al. 2007; Hassiotou et al. 2013b; Riskin et al. 2012). In cows, the somatic cells measurement in milk is routinely used as an indicator of udder infections (Olechnowicz \& Jaśkowski 2012). However, its potential utility for the detection of infections in the human mammary gland is not well described. Recent studies have reported that, in addition to epithelial and immune cells, human milk also contains stem and progenitor cells (Cregan et al. 2007; Hassiotou et al. 2012), which may be responsible for remodeling the breast to a milk-secretory organ during pregnancy and after delivery. However, little is known about stem cells functions, and although a potential role in the infant's tissue development has been suggested, whether they can exert these or other roles remains to be investigated.

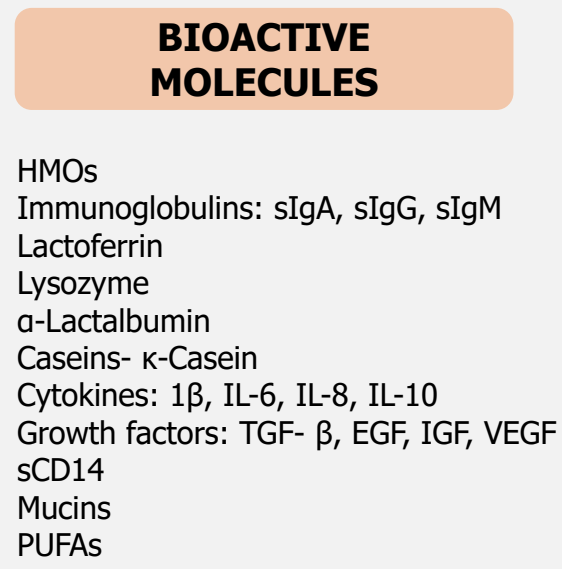

\section{CELLS}

Epithelial cells

- Lactocytes

- Myoepithelial cells

Leukocytes

- Macrophages (40\%-50\%)

- Polymorphonuclear neutrophils (40\%-50\%)

- Lymphocytes (5\%-10\%).

- T cells ( $80 \%$ of total lymphocytes).

Stem and progenitor cells

Figure 2. Bioactive components and cells in human milk 
The new-born's gut lacks the capacity to respond appropriately to foreign pathogens and the ability to produce a contained inflammatory response, tending to produce excessive inflammatory signalling. Growth factors and cytokines in breast milk exert wide-ranging effects on the infant's intestinal tract, and on the nervous, endocrine and vascular systems, and help control the inflammatory response (Ballard \& Morrow 2013; Garofalo 2010). For example, IL-10, a key immune-regulatory and anti-inflammatory cytokine, has been shown to inhibit blood lymphocyte proliferation, and is associated to a reduced risk and severity of Intestinal Bowel Disease and NEC. TGF- $\beta$ is the most abundant growth factor in human milk, and can reduce inflammation by decreasing proinflammatory cytokines while favours $\operatorname{IgA}$ production, thus enhancing mucosal immunity (Munblit et al. 2017). In addition, TGF- $\beta$ is necessary for induction of oral tolerance towards environmental antigens, and possibly prevents allergy development (Faria \& Weiner 2006). Other growth factors encountered in milk are: epidermal growth factor (EGF), key in the maturation and repair of the intestinal mucosa, while downregulates the production of pro-inflammatory cytokines; insulin-like growth factor (IGF) I and II, involved in tissue growth and erythropoiesis; vascular endothelial growth factor (VEGF), which regulates angiogenesis and the vascular system, etc. (Ballard \& Morrow 2013).

\section{Hormones}

Different hormones have been identified in human milk, which are receiving increased attention in the last years due to their potential influence on energy balance regulation and metabolic development in the infant. In particular, leptin, ghrelin, adiponectin and insulin, and their influence on food intake control and body weight regulation are being investigated (Chan et al. 2018; Savino \& Liguori 2008). Ghrelin and leptin regulate appetite, influencing growth and body weight. While ghrelin acts to increase appetite, ensures stomach acid preparedness for food intake and play a role as a reward molecule by interacting with dopaminergic neurons in the brain, leptin suppresses appetite and increases energy expenditure, and its production may be affected by maternal BMI (Dundar et al. 2005). Insulin regulates glucose metabolism (Savino \& Liguori 2008), and adiponectin improves insulin sensitivity and fatty acid metabolism, reduces inflammation and correlates negatively with liver fat content, glucose and body mass index (Newburg et al. 2010). Human milk has been linked to a reduced risk of obesity in childhood, but the underlying biological mechanisms remain unclear. Recent investigations point to human milk hormones as potential key elements in obesity prevention (Savino et al. 2013).

\section{Other milk components}

Among the vast diversity of human milk components, metabolites such as non-protein molecules containing nitrogen (free aminoacids, choline, creatine, nucleic acids, 
polyamines, urea, etc.) have important metabolic and physiological roles, participating in neurodevelopment, tissue development, sleep functions, immunity, etc. Extracellular vesicles (EVs) from human cells have been identified in human milk and may participate in cell communication and regulate immune responses (van Herwijnen et al. 2016; Zonneveld et al. 2014). Bacteria also secrete EVs, which can be involved in pathogenesis and regulation of immune responses, among others, and are likely to be present in milk (Schorey et al. 2015; Wang et al. 2018). Human milk is also rich in micro-RNAs (miRNAs), small noncoding RNAs that regulate gene expression at post-transcriptional levels and play an important role in regulating various biological processes through their interaction with cellular messenger RNAs (Weber et al. 2010). Human milk contains an appreciable amount of hydrogen peroxide $\left(\mathrm{H}_{2} \mathrm{O}_{2}\right)$ which has antimicrobial properties (Cieslak et al. 2018). In addition, soluble CD14 (sCD14), is a bacterial pattern recognition receptor actively secreted into human milk, involved in protection against pathogens and commensal tolerance (Vidal et al. 2001). Recently, a certain diversity of live bacteria and their genetic products have been detected in human milk from healthy mothers, which likely contribute to milk bioactive functions. Human milk microbiota will be extensively described in further sections.

\section{Breastfeeding, Infant Microbiota and Immune System Development}

Besides providing passive protection, breastfeeding stimulates the maturation of the infants' own mucosal immune system. Specific human milk components, such as cytokines, HMOs, anti-microbial enzymes and immunoglobulins are crucial for a correct immune maturation and balanced inflammation (Dzidic et al. 2018a; Newburg \& Walker 2007). Importantly, human milk plays a key role in shaping the infant's microbiota, the microbial communities inhabiting the human body. Human milk nurtures gut bacteria with HMOs, favoring their colonization. In 1983, a study showed that Bifidobacterium and Lactobacillus strains appeared highly increased in breastfed infants' feces over the first weeks of life, as compared to formula fed infants' (Yoshioka et al. 1983). Later studies identified HMOs as the principal milk factor responsible of this "bifidogenic effect" (Bode 2012; Marcobal et al. 2010). As a result of microbial fermentation in the distant gut, metabolites such as lactate and SCFA are produced. SCFA represent the main energy source for colonocytes and provide important immune protective functions. For example, acetate and butyrate regulate intestinal cell homeostasis and have potent effects on gene expression (Smith et al. 2013). Microbial colonization and establishment are key events for a correct gut maturation, and immune and metabolic systems development, including tolerance to commensal microorganisms (Dzidic et al. 2018a). The settlement of bacteria on the mucosal surfaces inhibits pathogen penetration in a process known as "colonization resistance", by which commensal bacteria compete with pathogens for nutrients and adhesion sites, and create a hostile environment for pathogen survival by producing specific metabolites and antimicrobial peptides, 
modifying the $\mathrm{pH}$, etc. (Lawley \& Walker 2013). Together with Bifidobacterium and Lactobacillus, other gut bacteria stimulated by breast milk, including Bacteroides and Clostridia, have been shown to improve intestinal barrier functions by enhancing mucine production and reducing intestinal permeability (Dzidic et al. 2018a). In addition, those bacteria stimulate $\mathrm{T}$ helper cells balance, prompting Th1 responses and compensating the inclination towards Th2 responses characteristic of the neonatal immature immune system, ultimately leading to mucosal barrier homeostasis and healthy immune system in early and adult life (Tourneur \& Chassin 2013). Milk secretory immunoglobulins, together with HMOs and other bioactive compounds, are also important factors that drive microbial colonization. In addition, recent studies revealed the presence of bacteria in human milk, which likely participates in the initial seeding of colonizers to the infant.

Neonatal microbial colonization is a fragile and step-wise process, and a disrupted microbiota development (for example, due to prematurity or the use of antibiotics) can lead to altered immunoglobulins production and tolerance, resulting in higher risk of developing autoimmune diseases, allergies or obesity (Dzidic et al. 2018a; Houghteling \& Walker 2015; Kamada et al. 2013). Mode of delivery is an important factor that can affect microbiota development, as that of vaginally-born infants resembles mother's vaginal and fecal microbiota, acquired through passing the birth canal. Infants born by C-section, on the other side, are first colonized with maternal skin and environmental bacteria, usually presenting lower bacterial diversity and altered microbial composition (Francino 2018). This dysbiosis is accompanied by lower levels of Th1-associated cytokines and immunoglobulins, which directly influence the immune system and may be, in part, responsible for the increased risk of immune-related diseases in children born by C-section, including asthma and atopic and allergic disorders (Dzidic et al. 2018a). Thus, the immature infant gut may be hyper-responsive to specific stimuli that could result in mucosal damage, but human milk has a cornucopia of factors that can modulate inflammatory responses and, together with an appropriate microbial colonization, favor the shift from hyper-stimulation towards tolerance, which reduces the risk of developing diseases later in life.

\section{Microorganisms in Human Milk}

Historically, human milk was considered a sterile fluid. Although, for over five decades, there have existed reports about the presence of live bacteria in human milk, it was attributed to milk contamination during and/or after expression, mammary gland infections or even to poor hygiene (Carroll et al. 1979; Eidelman \& Szilagyi 1979; Thomsen et al. 1983; West et al. 1979; Wyatt \& Mata 1969). Later, the isolation of bacteria from healthy mothers' milk by classic culture methods, including several lactic acid bacteria such as Lactobacillus, Lactococcus, Leuconostoc, Bifidobacterium, and many others, changed the perspective of human milk's sterility (Heikkila \& Saris 2003; Martín et al. $2003,2009)$. The presence of lactic acid bacteria with potential beneficial or "probiotic" 
properties raised the interest on human milk. Motivated by that interest, over the last decade there has been a rapid bloom of studies based on culture-independent, DNAbased techniques that have investigated milk-residing bacteria, their potential origins, and implications in maternal and infant health. These studies encompassed different methodologies, including qPCR that identified specific or total bacteria (Collado et al. 2009; Khodayar-Pardo et al. 2014), analysis of bacterial genetic patterns (DGGE and TGGE) (Delgado et al. 2008; Martín et al. 2007; Perez et al. 2007), and most importantly, the rise of the most powerful tool for the study of complex microbial communities: Nextgeneration sequencing (NGS) of the microbial DNA. Hunt and colleagues (Hunt et al. 2011) were the first to apply 454-pyrosequencing (Roche) to sequence the universal bacterial 16S ribosomal RNA gene, which exhibited the complete bacterial diversity of human milk. Several other studies followed Hunt's work, and as sequencing techniques evolved (with a progressive switch from 454-pyrosequencing to other platforms, such as Illumina MiSeq), more light was shed to human milk microbiota knowledge, including the study of the human milk metagenome, which put forth milk's total microbial composition (bacteria, fungi, virus and archaea) and showed microbial genetic functions (Ward et al. 2013). NGS and culture-independent methodologies revealed a higher diversity of microorganisms, previously overlooked by culture techniques. These included from typical oral inhabitants, such as Veillonella and Prevotella; to skin bacteria such as Staphylococcus and Propionibacterium; other lactic acid bacteria, including Enterococcus, Streptococcus, Leuconostoc, and Weissella; and Gram other negative bacteria, such as Pseudomonas (Cabrera-Rubio et al. 2012a; Fernández et al. 2013; Hunt et al. 2011; Jost et al. 2013). Altogether, these findings led to a shift in the milk "sterility" paradigm, showing that bacteria were normally present in the fluid under healthy conditions, and questions about the origin of milk bacteria started to arise.

\section{Potential sources of bacteria in human milk}

The detection of live bacteria and bacterial DNA from aseptically collected milk samples, including anaerobic endogenous gut bacterium that cannot survive aerobic conditions, triggered a debate about the origin of human milk bacteria. The principal potential routes and bacteria present in human milk are summarized in Figure 3.

\section{Maternal skin and infant oral cavity}

Initially, maternal skin was considered the main source of microorganisms to human milk, as some common skin-inhabitants, such as Staphylococcus, Corynebacterium and Propionibacterium, could be frequently isolated from the fluid (Eidelman \& Szilagyi 1979; Grice et al. 2009; West et al. 1979). Microbes residing on the breast skin, especially the nipple, areola and Montgomery glands, would likely seed some microorganisms to the milk during breastfeeding. In fact, Ramsay et al (Ramsay et al. 2004) demonstrated by ultrasound imaging that a substantial retrograde flow occurs during milk suckling, being this back-flow a plausible route for infant oral bacteria and maternal skin to enter 
the mammary ducts, and backwards. In addition, Streptococcus and other typical oral bacteria such as Prevotella and Veillonela can be commonly detected in colostrum and human milk. These bacteria are present in the infant oral cavity since very early life, suggesting that human milk could participate in shaping the infant's oral microbiome, and/or vice versa (Cephas et al. 2011; Dzidic et al. 2018b). Despite the fact that some bacteria are shared between human milk and the infant oral cavity and maternal skin, major differences in composition and relative abundances exist (Cabrera-Rubio et al. 2012a; Gueimonde et al. 2007; Hunt et al. 2011). Moreover, milk hosts some strict anaerobes, such as Bifidobacterium, Bacteroides, Faecalibacterium and Roseburia, whose presence in the fluid cannot be solely explained by a "contamination" from the infant mouth or breast skin (Gueimonde et al. 2007; Jost et al. 2013).

\section{Mammary epithelium}

The presence of bacterial DNA and live bacteria in milk before delivery (precolostrum) also supports the idea that human milk microbiota is not a mere contamination from the skin and oral cavity (Martín et al. 2004; Ruiz et al. 2019). In fact, bacterial DNA has been detected in the breast tissue of non-lactating mothers (Urbaniak et al. 2014, 2016b; Xuan et al. 2014), supporting microbial presence in the mammary gland even in the absence of pregnancy and lactation, which could be transferred to milk during lactation.

\section{Maternal gastrointestinal tract}

A theory that could explain the presence of strict anaerobes in breast milk was proposed, the so-called "entero-mammary pathway", which suggests that selective translocation of maternal gut bacteria to the mammary gland within immune cells would occur (Fernández et al. 2013). In particular, dendritic cells can project dendrites across the gut epithelium and sample specific gut lumen bacteria, and even retain them alive in the mesenteric lymph nodes for several days (Macpherson \& Uhr 2004). In addition, phagocytes have shown ability to disseminate intestinal bacteria to other organs (Vazquez-Torres et al. 1999). The hormonal changes produced in late pregnancy, labor and lactation could facilitate bacterial translocation. Lactogenic hormones regulate immune responses and trigger migration of immune cells from the gut- and respiratoryassociated lymphoid tissue to the mammary gland via the lymphatic system and blood circulation (Jeurink et al. 2013; Rodriguez 2014). Therefore, translocation of bacteria associated to these cells is likely to occur. In a study by Perez et al, bacterial translocation from the maternal gut to mesenteric lymph nodes and mammary gland was confirmed in a mice model during pregnancy and lactation (Perez et al. 2007). In the same study, it was shown that human milk and peripheral blood mononuclear cells contained a number of viable bacteria and bacterial DNA. Experiments in woman fed with probiotic Lactobacilli strains, also support this route, as the same ingested strains could be later detected in mother's milk (Arroyo et al. 2010; Jiménez et al. 2008). Furthermore, in a recent study, two labelled lactic acid bacteria fed to pregnant mice could be detected in the mammary tissue and milk (de Andrés et al. 2017). The entero-mammary route of 
transmission has recently been expanded to consider transfer of bacteria from other human mucosal sites like the oral cavity, facilitated by different physiological changes in the pregnant mother that would allow this microbial translocation (Mira \& Rodriguez 2016).

\section{Other potential sources of bacteria}

The intra-utero sterility dogma has been challenged. The isolation of some bacteria and/or the detection of their DNA have been reported in samples from meconium and umbilical cord (Gosalbes et al. 2013; Jiménez et al. 2005; Moles et al. 2013). Bacterial DNA has also been detected in placenta and amniotic fluid, and intrauterine infections and the presence of certain oral bacteria intra-utero have been associated to preterm deliveries (Aagaard et al. 2014; Bearfield et al. 2002). However, results are contradictory, and although some evidence suggest that bacteria or their genetic products could enter the intra-uterine environment, further research is needed to confirm microbial exposure to the fetus and its potential later effect on the infant (Lauder et al. 2016; Lim et al. 2018).

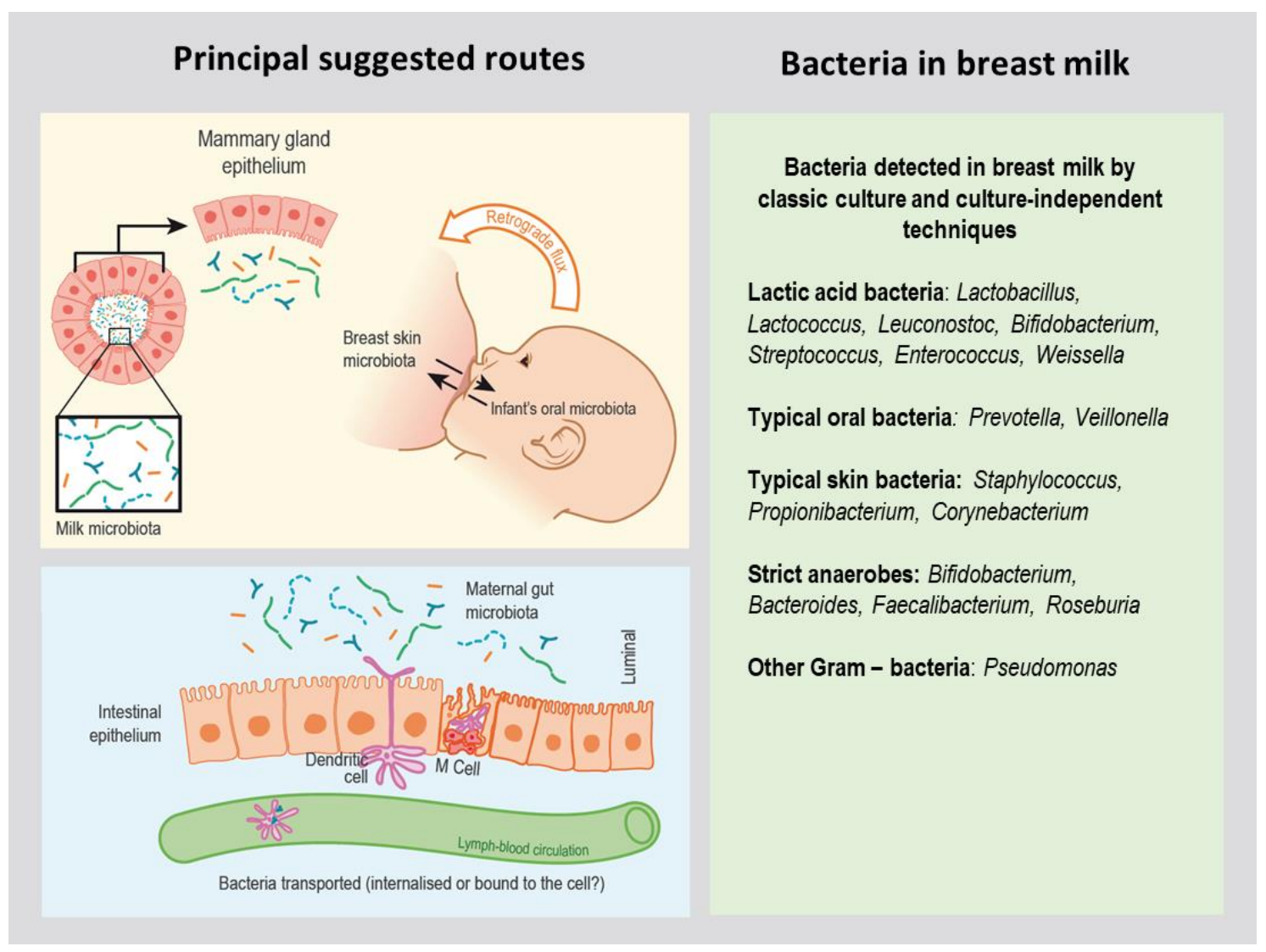

Figure 3. Potential routes for bacterial translocation to human milk, and bacteria isolated and detected in the fluid. Most likely routes of bacterial transmission to the mammary gland and milk include: breast skin microbiota, infant's oral microbiota, maternal gut microbiota and mammary gland epithelium microorganisms. The figure also shows the most commonly detected bacteria in human milk, as inferred by means of classic culture-dependent and cultureindependent techniques. Image adapted from Jeurink et al. 2013. 


\section{Plausible implications of human milk microbiota for infant health}

Independent from the source, bacteria encountered in human milk are transferred to the infant during breastfeeding, and its relevance may lay in the potential implications on maternal and infant health. Information about the potential human roles of milk bacteria is scarce, but it has been speculated that they may play several important functions in the infant (Figure 4).

\section{Vertical transmission and seeding of microbial colonizers}

As mentioned in previous sections, the initial colonization process has an important stimulating effect on the maturing intestine and immune system. A limited number of studies have shown specific shared bacteria or bacterial DNA between human milk with infant feces and oral samples (Martín et al. 2003, 2012); maternal feces, human milk and infant feces (Jost et al. 2014; Milani et al. 2015; Perez et al. 2007), and even with mother's PBMCs (Perez et al. 2007). In the study by Milani et al, two Bifidobacterium strains shared by mother and infant persisted in the infant's gut at 6 months of age. These results support a vertical transmission of human milk bacteria to the infant gut, which likely enhance development and maintenance of tolerance to commensal microbiota and intestinal host defense to pathogens. The seeding of bacteria to the baby has been shown to occur beyond the gut, as a recent study demonstrated that exactly the same bacterial strains could be isolated from precolostrum (before delivery) and from the infant oral cavity several weeks after birth (Ruiz et al. 2019).

\section{Metabolic activity}

Human milk bacteria facilitate digestive processes, for example, by fermenting HMOs, indigestible by the infant intestine (Fernández et al. 2013). Molecular analysis reported that these bacteria are metabolically active in increasing the production of functional metabolites such as butyrate. Butyrate can play several functions in the intestine, and its high presence in fecal samples may explain the increased fecal moisture, volume and stool frequency in breastfed infants (Lara-Villoslada et al. 2007).

\section{Anti-pathogenic activity}

Breast milk lactic acid bacteria protect the gut environment through different mechanisms, such as the production of anti-microbial peptides, organic acids and lowering of $\mathrm{pH}$ to inhibit the growth of opportunistic and pathogenic bacteria (Dzidic et al. 2018a). In vitro studies showed that several bacteria isolated from human milk, including lactic acid bacteria and commensal staphylococci and oral streptococci, inhibited Staphylococcus aureus growth (Heikkila \& Saris 2003). S. aureus is responsible of several human infections, including lactational mastitis (Delgado et al. 2011) and, several clinical trials have shown that the use of milk-isolated bacteria as probiotics can be effective against acute mastitis (Jiménez et al. 2008; Vázquez-Fresno et al. 2014). 
Lactococcus lactis strains isolated from human milk were shown to produce nisins, potent bacteriocins (Beasley \& Saris 2004). In addition, Olivares et al. showed that different strains of Lactobacillus isolated from human milk exerted in vitro bacteriostatic and/or bactericidal effects on an enteropathogenic Salmonella enterica strain, and also in a mice model infected with the pathogen. In particular, L. salivarius CECT5713 inhibited $S$. enterica binding to mucins (a pre-requisite of many pathogenic bacteria to infect gut epithelial cells) (Olivares et al. 2006). In another study, probiotic L. fermentum CECT5716 significantly reduced the incidence of gastrointestinal and respiratory infections in infants (Maldonado et al. 2012). Interestingly, several human milk lactic acid strains have shown potential to inhibit the infectivity of HIV by interacting with different coreceptors (Martín et al. 2010).

\section{Immuno-modulatory effect}

L. fermentum CECT5716 and L. salivarius CECT5713 milk isolates were able to modulate immune responses in vitro by activating NK cells, total T cells, CD4+ T cells, CD8+ T cells and regulatory $\mathrm{T}$ cells, and inducing the production of a broad array of cytokines and IgA. This effect was not seen in Lactobacillus strains of non-milk origin (Díaz-Ropero et al. 2007; Pérez-Cano et al. 2010). In addition, a metagenomic analysis of human milk revealed immunomodulatory DNA motifs which may help decrease exaggerated inflammatory responses to colonizing bacteria (Ward et al. 2013). It has been speculated that infant exposure to milk bacteria could be protective against allergic and immuneassociated diseases. Children exposed to unpasteurized cow's milk, source of live microorganisms, have lower incidence of allergic diseases, and thus, bacterial communities of human milk could be acting as a natural probiotic, which requires further elucidation (Braun-Fahrländer \& Von Mutius 2011). Animal studies have reported that animals devoid of normal host-microbe interactions early in life are more prone to developing allergic immune responses. This is in accordance with the "hygiene hypothesis", which states that a lack of early infancy exposure to pathogens and symbiotic microorganisms leads to a defective tolerance development, and ultimately to a higher risk of developing allergic and immune diseases (Okada et al. 2010). Differences exist between atopic and healthy infant's fecal bacteria, with the first showing lower levels of gram positive bacteria, including viridans Streptococcus and Staphylococcus, both dominant bacterial groups in human milk that can stimulate Th1 responses (Kirjavainen et al. 2001; Munblit et al. 2017).

Altogether, evidence suggests that the ingestion of such a wealth of bacteria and their genetic materials through breastfeeding likely play relevant roles in the infants' development. Human milk bacteria can colonize the infant and likely instruct the immune system to recognize specific bacterial molecular patterns and properly respond to pathogens and commensal organisms. Probably for this reason, breastfeeding duration was found to be the factor which had the largest impact on oral microbiota 
development, influencing bacterial composition years after breastfeeding had ended in a cohort of 90 Swedish children followed from birth to 7 years of age (Dzidic et al. 2018b).

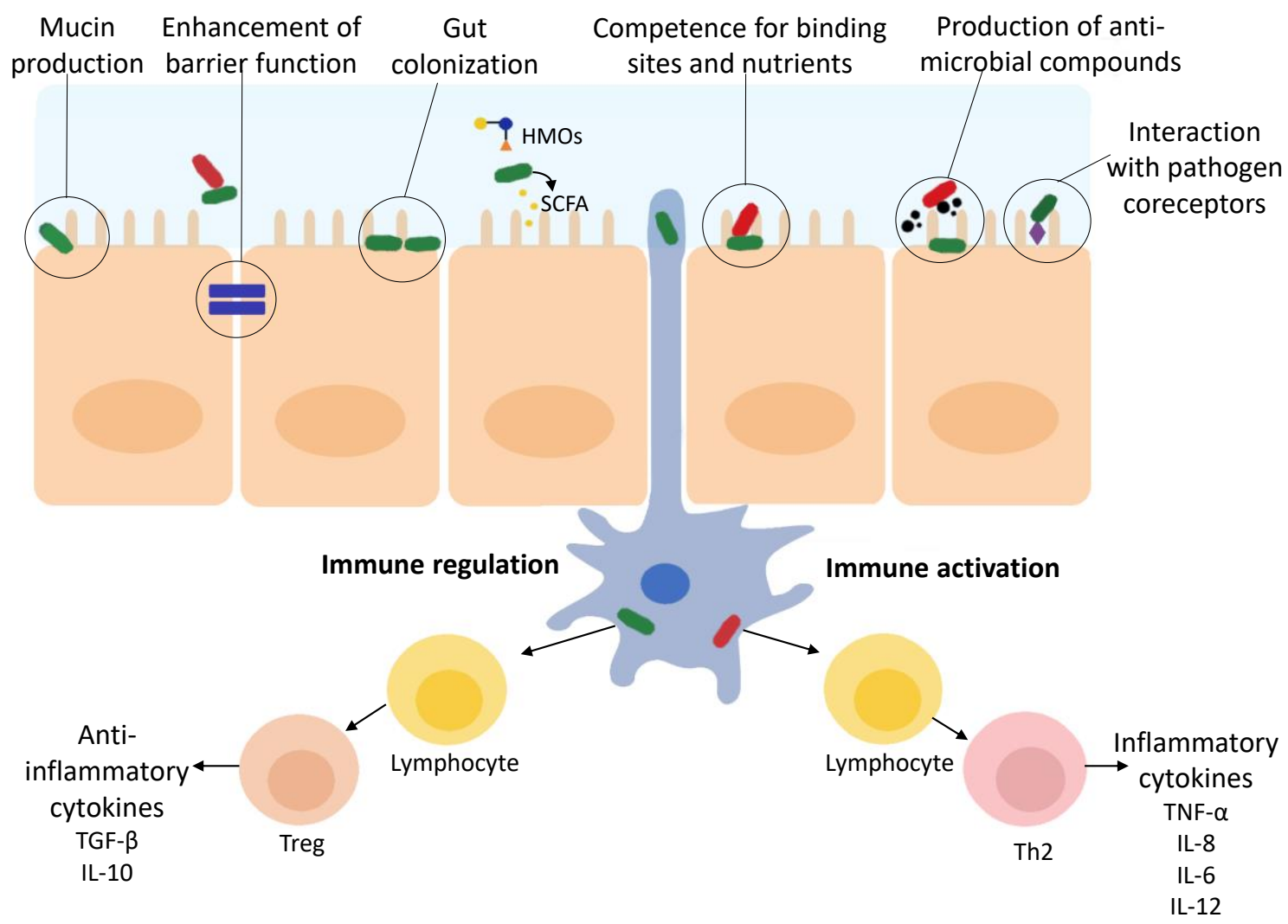

Figure 4. Schematic overview of the suggested mechanisms of action of human milk bacteria in the infant gut. Milk bacteria may colonize the gut epithelium, serve as probiotics (labelled in green) by fermenting prebiotic HMOs and leading to SCFA production; stimulate mucin production by intestinal cells and enhance the barrier function; kill specific pathogens (labelled in red) by release of anti-bacterial molecules and changing the $\mathrm{pH}$; act as decoy, by inhibiting pathogens binding to the gut epithelium, and binding to co-receptors and stimulate immune modulation (tolerance to symbionts and immune response towards pathogens).

Efforts on studying human microbiota have mainly targeted its bacterial fraction. In contrast, fungi, viruses and archaea have been generally overlooked. In particular, the fungal fraction of the microbiome, or the mycobiome, is starting to gain recognition as a fundamental part of our microbiome (Laforest-Lapointe \& Arrieta 2018). Despite fungi are present in the human gut in much lower abundances than bacteria, they are part of the microbial homeostasis and can have direct effects on host's health (Underhill \& Iliev 2014). Given that bacteria are present in milk under normal conditions, and that infants host fungi in their guts since early in life (Bliss et al. 2008; Heisel et al. 2015; Ward et al. 2017), it could be hypothesized that human milk may also contain yeasts and other fungi, whose presence should be evaluated.

\section{Human milk microbiota and maternal health}


Breastfeeding exerts several benefits for the nursing mother, including psychological and affective benefits, such as enhanced maternal bonding and decreased stress. In addition, it favors amenorrhea, thus contributing to spacing of pregnancies, and it has been inversely associated with type 2 diabetes and breast and ovarian cancer (Victora et al. 2016b). With the relatively recent discovery of naturally present bacteria in breast milk, and their potential effects on infant health, it could be speculated that a correct bacterial balance in milk could be important for the mammary gland health. In fact, alterations in milk's microbial communities (dysbiosis) could lead to an overgrowth of opportunistic pathogens and cause disorders in the mammary gland. For example, alterations in breast tissue's microbiota have been observed in women with breast cancer. A few studies that analyzed the bacterial composition in breast tumors and in the adjacent healthy tissue did not find significant differences in overall composition, although specific differences in bacterial abundances were identified (Costantini et al. 2018; Urbaniak et al. 2014; Xuan et al. 2014). For example, higher abundances of Escherichia coli, with cancer-promoting activity, was observed in women with cancer, as compared to healthy controls (Urbaniak et al. 2016b). In other studies, differences in bacterial composition were observed between breast tumor adjacent tissue and control tissue (Urbaniak et al. 2016a); and between cancer tissue and tissue from woman with benign disease (Hieken et al. 2016). On the other hand, lactational mastitis is a common and fastidious event, caused by an inflammation of the mammary ducts, which is thought to have an infectious origin, that if misdiagnosed or not correctly treated, can result in undesired weaning (Contreras \& Rodríguez 2011; Jiménez et al. 2015). Through classic culture-dependent approaches, Staphylococcus aureus was pointed out as the main responsible agent of acute mastitis, a disease that has a rapid onset and courses with intense pain and general symptoms. Acute mastitis can be identified relatively easily and is commonly treated with antibiotic therapies. Conversely, sub-acute mastitis, another type of mastitis, emerges gradually and courses with milder symptoms, as compared to the acute version. Its etiology appears to be complex, and several bacteria, including Staphylococcus epidermidis, other coagulase negative staphylococci (CNS), and viridans streptococci such as Streptococcus mitis and S. salivarius are thought to participate in its onset (Contreras \& Rodríguez 2011; Delgado et al. 2008; Osterman \& Rahm 2000). However, most studies targeting sub-acute mastitis are based on culturedependent and other classic methods. These bacteria can be commonly isolated from healthy mothers' milk, which, together with the difficulty of distinguishing sub-acute mastitis symptoms with other mammary inflammatory processes, makes its diagnose a challenge. Non-cultivable bacteria, undetected by classic approaches, and therefore, overlooked, could be key for understanding mastitis etiology. With the blossoming of culture-independent microbial analyses, and high throughput sequencing methodologies, new opportunities arise for the research of human mastitis. In a randomized clinical trial from Jimenez et al, breast milk-derived L. salivarius CECT5713 and L. gasseri CECT5714 strains were shown to be and effective substitute for antibiotics 
on the treatment of human acute mastitis (Jiménez et al. 2008). However, difficulty to define, diagnose, prevent and treat sub-acute mastitis poses a large problem to deal with this condition, which although is extremely prevalent, has been questioned by different authors to be the outcome of a microbe-derived infection (Amir et al. 2016; Baeza 2016).

Within this framework, specific milk and maternal urine compounds, including milk bacteria, may have the potential to serve as biomarkers of sub-acute mastitis. As previously mentioned, leukocytes are present in human milk and may have a potential protective role in the mammary gland. In particular, polymorphonuclear cells have been shown to increase during mastitis infections (Espinosa-Martos et al. 2016; Hassiotou et al. 2013b), and more studies are needed in order to identify specific differences with healthy controls that could be used for an accurate diagnose and/or treatment of the disease. In addition, DNA- or RNA-based methodologies are needed in order to clarify the potential bacterial etiology of sub-acute mastitis. Recently, a first attempt to use culture-independent approaches to study sub-acute mastitis has been performed (Patel et al. 2017), and a NGS-based network analysis has suggested that potential bacterial network alliances may be responsible of mastitis dysbiosis (Ma et al. 2015)

In 2007, the Human Microbiome Project was launched, aiming to unravel the composition and health implications of the human microbiota and its genetic traits (the microbiome) (Human Microbiome Project Consortium 2012). However, human milk was not included as part of the project, and therefore, despite big efforts have been made to investigate its microbial composition, information is still very scarce compared with other human niches, such as the human gut or the oral cavity. An extended knowledge of the microbial composition of human milk under healthy conditions and disease on the mammary gland is needed. In order to understand potential bacterial functions and interactions within the human milk environment and implications in infant and maternal health, the study of microbial relationships with other milk components is crucial. In addition, some studies have suggested a potential influence of specific environmental factors, including mode of delivery, or maternal BMI (Cabrera-Rubio et al. 2016; Khodayar-Pardo et al. 2014) on the composition of the human milk microbiota. Further studies are necessary in order to confirm this and other potential influencing factors. Classically, human milk microbiota was assessed through culture-dependent techniques, which are known to have some limitations. In order to better define microbial populations, it is essential to combine classic culture approaches with classic and novel culture-independent techniques, including qPCR, NGS, or flow cytometry. 


\section{Hypothesis and Aims of this Thesis}

The general aim of this thesis was to assess the composition of human milk microbiota, as well as its interactions with other milk components, in order to expand our knowledge about its nature and potential role in maternal and infant health. For this purpose, we applied several novel molecular culture-independent techniques, together with microscopic and classic culture-dependent microbiological analyses.

Our hypotheses were:

1) Human milk contains bacteria under normal conditions, their loads in the samples are measurable, and microbial composition and quantities vary throughout lactation and during health alterations.

2) Human milk contains fungi under normal conditions, and its composition varies depending on maternal geographic location and other perinatal factors, such as mode of delivery.

3) The presence and composition of human milk microorganisms are affected by milk elements, such as macronutrients and human cells.

4) Sub-acute mastitis has a microbial origin, and active bacterial DNA composition differs from the total DNA composition in the samples.

The specific aims of each individual chapters were:

1) To determine the bacterial composition of human milk throughout lactation in samples from healthy mothers, their distribution in the fluid and interactions with other milk macronutrients and cells, by applying several cultureindependent methodologies.

2) To explore the potential presence of yeasts and fungi in human milk from healthy donors throughout lactation, their numbers and potential interactions with milk macronutrients and cells, by applying culture-independent next-generation sequencing methodologies, together with classic culture-dependent approaches.

3) To confirm the presence of fungi and yeasts in human milk samples from different and distant geographic locations, with a look at the potential influence of mode of delivery and location on its composition, together with the study of fungal interactions with bacterial communities in human milk.

4) To quantify and characterize the total and active milk microbiota from healthy mothers and mothers suffering sub-acute mastitis. 


\section{Chapter 1}

\section{Relationship between Milk Microbiota, Bacterial Load, Macronutrients, and Human Cells during Lactation}

Alba Boix-Amorós, María Carmen Collado, Alex Mira

This chapter has been published as: Boix-Amorós A, Collado MC, Mira A. 2016. Relationship between Milk Microbiota, Bacterial Load, Macronutrients and Human Cells during Lactation. Frontiers in Microbiology, 7:492. 


\begin{abstract}
Human breast milk is considered the optimal nutrition for infants, providing essential nutrients and a broad range of bioactive compounds, as well as its own microbiota. However, the interaction among those components and the biological role of milk microorganisms is still uncovered. Thus, our aim was to identify potential relationships between milk microbiota composition, bacterial load, macronutrients, and human cells during lactation. Bacterial load was estimated in milk samples from a total of 21 healthy mothers through lactation by bacteria-specific qPCR targeted to the single-copy gene fusA. Milk microbiome composition and diversity was estimated by 16Spyrosequencing, and the distribution of bacteria in the fluid was analyzed by flow cytometry, qPCR, and microscopy. Fat, protein, lactose, and dry extract of milk, as well as the number of somatic cells were also analyzed. We observed that milk bacterial communities were generally complex, and showed individual-specific profiles. Milk microbiota was dominated by Staphylococcus, Pseudomonas, Streptococcus, and Acinetobacter. Staphylococcus aureus was not detected in any of these samples from healthy mothers. There was high variability in composition and number of bacteria per millilitre among mothers and, in some cases, even within the same mothers at different time points. The median bacterial load was estimated at $10^{6}$ bacterial cells $/ \mathrm{ml}$, higher than previously reported by $16 \mathrm{~S}$ gene PCR and culture methods. Furthermore, milk bacteria were present in a free-living, "planktonic" state, but also in equal proportion associated to human immune cells. There was no correlation between bacterial load and the amount of cells in milk, strengthening the idea that milk bacteria are not sensed as an infection by the immune system.
\end{abstract}




\section{Introduction}

Human milk is a complex fluid adapted to satisfy the nutritional requirements of the infant, and also provides protective compounds which help to create the right microenvironment for gut development and maturation of the immune system (Petherick 2010; Walker 2010). Recently, milk has been recognized to host commensal and potential probiotic bacteria, which together with milk's growth factors and other components may have health implications. For example, they could be involved in the utilization of nutrients, facilitating the digestion process, although the most likely role of these microorganisms is immune modulation (Fernández et al. 2013). Culturedependent methods have long confirmed the presence of viable bacteria in aseptically collected samples (Heikkila \& Saris 2003). However, an important part of milk bacteria have not been cultured under laboratory conditions, and subsequently the diversity of human milk could be underestimated by classical approaches. Although partial contamination from skin microbes likely occur, the presence of strictly anaerobic species such as Bifidobacterium, Clostridium, and some Bacteroides spp., which are absent in the skin microbiota, supports that breast milk hosts a unique microbiome (Cabrera-Rubio et al. 2012a; Hunt et al. 2011; Jost et al. 2013). In addition, accumulating evidence suggests that milk microbiota is influenced by perinatal factors such as mode of delivery, lactation stage, gestational age, maternal health, or geographical locations (Cabrera-Rubio et al. 2016; Khodayar-Pardo et al. 2014).

It has been estimated that an infant consumes $\sim 800 \mathrm{~mL} /$ day, ingesting between $10^{4}$ and $10^{6}$ bacteria daily (Heikkila \& Saris 2003), but those data were based on culture techniques and may have underestimated the total load of microorganisms. Other culture independent methods, such as molecular techniques or cytometry should be implemented in order to make more accurate estimates of milk's bacterial densities (Collado et al. 2009). Knowing total bacterial numbers in milk will be useful to understand bacterial behaviour and also, to estimate bacterial loads under infectious situations. This would open new possibilities for developing potential tools to detect problems in the nursing mother. Furthermore, it's known that milk contains a wide range of nutrients, such as lactose, fat or proteins, which can serve as bacterial food source (Petherick 2010). Milk also contains a variable number of human cells, including epithelial and immune cells, and the number of the latter has been related to lactational mastitis problems (Hassiotou et al. 2013b). The relationship between bacterial load and other factors such as milk developmental stage, nutrient composition, number of somatic cells, or bacterial diversity have not been studied in depth. Therefore, the purpose of the present study was to develop and establish a protocol, using molecular techniques and flow cytometry, to calculate the exact number of bacteria present in milk at three lactation stages from different mothers, and correlate this bacterial load to the abovementioned factors that could influence it. 


\section{Materials and Methods}

\section{Subjects and sampling}

A total of 21 healthy Spanish mothers with exclusive breastfeeding practices participated in the study and provided samples of breast milk within 1 month after delivery. Breast milk samples were collected within 5 days after birth (colostrum), between 6 and 15 days (transitional milk) and after 15 days (mature milk). However, only 57 samples were analyzed, as not every mother provided a sample at the three time points. Details of delivery and gestational age were collected after birth. Written informed consent was obtained from the participants and the study protocol was approved by the Ethics Committee of the CSIC (Spanish National Research Council). Before sample collection, mothers were given oral and written instructions for standardized collection of the samples. Previously, nipples and mammary areola were cleaned with soap and sterile water and soaked in chlorhexidine to reduce bacteria residing on the skin. The milk samples were collected in a sterile tube manually, discarding the first drops. All samples were kept frozen at $-20^{\circ} \mathrm{C}$ until delivery to the laboratory.

\section{DNA isolation}

Milk samples (5-10 mL) were thawed and centrifuged at $4000 \times \mathrm{g}$ for $20 \mathrm{~min}$ to separate fat and cells from whey. Thereafter, total DNA was isolated from the pellets by using the MasterPure Complete DNA and RNA Purification Kit (Epicenter) according to the manufacturer's instructions with some modifications (Simón-Soro et al. 2015). Two hundred and fifty microliters of saline solution and $250 \mu \mathrm{l}$ of lysis buffer were added to the pellets, together with Pathogen Lysis Tubes (QIAGEN) glass beads. Both chemical and physical cells disruption were performed after vigorous mixing of the samples in a TissueLyser II (QIAGEN), during $5 \mathrm{~min}$ at $30 \mathrm{~Hz}$, incubating in dry ice 3 and $5 \mathrm{~min}$ at $65{ }^{\circ} \mathrm{C}$ in a thermoblock, repeating the process 2 times. Fifty microliters of lysozyme (20 $\mathrm{mg} / \mathrm{ml})$ and $5 \mu \mathrm{l}$ of lysostaphin $(20 \mu \mathrm{g} / \mathrm{ml})$ were added to the tubes, and samples were incubated for $1 \mathrm{~h}$ at $37^{\circ} \mathrm{C}$. Two microliters of proteinase $\mathrm{K}$ were added and samples were incubated for $15 \mathrm{~m}$ at $65^{\circ} \mathrm{C}$. The reaction was ended putting tubes on ice, and proteins were precipitated using $350 \mu \mathrm{l}$ of the protein precipitation agent, discarding the pellets. DNA was then precipitated using isopropanol, washed with $70 \%$ ethanol and resuspended with $30 \mu \mathrm{l}$ TE buffer. The total DNA isolated was quantified with a NanoDrop ND-1000 (ThermoScientific) spectrophotometer.

\section{Quantitative real-time polymerase chain reaction analysis and bacterial load}

qPCR amplification and detection were performed with primers targeting the fusA gene, a bacterial gene which is present in a single and unique copy per bacterial cell (Santos \& Ochman 2004), making it a more accurate target for bacterial load estimations, as compared to the 16S rRNA gene, which is present in variable copy numbers among different bacterial species. The use of a single-copy gene in qPCR analyses implies that the number of gene copies equals the number of bacterial cells, improving measurements 
of bacterial densities. In this work, we used modified fusA gene primers from Santos and Ochman (2004), based on multiple alignments with all sequences of this gene from the Ribosomal Database Project Functional Gene Repository (Fish et al. 2013) as available on January 2015, using an annealing temperature of $62^{\circ} \mathrm{C}$ in a Light Cycler 480 Real-Time PCR System (Roche Technologies). The primer sequences were as follows: 138FGCTGCAACCATGGACTGGAT, and 293R- TCRATGGTGAAGTCAACGTG. Each reaction mixture of $20 \mu \mathrm{l}$ was composed of KAPA Sybr Fast qPCR Kit (KAPA Biosistems), $0.4 \mu \mathrm{l}$ of each primer (10 $\mu \mathrm{M}$ concentration) and $1 \mu \mathrm{l}$ of template DNA, using an annealing temperature of $62^{\circ} \mathrm{C}$ in a Light Cycler 480 Real-Time PCR System (Roche Technologies). All amplifications were performed in duplicates. The bacterial concentration in each sample was calculated by comparison with the Ct values obtained from standard curves. These were generated using serial 10-fold dilutions of DNA extracted from 10 million bacteria, quantified and sorted from a pool of four milk samples from different mothers using a MoFlo XDP cytometer, after mild sonication to separate aggregated cells (Simón-Soro et al. 2015).

\section{PCR amplification and pyrosequencing}

Partial 16S rRNA genes were amplified by PCR with the universal bacterial primers 8F and 785R (Simón-Soro et al. 2014) by the use of high-fidelity AB-Gene DNA polymerase (ThermoScientific) with an annealing temperature of $52^{\circ} \mathrm{C}$ and 20 cycles. A secondary amplification was performed by using the purified PCR products as a template, in which the universal primers were modified to contain the pyrosequencing adaptors $\mathrm{A}$ and $\mathrm{B}$ and an 8-bp "barcode" specific to each sample, following the method used in (BenítezPáez et al. 2013). The DNA was purified by using an Ultrapure PCR purification kit (Roche), and its concentration was measured by PicoGreen fluorescence in a Modulus 9200 fluorimeter from Turner Biosystems. PCR products were pyrosequenced from the forward primer end using a 454 Life Sciences system, in a GS-FLX sequencer with Titanium chemistry (Roche) at the Foundation for the Promotion of Health and Biomedical Research (FISABIO, Valencia, Spain). Sequences were deposited in the MGRAST public repository under the project name "Relationship between milk microbiota, bacterial load, macronutrients, and human cells during lactation" with Accession Numbers 4689674.3-4689703.3.

\section{Sequence analysis}

Sequences with an average quality value $<20$ and/or with $>4$ ambiguities in homopolymeric regions in the first 360 flows were excluded from the analysis. Obtained $16 S$ rRNA reads were end-trimmed in $10 \mathrm{pb}$ sliding windows with average quality value $>20$, then length (200 bp) and quality filtered (average $Q>20$ ). Only sequences longer than $400 \mathrm{bp}$ were considered and chimeric reads were eliminated using UCHIME (Edgar et al. 2011). Sequences were assigned to each sample by the 8-bp barcode and phylum-, family-, and genus-level taxonomic assignment of sequences that passed quality controls were made using the Ribosomal Database Project classifier software (Wang et al. 2007) 
within an $80 \%$ confidence threshold. Sequences $>97 \%$ identical were considered to correspond to the same operational taxonomical unit (OTU), representing a group of sequences that presumably correspond to the same species (Yarza et al. 2008). Sequences were clustered at $97 \%$ nucleotide identity over $90 \%$ sequence alignment length using the CD-hit software (Li \& Godzik 2006). Rarefaction curves were calculated with the RDP pyrosequencing pipeline (Cole et al. 2009) using the same number of randomly selected sequences per group and Chao1 and Shannon estimations (representing species richness and diversity, respectively) were obtained. For those genera found at higher than $1 \%$ frequency, a BLASTn (Altschul et al. 1990) was performed against the RDP database, selecting those hits with nucleotide identity values $>97 \%$ and alignment lengths $>400$ bp, following (Cabrera-Rubio et al. 2012b).

\section{Milk composition analysis}

We analyzed 38 milk samples from 17 mothers with known bacterial load to elucidate their fat, protein, and lactose composition $(\% \mathrm{w} / \mathrm{w})$ by spectrophotometry using a MilkoScan FT 6000 (FOSS), and the number of somatic cells (cells/ml) using an Integrated Milk Testing Fossomatic FC (FOSS) cytometer, in LICOVAL (Valencia, Spain).

\section{Bacterial fractions in milk}

Bacterial distribution in human milk was determined after analyzing $10 \mathrm{ml}$ of colostrum $(n=9)$ and mature milk $(n=9)$ samples, using a MoFloXDP cytometer with sorter. Transition samples were not analyzed due to lack of volume availability. Light was produced by an argon laser of $400 \mathrm{~nm}$ (blue light) and $200 \mathrm{Mw}$. First, the machine was calibrated using electromagnetic beads (Fluorospheres, Beckman Coulter Inc.) with known size $(1,3$, and $10 \mu \mathrm{m})$. Then, events under $3 \mu \mathrm{m}$ (containing planktonic bacteria) and those over $3 \mu \mathrm{m}$ (containing human cells) were counted and sorted in two different tubes. DNA was extracted from both fractions for each sample, and qPCR was performed to determine the number of bacteria present in each of them, corresponding to free-living and human cells-associated bacteria. Fluorescence microscopy was performed on a selected number of samples after marking with DAPI dye, and visualized on a Nikon Eclipse E800 microscope. For Scanning Electron Microscopy, samples were kept on Karnovsky solution and further fixed with $1 \% \mathrm{OsO}_{4}$ in $\mathrm{PBS}_{\text {buffer. }}$ Samples were then dehydrated with ethanol and critical-point drying, attached to a stub and coated with gold. Images were obtained in a Hitachi S-4800 Scanning electron Microscope with default settings at University of Valencia. 


\section{Results and Discussion}

\section{Bacterial load in milk}

Bacterial load values at each milk lactation stage are shown in Figure 1. After analysing 56 milk samples by qPCR, results showed large individual differences in bacterial load over time between samples from the different mothers and in some cases even within individuals at different time points, indicating that human milk samples are highly variable in microbial content. Median values for colostrum, transition and mature milk were around $10^{6}$ bacterial cells per $\mathrm{ml}$, with no significant differences between the three time points. Data from other researchers had indicated bacterial densities of $10^{3}-10^{4}$ per $\mathrm{ml}$ of breast milk, but they were based on laboratory culture (Heikkila \& Saris 2003) or on qPCR methods calibrated by culture (Khodayar-Pardo et al. 2014), which account for a limited fraction of the total bacteria in human samples. In addition, a significant fraction of microorganisms were found to be adhered to the extracellular matrix of human cells (see section Bacterial Distribution in Milk below), which could further prevent the growth on culture media. The molecular approach used in the current manuscript expands these pioneering estimates, allowing now the study of potential relationships between bacterial load and other parameters. Although our molecularbased methods suggest bacterial loads between two and three orders of magnitude higher than those estimated by culture, it has to be taken into account that DNA from non-viable bacteria and extracellular DNA would also be amplified by qPCR, and therefore the real number of viable bacteria would probably be lower.
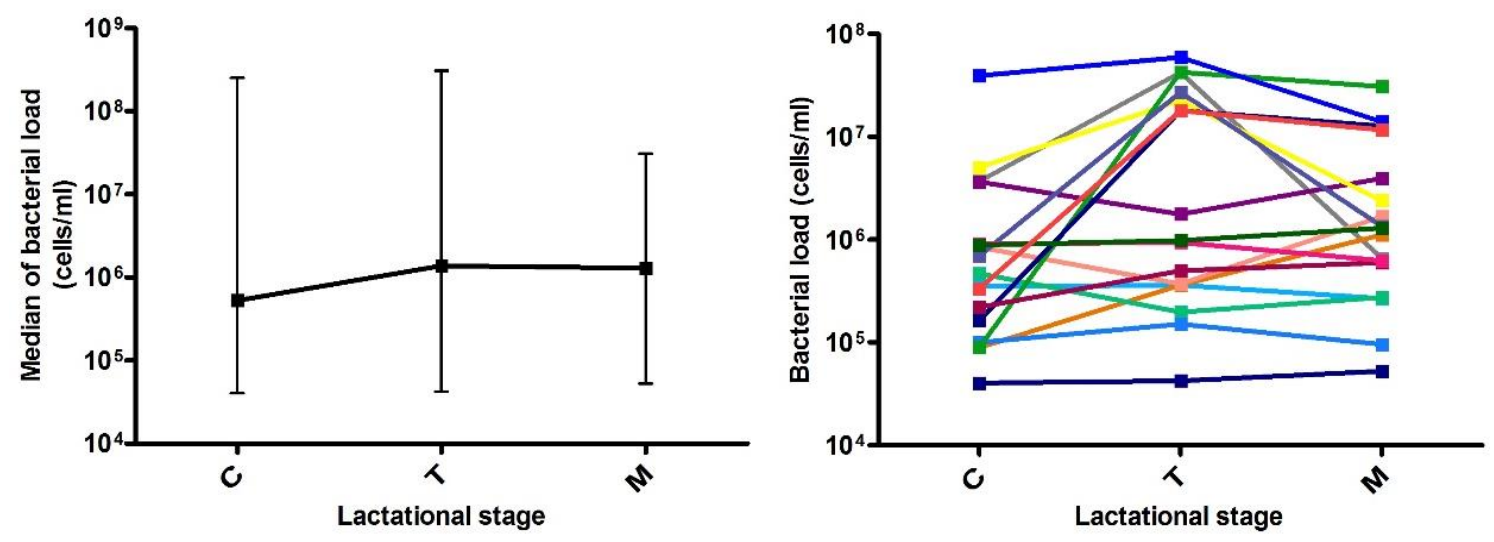

Figure 1. Bacterial load over lactational stages. (A) Data show the median with ranges (maximum and minimum values for each group) of bacterial load at the three time points. $C$, colostrum samples $(n=19) ; \mathrm{T}$, transition milk samples $(n=20) ; \mathrm{M}$, mature milk samples $(n=17)$. (B) Lines show individual bacterial load for each mother at the three time points $(n=17)$. 


\section{Milk bacterial composition throughout lactation}

After quality filtering and length trimming, 174,886 16S rRNA sequences were analyzed, with an average number of taxonomically assigned, high-quality sequences of 4,353 reads per sample. The taxonomic assignment of the sequences showed that human breast milk composition is dominated by Staphylococcaceae, which account for $>62 \%$ of the total number of sequences obtained (Figure 2). At the three lactation times, the most common genera was Staphylococcus, followed by Acinetobacter in colostrum, Pseudomonas and Streptococcus in transition milk and also Acinetobacter in mature milk samples (Figure 3A). Milk from the three lactation points showed different patterns of bacterial diversity, but no statistically significant differences were found between time points for any bacterial genus. Rarefaction curves after analyzing 35,000 reads per lactation time point indicated 223 OTUs in colostrum samples, 251 in transition and 203 in mature samples when sequences were clustered at $97 \%$ sequence identity (the consensus value for determining species boundaries; Figure 3B). The number of OTUs obtained suggests values of several hundred species in human breast milk, with transition samples having higher diversity than colostrum and mature milk, containing up to nine genera that were only found at that stage (Figure 3B). Similar estimates of several hundred bacterial species were also obtained by other studies (Cabrera-Rubio et al. 2012a; Hunt et al. 2011), confirming that human breast milk is highly diverse. However, most diversity in the samples corresponded to a few bacterial genera, which appeared to be dominant. Among them, we found a core of seven genera that were present at the three time points: Finegoldia, Streptococcus, Corynebacterium, Staphylococcus, Acinetobacter, Peptoniphilus, and Pseudomonas. Although determining the bacterial species composition with partial 16S rRNA sequences should be taken with care, the relatively long sequences obtained by pyrosequencing (average read length $718 \mathrm{bp}$ ) allowed us to assign reads to the species taxonomic level with some degree of reliability. This analysis revealed that the most common species within Staphylococci was S. epidermidis, and S. aureus was not detected in these healthy mothers (a full list of species composition can be found in Table 1). It must be underlined that although some bacteria typically associated to human breast milk like Bifidobacterium spp (Collado et al. 2009) were detected at low proportions in our samples, this could be due to low amplification efficiency of "universal" primers in these high G+C content taxa (Sim et al. 2012). It is interesting to note that the bacterial genera found in our samples, which were obtained from Spanish mothers, was different to those found in other high-throughput sequencing studies from American or Finnish origin (Cabrera-Rubio et al. 2012a; Hunt et al. 2011), suggesting that geographic, genetic, and dietary factors could be influencing microbial diversity in breast milk. 


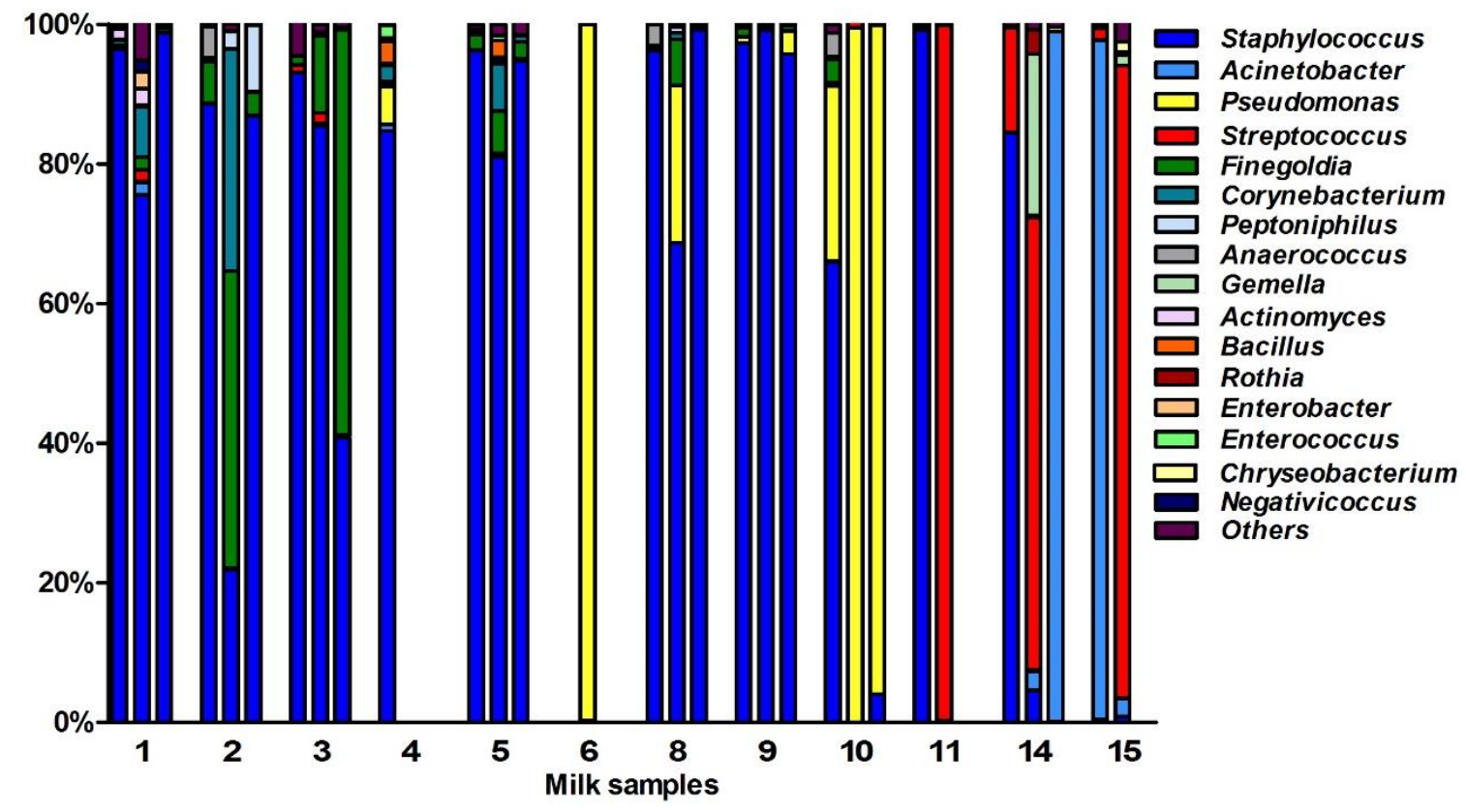

Figure 2. Bacterial taxonomic composition of human breast milk. The bar plot shows the proportion of bacterial genera as inferred by pyrosequencing of the 16S rRNA gene in healthy mothers $(n=12)$. Each number in the $\mathrm{X}$ axis represent a donor, with first column representing the colostrum sample, second the transition milk and third the mature milk samples. In some cases, data from the three breastfeeding stages could not be obtained due to sample unavailability or sequencing failure. Bacterial genera that were under $1 \%$ were grouped in the "Others" category.
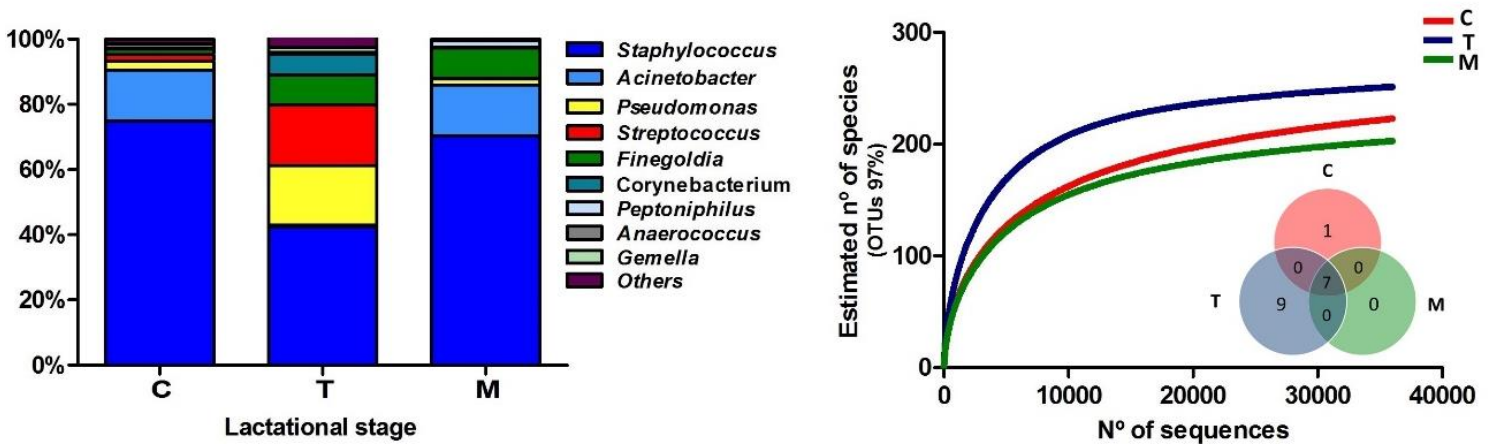

Figure 3. Bacterial diversity of human breast milk. (A) Shows the proportion of each bacterial genera in the three lactational-stages, as inferred by PCR amplification and pyrosequencing of the $16 \mathrm{~S}$ rRNA gene. (B) Shows the rarefaction curves of the three groups, relating the sequencing effort with an estimate of the number of bacterial species, as inferred by the number of OTUs. An OTU is a cluster of 16 SrRNA sequences that were $>95 \%$ identical, a conservative estimate for the boundary between species, established at $97 \%$ for full-length $16 \mathrm{~S}$ rRNA sequences. The inlet Venn's diagram shows the number of bacterial genera shared between and unique to the three sample types, excluding bacterial genera present at $<1 \%$ proportion. Seven genera are shared at the three breastfeeding stages: Finegoldia, Streptococcus, Corynebacterium, Staphylococcus, Acinetobacter, Peptoniphilus, and Pseudomonas. C, colostrum samples $(n=11) ; \mathrm{T}$, transition samples $(n=11) ; \mathrm{M}$, mature samples $(n=8)$. 


\section{Relationship between bacterial load and milk's composition and diversity}

After comparing the number of somatic cells and bacterial load in the same samples, no significant correlation was found (Figure 4). Given that the number of somatic cells in milk is considered the gold standard for detecting infections (e.g., lactational mastitis) in farm animals (Olechnowicz \& Jaśkowski 2012), the absence of a somatic cell increase in our samples suggests a lack of significant immune response. Thus, the data presented in the current work suggest that high counts of bacteria in milk are not associated with infection in these healthy mothers without lactation problems. However, a positive correlation was found between the proportion of the common mastitis pathogen Staphylococcus and the number of somatic cells (Pearson correlation coefficient: $0.48, p=$ 0.046). Given that a negative relationship was found between the proportion of Staphylococcus and the total bacterial load (correlation coefficient: $-0.456, p=0.056$ ), the data suggest that it is not the number of bacteria but the specific composition of the milk microbiota that could be inducing an immune response in the mammary gland, although the major mastitis pathogen $S$. aureus was not detected in our samples (Table 1). Other bacteria appeared to show a positive relationship with the number of somatic cells were Peptoniphilus and Finegoldia (Figure 5), although the correlations were not statistically significant in these cases. It has to be kept in mind that breast milk contains several antiinflammatory components (He et al. 2016) that could partly reduce somatic cells counts.

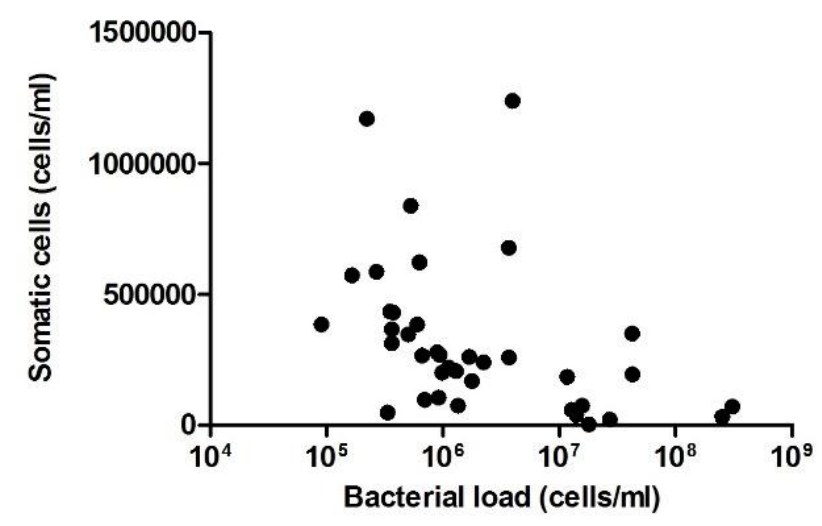

Figure 4. Relationship between the number of somatic cells and bacterial load in breast milk. The graph shows a comparison between the number of bacterial cells per milliliter (estimated by qPCR) and the number of somatic cells per milliliter, estimated with an Integrated Milk Testing Fossomatic 5000 (FOSS) cytometer. $(\mathrm{n}=38, \mathrm{R} 2=0.0066) . \mathrm{C}$, colostrum samples $(n=12)$; T, transition samples $(n=15) ; \mathrm{M}$, mature samples $(n=11)$.

Additionally, we estimated the bacterial diversity and richness in the samples by the statistic indexes "Shannon" and "Chao1," respectively. Neither diversity nor richness increased or decreased significantly with bacterial load (Figure 6). This also supports a lack of subclinical or sub-acute mastitis, as an increase of a few dominant bacteria would be expected in case of infection, and suggests that milk microbiota is not activating an immune response in the host, although inflammatory markers have not been measured. 
Fat, protein, lactose and non-fatty solid fractions of milk were also analyzed, and were compared with the bacterial load, in order to find any possible correlations (Supplementary Figure 1). No significant correlations were found with the number of bacteria per ml. However, some positive and negative relationships were found between some nutrients and specific bacterial genera (Figure 5). For instance, the amount of proteins were positively correlated with the proportion of Bacillus, Peptoniphilus, and Anaerococcus in the samples, whereas lactose levels were negatively correlated with Enterobacter and Actinomyces, indicating potential prebiotic and antagonistic effects for bacterial growth, which should be evaluated in bigger sample sizes. In the case of fat, whose content in milk is known to increase through breastfeeding, it was negatively correlated with the proportion of Staphylococcus (Pearson correlation coefficient: -0.425 , $p=0.044$ ), and therefore if this negative relationship is confirmed in larger cohorts, high fat content in milk could potentially be protective of mastitis risk.

Table 1. Prevalence of bacterial genera and species in breast milk samples

\begin{tabular}{|c|c|c|c|}
\hline Genera & Prevalence $^{a}$ & Species & Prevalence \\
\hline \multirow[t]{6}{*}{ Staphylococcus } & $24 / 30$ & Staphylococcus epidermidis & $22 / 24$ \\
\hline & & Staphylococcus lugdunensis & $5 / 24$ \\
\hline & & Staphylococcus hominis & $5 / 24$ \\
\hline & & Staphylococcus microti & $3 / 24$ \\
\hline & & Staphylococcus warneri & $1 / 24$ \\
\hline & & Staphylococcus equorum & $1 / 24$ \\
\hline \multirow[t]{8}{*}{ Streptococcus } & $13 / 30$ & Streptococcus mitis & $7 / 13$ \\
\hline & & Streptococcus infantis & $6 / 13$ \\
\hline & & Streptococcus cristatus & $5 / 13$ \\
\hline & & Streptococcus salivarius & $4 / 13$ \\
\hline & & Streptococcus mutans & $3 / 13$ \\
\hline & & Streptococcus sanguinis & $3 / 13$ \\
\hline & & Streptococcus gordonii & $1 / 13$ \\
\hline & & Streptococcus sanguinosus & $1 / 13$ \\
\hline Finegoldia & $9 / 30$ & Finegoldia magna & $9 / 9$ \\
\hline \multirow[t]{7}{*}{ Pseudomonas } & $8 / 30$ & Pseudomonas deceptionensis & $3 / 7$ \\
\hline & & Pseudomonas fragi & $3 / 7$ \\
\hline & & Pseudomonas meridiana & $3 / 7$ \\
\hline & & Pseudomonas gessardii & $2 / 7$ \\
\hline & & Pseudomonas moorei & $1 / 7$ \\
\hline & & Pseudomonas japonica & $1 / 7$ \\
\hline & & Pseudomonas sasplenii & $1 / 7$ \\
\hline \multirow[t]{8}{*}{ Acinetobacter } & $7 / 30$ & Acinetobacter haemolyticus & $4 / 7$ \\
\hline & & Acinetobacter junii & $2 / 7$ \\
\hline & & Acinetobacter ursingii & $2 / 7$ \\
\hline & & Acinetobacter Iwoffii & $2 / 7$ \\
\hline & & Acinetobacter parvus & $1 / 7$ \\
\hline & & Acinetobacter guillouiae & $1 / 7$ \\
\hline & & Acinetobacter pittii & $1 / 7$ \\
\hline & & Pseudomonas alcaliphila & $1 / 7$ \\
\hline
\end{tabular}

\begin{tabular}{|c|c|c|c|}
\hline Genera & Prevalence $^{\mathrm{a}}$ & Species & Prevalence ${ }^{\mathrm{b}}$ \\
\hline \multirow[t]{3}{*}{ Anaerococcus } & $5 / 30$ & Anaerococcus octavius & $5 / 5$ \\
\hline & & Anaerococcus murdochii & $1 / 5$ \\
\hline & & Anaerococcus prevotii & $1 / 5$ \\
\hline \multirow[t]{2}{*}{ Actinomyces } & $4 / 30$ & Actinomyces radingae & $3 / 4$ \\
\hline & & Actinomyces neuii & $2 / 4$ \\
\hline \multirow[t]{5}{*}{ Enterobacter } & $4 / 30$ & Enterobactercancerogenus & $2 / 3$ \\
\hline & & Enterobacteraerogenes & $1 / 3$ \\
\hline & & Enterobacterhormaechei & $1 / 3$ \\
\hline & & Enterobacterasburiae & $1 / 3$ \\
\hline & & Enterobacterkobei & $1 / 3$ \\
\hline Rothia & $3 / 30$ & Rothia mucilaginosa & $3 / 3$ \\
\hline \multirow[t]{3}{*}{ Corynebacterium } & $2 / 30$ & Corynebacterium simulans & $1 / 2$ \\
\hline & & Corynebacterium xerosis & $1 / 2$ \\
\hline & & Corynebacterium amycolatum & $1 / 2$ \\
\hline \multirow[t]{3}{*}{ Bacillus } & $2 / 30$ & Bacillus thuringiensis & $1 / 2$ \\
\hline & & Bacillus circulans & $1 / 2$ \\
\hline & & Bacillus megaterium & $1 / 2$ \\
\hline Chryseobacterium & $1 / 30$ & Chryseobacteriumdaeguense & $1 / 1$ \\
\hline
\end{tabular}

Assignment to the species taxonomic level was performed by BLASTn selecting only alignments $>300$ bp and sequence identity $>97 \%$.

a Data indicate the number of samples containing the indicated genus.

$b$ Data indicate the number of samples containing the indicated species referred to the number of samples containing the corresponding genus. 

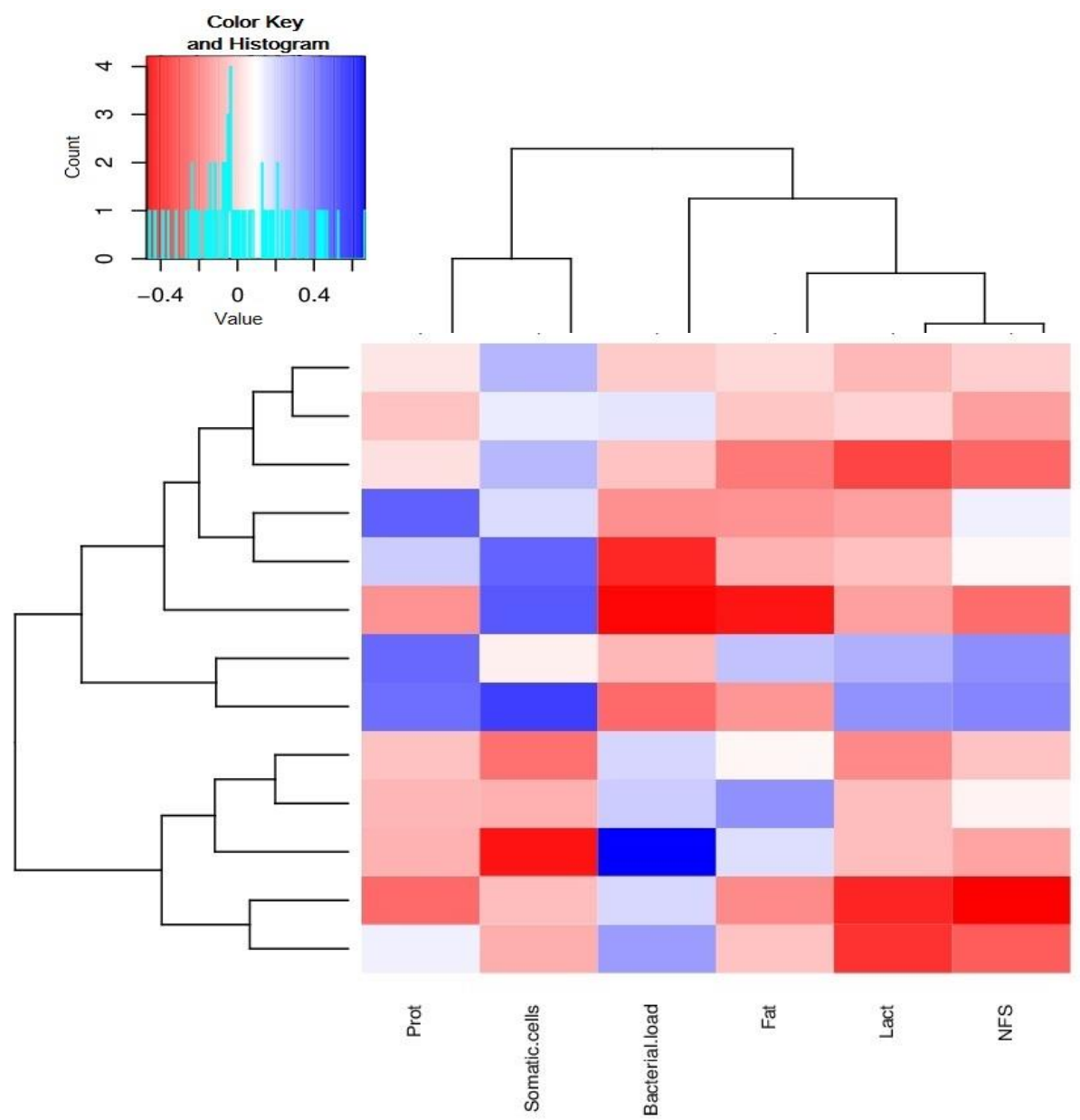

Enterococcus

Corynebacterium

Others

Anaerococcus

Finegoldia

Staphylococcus

Bacillus

ญับ

Peptoniphilus

Streptococcus

Acinetobacter

Pseudomonas

Enterobacter

Actinomyces

\section{Milk components}

Figure 5. Relationships between bacterial composition and components of breast milk. The figure shows a heatmap where samples are clustered according to their compositional profile. Relationships between bacterial genera and milk components appear color-coded according to their negative-(red) or positive-(blue) correlations. Prot= protein content; Lact= lactose content; NFS $=$ non-fatty solids $(n=30)$.
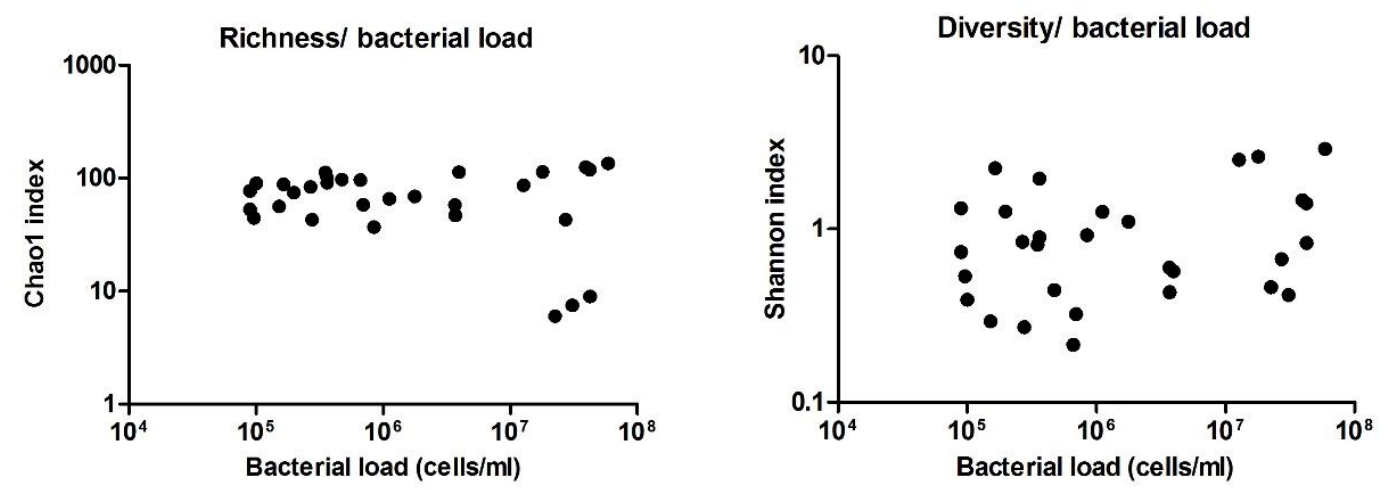

Figure 6. Richness and diversity of milk samples. (A) Shows the richness in the samples as inferred by computation of Chao1 index, compared with bacterial load in cells per $\mathrm{ml}$, as estimated by qPCR. (B) Shows the diversity in the samples as inferred by Shannon index, compared with bacterial load. ( $n=30$ in both cases). 


\section{Bacterial distribution in milk}

Bacterial loads in planktonic and human cell-associated fractions of nine samples of colostrum and nine samples of mature milk were calculated, showing that the microorganisms were present in both fractions, although aggregated bacteria appeared to be more abundant in colostrum $(65.75 \%)$, and planktonic bacteria were found to be more abundant in mature samples (63.92\%, Figure 7A). Mann-Whitney statistical tests showed significant differences $(p<0.05)$ between the two time points (but not within the same time point) for both free and human cell-associated bacteria. The high proportion of bacteria associated with human immune cells was confirmed by fluorescence and Scanning Electron microscopy (Figures 7B-D). Bacteria in the aggregated fraction seemed to be adhered to the membrane of human cells (identified as immune cells according to their shape and size) but not intracellular. We confirmed the presence of live bacteria moving inside the extracellular matrix of immune cells (Supplementary Video).

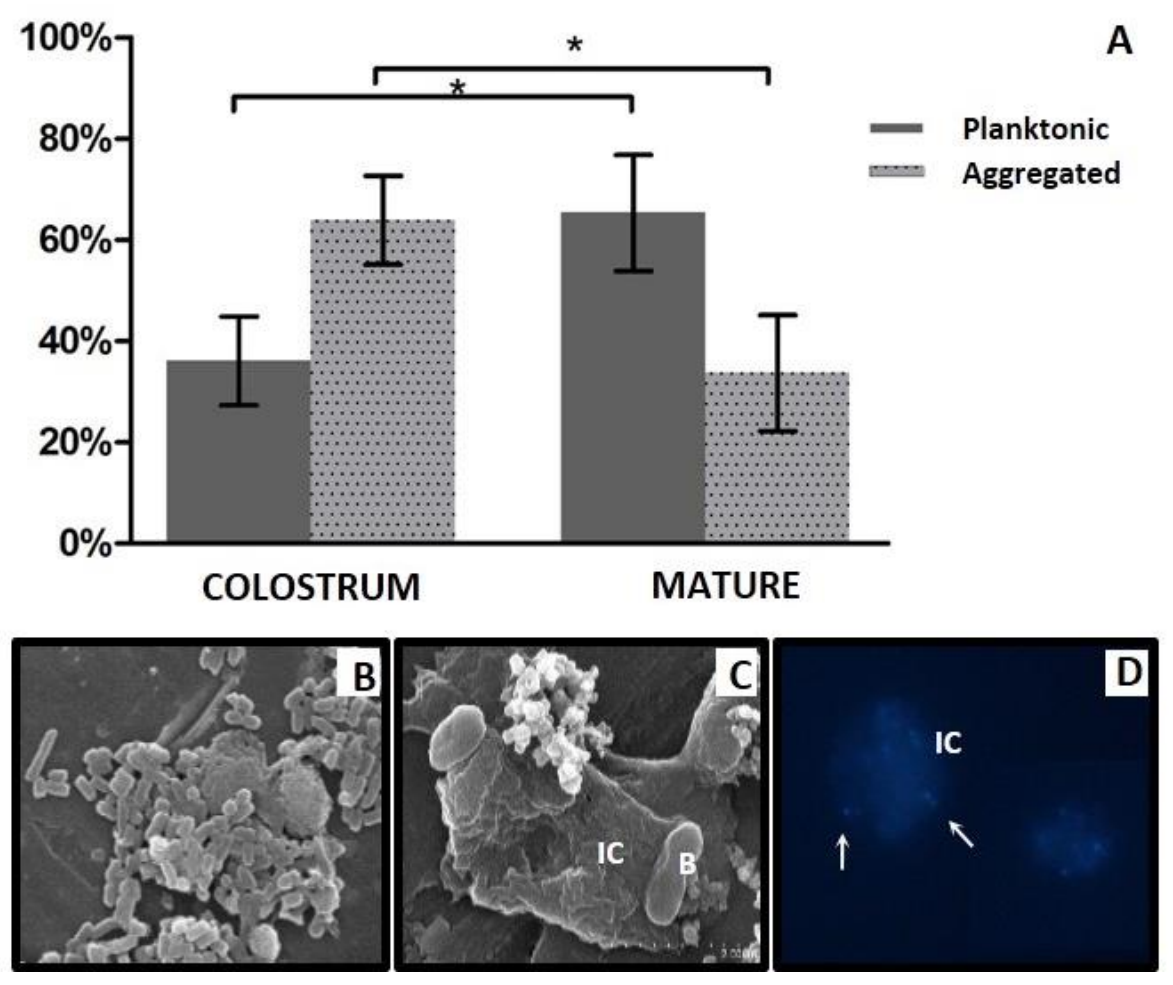

Figure 7. Bacterial fractions in human breast milk. (A) Proportion of bacteria present in a freeliving, "planktonic" state and aggregated to human immune cells in colostrum and mature milk samples. Bacteria from $10 \mathrm{ml}$ of milk were counted and sorted by size and complexity using a Moflo cytometer. *indicates a $p<0.05$, Mann-Whitney test. (B) Planktonic bacteria in milk observed by SEM microscopy. (C) Bacteria associated to human immune cells, observed with SEM microscopy. (D) Bacteria associated to human immune cells, observed with fluorescence microscopy. DNA was stained with DAPI fluorophore. Bacteria are indicated with arrows. IC, human immune cell; B, bacteria. 
Bacterial cells in this extracellular matrix have also been observed in blood samples from pregnant mothers by other researchers (Donnet-Hughes et al. 2010). An "enteromammary pathway" has been proposed to explain the translocation of bacteria to the mammary gland through blood and/or lymph stream through its association to human immune cells (Martín et al. 2004). If this translocation process is confirmed, the milk cellbacterial association described here could be a consequence of such a relationship. An alternative explanation would be that bacteria originated from skin and the oral cavity of the lactating child invades the mammary gland and binds to immune cells without eliciting a response (Hagi et al. 2013). Future studies should determine the type of immune cells involved in the observed bacterial adhesion and the nature of the bacteriahuman recognition (Langa 2006; Perez et al. 2007), including the identification of which microorganisms are free and which are human cell-associated.

\section{Conclusions}

Our estimates of bacterial load provided by molecular methods indicate that a lactating infant feeding $800 \mathrm{ml}$ of breast milk per day could ingest $10^{7}-10^{8}$ bacterial cells daily, about 100 times higher than previous estimates based on laboratory culture methodologies. Our data show that samples with higher bacterial load in healthy mothers do not suffer from lower diversity, as it would be expected from microbial infections. In addition, no correlation between human and bacterial cells was found in milk, suggesting that milk microbiota is not seen as an infection by the mother's immune system, and that the immune response is directed toward specific microorganisms such as Staphylococcus. Furthermore, specific relationships between macronutrients and specific bacteria have been described. However, more studies with higher number of samples are needed to confirm and identify key interactions between bacteria and nutrients and their potential impact in infant health. Thus, the biological function of these potentially symbiotic bacteria for infant health could be relevant, including a role in the development of their immune system, and should be elucidated. 


\section{Supplementary Material}

Supplementary Video (available online at: www.ncbi.nlm.nih.gov/pmc/articles/PMC4837678/). Time-lapse photography of a human milk immune cell containing a live bacterial cells embedded in its surface. Apart from free-living, $40-60 \%$ of milk bacteria were found attached to human cells, as estimated by qPCR of planktonic and aggregated bacteria.
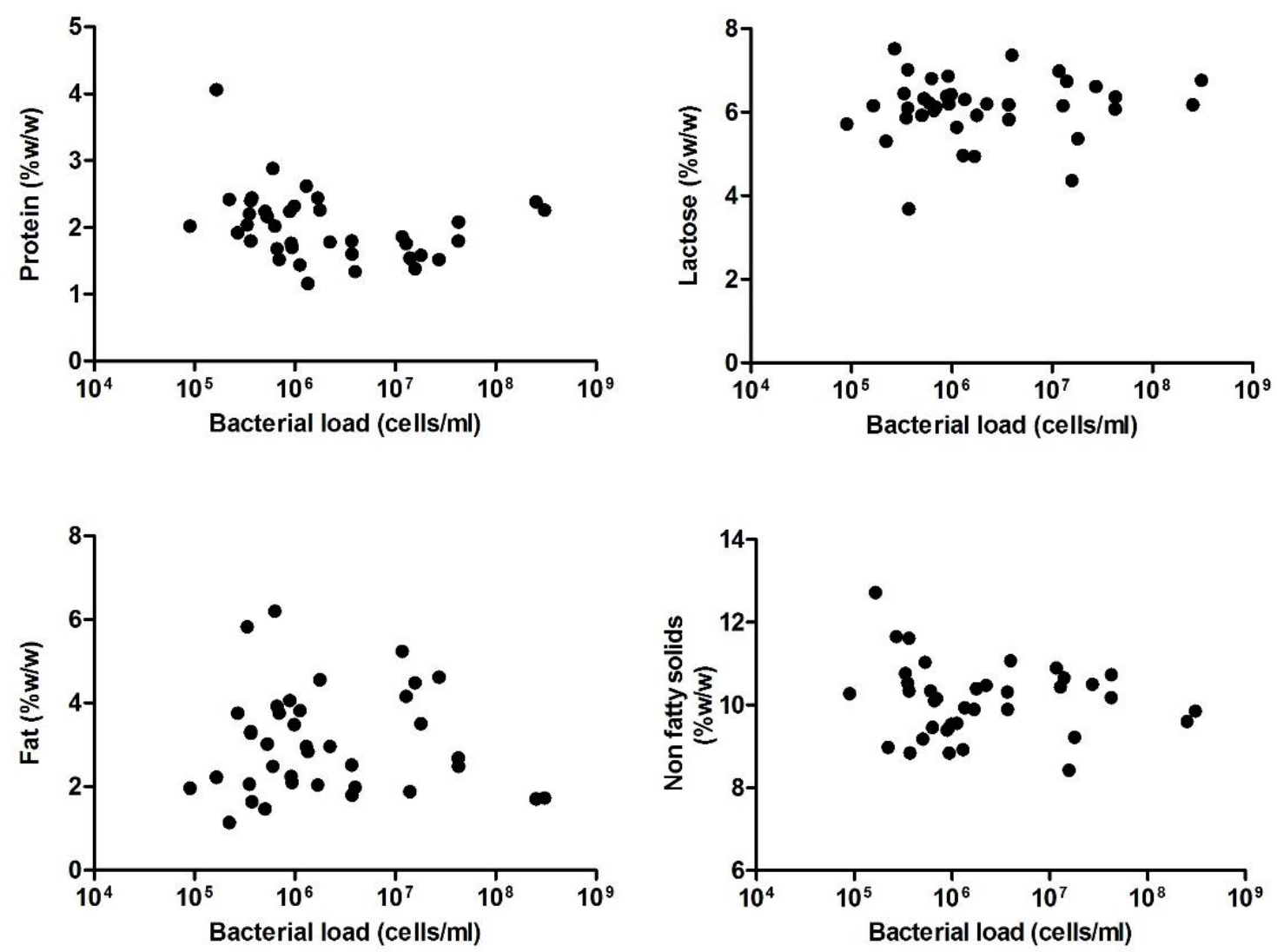

Supplementary Figure 1. Relationships between bacterial load and macronutrients in human milk. The graphs show the comparison between bacterial load and: (A) protein, (B) lactose, (C) fat, and (D) non fatty solids in the samples $(n=38)$. 


\section{Chapter 2}

\section{Multiple Approaches Detect the Presence of Fungi in Human Breast milk Samples from Healthy Mothers}

Alba Boix-Amorós, Cecilia Martínez-Costa, Amparo Querol, María Carmen Collado, Alex Mira

This chapter has been published as: Boix-Amorós A, Martinez-Costa C, Querol A, Collado MC, Mira A. 2017. Multiple Approaches Detect the Presence of Fungi in Human Breastmilk Samples from Healthy Mothers. Scientific Reports, 7(1): 13016. 


\begin{abstract}
Human breast milk contains a variety of bacteria that are transmitted to the infant and have been suggested to contribute to gut microbiota development and immune maturation. However, the characterization of fungal organisms in milk from healthy mothers is currently unknown, although their presence has been reported in the infant gut and also in milk from other mammals. Breast milk samples from healthy lactating mothers $(n=65)$ within 1 month after birth were analyzed. Fungal presence was assessed by different techniques, including microscopy, growth and identification of cultured isolates, fungal load estimation by qPCR, and fungal composition using $28 \mathrm{~S}$ rRNA gene high-throughput sequencing. In addition, milk macronutrients and human somatic cells were quantified by spectrophotometry and cytometry. qPCR data showed that $89 \%$ of samples had detectable levels of fungal DNA, at an estimated median load of $3,5 \times 10^{5}$ cells/ml, potentially including both viable and non-viable fungi. Using different culture media, 33 strains were isolated and identified, confirming the presence of viable fungal species. Pyrosequencing results showed that the most common genera were Malassezia (44\%), followed by Candida (19\%) and Saccharomyces (12\%). Yeast cells were observed by fluorescence microscopy. Future work should study the origin of these fungi and their potential contribution to infant health.
\end{abstract}




\section{Introduction}

Microbiome development in the new-born is a stepwise and crucial process, contributing at the physiological level and influencing the development and maturation of the immune system. During delivery, the neonate is exposed to maternal microbes, first from the mother's reproductive system, rapidly after from the maternal skin and the environment, and later is influenced by diet, including breastfeeding. Breast milk plays an important role in the microbial supply as it contains a variety of potential beneficial bacteria, as well as a wide source of nutrients and essential protective substances that makes it the optimal nutrition for the infant (Petherick 2010; Walker 2010). Those bacteria residing in breast milk are transmitted to the infant during breastfeeding, getting to the intestine and contributing to the settlement of the gut microbiota and acquired immunity (Jost et al. 2014). Although bacteria in human milk have been widely assessed, information about the natural presence of fungal species is generally lacking, and it is limited to a few studies focused on mammary infections describing breast candidiasis (Amir et al. 1996, 2013), and a recent metagenomic study on human breast milk from mothers suffering from mastitis, which confirmed the presence of fungal sequences, in addition to the dominant bacterial fraction (Jiménez et al. 2015). However, fungal presence in the milk of other mammals has been widely described in several studies (Callon et al. 2006, 2007; Cocolin et al. 2002; Corbo et al. 2001; Delavenne et al. 2011; Spanamberg et al. 2014), which supports the idea that human milk could also contain fungi under normal, healthy conditions. Furthermore, there is evidence that fungal species (yeast-like mainly) can be found in the infant gut early in life (Bliss et al. 2008; Heisel et al. 2015; LaTuga et al. 2011; Schulze \& Sonnenborn 2009; Seddik et al. 2016). The importance of the fungal component -mycobiome- in the human gut has received increased attention by researchers, as it is part of human microbial homeostasis, and changes on it can have direct effects on the host health status (Hatoum et al. 2012; Oever \& Netea 2014; Underhill \& Iliev 2014). It is therefore plausible that colonization of fungal species in the new-born would be important in the early settlement of human microbiota and for immune system development. Therefore, there exists the possibility that breast milk could be playing an important role in the supply of fungal, as well as bacterial, species to the new-born. In this pilot study, we aimed to study and identify the presence of fungal species in breast milk samples from healthy mothers by using molecular approaches and high throughput sequencing, as well as through classical culture methods. We also studied the potential relationships between fungal load and diversity with milk macronutrients composition and human cells' counts. 


\section{Material and Methods}

\section{Subjects and sampling}

Breast milk samples from healthy lactating mothers $(n=65)$ within 1 month after birth were analyzed in this study (colostrum: $n=16$; transitional milk: $n=14$; mature milk samples: $\mathrm{n}=28$ ). Details of mode of delivery and gestational age were collected after birth. All infants were in good health. Previous to sample collection, nipples and mammary areola were cleaned with soap and sterile water and soaked in chlorhexidine to reduce sampling of microorganisms residing on the skin. Milk samples were collected in a sterile tube manually, discarding the first drops. All samples were frozen at $-20^{\circ} \mathrm{C}$ until further processing. Before sample collection, the mothers received oral and written information, and gave written informed consent to the protocol, which had been approved by the Ethics Committee of the Hospital Clínico Universitario de Valencia (Spain), and the Bioethics Subcommittee of Consejo Superior de Investigaciones Cientificas (CSIC). All the methods were carried out in accordance with the relevant guidelines and regulations.

\section{Culture and identification of fungal colonies}

One $\mathrm{ml}$ of each breast milk sample was centrifuged 10 minutes at 9,000 rpm; fat was removed and pellets were resuspended in $400 \mu \mathrm{l}$ of sterile water. $100 \mu \mathrm{l}$ were plated in four solid fungal-selective media: Sabouraud (40 g/l dextrose, $10 \mathrm{~g} / 1$ peptone and $20 \mathrm{~g} / \mathrm{l}$ agar) supplemented with cloramphenicol $0.05 \mathrm{~g} / \mathrm{l}$ (Roche); Rose Bengal (CondaPronadisa); CHROMagar ${ }^{\mathrm{TM}}$ Malassezia and YPD (40 g/l dextrose, $40 \mathrm{~g} / \mathrm{l}$ peptone, $20 \mathrm{~g} / \mathrm{l}$ yeast extract and $40 \mathrm{~g} / \mathrm{l}$ agar) supplemented with $25 \mu \mathrm{g} / \mathrm{ml}$ of streptomycin and $25 \mathrm{U} / \mathrm{ml}$ of penicillin (Biowest), and incubated aerobically at $37^{\circ} \mathrm{C}$. Positive control for Malasezzia CHROMagar medium was Malassezia cuniculi (CECT 13051; CBS 11721). Negative controls were included for each culture medium. All isolated colonies were analyzed under the microscope to confirm fungal morphology and were further isolated to obtain single-cell pure colonies. DNA extraction was performed following the method described in detail in the Fungal DNA Isolation Section, and $4 \mu 1$ were amplified by PCR using primers targeting the $18 \mathrm{~S}$ rRNA gene (forward: 5'-GTAGTCATATGCTTGTCTC; and reverse: $5^{\prime}$-CCATTCCCCGTTACCCGTTG); and the ribosomal Internal Transcribed Spacer (ITS) region, using ITS1F: 5'-TCCGTAGGTGAACCTGCGG (White TJ, Bruns T, Lee S 1990); and 5.8R: 5'-CGCTGCGTTCTTCATCG (Vilgalys \& Hester 1990) primers. PCR products were sequenced in an Applied Biosystems ${ }^{\circledR}$ 3730/3730xl DNA Analyzer at University of Valencia (Spain) and fungal isolates were identified by using the BLAST algorithm in the NCBI database, with minimum $98 \%$ sequence identity. To test if all C. parapsilosis isolates and all $R$. mucilaginosa isolates, the two more prevalent isolates detected in our samples, were genetically identical, we performed a multiple alignment and generated a homology tree using DNAMAN software (version 7.212, Lynnon Corp., Canada). 


\section{Phenotypic characterisation of fungal isolates}

Sugars utilization and growth at different temperatures

Isolates were plated on Yeast Nitrogen Base agar without amino acids (Difco). Four different plate types were prepared: YNB without sugars, and YBN with a sole carbohydrate source (lactose, and glucose and sucrose as controls). Media were prepared by making a 10x concentrated stock solution with $6.8 \mathrm{~g}$ yeast nitrogen base powder, $1.5 \mathrm{~g}$ agar and $5 \mathrm{~g}$ of the selected sugar (except in the "no-sugar" plates), in $100 \mathrm{~mL}$ water, that was filtered and further diluted in $900 \mathrm{ml}$ sterile water. Isolates were resuspended in $1 \mathrm{ml}$ of sterile water and incubated at $30^{\circ} \mathrm{C}$ degrees for 1 hour to induce starvation. $50 \mu \mathrm{l}$ were plated in the corresponding medium and incubated at $30^{\circ} \mathrm{C}$ until colonies appeared (1-3 days). In order to check for temperature resistance, isolates were plated on GPY agar plates $(0.5 \% \mathrm{w} / \mathrm{v}$ yeast extract (Pronadisa), 0.5\% w/v peptone (Oxoid LTD), $4 \% \mathrm{w} / \mathrm{v}$ glucose (Panreac), and $2 \% \mathrm{w} / \mathrm{v}$ agar (Panreac)), and were incubated at three different temperatures: $28^{\circ} \mathrm{C}, 37^{\circ} \mathrm{C}$ and $42^{\circ} \mathrm{C}$ until colonies appeared (1-3 days).

\section{Resistance to oxidative stress}

Strains were grown overnight in GPY agar plates at $30^{\circ} \mathrm{C}$. S. cerevisiae wine strain (T73) and baker strain ("Cinta Roja") were included as controls. After adjusting to $0.1 \mathrm{OD}$ in PBS, $6 \mathrm{mM}$ hydrogen peroxide $\left(\mathrm{H}_{2} \mathrm{O}_{2}\right)$ (Panreac) were added and samples were incubated for one hour at $30^{\circ} \mathrm{C}$ with shaking. Dilutions 1:10, 1:100 and 1:1000 were done and $15 \mu \mathrm{l}$ from each dilution were deposited in a drop on GPY agar plates. Plates were incubated for $48 \mathrm{~h}$ at $30^{\circ} \mathrm{C}$.

\section{Genetic characterization of breast milk S. cerevisiae strain: mtDNA restriction patterns and $\delta$-PCR amplification patterns analysis}

DNA of the S. cerevisiae FBMI18 isolate, as well as DNA from three S. cerevisiae control strains (Wine yeast T73, baker yeast "Cinta roja" and S. boulardii, which is a therapeutic S. cerevisiae strain marketed as Ultralevura ${ }^{\circledR}$ for probiotic purposes) were isolated according to De Llanos et al. (de Llanos et al. 2006). The 5.8S-ITS region was amplified using the primers, PCR reaction conditions and thermal cycling parameters described previously by De Llanos et al. (de Llanos et al. 2004) The mtDNA restriction analysis was performed according to the method described by Querol et al (Querol et al. 1992). The amplified DNA $(10 \mu \mathrm{l})$ was digested with Hinf I restriction endonuclease (Roche Molecular Biochemicals), following the supplier's instructions. Restriction fragments were separated in $0.8 \%(\mathrm{w} / \mathrm{v})$ agarose (Pronadisa) gels in $1 \times$ TAE buffer. Electrophoresis gels were stained with ethidium bromide $(0.5 \mu \mathrm{g} / \mathrm{ml})$ (Sigma-Aldrich Chemie) and visualized with UV light. The DNA of phage $\lambda$ digested with Pst I (Roche Molecular Biochemicals) served as size standard. $\delta$ sequences were amplified in a GeneAmp PCR System 9700 (Perkin Elmer, California, USA) using the primers, PCR reaction conditions and thermal cycling parameters described previously by De Llanos et al. (de Llanos et al. 
2004). The PCR products were separated on $1.4 \%(\mathrm{w} / \mathrm{v})$ agarose (Pronadisa) gel in $1 \times$ TAE buffer. After that, electrophoresis gels were stained and visualised as described above.

\section{FISH detection of fungi in milk}

Fluorescent in situ hybridization (FISH) was performed on 5 milk samples to detect fungi, as an alternative method to DNA sequencing and culture-based methods, by using the Euk516 probe (5'-ACCAGACTTGCCCTCC) targeting the $18 \mathrm{~S}$ rRNA gene (Amann et al. 1990), labeled with fluorescein isothiocyanate (FITC) at the $5^{\prime}$ end. Suspensions of previously fixed breast milk samples (fixed with paraformaldehyde at $4 \%$ final concentration, overnight incubation) were vortexed thoroughly, and $100 \mu \mathrm{l}$ aliquots were dispensed to new microcentrifuge tubes and pelleted (6000 rpm, $10 \mathrm{~min})$. Supernatant was removed and cell pellets were resuspended in $100 \mu \mathrm{l}$ of hybridization buffer preheated to $50^{\circ} \mathrm{C}$. Hybridization buffer consisted of $20 \mathrm{mM}$ Tris [pH 8.0], 0.9 $\mathrm{M} \mathrm{NaCl}, 0.01 \%$ SDS and miliQ water. One microliter of the probe was added to the mix (concentration $100 \mathrm{mM}$ ), and suspensions were hybridized at $53^{\circ} \mathrm{C}$ overnight on an AccuBlock $^{\mathrm{TM}}$ heat block. After that, $500 \mu \mathrm{l}$ wash buffer (hybridization buffer without probe, preheated to $50^{\circ} \mathrm{C}$ ) was added, samples were vortexed and centrifuged $5 \mathrm{~min}$ at 9,000 rpm and pellets resuspended in $100 \mu \mathrm{l}$ of PBS. Calcofluor White Stain (SigmaAldrich) at $0.01 \%$ was added to the suspension and used as second marker, as it binds to cellulose and chitin of fungal cell walls (Harriott \& Noverr 2009). An isolated strain of Candida parapsilosis from one of our samples was included as positive control (FBMI4). Samples were visualized with fluorescence microscopy using a Nikon Eclipse E90i microscope (Nikon Corporation) with a 100× objective. Images were processed using NIS-Elements BR v3.22 software (Nikon).

\section{Fungal DNA isolation}

Milk samples $(5 \mathrm{ml})$ were thawed and centrifuged at 4,000 $\mathrm{x}$ g for 20 minutes to separate fat and cells from whey. Thereafter, total DNA was isolated from the pellets by using the MasterPure Complete DNA \& RNA Purification Kit (Epicentre) according to the manufacturer's instructions with some modifications (Simón-Soro et al. 2015). $250 \mu \mathrm{l}$ of sterile saline solution and $250 \mu \mathrm{l}$ of lysis buffer were added to the pellets, together with a mix of 150-212 $\mu \mathrm{m}$ and 425-600 $\mu \mathrm{m}$, acid-washed glass beads (Sigma). To enhance the disruption of fungal cell walls, samples were put through three cycles of vigorous mixing in a TissueLyser II (QIAGEN) $5 \mathrm{~min}$ at $30 \mathrm{~Hz}$, incubation in dry ice 3 minutes and 5 minutes at $65^{\circ} \mathrm{C}$ in a heat block. Lysozyme $(20 \mathrm{mg} / \mathrm{ml})$ and zymolyase $(0.25 \mathrm{mg} / \mathrm{ml})$ were added to the tubes, and samples were incubated for $1 \mathrm{~h}$ at $37^{\circ} \mathrm{C}$. $2 \mu \mathrm{l}$ of proteinase $\mathrm{K}$ were added and samples were incubated for 15 minutes at $65^{\circ} \mathrm{C}$. The reaction was stopped by putting tubes on ice and proteins were precipitated using $350 \mu \mathrm{l}$ of MPC Protein Precipitation Solution, and discarding the pellets. DNA was precipitated using 
isopropanol, washed with $70 \%$ Ethanol and resuspended with $30 \mu \mathrm{l} \mathrm{TE} \mathrm{buffer.} \mathrm{The} \mathrm{total}$ DNA isolated was quantified with a Qubit ${ }^{\mathrm{TM}} 3$ Fluorometer (ThermoScientific).

\section{Quantitative real-time polymerase chain reaction analysis of fungal loads}

qPCR amplification and detection were performed with primers targeted to the conserved ITS1-5.8S rRNA fungal region, described in detail in the Culture and Identification of Fungal Colonies Section, using an annealing temperature of $61^{\circ} \mathrm{C}$ in a Light Cycler 480 Real-Time PCR System (Roche Technologies). Each reaction mixture of $20 \mu \mathrm{l}$ was composed of $10 \mu \mathrm{l}$ of KAPA Sybr Fast qPCR Kit (KAPA Biosistems), $0.4 \mu \mathrm{l}$ of each primer (10 $\mu \mathrm{M}$ concentration) and $2 \mu \mathrm{l}$ of template DNA. All amplifications were performed in duplicates and a negative control was included in each qPCR reaction run. The fungal concentration in each sample was calculated by comparison with the $\mathrm{Ct}$ values obtained from a standard curve. These were generated using serial ten-fold dilutions of DNA extracted from 10 million fungal cells from 5 pure cultures from different fungal species (Candida albicans, Malassezia cuniculi, Sacharomyces boulardii, Thrichosporon cutaneum and Mucor circinelloides), that were pooled to create a single standard curve. Fungal cells were quantified and sorted using a BD FACSAriaTM II cytometer after mild sonication to separate aggregated cells. Under the described PCR conditions, the fungal primers did not amplify human or bacterial DNA, when using DNA from human umbilical vein endothelial cells (Advancell, Spain) (García-Tejedor et al. 2015) and a mix of bacterial-species DNA (Staphylococcus epidermidis, Pseudomonas aeruginosa, Streptococcus mitis, Bifidobacterium dentium and Rothia mucilaginosa). Averages were calculated for duplicates of Ct values in every sample, and inconsistent duplicates were re-run. A standard curve was included in each run (three runs were needed in total). Milk samples that showed Ct values equal or higher than the negative control were considered to be negative for fungal DNA. One-way ANOVA (Kruskal-Wallis test) was performed for groups' comparison, using GraphPad PRISM ${ }^{R} 6$ (GraphPad Software). Bacterial load data from the same samples were also obtained using primers targeting the bacterial universal single-copy gene fusA (Boix-Amorós et al. 2016).

\section{PCR amplification and sequencing}

Fungal DNA for sequencing was amplified by PCR from the 15 milk samples with the highest fungal load previously obtained by $\mathrm{qPCR}$, using universal fungal primers against the 28S rRNA gene: LROR: 5'-ACCCGCTGAACTTAAGC; and LR3: 5' CCGTGTTTCAAGACGG (Liu et al. 2012), by the use of high-fidelity AB-Gene DNA polymerase (ThermoScientific) with an annealing temperature of $52^{\circ} \mathrm{C}$ and 20 cycles. A secondary amplification was performed by using the purified PCR product as a template, in which the universal primers were modified to contain the pyrosequencing adaptors A and B and an 8-bp "barcode" specific to each sample, following the method used in Benitez-Paez et al (Benítez-Páez et al. 2013). Negative controls were included in primary and secondary amplifications using water and the purified PCR product from 
the primary amplification, respectively. The purification of the $610 \mathrm{bp}$ PCR products was performed with NucleoFast 96 PCR filter plates (Macherey-Nagel), and the final concentration of the DNA per sample was measured with a Qubit ${ }^{\mathrm{TM}} 3$ Fluorometer (ThermoScientific). PCR products were pyrosequenced from the reverse primer end using a 454 Life Sciences system, in a GS-FLX sequencer with Titanium chemistry (Roche) at Macrogen Korea (Rep. of Korea). A negative control for the sequencing run was also included by Macrogen to discard contamination. The amplification of a long $28 \mathrm{~S}$ rRNA region increases accuracy in taxonomic assignment due to the implementation of a machine-learning algorithm from the Ribosomal Database Project (RDP) platform (Liu et al. 2012) and to the amplification of fragments with the same size, as opposed to ITS regions of variable length that would be differentially sequenced in secondgeneration sequencing platforms.

\section{Data analysis}

Sequences with an average quality value $<20$ and/or with $>4$ ambiguities in homopolymeric regions in the first 360 flows were excluded from the analysis. 28S rRNA gene reads were end-trimmed in $20 \mathrm{bp}$ sliding windows with average quality value $>20$, then length ( $>400 \mathrm{bp}$ ) and quality filtered (average $Q>20$ ), through the Galaxy server (http;//getgalaxy.org/). Chimeric reads were eliminated using UCHIME (Edgar et al. 2011), and only sequences longer than $400 \mathrm{bp}$ were considered, resulting in a total of 17,000 reads with a mean of $1,700 \pm 444.9$ (SE) sequences per sample. Sequences were assigned to each sample by the 8-bp barcode and phylum-, family- and genus-level taxonomic assignment of sequences that passed quality control were made using the Ribosomal Database Project classifier software (Wang et al. 2007) within an 80\% confidence threshold. Sequences $>97 \%$ identical were considered to correspond to the same operational taxonomical unit (OTU), representing a group of sequences that presumably correspond to the same species (Strati et al. 2016). Sequences were clustered at $97 \%$ nucleotide identity over $90 \%$ sequence alignment length using the CD-hit software (Li \& Godzik 2006). BLASTn was performed against the RDP LSU database for taxonomically assigning reads at the species level (Altschul et al. 1990). Only top hits with $>98 \%$ similarity and $>400$ bp alignment length were considered.

\section{Milk macronutrient composition analysis}

Fat, protein and lactose composition (\% w/w) was analyzed by spectrophotometry using a MilkoScan FT 6000 (FOSS). Somatic cells (cells/ml) were determined using an Integrated Milk Testing Fossomatic FC (FOSS) cytometer, in LICOVAL-UPV, Polytechnic University of Valencia (Spain), when the samples' volume was sufficient $(\mathrm{n}=34)$. 


\section{Statistical analysis}

$R$ software (version 3.2.2) (R Development Core Team. 2011) was used for computing Spearman's correlation coefficients using the stats package, and heatmap plots with gplots package (Warnes et al. 2015). Other statistical analysis and graphs were performed using GraphPad PRISMR 6 (GraphPad Software).

\section{Data availability}

The datasets generated during the current study are available in the European Nucleotide Archive (ENA, EMBL-EBI) repository at http://www.ebi.ac.uk/ena/data/view/PRJEB19310, with accession num. PRJEB19310.

\section{Results}

\section{Viable fungi in breast milk and fluorescence microscopy}

The cultivable fraction of breast milk fungi from 41 healthy mothers was investigated through isolation in selective culture media. Fungi were detected in 17 of the samples (representing $41 \%$ of all analyzed samples) leading to the identification of 33 isolates, either with one or two primer pairs used in an identification PCR (Table 1). Twenty-five of them were well-assigned to a specific species with one pair of primers or both of them, three presented inconsistencies in the results between the two primers used, and the rest were assigned to uncultured species. The majority of the well-assigned isolates corresponded to the yeasts Candida parapsilosis and Rhodotorula mucilaginosa, and were found to belong to different strains as inferred from phylogenetic trees (Supplementary Figure 1), discarding contamination from a given strain in the laboratory and supporting the unique presence of both of these species in breast milk. The presence of fungal species in breast milk was also confirmed by Fluorescent in situ Hybdirization (FISH) targeting the 18S rRNA gene (EUK516-FITC probe) and by Calcofluor White staining by fluorescence microscopy. Only yeast cells and no hyphal forms were visualized in the analyzed samples (Figure 1). 
Table 1. Fungal species isolated in selective growth media.

\begin{tabular}{|c|c|c|c|c|c|c|c|}
\hline $\begin{array}{l}\text { Isolate } \\
\text { Code }\end{array}$ & Species & \begin{tabular}{|l|} 
Max \\
score $^{a}$
\end{tabular} & $\begin{array}{l}\text { query } \\
\text { cover }^{\mathrm{b}}\end{array}$ & $\begin{array}{l}\text { BLAST } \\
\text { e-value }\end{array}$ & Max identity & Accession $\mathrm{N}^{\circ}$ & $\begin{array}{l}\text { Culture } \\
\text { medium }\end{array}$ \\
\hline FBMI1 & Candida parapsilosis ${ }^{1}$ & 337 & $94 \%$ & 6,00E-89 & $100 \%$ & KT876525.1 & SB \\
\hline FBMI2 & Candida parapsilosis ${ }^{1}$ & 324 & $94 \%$ & 5,00E-85 & $99 \%$ & KT694025.1 & SB \\
\hline FBMI3 & Uncultured fungus $^{1}$ & 204 & $97 \%$ & 4,00E-49 & $96 \%$ & FJ235880.1 & SB \\
\hline FBMI4 & Candida parapsilosis $^{1}$ & 549 & $98 \%$ & $2,00 \mathrm{E}-152$ & $94 \%$ & KJ880928.1 & SB \\
\hline \multirow[t]{2}{*}{ FBMI5 } & Talaromyces stollii ${ }^{1}$ & 392 & $61 \%$ & $3,00 \mathrm{E}-105$ & $99 \%$ & AB910938.1 & M \\
\hline & Talaromyces purpurogenus ${ }^{2}$ & 568 & $100 \%$ & $4,00 \mathrm{E}-158$ & $99 \%$ & KC009578.1 & M \\
\hline \multirow[t]{2}{*}{ FBMI6 } & Rhodotorula mucilaginos $a^{1}$ & 350 & $96 \%$ & 9,00E-93 & $99 \%$ & EU781664.1 & M \\
\hline & Rhodotorula mucilaginos $a^{2}$ & 351 & $59 \%$ & 7,00E-93 & $94 \%$ & LT220852.1 & M \\
\hline \multirow[t]{2}{*}{ FBMI7 } & Candida parapsilosis ${ }^{1}$ & 348 & $99 \%$ & 3,00E-92 & $100 \%$ & KU739407.1 & M \\
\hline & Candida parapsilosis ${ }^{2}$ & 571 & $99 \%$ & 3,00E-159 & $100 \%$ & HE605209.1 & M \\
\hline \multirow[t]{2}{*}{ FBMI8 } & Rhodotorula mucilaginos $a^{1}$ & 346 & $100 \%$ & 1,00E-91 & $100 \%$ & KU724343.1 & M \\
\hline & Rhodotorula mucilaginos $a^{2}$ & 560 & $99 \%$ & 6,00E-156 & $100 \%$ & FJ538169.1 & M \\
\hline \multirow[t]{2}{*}{ FBMI9 } & Rhodotorula mucilaginos $a^{1}$ & 335 & $95 \%$ & $2,00 \mathrm{E}-88$ & $98 \%$ & KT876599.1 & SB \\
\hline & Rhodotorula mucilaginos $a^{2}$ & 560 & $99 \%$ & 6,00E-156 & $100 \%$ & FJ538169.1 & SB \\
\hline \multirow[t]{2}{*}{ FBMI10 } & Cryptococcus diffluens $^{1}$ & 357 & $99 \%$ & 5,00E-95 & $99 \%$ & LN808927.1 & SB \\
\hline & ${\text { Uncultured fungus }{ }^{2}}$ & 569 & $99 \%$ & 1,00E-158 & $100 \%$ & KC670786.1 & SB \\
\hline FBMI11 & Rhodotorula mucilaginosa $a^{1}$ & 357 & $100 \%$ & 5,00E-95 & $99 \%$ & EU781664.1 & RB \\
\hline FBMI12 & ${\text { Rhodotorula mucilaginos }{ }^{1}}^{1}$ & 351 & $98 \%$ & 2,00E-93 & $100 \%$ & EU781664.1 & RB \\
\hline FBMI13 & Uncultured fungus ${ }^{2}$ & 58.4 & $94 \%$ & 1,00E-04 & $100 \%$ & HQ190233.1 & M \\
\hline FBMI14 & Yarrowia lipolytica $^{2}$ & 488 & $99 \%$ & $3,00 \mathrm{E}-134$ & $99 \%$ & AF156969.1 & SB \\
\hline \multirow[t]{2}{*}{ FBMI15 } & Yarrowia deformans $^{1}$ & 189 & $96 \%$ & 9,00E-45 & $100 \%$ & KY105960.1 & RB \\
\hline & Yarrowia lipolytica $^{2}$ & 488 & $99 \%$ & 3,00E-134 & $99 \%$ & AF156969.1 & RB \\
\hline FBMI16 & Rhodotorula mucilaginos $a^{2}$ & 562 & $97 \%$ & 2,00E-156 & $99 \%$ & FJ538169.1 & M \\
\hline \multirow[t]{2}{*}{ FBMI17 } & Rhodotorula mucilaginos $a^{1}$ & 316 & $99 \%$ & $7,00 \mathrm{E}-83$ & $100 \%$ & KY104848.1 & SB \\
\hline & Rhodotorula mucilaginosa ${ }^{2}$ & 538 & $100 \%$ & 3,00E-149 & $100 \%$ & JQ838010.1 & SB \\
\hline FBMI18 & Saccharomyces cerevisiae $^{2}$ & 564 & $91 \%$ & 6,00E-157 & $99 \%$ & KX270743.1 & SB \\
\hline \multirow[t]{2}{*}{ FBMI19 } & ${\text { Rhodotorula mucilaginos }{ }^{1}}^{1}$ & 287 & $90 \%$ & $6,00 \mathrm{E}-74$ & $98 \%$ & KX866274.1 & M \\
\hline & Rhodotorula mucilaginos $a^{2}$ & 534 & $98 \%$ & $4,00 \mathrm{E}-148$ & $100 \%$ & JQ838010.1 & M \\
\hline \multirow[t]{2}{*}{ FBMI20 } & Uncultured fungus $^{1}$ & 250 & $100 \%$ & $8,00 \mathrm{E}-63$ & $92 \%$ & FM875845.1 & M \\
\hline & Rhodotorula mucilaginosa ${ }^{2}$ & 542 & $100 \%$ & $2,00 \mathrm{E}-150$ & $100 \%$ & JQ838010.1 & M \\
\hline FBMI21 & Cryptococcus sp. ${ }^{1}$ & 281 & $100 \%$ & 2,00E-72 & $100 \%$ & KU961663.1 & M \\
\hline \multirow[t]{2}{*}{ FBMI22 } & Rhodotorula mucilaginos $a^{1}$ & 315 & $98 \%$ & $3,00 \mathrm{E}-82$ & $100 \%$ & KY104848.1 & M \\
\hline & Rhodotorula mucilaginos $a^{2}$ & 529 & $100 \%$ & $2,00 \mathrm{E}-146$ & $99 \%$ & KM222229.1 & M \\
\hline FBMI23 & Rhodotorula mucilaginos $a^{2}$ & 534 & $99 \%$ & 3,00E-148 & $100 \%$ & JQ838010.1 & SB \\
\hline FBMI24 & Uncultured eukaryote $^{2}$ & 518 & $96 \%$ & $4,00 \mathrm{E}-143$ & $99 \%$ & KT752764.1 & RB \\
\hline \multirow[t]{2}{*}{ FBMI25 } & Clavispora lusitaniae $^{1}$ & 196 & $93 \%$ & $6,00 \mathrm{E}-47$ & $99 \%$ & KY102561.1 & SB \\
\hline & Clavispora lusitaniae $^{2}$ & 523 & $100 \%$ & $8,00 \mathrm{E}-145$ & $99 \%$ & KP317754.1 & SB \\
\hline \multirow[t]{2}{*}{ FBMI26 } & Candida parapsilosis ${ }^{1}$ & 268 & $98 \%$ & 2E-68 & $100 \%$ & KY619304.1 & M \\
\hline & Candida parapsilosis ${ }^{n}$ & 549 & $100 \%$ & 1E-152 & $100 \%$ & KT199380.1 & M \\
\hline \multirow[t]{2}{*}{ FBMI27 } & Candida parapsilosis ${ }^{1}$ & 267 & $100 \%$ & 7E-68 & $99 \%$ & KY619304.1 & M \\
\hline & Candida parapsilosis $^{n}$ & 536 & $98 \%$ & 1E-148 & $99 \%$ & KT199380.1 & M \\
\hline \multirow[t]{2}{*}{ FBMI28 } & Candida parapsilosis ${ }^{1}$ & 333 & $100 \%$ & $8 \mathrm{E}-88$ & $100 \%$ & KJ880926.1 & YPD \\
\hline & Candida parapsilosis ${ }^{2}$ & 531 & $100 \%$ & $5 \mathrm{E}-147$ & $99 \%$ & KT199380.1 & YPD \\
\hline \multirow[t]{2}{*}{ FBMI29 } & Candida parapsilosis ${ }^{1}$ & 335 & $97 \%$ & $2 \mathrm{E}-88$ & $100 \%$ & KT694025.1 & SB \\
\hline & Candida parapsilosis ${ }^{2}$ & 540 & $100 \%$ & $8 \mathrm{E}-150$ & $100 \%$ & KT199380.1 & SB \\
\hline FBMI30 & Candida orthopsilosis $^{2}$ & 510 & $99 \%$ & $6 \mathrm{E}-141$ & $99 \%$ & KU058170.1 & YPD \\
\hline FBMI31 & Candida albicans $^{2}$ & 520 & $100 \%$ & 1E-143 & $100 \%$ & XR002086442.1 & YPD \\
\hline FBMI32 & Candida albicans $^{2}$ & 438 & $74 \%$ & 3E-119 & $100 \%$ & XR002086442.1 & YPD \\
\hline FBMI33 & Uncultured Ascomycota ${ }^{2}$ & 556 & $93 \%$ & 9,00E-155 & $99 \%$ & GQ404735.1 & YPD \\
\hline
\end{tabular}

${ }^{1}$ Isolates identified with ITS1-ITS2 primers. ${ }^{2}$ Isolates identified with 185 primers. ${ }^{\text {aBLAST }}$ alignment score from the top hit against the NCBI database. bPercentage of query sequence covered by the alignment. cHighest percent identity of all query-subject alignments. ${ }^{\text {SBSabouraud. MMalassezia CHROMagar. }{ }^{\mathrm{RB}} \text { Rose }}$ Bengal. 


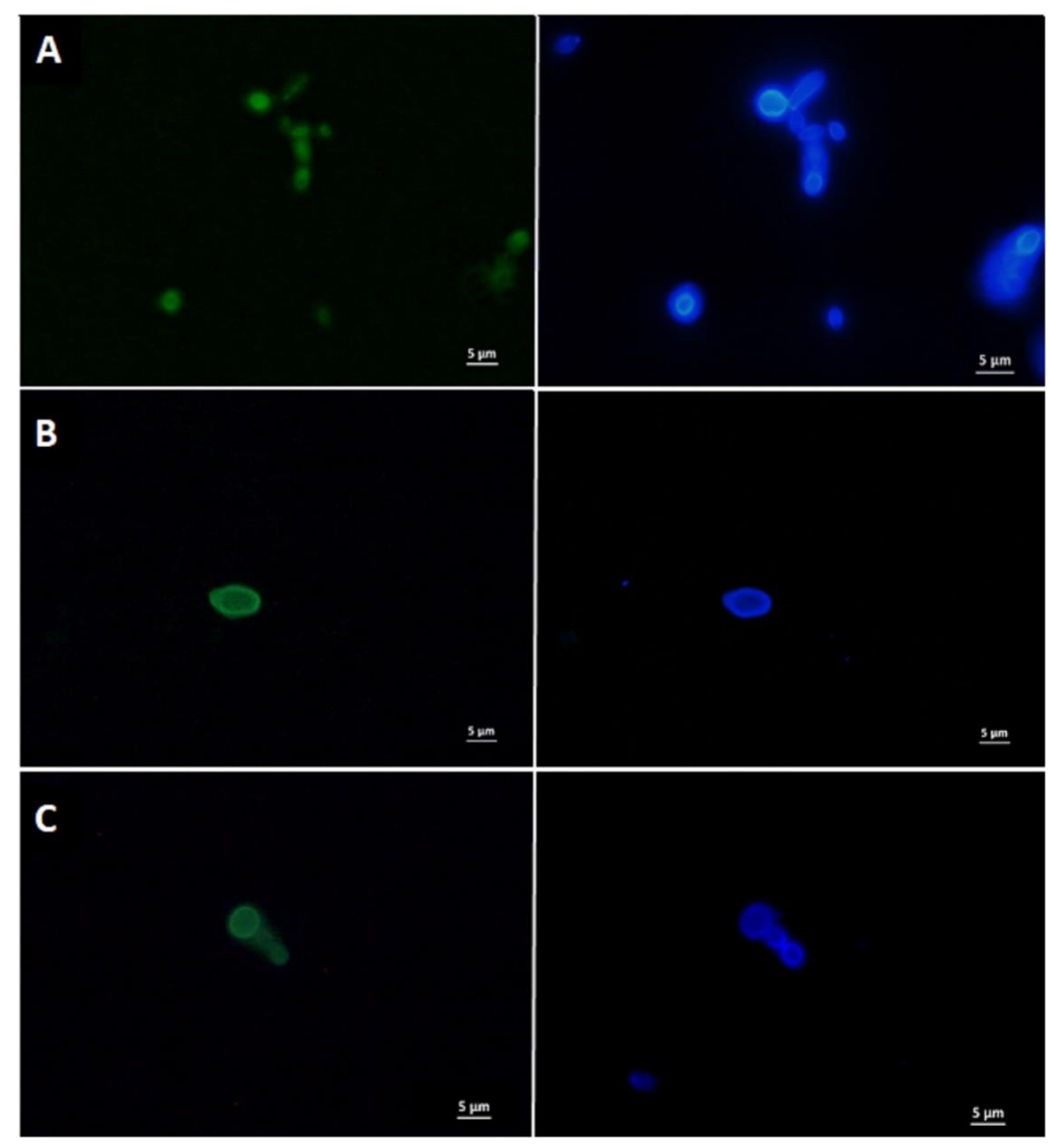

Figure 1. Fluorescent microscopy images of yeasts detected in breast milk. Left panels are showing the yeasts stained in green with the EUK516 FISH probe targeting the 18S rRNA gene. Right panels are showing the yeasts stained in blue with calcofluor. (A) Candida parapsilosis isolate FBMI4 (positive control). (B) Yeast from fixed transitional breast milk sample BMF9. C) Yeasts from fixed colostrum sample BMF5.

\section{Isolates phenotypic characterization}

One sample from each of the two most prevalent isolates, Rhodotorula mucilaginosa (isolate FBMI6) and Candida parapsilosis (isolate FBMI7) were further characterized in order to determine their potential adaptation to human milk. For reference, we also included the Saccharomyces cerevisiae isolate (FBMI18), due to its interest for the biotechnological industry.

Sugars utilization and growth at different temperatures

Yeasts growth at different temperatures $\left(28^{\circ} \mathrm{C}, 37^{\circ} \mathrm{C}\right.$ and $\left.42^{\circ} \mathrm{C}\right)$, and their ability to metabolize sugars naturally present in human milk (lactose) are shown in Supplementary Figure 2 (a). The optimal growth temperature for Saccharomyces species 
is usually $\sim 24-26^{\circ} \mathrm{C}$, for Rhodotorula mucilaginosa $\sim 24^{\circ} \mathrm{C}$, and for Candida parapsilosis $\sim 30^{\circ} \mathrm{C}-35^{\circ} \mathrm{C}$ (temperature conditions according to the American Type Culture Collection, www.atcc.org). The fact that we were able to obtain viable isolates of these strains from human milk, which is at a temperature of $\sim 37^{\circ} \mathrm{C}$, suggests an adaptation to the human body. We tested the strains viability at $37^{\circ} \mathrm{C}$ and $42{ }^{\circ} \mathrm{C}$. The three isolates were able to grow at any temperature, although the growth of isolate FBMI6 ( $R$. mucilaginosa) was reduced at $42^{\circ} \mathrm{C}$ compared to the other species. The Sacharomyces cerevisiae T73 wine strain included as a control was not able to grow at $37^{\circ} \mathrm{C}$ nor $42^{\circ} \mathrm{C}$, as expected. The Saccharomyces cerevisiae "Cinta Roja" baker strain, adapted to survive high temperatures was also included as a control, and was able to grow at both tested temperatures. All strains were able to use glucose and sucrose with no growth differences, but none of them were able to grow in the sole presence of lactose, the main sugar present in human milk. Negative control medium (without any sugar) did not support growth of any of the strains.

\section{Resistance to oxidative stress}

The three tested isolates were able to grow in the presence of high levels of hydrogen peroxide $\mathrm{H}_{2} \mathrm{O}_{2}(6 \mathrm{mM})$, and did not differ dramatically from control strains (Supplementary Figure 2(b)).

\section{Genetic characterisation of breast milk S. cerevisiae strain}

The mtDNA restriction patterns of the isolated S. cerevisiae strain (FBMI18) from our milk samples was identical to the commercial baker strain "Cinta roja" profile, and the $\delta$-PCR amplification patterns were highly similar, suggesting a correspondence between both strains (Supplementary Figure 2c).

\section{Fungal load in breast milk}

After analyzing 65 milk samples by qPCR, results showed that $58(89 \%)$ had detectable levels of fungi when using primers targeting the ITS1-5.8S rRNA region, with high interindividual variability and a total median of $3,5 \times 10^{5}$ cells $/ \mathrm{ml}$. Samples were classified in three groups according to their collection time point: colostrum (1st-5th day postpartum), transitional (6th-14th day postpartum) and mature milk (from 15th day onwards). Similar fungal load values at the three time points were observed, with higher levels in colostrum $\left(4,1 \times 10^{5} \mathrm{cells} / \mathrm{ml}\right)$ and transitional milk $\left(4,5 \times 10^{5} \mathrm{cells} / \mathrm{ml}\right)$ and slightly lower values in mature milk $\left(2,8 \times 10^{5} \mathrm{cells} / \mathrm{ml}\right)$ although no statistical differences were found between them (Figure 2). The prevalence of samples with detectable fungal presence was 16/18 in colostrum, 14/18 in transitional milk and 28/29 in mature milk. Total bacterial load for the same samples was $8,9 \times 10^{5}$ cells $/ \mathrm{ml}$ when using primers against the single copy gene fusA. 


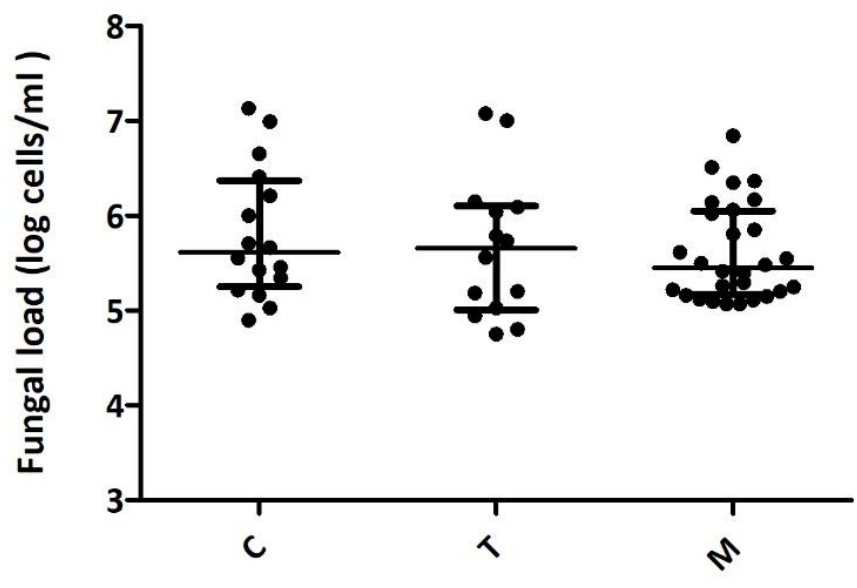

Figure 2. Fungal load in breast milk over time. The plot shows the median with interquartile ranges of fungal load at three time points in the $89 \%$ of samples that showed fungal presence by qPCR. C, colostrum samples $(n=16) ; T$, transitional milk samples $(n=14) ; M$, mature milk samples $(\mathrm{n}=28)$. Detection limit was established at $10^{3} \mathrm{cells} / \mathrm{ml}$, estimated as the lowest concentration at which $95 \%$ of the positive samples are detected.

\section{Fungal composition in breast milk}

To better characterize the breast milk fungal community of healthy donors, we further analyzed a subset of 15 samples (qPCR-positive for fungi) by means of $28 \mathrm{~S}$ rRNA gene pyrosequencing using the 454 Roche platform. This technology allows the analysis of long-sequences for reliable taxonomic assignment and prevents the sequencing bias of PCR fragments of variable length such us those of the ITS region. The pyrosequencing of negative controls yielded no sequences. Five of the samples were removed from the analysis as the number of quality-filtered sequences was under 400 . We obtained an average number of taxonomically assigned, high-quality sequences of 1,250 per sample (SE: \pm 444.94 ), with an average of 580 bp length. $61 \%$ of the reads corresponded to the Basidiomycota phylum, and $39 \%$ to the Ascomycota phylum. The analysis led to the identification of 10 classified fungal taxa (to the genus level) which were present in $>1 \%$ of the total sequences in more than $20 \%$ of the samples (Figure 3). The taxonomic assignment of the sequences showed that the fungal composition of human breast milk was dominated by Malassezia, which corresponded to $44 \%$ of the total number of sequences obtained, followed by Candida (19\%) and Saccharomyces (12\%). Malassezia and Saccharomyces could be detected in all 10 samples (Figure 3). Through BLAST alignment of the sequences against the RDP LSU database, 30 fungal species could be identified, which corresponded to 9,910 sequences taxonomically assigned after strict filtering ( $>98 \%$ identity and $>400$ bp length). These species are presented in Table 2 together with their mean percentage and prevalence in the samples. 


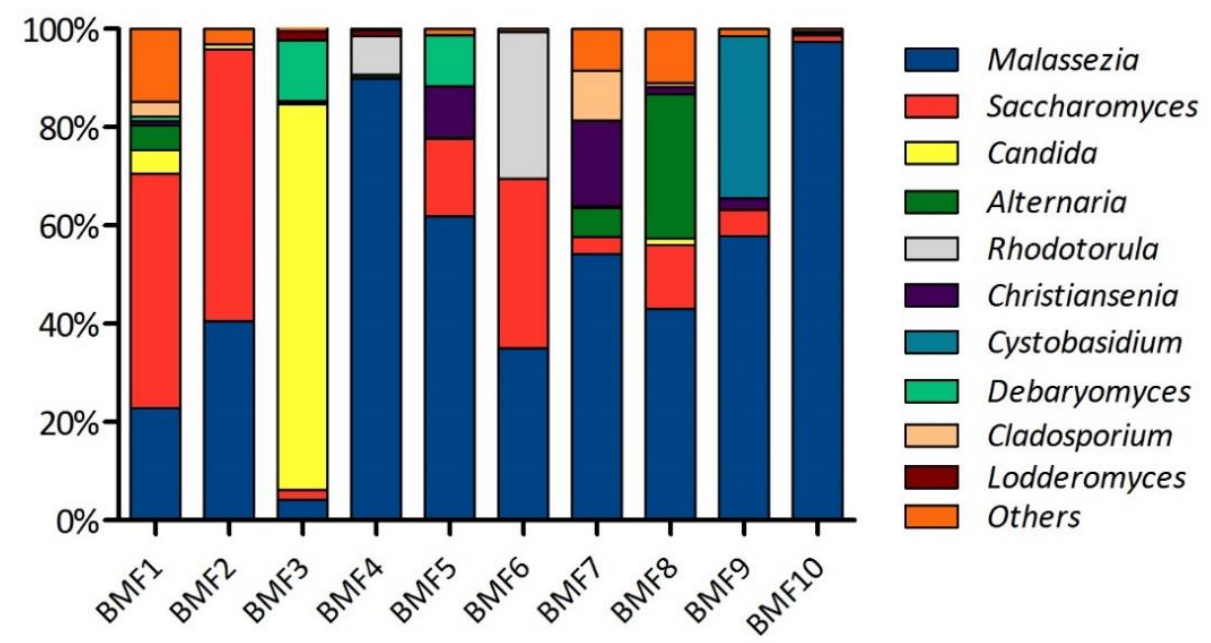

Figure 3. Fungal taxonomic composition of human breast milk. Bars show the proportion of fungal genera as inferred by PCR amplification and pyrosequencing of the 28S rRNA gene in healthy mothers $(\mathrm{n}=10)$. Each code in the $\mathrm{X}$ axis corresponded to a donor. Fungal genera that were under $1 \%$ were grouped in the "Others" category. The majority of the samples presented correspond to mature milk samples, except for BMF5 and BMF8 (colostrum) and BMF9 (transitional milk).

Table 2. Fungal species detected by pyrosequencing, mean proportions per total number of sequences and prevalence. All sequences included in the table had $>98 \%$ sequence identity over $>400$ bp alignment length.

\begin{tabular}{|l|l|l|}
\hline Species & $\%$ & Prevalence \\
\hline Malassezia globosa & 34.63 & $6 / 10$ \\
\hline Candida sp. HA1671 & 19.54 & $3 / 10$ \\
\hline Saccharomyces cerevisiae & 14.56 & $7 / 10$ \\
\hline Malassezia restricta & 9.07 & $10 / 10$ \\
\hline Alternaria arborescens & 4.82 & $4 / 10$ \\
\hline uncultured Candida & 3.48 & $2 / 10$ \\
\hline Cladosporium bruhnei & 3.28 & $1 / 10$ \\
\hline Alternaria sp. NT-2015a & 2.67 & $5 / 10$ \\
\hline Candida sake & 1.93 & $2 / 10$ \\
\hline Alternaria tenuissima & 1.57 & $5 / 10$ \\
\hline Debaryomyces hansenii & 1.24 & $3 / 10$ \\
\hline Cystobasidium sp. CBS7295 & 1.20 & $1 / 10$ \\
\hline uncultured Debaryomyces & 0.63 & $3 / 10$ \\
\hline Candida zeylanoides & 0.33 & $2 / 10$ \\
\hline Candida parapsilosis & 0.24 & $2 / 10$ \\
\hline Cladosporium sp. PAB-2014 & 0.22 & $2 / 10$ \\
\hline Malassezia sp.PH-2014 & 0.16 & $4 / 10$ \\
\hline Cladosporium delicatulum & 0.12 & $1 / 10$ \\
\hline Cladosporium phyllophilum & 0.08 & $1 / 10$ \\
\hline Cladosporium cladosporioides & 0.07 & $1 / 10$ \\
\hline Cladosporium herbarum & 0.05 & $2 / 10$ \\
\hline Alternaria alternata & 0.03 & $1 / 10$ \\
\hline Alternaria obclavata & 0.02 & $1 / 10$ \\
\hline Alternaria terricola & 0.02 & $1 / 10$ \\
\hline Candida albicans & $1 / 10$ \\
\hline Cladosporium langeronii & $1 / 12$ \\
\hline
\end{tabular}




\section{Relationship between breast milk microbiota and milk components}

Relative abundances of fungal genera from the 10 sequenced milk samples were compared with the amounts of nutritional components (fat, protein, lactose and nonfatty solids), and the number of human somatic cells, as well as with the microbial (bacterial and fungal) load content in paired milk samples, in order to find potential correlations among them (Figure 4). Positive significant correlations were found between the genus Malassezia and bacterial load (Spearman's correlation coefficient $\mathrm{Q}=$ 0.93, $p$-value $=0.007$ ); Malassezia and lactose ( $(0.78, p=0.048)$; and Candida with protein content $(\varrho=0.77, p=0.044)$. Lodderomyces and human somatic cells showed a negative correlation ( $\mathrm{Q}=-0.79, p=0.035)$, as well as Christiansenia and fungal load ( $\mathrm{Q}=-0.81, p=$ 0.027). We also compared nutritional factor composition and human somatic cell numbers with fungal and bacterial load in all of the available samples ( $n=34$, Figure 5), and a strong negative correlation was found between bacterial load and human somatic cells $\left(\varrho=-0.69, p==6.28 \times 10^{-6}\right)$. In addition, a non-significant negative correlation was detected between bacterial and fungal load $(\varrho=-0.055, p=0.756)$.

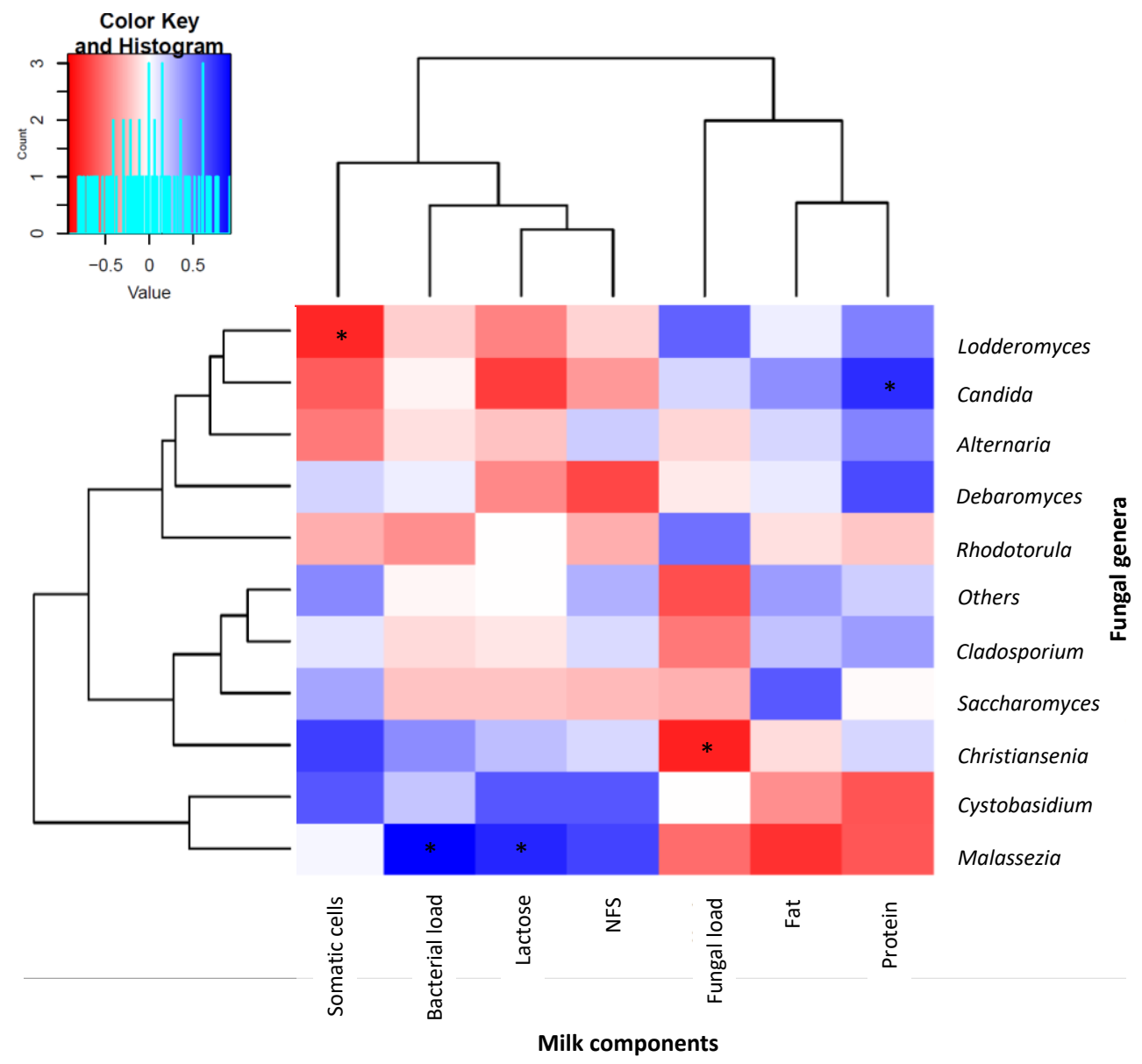

Figure 4. Relationships between fungal relative abundance and nutritional, cellular and bacterial content of breast milk. The heatmap shows samples clustered by their compositional profile. Relative abundance of fungal genera is colour-coded according to their negative- (red) or positive- (blue) correlations with the amounts of milk components: fat, protein, bacterial load, lactose, fungal load, somatic cells and non-fatty solids (NFS). Significant correlations are represented with an asterisk $\left(^{*}\right) .(n=10)$. 


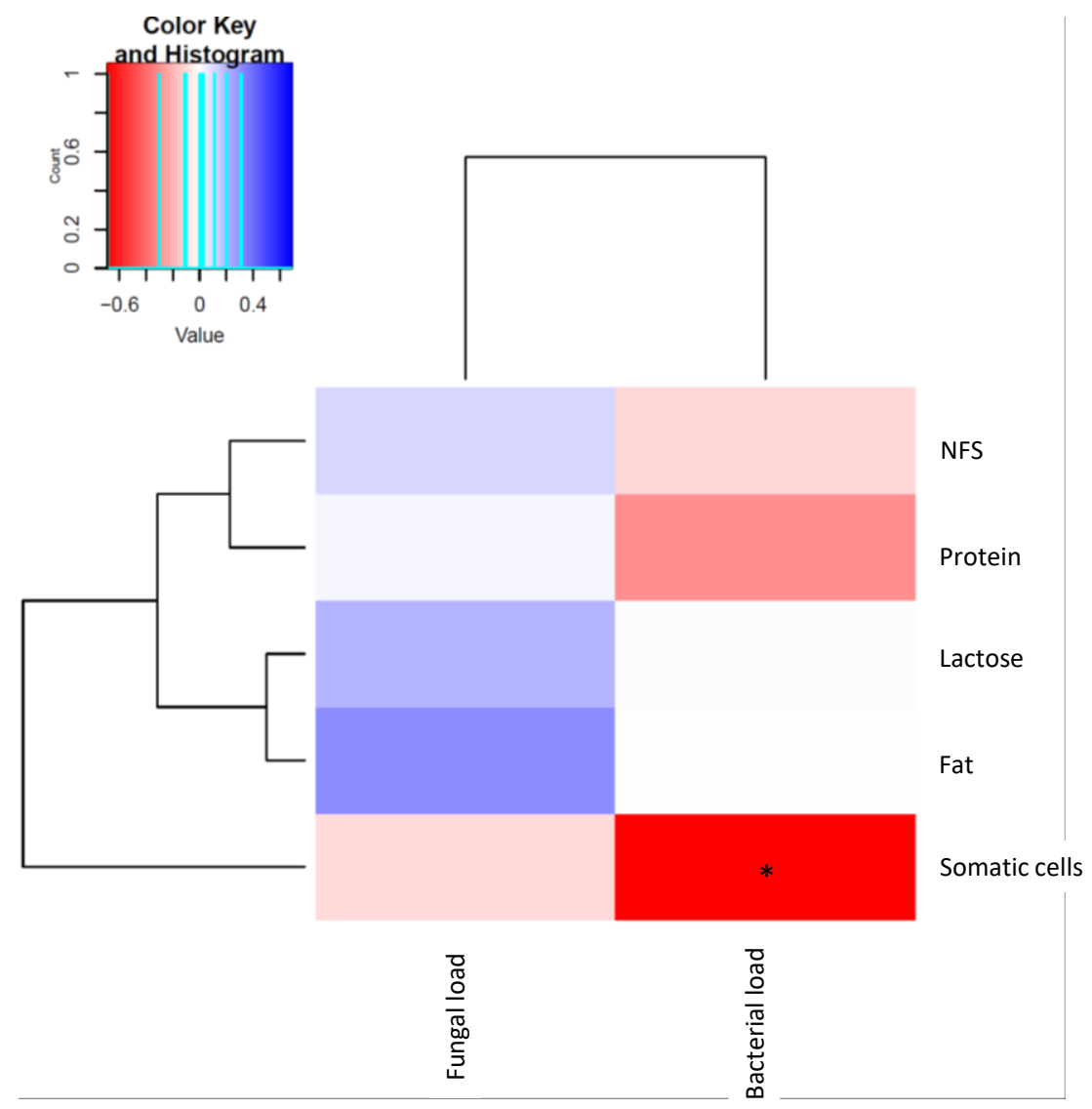

Figure 5. Relationships between fungal and bacterial loads with nutritional and cellular content of human breast milk. Correlations of fungal and bacterial load appear colour-coded according to their negative- (red) or positive- (blue) correlations with fat content, lactose content, protein content, somatic cells density and non-fatty solids content (NFS). Significant correlations are represented with an asterisk $(n=34)$.

\section{Discussion}

Previous studies have shown that breast milk harbors an important diversity of bacteria, which are transmitted to the new-born together with many other nutrients and immunological compounds. Those bacteria may have a protective role, activating the immune system and seeding some of the first colonizers in the infant (Jost et al. 2014). Prior to this study, the identification of fungi in milk has only been reported for dairy animals. In the study carried out by Delavenne et al., fungal composition from cow's, ewe's and goat's milk were compared, identifying 27 fungal species belonging to a variety of genera, including: Candida, Cryptococcus, Debaryomyces, Geotrichum, Kluyveromyces, Malassezia, Pichia, Rhodotorula, Trichosporon, Aspergillus, Chrysosporium, Cladosporium, Engyodontium, Fusarium, Penicillium and Torrubiella (Delavenne et al. 2011). Spanamberg et al. also confirmed the presence of fungi in ewe's milk (Spanamberg et al. 2014). The possibility that human milk also harbored fungi had not been previously explored. In this work, we have been able to detect a variety of fungal species in breast milk samples from healthy lactating mothers through different approaches. Fungal 
culture isolation results revealed that $41 \%$ of the samples showed presence of viable fungi. On the other hand, results yielded by qPCR showed that $89 \%$ of the samples had detectable levels of fungal DNA, which was present at high proportions with a median load of $3.5 \times 10^{5}$ cells $/ \mathrm{ml}$. Bacterial load median for the same samples was $8.9 \times 10^{5} \mathrm{cells} / \mathrm{ml}$. This value was close to the results found in a previous study, where the same qPCR protocol was followed to estimate bacterial loads in breast milk samples from healthy mothers. In this previous study, milk samples were found to have around $10^{6}$ bacterial cells/ml when detecting the single copy bacterial gene fusA (Boix-Amorós et al. 2016), that is ten-fold higher than the fungal fraction estimated in the current work. However, it should be noted that this fungal estimate is based on the study of the 28S rRNA gene, which is present in a variable number of copies per species, and although we used standard curves from a mix of different fungal species, these measures could overestimate the real fungal levels, and can't be compared to results obtained with a single copy gene. No correlation was found between bacterial and fungal loads, indicating that the same nutrients or selective pressures that favour a high bacterial density may not be the same that support fungal presence. Nevertheless, a significant correlation was found between bacterial load and the relative abundance of Malassezia, and future work should determine if this is the outcome of symbiotic or synergistic relationships as it has been shown in other human samples (Scheres \& Krom 2016; Willems et al. 2016).

In our pilot study, long fragment sequencing of the $28 \mathrm{~S}$ rRNA gene performed in 15 of the samples allowed reliable taxonomic assignment of the sequences from 10 of them, and showed that breast milk hosts a variety of fungal genera, with Malassezia, Candida and Saccharomyces being the most abundant. Although their origin is unknown, most of the species detected in our work can be found in other human niches. Work describing the oral fungal microbiome have reported that Candida species (mainly C. albicans, and others like $C$. parapsilosis) are the most frequent in the oral cavity, but also others like Cladosporium, Aureobasidium, Saccharomycetales (S. cerevisiae among others), Aspergillus, Fusarium, Cryptococcus or Penicillium (Ghannoum \& Mukherjee 2013; Jabra-Rizk et al. 2001; Kraneveld et al. 2012; Salonen et al. 2000). Malassezia has been described as the most common genus on human skin, but other genera like Candida, Aspergillus or Penicillium are also common inhabitants in this body niche (Findley et al. 2013). Some fungal species found in our samples have also been detected in the human gut, namely Candida species, Malassezia, Cladosporium, Debaromyces and S. cerevisiae (Li et al. 2013; Strati et al. 2016). As some of the species found in our milk samples can also be detected in the oral cavity and the human skin, we cannot discard the possibility of fungal transference from the skin surrounding the breast, to the breast milk, as well as from the baby's skin or mouth during suckling (Cabrera-Rubio et al. 2012a; Ramsay et al. 2004). Another possible explanation would be that these fungal species originate from the mother's mucosal surfaces, through an internal route, like the previously proposed entero-mammary pathway to explain the presence of bacteria in the mammary gland (Martín et al. 2004). 
If this entero-mammary pathway exists, the presence of fungi in breast milk could be more than the outcome of environmental contamination, and future work should aim to understand how fungal organisms reach human milk and if this pathway exists for fungi as well as bacteria. Whatever their origin, fungi are clearly present in breast milk and are likely contributing to the establishment of infant microbiomes.

Culture techniques provide a complementary vision of fungal populations in breast milk. Contrary to pyrosequencing results, the most abundant viable fungus detected was Rhodotorula mucilaginosa, which is a common airborne and highly ubiquitous fungus. It can also be found in the human body, where it can live as an opportunistic pathogen, particularly in immunocompromised patients (Wirth \& Goldani 2012). The Rhodotorula genus is also part of the normal skin microbiota (Findley et al. 2013). In the current study, we also found Rhodotorula DNA by pyrosequencing of breast milk, but we could not classify any sequences to the species level even after manual filtering of the BLAST output. Candida parapsilosis was the second most prevalent strain isolated by culture techniques. Previous work has described this species as a normal commensal in the infant oral cavity (Kleinegger et al. 1996; Russell \& Lay 1973), and its presence has been reported in low birthweight infant's stool (LaTuga et al. 2011). Higher presence of this species in the infant gut has been correlated with higher risk of inflammatory bowel's disease (IBD) (Chehoud et al. 2015). C. parapsilosis sequences were also obtained in this work by high-throughput sequencing technology, although it was not among the most prevalent species.

The phenotypical and molecular characterization of the most prevalent isolates from our milk samples (R.mucilaginosa and C.parapsilosis) as well as the single S. cerevisiae isolate provided additional biological information regarding these organisms. The growth of all isolates at $37^{\circ} \mathrm{C}$ and $42^{\circ} \mathrm{C}$ demonstrated the ability of these strains to survive at human body temperature. However, none of them were able to grow in the presence of lactose as unique carbon source, which leads us to hypothesize that there are factors in breast milk that allow their survival at higher temperatures and, further, that these species are utilizing alternative carbon sources in breast milk. The presence of an isolate highly similar to a commercial baker Saccharomyces cerevisiae strain ("Cinta roja") in one of our samples is interesting. S. cerevisiae has traditionally been used in fermentative processes to produce beer, bread and wine, and is even consumed as a nutritional supplement, and humans can get in contact with it through diet and through its manipulation during baking. This strain could be a saprophytic colonizer of the human body as S. cerevisiae has been isolated from the digestive tract, vagina, skin and oropharynx of healthy hosts where their presence is benign and asymptomatic (Kwon-Chung \& Bennett 1992). A recent study reported a decrease in $S$. cerevisiae levels in patients suffering from inflammatory bowel disease, whereas Candida albicans levels were higher than in healthy patients (Sokol et al. 2016). S. cerevisiae var. boulardii is a yeast that has been used as dietary supplement due to its apparent probiotic effects (Moré \& Swidsinski 2015; 
Zanello et al. 2009). Administration of S. boulardii has been shown to be associated with beneficial health effects in children with gastrointestinal disorders (Demirel et al. 2013; Szajewska et al. 2016). It also improves feeding tolerance and its supplementation in formula has shown beneficial effects on premature infants. However, some S. cerevisiae isolates have been responsible for human infections that are not life threatening except in severely immunocompromised patients where systemic infection may occur (De Llanos et al. 2011). Pathogenic Saccharomyces clinical strains have shown resistance to high oxidative stress conditions (Diezmann \& Dietrich 2011). Upon exposing the S.cerevisiae isolate to high hydrogen peroxide $\left(\mathrm{H}_{2} \mathrm{O}_{2}\right)$ concentrations, in order to study its oxidative stress resistance, no differences were found when comparing with the other strains and the industrial S. cerevisiae T73 and "Cinta Roja" strains. The presence of $\mathrm{H}_{2} \mathrm{O}_{2}$ in breast milk has an antibacterial role and when combined with lactoperoxidase (a milk peroxidase) and iodide, a strong anti-bacterial system is produced: the Lactoperoxidase system (Al-Kerwi et al. 2005). However, all of our tested isolates were able to survive under these conditions. The discrepancies observed between culture isolation and culture-independent high throughput sequencing for the identification of fungi are not surprising. As we are currently unable to cultivate many microbial species under laboratory conditions, many fungal species may not be detected by standard culturing methods. In addition, fungi are present at much lower numbers, as compared to bacteria, in most human samples, making their isolation more difficult. Especially intriguing is the absence of Malasezzia isolates from our cultures, despite their high prevalence in pyrosequencing data. It remains to be determined whether the Malasezzia reads correspond to non-viable microorganisms. Future studies are needed to understand how breast milk affects the viability of bacteria and fungi as well as the origin of fungi, such as Malasezzia, that are found in breast milk. Malasezzia yeasts are considered to be part of the normal microbiota of healthy individuals (Findley et al. 2013). However, under some circumstances, they may act as opportunistic pathogens. Owing to their lipophilic nature, they colonize the seborrheic parts of the skin and they sustain themselves by using the fatty acids present in normal sebum, as they have the property of using lipids as a source of carbon (Guého et al. 1996). This could favor their survival and growth in breast milk, which contains high fat levels, but our results comparing breast milk fungi and macronutrients did not show a positive correlation between the Malassezia genus and fat, as might be expected. We observed a positive correlation between the Malassezia genus and lactose, although this genus has been found to be unable to metabolize lactose (Vijayakumar et al. 2006). In this study, Malasezzia was not isolated from any of the tested human milk samples and lactose utilization could not be assessed to confirm the correlation found. In the future, it will be important to establish the metabolic capabilities of Malassezia isolated from breast milk with respect to sugars, in order to understand the observed correlation with lactose utilization. Although we found positive relationships between fungal load and milk fat and non-fatty solids, no correlation was found with human somatic cells counts. Given that the number of 
somatic cells in milk is considered the gold standard for detecting bacterial infections (e.g. mastitis) in farm animals (Olechnowicz \& Jaśkowski 2012), the absence of a somatic cell increase in our samples suggests a lack of significant immune response (although it cannot be ruled out that breast milk fungi may be interacting with immune cells without causing inflammation). Thus, the data presented in the current work suggest that the presence of fungi in milk is not associated with infection in these healthy mothers without lactation problems. In addition, we found a highly significant negative correlation between bacterial load and human somatic cells, confirming that the presence of microorganisms did not correlate with an increase in somatic cells. This negative correlation, yet not significant, was also found in a previous study with a smaller sample size (Boix-Amorós et al. 2016), confirming that this general measure (total somatic cell number) may not be a good method for detecting microbial infections in human milk and that specific immune cells, such as polymorphonuclear leukocytes, could be more informative (Espinosa-Martos et al. 2016). The potential for fungi to enter the gastrointestinal tract via breast milk should be considered as a mechanism for their initial colonization of the infant gut. In humans, the fungal composition of breast milk has not been reported in healthy women and there are relatively few studies of fungal colonization patterns in the infant gut ${ }^{39}$. However, the impact of the fungal component of the gut microbiome could be relevant, and scarce information is available regarding gut bacteria-fungi relationships. Available data suggest a potential beneficial role of various fungi for human health (Demirel et al. 2013; Moré \& Swidsinski 2015; Szajewska et al. 2016; Zanello et al. 2009) and further work should be performed in order to better understand their mode of action.

\section{Conclusions}

Through multiple methodological approaches, we have detected, isolated and identified fungi from human breast milk. Although the natural presence of fungi in the milk of other mammals is well-accepted, there are no previous descriptions of specific fungal species in human samples from healthy mothers. Although their origin and role still remain to be elucidated, we show that fungi are clearly present in human breast milk. Further research with larger cohorts should be performed in order to uncover their possible contribution to gut microbiota development and their potential role for infant health. 


\section{Supplementary Information}

a
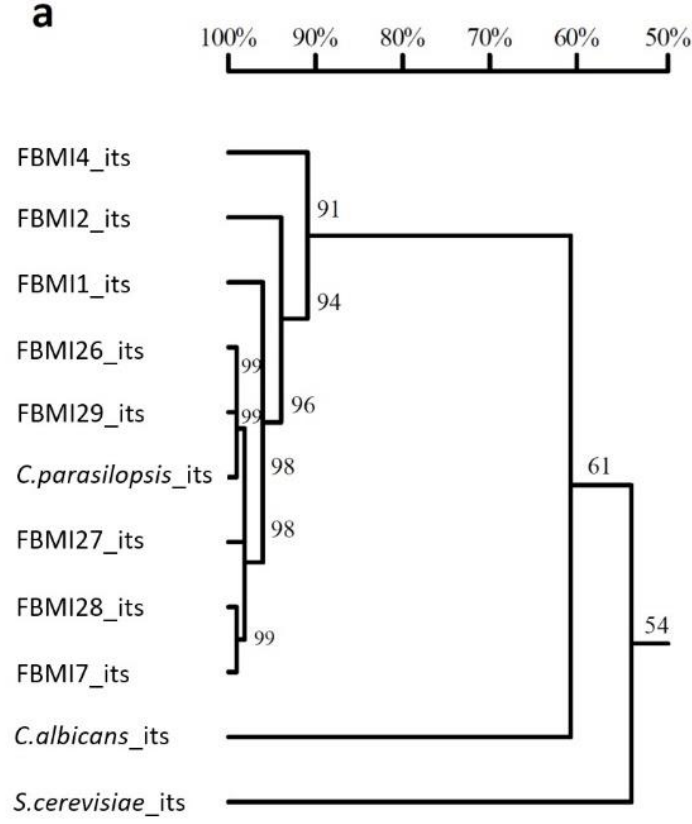

b

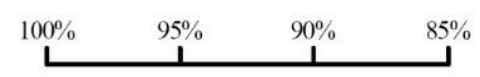

FBMI6_18S

FBMI8_18S

FBMI16_18S

FBMI9_18S

FBMI17_18S

FBMI19_18S

FBMI20_18S

FBMI23_18S

R.glutinis_18S

R.mucilaginosa_18S

C.albicans_18S

Supplementary Figure 1. Homology trees for C.parapsilosis and R.mucilaginosa isolates from breast milk. (a) Shows a homology tree for Candida parapsilosis isolates from breast milk samples $(n=8)$ PCR-amplified with ITS1-5.8 primers and Sanger-sequenced. Three reference strains were included as controls (C.parapsilosis, C.albicans and S.cerevisiae). (b) Shows a homology tree for Rhodotorula mucilaginosa isolates from breast milk samples $(n=8)$ PCR-amplified with $18 S$ rRNA primers and Sanger-sequenced. Three reference strains were included as controls (R.mucilaginosa, R.glutinis and C.albicans). Multiple alignments and homology trees were performed with DNAMAN software. 
a

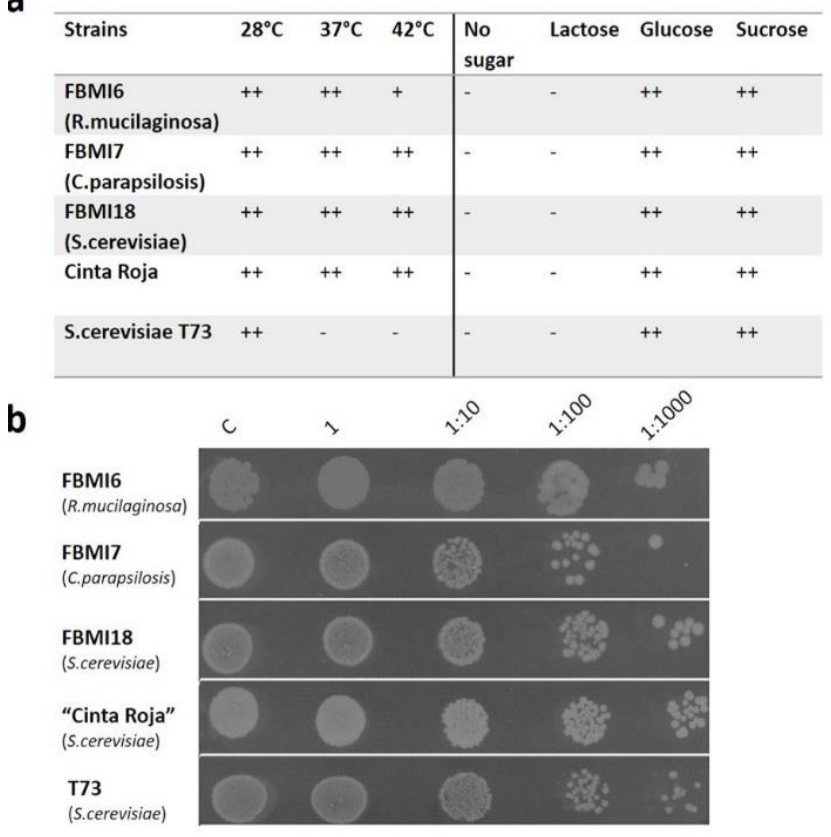

C

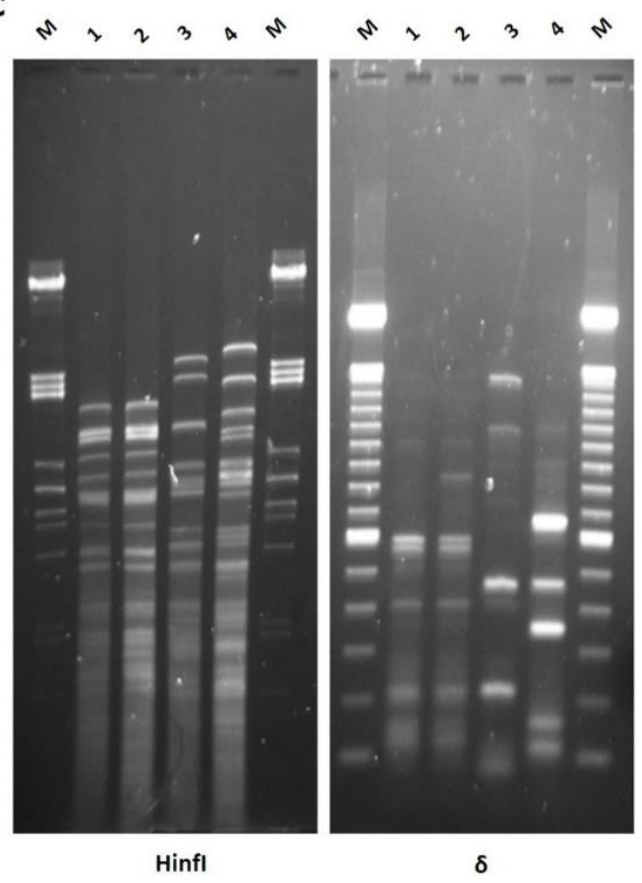

Supplementary Figure 2. Phenotipic and genetic characterization of fungal isolates from human breast milk. a) Isolates viability at different temperatures and utilization of different sugars. (-) indicates no growth, (+) indicates moderate growth, and (++) indicates high growth. $b$ ) Isolates' resistance to oxidative stress. The picture shows the differential growth of isolates after 1-hour exposure to $6 \mathrm{mM} \mathrm{H}_{2} \mathrm{O}_{2}$. The first column corresponds to the growth of isolates without $\mathrm{H}_{2} \mathrm{O}_{2}$ exposure. The remaining columns of growth correspond to isolates exposed to $\mathrm{H}_{2} \mathrm{O}_{2}$ : 1 (no dilution), and dilutions 1:10, 1:100 and 1:1000. c) Hinf I mtDNA restriction patterns (HinfI) and $\delta$-PCR amplification patterns $(\delta)$ of the DNA of yeast strains. 1 (FBMI18 strain), 2 (Baker's yeast "Cinta roja"), 3 (Wine strain T73), 4 (S.boulardii, Ultralevura). The DNA of phage $\lambda$ digested with Pst I (Roche Molecular Biochemicals) and a 100-bp DNA ladder marker (Gibco BRL, Gaithersburg, MD.) served as the size standard respectively (M). 


\title{
Chapter 3
}

\section{Mycobiome Profiles in Breast Milk from Healthy Women Depend on Mode of Delivery, Geographic Location and Interaction with Bacteria}

\author{
Alba Boix-Amorós, Fernando Puente-Sánchez, Elloise \\ du Toit, Kaisa M. Linderborg, Yumei Zhang, Baoru \\ Yang, Seppo Salminen, Erika Isolauri, Javier Tamames, \\ Alex Mira, María Carmen Collado.
}

This chapter has been published as: Boix-Amorós A, Puente-Sánchez F, du Toit E, Linderborg KM, Zhang Y, Yang B, Salminen S, Isolauri E, Tamames J, Mira A, Collado MC. 2019. Mycobiome profiles in breast milk from healthy women depend on mode of delivery, geographic location and interactions with bacteria. Applied and Environmental Microbiology, 85(9). 


\begin{abstract}
Recent studies report the presence of fungal species in breast milk of healthy mothers, suggesting a potential role in infant mycobiome development. In the present work, we aimed to determine whether the healthy human breast milk mycobiota is influenced by geographical location and mode of delivery, as well as to investigate its interaction with bacterial profiles in the same samples. A total of 80 mature breast milk samples from 4 different countries were analyzed by Illumina sequencing of the internal transcribed spacer 1 (ITS1) region, joining the $18 \mathrm{~S}$ and $5.8 \mathrm{~S}$ regions of the fungal rRNA region. Basidiomycota and Ascomycota were found to be the dominant phyla, with Malassezia and Davidiella being the most prevalent genera across countries. A core formed by Malassezia, Davidiella, Sistotrema and Penicillium was shared in the milk samples from the different origins, although specific shifts in mycobiome composition were associated with geographic location, and delivery mode. The presence of fungi in the breast milk samples was further confirmed by culture and isolates characterization, and fungal loads were estimated by quantitative PCR (qPCR) targeting the fungal ITS1 region. Cooccurrence network analysis of bacteria and fungi showed complex interactions that were influenced by geographical location, mode of delivery, maternal age, and pregestational body mass index. The presence of a breast milk mycobiome was confirmed in all the samples analyzed, regardless of the geographic origin.
\end{abstract}




\section{Introduction}

Early human microbial gut colonization is an essential stepwise process with an impact on the immunological and metabolic programming of later health (Chervonsky 2010; Houghteling \& Walker 2015; Tamburini et al. 2016). Fungi residing in the human gut have been recognized as an important part of the gut microbiota, and although research on the field is scarce, the mycobiome could have important roles in human health status (Cui et al. 2013; Hatoum et al. 2012; Laforest-Lapointe \& Arrieta 2018; Sokol et al. 2016; Underhill \& Iliev 2014). Although information about fungal communities in the infant is generally lacking, there is evidence that fungal species (mainly yeast-like species) can be found in the gut early in life (Seddik et al. 2016; Ward et al. 2017, 2018). A few reports have documented fungal transfer from mothers to infants, but little is known about how the mycobiome is shaped during this period (Bliss et al. 2008; Drell et al. 2017; Schei et al. 2017). Recent prospective studies have revealed that altered gut mycobial patterns precede atopic wheeze and asthma development and have suggested fungal-bacterial interactions that would influence early-life patterns of microbial alpha diversity (Arrieta et al. 2017). Breast milk is an important source of bacteria to the infant, and together with oligosaccharides, contributes to the settlement of the gut microbiota characteristic of the healthy breast-fed child, with a strong impact on immune surveillance within the gastrointestinal environment and thereby also other membranes of the body (BoixAmorós et al. 2016; Jost et al. 2014; Walker \& Iyengar 2015). A recent study reported the presence of a diversity of fungal species in human breast milk of healthy mothers, including Malassezia, Candida, and Saccharomyces as the most common genera, by means of high-throughput sequencing, microscopy, and other culture-independent techniques (Boix-Amorós et al. 2017). Moreover, viable yeasts, predominantly Candida parapsilosis and Rhodotorula mucilaginosa species, were isolated and characterized. This finding provides a new angle to the infant mycobiome development, and calls for further evaluation of the key determinants of their composition. Furthermore, complex interactions between bacteria and fungi have been reported in the human gut, oral cavity, skin, and vagina (Arrieta et al. 2017; Hoffmann et al. 2013; Mason et al. 2012; Parolin et al. 2015; Peleg et al. 2010) and, therefore, such are also likely to occur in breast milk. In addition, accumulating evidence suggests that some environmental factors might influence breast milk composition (Gay et al. 2018; McGuire et al. 2017; Sundekilde et al. 2016). In particular, geographic location, delivery mode, maternal body mass index (BMI), and age have been suggested to have an impact on breast milk bacterial composition (Cabrera-Rubio et al. 2012a, 2016; Gómez-Gallego et al. 2018; Hoashi et al. 2016; Khodayar-Pardo et al. 2014; Kumar et al. 2016; Li et al. 2017; Toscano et al. 2017b), although their potential impact on the milk's fungal fraction is still to be elucidated. In the present study, we characterized the breast milk mycobiota of healthy breast-feeding mothers from four different countries (Spain, Finland, South Africa, and China), in order to investigate the potential influence of geographic location and mode of delivery on its composition. Fungal loads in the samples were estimated, and co-occurrence networks 
between specific fungi and bacteria were analyzed for potential interactions depending on mode of delivery across the different countries.

\section{Materials and Methods}

\section{Subjects and Sampling}

Breast milk samples at 1-month postpartum were obtained from 80 healthy, lactating women from 4 different geographical locations (20 in each location), including China (Beijing area), South Africa (Cape Town), Finland (southwestern area), and Spain (Valencia, Mediterranean area). All mothers were practicing exclusive breastfeeding. Subjects were grouped according to mode of delivery: vaginal ( $n=10$ per country) and Caesarean-section (C-section) ( $\mathrm{n}=10$ per country). Maternal characteristics such as age, weight, and pregestational body mass index (BMI) were collected at the time of enrolment. All women who delivered via C-section received prophylactic antibiotics, except Finnish women, for whom no prophylaxis is routinely used per the hospital policy. All participants were given detailed oral and written information, and written informed consent was obtained for participation. The study protocol was approved by the ethics committees of the respective participating institutions: Bioethics Committee of CSIC and the Regional Ethics Committee for Biomedical Research (Spain), Ethics Committee, Hospital District of Southwest Finland (Finland), Medical Research Board of Peking University (China) and University of Cape Town, Human Research Ethics Committee (South Africa). Before sample collection, nipples and mammary areolas were cleaned with soap and sterile water and soaked in chlorhexidine to reduce sampling of microorganisms residing on the skin. Milk samples were collected in a sterile tube manually, with the first drops discarded. All samples were frozen at $-20^{\circ} \mathrm{C}$ until further processing. To avoid bias, samples were collected using the same standardised protocol in the four countries and were processed and analyzed in a single laboratory.

\section{Microbial DNA Extraction and Sequencing}

Breast milk samples $(1.5 \mathrm{ml})$ were centrifuged at $14,000 \mathrm{rpm}$ for $20 \mathrm{~min}$ at $4^{\circ} \mathrm{C}$ to remove fat, and pellets were used for total DNA extraction, which involved mechanical and chemical cell lysis. Bead beating was carried out using FastPrep (FP120-230, Bio 101; ThermoSavant, Holbrook, NY, USA), and the InviMag stool DNA kit (Stratec Molecular, Berlin, Germany) was used with the King Fisher magnetic particle processor (Thermo Fisher Scientific Oy, Vantaa, Finland). The DNA extraction protocol was also used with water to serve as negative controls. Isolated DNA concentrations were measured using a Qubit 2.0 fluorometer (Life Technology, Carlsbad, CA, USA). Primers targeting the highly variable fungal internal transcriber spacer ITS1 of the fungal 18S ribosomal rRNA gene (forward: TAGAGGAAGTAAAAGTCGTAA, reverse: TTYRCTRCGTTCTTCATC) (Toju et al. 2012) with adaptors were used for sequencing on an Illumina MiSeq platform. 
Sequencing was carried out at the Foundation for the Promotion of Health and Biomedical Research, FISABIO (Valencia, Spain). No-template controls (NTCs) and negative controls during DNA extraction were included to rule out potential contaminations at the time of DNA extraction or sequencing.

\section{Fungal load}

qPCR amplification and detection of the ITS1-5.8S rRNA conserved fungal region was performed as previously described (Boix-Amorós et al. 2017), using the primers ITS1F (5'-TCCGTAGGTGAACCTGCGG) and 5.8 R (5'-CGCTGCGTTCTTCATCG). Each reaction mixture of $20 \mu \mathrm{l}$ was composed of $10 \mu \mathrm{l}$ of KAPA Sybr Fast qPCR master mix (KAPA Biosistems), $0.4 \mu \mathrm{l}$ of each primer (10 $\mu \mathrm{M}$ concentration) and $2 \mu \mathrm{l}$ of template DNA, with an annealing temperature of $61^{\circ} \mathrm{C}$ in a LightCycler 480 real-time PCR system (Roche Technologies). All amplifications were performed in duplicate, and a negative control was included in each reaction plate. Samples with threshold cycle $\left(\mathrm{C}_{T}\right)$ values equal to or higher than the negative control were considered negative for fungal DNA.

\section{Breast milk culture and identification of fungal colonies}

One-hundred-microliter volumes of selected breast milk samples were plated in four solid fungus-selective media: Sabouraud (Conda-Pronadisa) supplemented with chloramphenicol, 0.05 g/liter (Roche); Rose Bengal (Conda-Pronadisa) supplemented with chloramphenicol, $0.5 \mathrm{~g} /$ liter (Roche); YPD (40 g/liter dextrose, $40 \mathrm{~g} /$ liter peptone, 20 $\mathrm{g} /$ liter yeast extract, and $40 \mathrm{~g} /$ liter agar) supplemented with $25 \mu \mathrm{g} / \mathrm{ml}$ of streptomycin $25 \mathrm{U} / \mathrm{ml}$ of penicillin (Biowest); and YNB (Sigma) with $8 \%$ ethanol and $25 \mu \mathrm{g} / \mathrm{ml}$ of streptomycin $-25 \mathrm{U} / \mathrm{ml}$ of penicillin (Biowest). All plates were incubated aerobically at $37^{\circ} \mathrm{C}$, as previously described (Boix-Amorós et al. 2017). DNA from the isolated colonies was extracted and amplified by PCR using primers targeting the $18 \mathrm{~S}$ rRNA gene (forward, 5'-GTAGTCATATGCTTGTCTC; reverse, 5'-CCATTCCCCGTTACCCGTTG). PCR products were sequenced in an Applied Biosystems 3730/3730xl DNA analyzer at the University of Valencia (Spain), and isolates were identified by using the BLAST algorithm in the NCBI database, with minimum of $98 \%$ sequence identity.

\section{Microscopic analyses of fungi in milk}

In order to identify fungal cells in breast milk, samples were incubated with calcofluor white stain that dyes the cell walls of the fungi and yeasts. Samples were visualized with fluorescence microscopy using a Nikon Eclipse E90i microscope (Nikon Corporation) with a 100X objective. Image processing was performed using the NIS-Elements BR v3.22 software (Nikon).

\section{Data Analysis}

ITS1 reads were pair-end joined using FLASH program (Magoc \& Salzberg 2011) with default parameters applied. The resulting sequences were end-trimmed in $20 \mathrm{bp}$ sliding 
windows with an average quality value of $>30$ and a length of $>50 \mathrm{bp}$, using the Prinseqlite program (Schmieder \& Edwards 2011). Chimeric reads were eliminated using the UCHIME algorithm (Edgar et al. 2011), resulting in a total of 9,797,578 reads. Taxonomy assignment of the remaining sequences was performed using the Ribosomal Database Project Classifier stand-alone tool (Wang et al. 2007) with the UNITE fungal ITS v 7.2 trainset (Kõljalg et al. 2013) and an 80\% confidence threshold. Sequences where clustered into operational taxonomical units (OTUs) based on 99\% identity, and representative OTUs sequences were obtained using CD-hit software (Li \& Godzik 2006). OTU tables were rarefied to 9,200 sequences per sample to avoid variations in sequencing depth, and Shannon and Chao1 indexes were calculated using the "plyr" and "vegan" packages from R software (version 3.2.2) (R Development Core Team. 2011).

\section{Statistical Analysis}

Calypso software (version 8.2) (Zakrzewski et al. 2016) was used to obtain Venn diagram for shared phylotypes, discriminant analysis of principal components (DAPC) was performed at the OTU level, using geographic location as a factor; and PERMANOVA and redundancy analysis (RDA) were applied to study the statistical effect of country and delivery mode on breast milk fungal composition. The Kruskal-Wallis test was implemented to study genus-level taxonomical differences between countries and delivery modes, using GraphPad PRISM 6 (GraphPad Software). Linear discriminant analysis effect size (LefSe) (Segata et al. 2011) algorithm was used to detect the most differentially abundant fungi between countries, and between vaginal and C-section deliveries in each country, at the species level. In order to control the potential effects of maternal age, maternal BMI predelivery, and antibiotic use at delivery, MaAsLin (multivariate analysis with linear model) (Morgan et al. 2012), which finds associations between metadata and microbial abundances, was applied. Other statistical analysis and graphing were performed using GraphPad PRISM 6.

\section{Analysis of bacterial and fungal co-occurence}

Sequences from the 16S rRNA gene of the same samples, from a report by Kumar et al (Kumar et al. 2016), were obtained from NCBI (SRA accession: SRP082263 and submission ID: SUB1772296). Quality filtering, chimera checking, and OTU clustering were done the same way as for the ITS1 reads. RDP classifier was used to taxonomically assign the bacterial (against RDP 16S rRNA training set 16) (Cole et al. 2014) and fungal (against the UNITE v 07-04-2014 trainset) (Kõljalg et al. 2013) representative OTU sequences. Samples with fewer than 1,500 sequences were excluded from the analysis. For the bacterial data sets, OTUs with a higher relative abundance in any of the two controls than in the breast milk samples were treated as putative contaminants and discarded. This procedure could not be performed on the fungal data sets, since the sequencing of the two controls yielded too few reads. Nevertheless, the low fraction of reads assigned to putative contaminants in the bacterial datasets ( $2 \%$ on average) leads 
us to believe that the samples were essentially contamination-free. Both the bacterial and fungal OTU tables were rarefied to 1,500 sequences per sample. OTUs from both the bacterial and fungal data sets having an overall relative abundance higher than $1 \%$ of the total reads, or appearing in at least one sample with a relative abundance higher than $5 \%$, were combined into a single table. Associations between pairs of bacterial and fungal OTUs were calculated using the maximal information coefficient, as implemented in MICtools (Albanese et al. 2017). Pseudo $P$ values were obtained by generating 200,000 null matrices and further transformed to Storey's Q-values to correct for multiple hypothesis testing with the Benjamini-Hochberg method. Correlations with a false discovery rate lower than 0.01 were deemed significant. Further, we divided the samples into eight groups according to the combination of the four countries and two delivery modes. We used linear regression to calculate correlations between pairs of OTUs and factors (age, BMI) in a given group. For each group, only OTUs appearing in at least four samples and with a relative abundance higher than $2 \%$ in at least one sample were included. Correlations with a $P$ value lower than 0.05 were deemed significant. Network analysis was performed on Cytoscape (Shannon et al. 2003).

\section{Phylogenetic relationships between Malassezia reads}

ITS sequences of the 20 most abundant OTUs assigned to the Malassezia genus by the RDP classifier were combined with those of known Malassezia representatives from the UNITE v07-04-2014 database (Kõljalg et al. 2013). A multiple sequence alignment was constructed with MAFFT v7.313 (Katoh, K. \& Standley 2013). Cryptococcus neoformans was selected as an outgroup, and its ITS sequence was added to the alignment using the "add" option from MAFFT. The resulting alignment was manually curated and further refined with MUSCLE v3.8.31 (Edgar 2004). Phylogenetic trees were inferred with RaxML v8 (Stamatakis 2014) and MrBayes v3.2 (Ronquist et al. 2012), using 1,000 replicates and 1,000,000 generations respectively. TreeGraph2 (Stöver \& Müller 2010) was used to combine and visualize the maximum likelihood and Bayesian inference trees.

\section{Data availability}

All ITS1 sequences have been deposited in the European National Archive (ENA) server under the study ID PRJEB25581. Samples were deposited under accession numbers ERS2312706 to ERS2312785. 


\section{Results}

\section{Subjects Description}

The characteristics of the subjects participating in the study are listed in Table 1. The mean age of the mothers ( $n=80$ ) was 33.52 years (standard deviation [SD], \pm 4.87 years), with no statistical differences between countries. The mean pregestational BMI was 24.06 (SD, \pm 3.85$)$, normal weight. Chinese mothers had significantly lower BMI, 21.71 (SD \pm 1.97), considered normal weight. Differences in BMI between mothers delivering vaginally or by Cesarean section (C-section) were observed only in South African and Finish women, where mothers delivering by C-section had higher BMIs, $26.67 \pm 1.41$ and $26.30 \pm 2.57$, respectively, although this difference was only significant in the South African group $(p<0.05)$.

Table 1. Clinical characteristics of donors providing human milk samples for the study

\begin{tabular}{llllll}
\hline Country & $\begin{array}{l}\text { Delivery mode } \\
\text { (no. of samples) }\end{array}$ & Age (yr) \pm SD & $P$ value & BMI \pm SD & $P$ value \\
\hline Finland & C-section (10) & $35.20 \pm 4.07$ & 0.820 & $26.30 \pm 2.57$ & 0.185 \\
& Vaginal (10) & $33.70 \pm 6.02$ & & $22.65 \pm 8.60$ & \\
& Total (20) & $34.45 \pm 5.06$ & ns & $24.47 \pm 6.46$ & ns \\
& & & & \\
Spain & C-section (10) & $34.50 \pm 2.59$ & 0.288 & $24.34 \pm 1.47$ & 0.630 \\
& Vaginal (10) & $32.20 \pm 5.16$ & & $24.25 \pm 1.43$ & \\
& Total (20) & $33.35 \pm 4.14$ & ns & $24.30 \pm 1.41$ & ns \\
South Africa & C-section (10) & $36.60 \pm 6.08$ & 0.944 & $26.67 \pm 1.41$ & 0.043 \\
& Vaginal (10) & $31.50 \pm 5.76$ & & $24.81 \pm 2.67$ & \\
& Total (20) & $34.05 \pm 2.29$ & ns & $25.75 \pm 2.29$ & ns \\
China & & & & \\
& C-section (10) & $32.60 \pm 2.95$ & 0.970 & $21.49 \pm 2.29$ & 0.449 \\
& Vaginal (10) & $31.90 \pm 4.25$ & & $21.92 \pm 1.54$ & \\
All & Total (20) & $32.25 \pm 3.58$ & ns & $21.71 \pm 1.97$ & 0.004 \\
& & & & & \\
& C-section (40) & $34.72 \pm 4.25$ & 0.058 & $24.70 \pm 2.83$ & 0.072 \\
& Vaginal (40) & $32.32 \pm 5.20$ & & $23.41 \pm 2.11$ & \\
& Total (80) & $33.52 \pm 4.87$ & ns & $24.06 \pm 3.85$ & ns \\
\hline
\end{tabular}

ns, not significant.

\section{Fungal Cells Detection in Breast Milk}

Eighty milk samples were analyzed by quantitative PCR (qPCR) targeting the ITS1-5.8S rRNA region. Results showed that 16 of 20 Spanish samples (80\%; median value, 195,142 cells $/ \mathrm{ml}$ ), 9 of 20 Chinese samples (45\%; median value, 170,732 cells/ml); 7 of 20 Finish samples (35\%; median value, 199,480 cells/ml), and 14 of 20 South African samples (70\%; median value, 371,119 cells $/ \mathrm{ml}$ ) had detectable levels of fungi. No significant differences were observed between geographic locations or by mode of delivery (see Fig. S1 in the supplemental material). The presence of fungal cells in the milk was further confirmed by culture in fungus-specific culture medium and identification of the isolates by $18 \mathrm{~S}$ 
rRNA sequencing, as well as by microscopy after incubation of the milk samples with calcofluor white fungal stain. A summary of the results is available in Table 1 and Fig. S2 in the supplemental material.

\section{Fungal Composition of Breast Milk: Impact of Geographical Area and Perinatal Factors}

After sequencing of the ITS1 fungal region, a mean of 107,765 taxonomically assigned, clean, filtered sequences per sample (SD, $\pm 45,493)$, with an average length of $301 \mathrm{bp}$, was obtained. All breast milk samples contained fungal DNA, and they were dominated by two phyla: Basidiomycota (58.65\%) and Ascomycota (41.03\%). South African samples had significantly higher levels of Ascomycota and lower levels of Basidiomycota than the other countries $(P<0.05)$. Discriminant analysis of principal components (DAPC), which transforms data using a principal-component analysis (PCA) and subsequently identifies clusters using discriminant analysis (DA), showed that South African samples clustered at a distance from the other countries, mainly due to the increased levels of Rhodotorula mucilaginosa (Fig. 1). Taxonomic analysis at the genus level showed that breast milk samples were dominated by Malassezia (40.6\% average abundance), followed by Davidiella (9.0\%), which was prevalent regardless of the location or the donor's type of delivery (Fig. 2a). The effects of country of origin and mode of delivery on breast milk fungal composition were analyzed and reflected that milk mycobiota differed significantly across geographic location (permutational multivariate analysis of variance [PERMANOVA], $p=0.005$ ) and mode of delivery (PERMANOVA, $p=0.023$ ). Redundant analysis (RDA) confirmed the effect of geographic location on breast milk fungal composition $(p=0.001)$, although that of mode of delivery did not reach statistical significance. The Kruskal-Wallis test was implemented to compare phylotypes at the genus level across samples. Results showed that Malassezia was statistically less abundant in South African samples $(p<0.05)$, and Penicillum and Rhodotorula abundances were lower in Chinese samples $(p<0.01)$, while Saccharomyces was more abundant in Spanish and Finnish samples $(p<0.01)$ than in samples from the rest of the locations. No statistically significant effect of maternal age, gestational BMI, or antibiotic intake during delivery was detected for breast milk microbial composition by using MaAsLin (multivariate analysis with linear model). Despite the differences, a core of four genera shared across the four countries was identified, including Malassezia, Davidiella, Sistotrema, and Penicillium. Wallemia and Aspergillus were found only in samples from Finland, Botrytis and an unidentified Saccharomycetales were found only in South African samples, and an unidentified Malasseziales was found only in Spanish samples. Rhodotorula was present in samples from all countries except China (Fig. 2b). Comparisons between samples were further analyzed at the species level. Linear discriminant analysis effect size (LefSe) results showed differentially abundant fungi between countries. Rhodotorula mucilaginosa and Saccharomycetales species were more abundant in South African samples, while Malassezia furfur was more prevalent in 
Chinese samples, and an Ascomycota sp. was more abundant in Spanish samples (Fig. 2c).
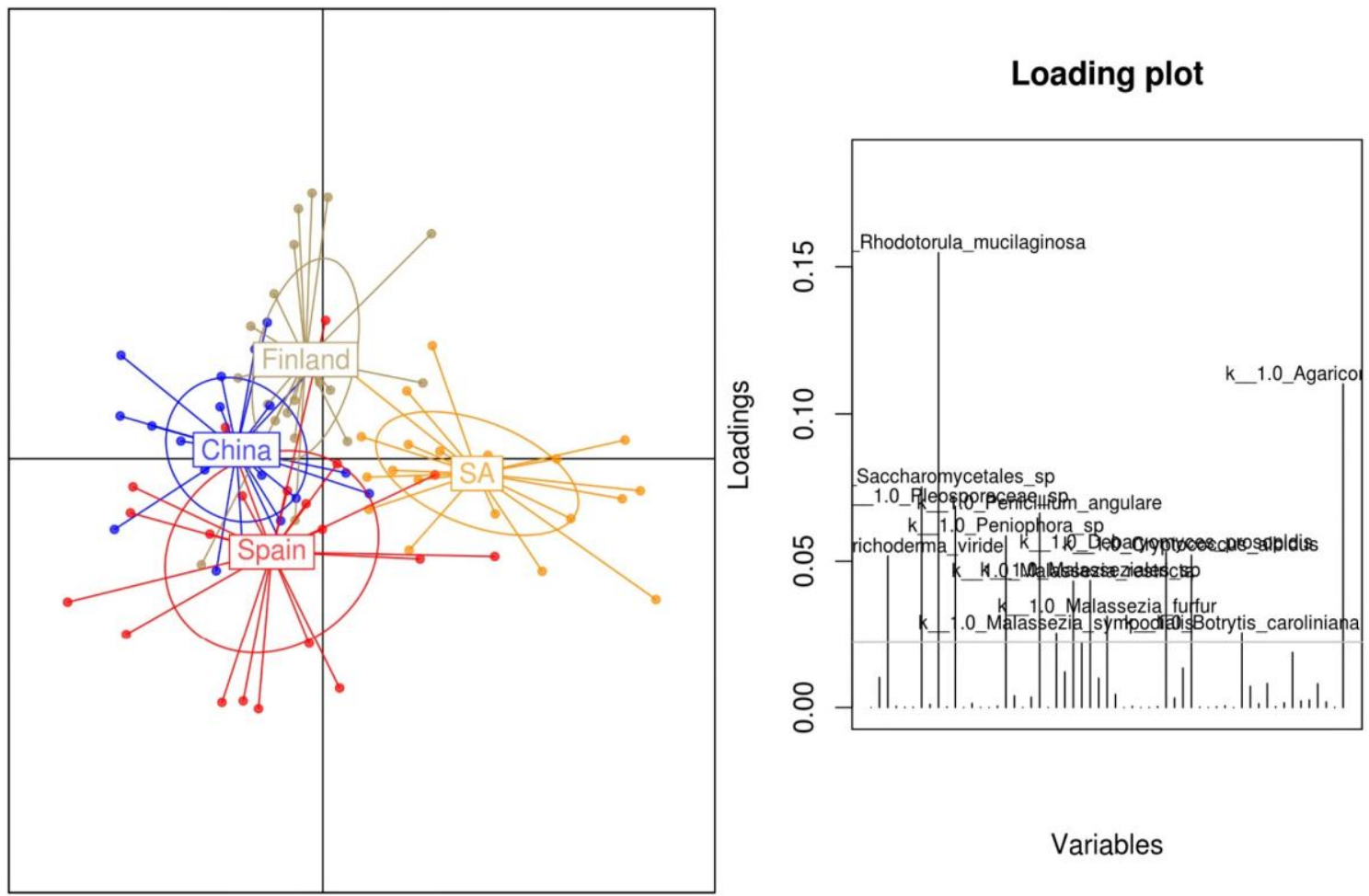

Figure 1. Breast milk samples cluster separately according to fungal composition. DAPC analysis shows relationships in fungal composition among samples from different locations. A canonical loading plot shows differentially abundant bacterial OTUs in the groups. The individual peaks show the magnitude of the influence of each variable on the separation of the groups (threshold level= 0.05). Total number of samples, 80 (number per country, 20). SA, South Africa.

Taking into account mode of delivery, mycobiota compositions were different across the milk samples from different geographic origins. The Kruskal- Wallis test reflected that the occurrence of Cryptococcus was statistically significantly higher in milk samples of women delivering vaginally than in those who delivered by C-section $(p=0.028)$. At the species level, in Chinese breast milk samples, Candida smithsonii was significantly more abundant in samples pf women with vaginal deliveries, Sistotrema sp. in samples from Spanish women with C-sections, Ascomycota sp. in samples from Finnish women with vaginal deliveries, Malasezzia restricta in samples from Finnish women with C-sections, and Malassezia restricta and Davidiella tassiana in samples from South African women with C-sections (LefSe analysis, $p<0.05$ ) (Fig. 2d). Indices of alpha diversity and richness across the samples were similar, and no statistical differences were observed between geographic locations or delivery modes (Fig. S3). 


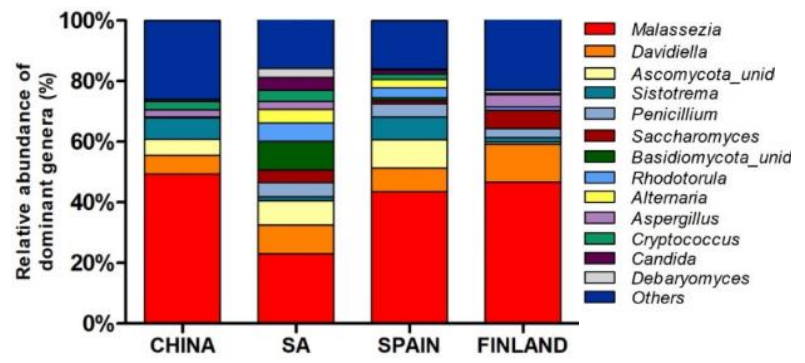

b

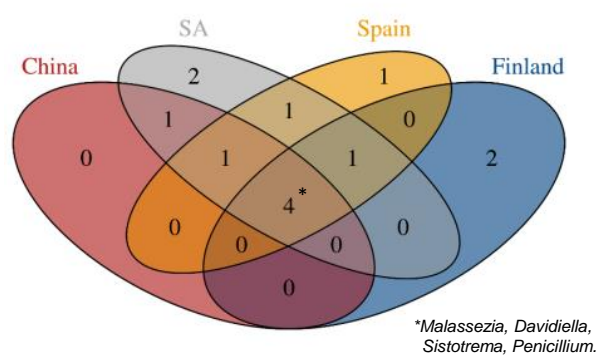

C

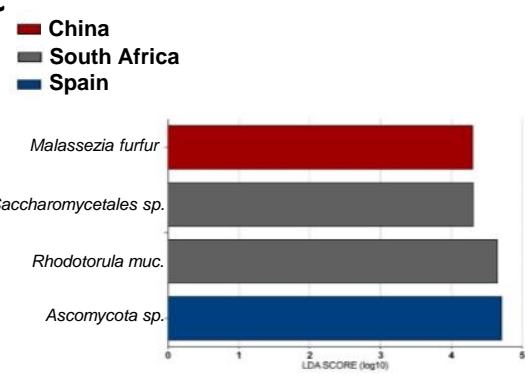

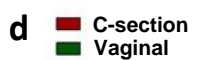
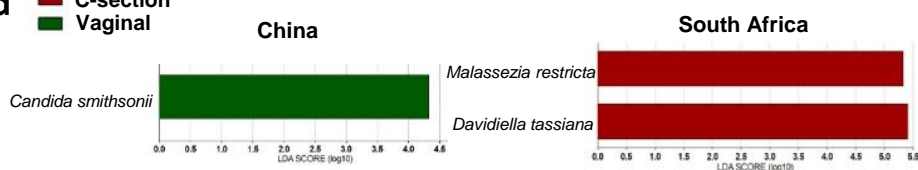

Finland

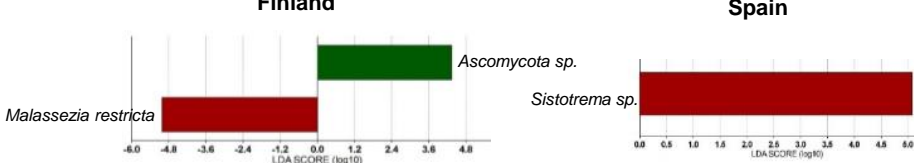

Figure 2. Effect of geographical location and mode of delivery on fungal composition in breast milk samples. (a) Fungal relative abundances at the genus level across countries. Only genera present in more than $1 \%$ abundance in at least $20 \%$ of the samples are represented. (b) Shared phylotypes across countries at the genus level. ${ }^{*}$, core of four fungal genera shared across geographic locations. Venn diagram cutoff, 0.5. (c) Differentially abundant species in breast milk samples depending on geographic location, as inferred by the LefSe algorithm. The threshold for the logarithmic discriminant analysis (LDA) score was 2 , with a $p$ value of $<0.05$. Number of samples per country, 20 (total number, 80). (d) Differentially abundant species in breast milk samples depending on delivery mode and geographic location, as inferred by the LefSe algorithm. The threshold for the LDA score was 2 , with a $p$ value of $<0.05$. Total number of samples, 80 (samples from vaginal deliveries, 40; samples from C-section deliveries, 40). SA, South Africa.

\section{Fungal and bacterial interactions: a network analysis}

Network analyses of the bacteria and fungi present in the breast milk samples showed complex intra- and interdomain interactions, with different associations among organisms depending on the country of origin and delivery mode, some of which were also influenced by maternal features. For example, a Malassezia operational taxonomic unit (OTU) (Fungi_1) correlated positively with a Streptococcus (Bact_6) from vaginal delivery samples, and with a Streptococcus (Bact_1) from C-section deliveries among Finnish samples, and the abundances were dependent on maternal age. The same Malassezia OTU correlated positively with several Streptococcus OTUs in samples from C-section deliveries from Chinese mothers and also positively with an unclassified member of Bacilli (Bact_2) from South African samples and vaginal deliveries. Significant influences of maternal age and BMI on specific bacterial and fungal organisms were also observed (Fig. 3). However, given that the density of fungal cells is at least 1 order of magnitude lower than that of bacteria, the influence of fungi on the breast milk ecosystem needs to be elucidated. In order to study the diversity of the most 
common yeast in our samples, a phylogenetic tree of the most prevalent Malassezia OTUs detected in this work across geographic locations was determined, including known members of the Malassezia genus as a reference (Fig. S4). The tree shows a large diversity of Malassezia isolates with similarity to at least four known species, including OTUs which could potentially represent new species. With the exception of one OTU (Fungi 37, which was found to be uniquely present in China), all other sequences were found in all countries and appear to be therefore ubiquitous. In relation to mode of delivery, all the OTUs were present in breasmilk from mothers with both delivery types. 


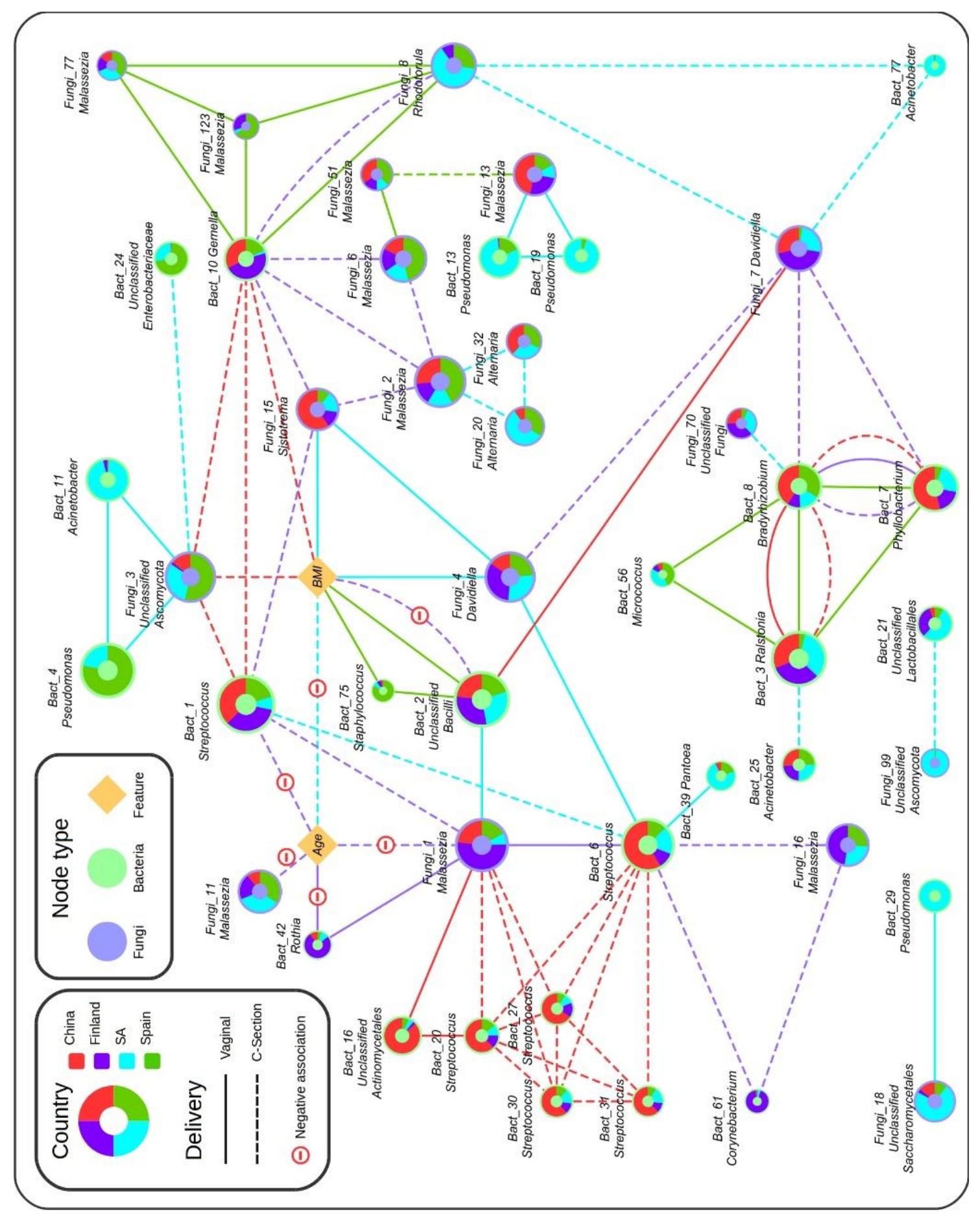

Figure 3. Cooccurrence network of bacteria and fungi in breast milk samples depending on maternal features and delivery mode. Green nodes represent bacterial OTUs, blue nodes represent fungal OTUs, and yellow nodes represent features. Node size indicates OTU abundance. Pie chart colours represent the overall distribution of each OTU across country. Each link indicates a significant $\left(\mathrm{P}_{-}{ }_{0.05}\right)$ interaction between OTUs or features in samples from a given combination of country and delivery mode (vaginal, C-section). Link colour denotes the country, and line type indicates delivery mode. SA, South Africa. 


\section{Discussion}

Breast milk is a continuous source of microbes that are transmitted, together with many nutrients and protective compounds, to the infant gut during a critical period when the key regulatory systems of the body are immature (Jost et al. 2014; Walker \& Iyengar 2015). Although bacteria inhabiting human breast milk have been extensively studied, the presence of fungi in the fluid had not been assessed until recently, when a diversity of fungal phylotypes in breast milk from healthy Spanish mothers was reported by our group (Boix-Amorós et al. 2017). The mycobiome, the fungal fraction of the human microbiome, is present in lower abundances and has been much less explored than the bacterial fraction. However, its potential importance for human health and disease has stimulated an increased interest in this field (Hatoum et al. 2012; Sokol et al. 2016; Underhill \& Iliev 2014; Ward et al. 2017). In the infant, fungal species can be detected very early in life (Schei et al. 2017; Seddik et al. 2016; Ward et al. 2017). However, the infant mycobiome is almost unexplored, and information about its development is scarce. To ascertain the presence of fungi in breast milk is difficult because of the possibility of contamination in samples with low microbial density, and therefore multiple approaches and strict negative controls are needed (Salter et al. 2014). A recent study reported higher gut fungal diversities during the first months of life, which decreased over time, while the diversities of the bacterial fraction increased in reciprocal correlation, suggesting that potential inter-kingdom associations may drive microbial gut dynamics (Fujimura et al. 2016).

In the present study, we have confirmed the presence of diverse fungal communities in breast milk samples from Spain, Finland, China, and South Africa. Fungi were detected in all breast milk samples through massive DNA sequencing, with the two phyla Basidomycota and Ascomycota being the most prevalent and presenting reciprocal patterns of abundance in all countries except for South Africa, where Ascomycota levels were significantly higher, and Basidiomycota levels lower, than those of the other countries. At the genus level, Malassezia predominated in all countries, followed by Davidiella. In our previous work reporting the presence of fungi in breast milk, Malassezia also represented the most abundant genus (Boix-Amorós et al. 2017). Other genera found in the current study, such as Alternaria, Rhodotorula, Saccharomyces, and Candida, were also found in the previous study. Results yielded by qPCR showed that $>70 \%$ of Spanish and South African samples, $45 \%$ of Chinese samples, and only $35 \%$ of Finish samples had detectable levels of fungal DNA. The median fungal load in all the samples was 2.5 $x 10^{5}$ cells $/ \mathrm{ml}$, in agreement with our previous results for Spanish samples. Our findings reinforce the potential influence of environmental factors, in particular geographic location and delivery mode, on breast milk fungal composition. Samples from South Africa clustered at a distance from those from the other countries according to their fungal composition, because of the influence of the higher levels of Rhodotorula mucilaginosa in those samples (Fig. 1). Although differences among samples from 
different geographic locations were observed, a core constituted by four genera, Malassezia, Davidiella, Sistotrema, and Penicillium, was shared in all countries (Fig. 2b). Breast milk mycobiota also differed depending on the mode of delivery (vaginal or Csection) across countries. Specific fungi, such as the genus Cryptococcus, appeared to be more prevalent among samples from mothers delivering vaginally, and specific shifts at the species level were also observed within each country. No differences in fungal diversity or richness were observed in the present study. Previously, we identified changes in breast milk microbiota between locations, as well as in the milk metabolite profile (Gómez-Gallego et al. 2018; Kumar et al. 2016), using the same samples analyzed in this study.

Although the origin of breast milk fungi is unknown, most of the organisms detected in this study can be found in other human niches. Malassezia species are yeasts whose primary niche is the human body (and other animals). In healthy individuals, they are part of the normal microbiota, where they predominantly colonize the seborrheic parts of the skin (Findley et al. 2013), and are commonly found in infants (Gouba et al. 2013; Jo et al. 2016; Suhr et al. 2016; Ward et al. 2018). Malassezia has also been detected in significant abundance in adult (Findley et al. 2013; Nash et al. 2017; Seddik et al. 2016) and infant fecal samples (Strati et al. 2016), and therefore may play a role at the intestinal level; it has also been described as an oral commensal (Dupuy et al. 2014). Although Malassezia DNA has been detected in high proportions in breast milk before, no viable cells could be recovered by classic culture methods from breast milk, (Boix-Amorós et al. 2017) and further efforts should be made to culture this organism, which has also been shown to be able to penetrate the cell and survive intracellularly. Davidiella, the second most prevalent fungus found in the samples of this study, was detected in the only published study about the characterization of vaginal microbiota and mycobiota of asymptomatic women (Drell et al. 2013). In the same study, Candida was found to be the predominant genus. Therefore, these fungi may play an important role in the early colonization of vaginally born infants. In our previous study on breast milk fungi, Davidiella could not be detected (Boix-Amorós et al. 2017), which could be associated with the differences on sequencing platforms and genes targeted in both studies, as has been previously shown (Allali et al. 2017; Clooney et al. 2016). In addition, Davidiella represents the sexual form of the Cladosporium genus (Schubert et al. 2007). Fungi can have an asexual form (anamorph) and sexual form (teleomorph) that may be classified into different genera. This sexual dimorphism can be a significant problem when classifying fungal sequences, and the use of different databases and/or sequencing of different genes can lead to conflicting classifications. In a study with paediatric inflammatory bowel disease (IBD) patients, Cladosporium cladosporiodes abundance decreased in IBD, while Pichia jadinii and Candida parapsilosis increased in comparison to controls (Chehoud et al. 2015). Candida is probably the most ubiquitous genus of the human mycobiome. It is the major fungal genus detected in the adult oral cavity (Ghannoum \& Mukherjee 2013; Kraneveld et al. 2012), and has also been detected in the 
infant mouth, including several species as common inhabitants (C. parapsilosis, C. tropicalis, C. orthopsilosis, etc.) (Kleinegger et al. 1996; Stecksén-Blicks et al. 2015; Ward et al. 2018). Several Candida species are also commonly present in adult skin and fecal samples (Nash et al. 2017; Underhill \& Iliev 2014) and in infant anal and fecal samples (LaTuga et al. 2011; Ward et al. 2018). Although Candida can be responsible for vaginal infections (Trama et al. 2005), it is the most prevalent fungus in the vaginal mycobiome of healthy women (Drell et al. 2013). Transmission of Candida from mother to infant likely occurs, as the same fingerprinting of the DNA has shown identity between maternal Candida from vagina, rectum, oral cavity, and skin, and infant oral Candida from oral cavity and rectum (Bliss et al. 2008). Other prevalent fungi detected in our samples are commonly found in several body niches. Saccharomyces is among the most abundant fungus in the gut (Nash et al. 2017; Underhill \& Iliev 2014), and Saccharomyces cerevisiae has been reported to be highly prevalent and abundant in the infant oral and anal mycobiome during the first month of life (Ward et al. 2018). In a recent study, bacteria and fungi from fecal samples in children suffering atopic wheeze were analyzed, and Saccharomycetales taxa appeared to be decreased in the atopic wheeze group, while the species Pichia kudriavzevii was increased, compared to controls (Arrieta et al. 2017). Others, such as Penicillium or Aspergillus, can also be detected in fecal samples, and Debaromyces hansenii represents one of the main species present in gut of breastfed infants (Schei et al. 2017). In the present study, we detected Debaromyces, although none of the sequences have been classified as D. hansenii. However, DNA from this species was previously detected in breast milk (Boix-Amorós et al. 2017).

The study of interspecies interactions within a population is necessary to better understand the microbiota's role. It is known that microorganisms can interact by competition and sometimes collaboration, thereby influencing microbiota composition and the host's health. It has been demonstrated that cross talk between bacteria and fungi can exist, modulating host defense mechanisms, protecting against infections, or collaborating to cause them (Sam et al. 2017; Ten Oever \& Netea 2014). For example, synergies between oral Streptococcus oralis and C. albicans enhanced C. albicans invasion through the activation of host enzymes that cleave epithelial junction proteins ( $\mathrm{Xu}$ et al. 2016). On the contrary, Streptococcus mutans showed the ability to modulate biofilm formation and to reduce C. albicans virulence in an animal model (Barbosa et al. 2016). Some vaginal isolates of Lactobacillus strains have shown anti-fungal activity in vitro against Candida spp., and probiotic Lactobacillus rhamnosus and Lactobacillus reuterii strains showed in vitro efficacy against $C$. albicans responsible for vaginal infections (Parolin et al. 2015). To understand microbial relationships, microbial network analyses are indispensable, allowing the identification and representation of the most influential members in a bacterial community and their interactions with other microorganisms (Layeghifard et al. 2017). In a recent work, bacterial interactions in the colostrum and mature milk of Italian and Burundian mothers were analyzed and showed different bacterial networks among the two populations. The identified networks were complex 
and dynamic, changing from colostrum to mature milk (Drago et al. 2017). In the present study, we have analyzed cooccurrence relationships between fungi and bacteria in breast milk, observing a complex network of interactions between fungi and bacteria, and within the same domain. Microbial interactions were influenced by delivery characteristics (mode of delivery and geographic location), and maternal features (maternal BMI and age) influenced the prevalence of particular microorganisms. Interesting positive correlations were observed between several Malassezia spp., the most prevalent fungus detected in breast milk by sequencing, and different streptococci, the latter representing one of the most common bacterial genera in breast milk (Jost et al. 2013). Interestingly, in our previous study, we observed a significant positive correlation between Malassezia and bacterial load (Boix-Amorós et al. 2017), and further experimental research should analyze potential synergistic relationships between these genera.

Our data confirmed the presence of fungal DNA and fungal cells (including viable cells) in breast milk samples from healthy mothers from four different geographic locations, by using different approaches. This supports the existence of a "breast milk mycobiota" under healthy conditions. Differences in composition associated to mode of delivery and country of origin were observed. In addition, we observed some interdomain microbial interactions in breast milk that could lead to further in vitro studies. The presence of viable fungal cells suggests a potential influence of breast milk on the infant's mycobiota development. However, data from the infant gut mycobiota is missing in the present study, and further studies should address the potential fungal transference from breast milk to the infant gut mycobiome. Although we tried to prevent the contamination of maternal skin mycobiota by cleaning the breast prior to sample collection (which has been previously shown to reduce bacteria in breast milk samples (Sakwinska et al. 2016)), it should be taken into account that certain retrograde flux occurs during breastfeeding, and fungal species present in maternal skin and the infant's mouth could be translocated to breast milk, and vice versa (Ramsay et al. 2004). A greater understanding of the environmental influence on the bacterial and fungal communities and their metabolic functions is also needed. 


\section{Supplemental Material}

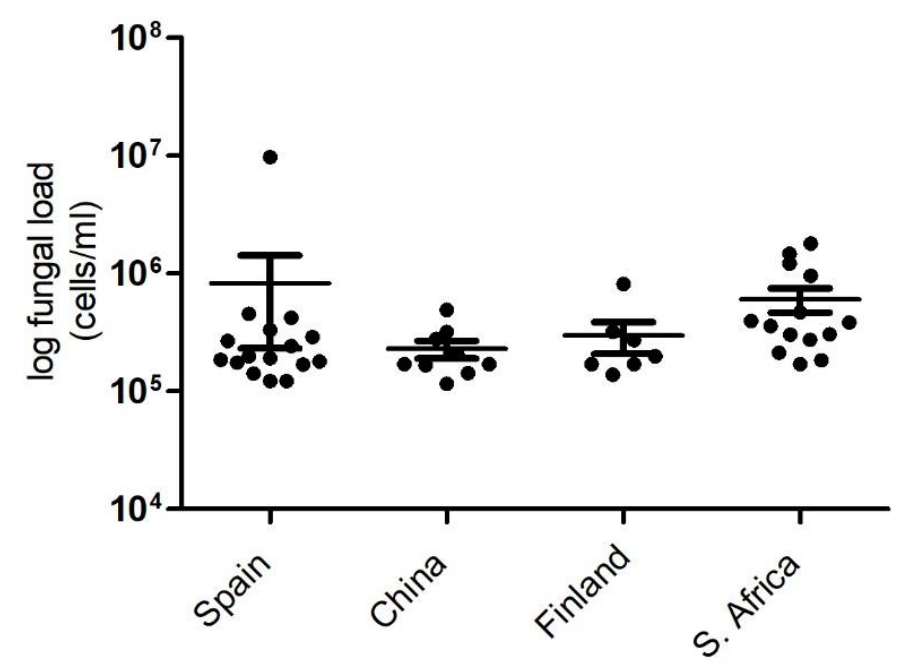

Figure S1. Fungal load in breast milk across geographic locations. The plot shows median fungal loads with interquartile ranges in those samples that showed fungal presence by qPCR in each country. Spain, $n=16$; China, $n=9$; Finland, n=7; South Africa, $n=14$. Detection limit was $10^{3}$ cells $/ \mathrm{ml}$, estimated as the lowest concentration at which $95 \%$ of the positive samples are detected.

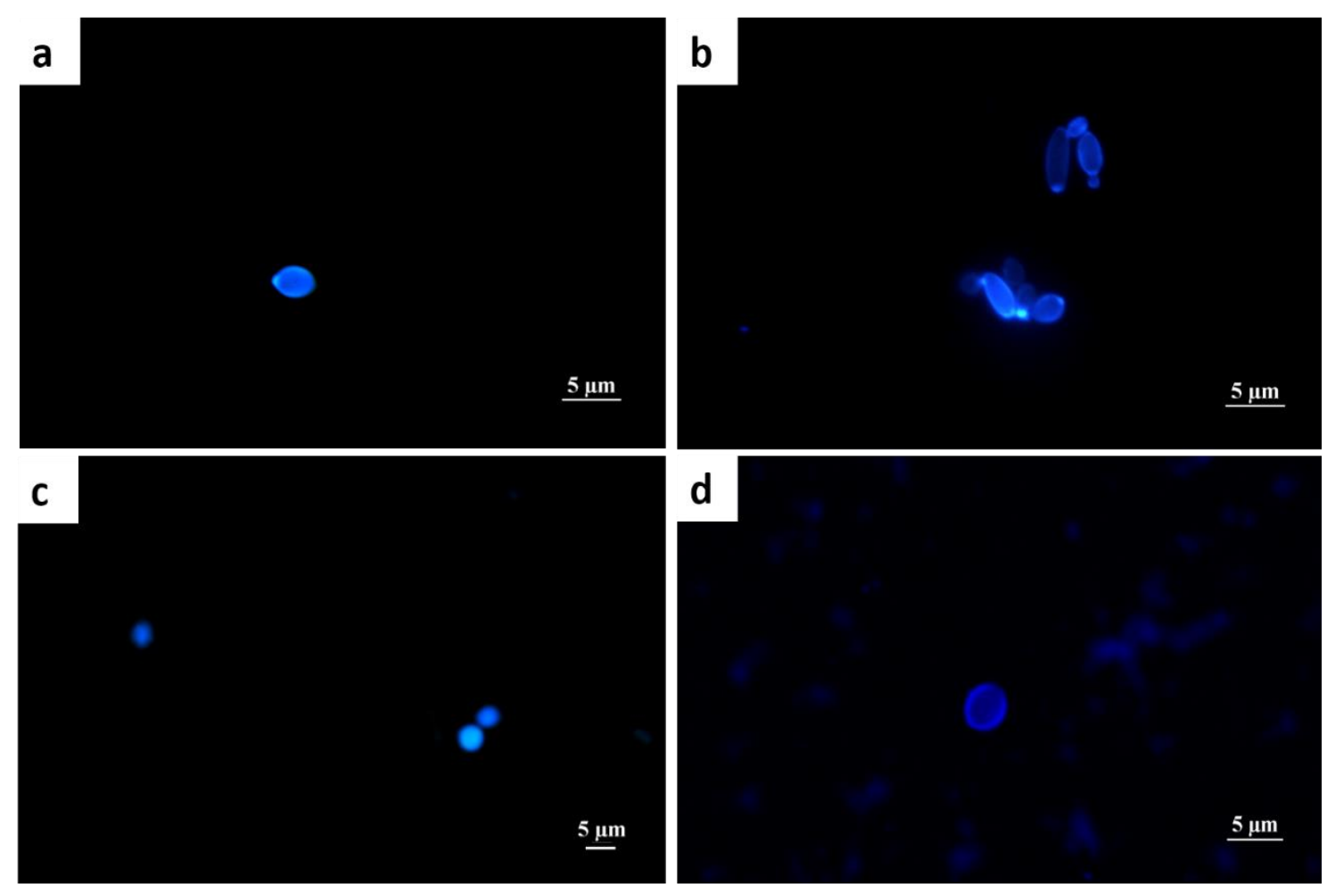

Figure S2. Fluorescence microscopy images of yeasts in human breast milk. Panels are showing yeasts stained in blue with calcofluor-white from breast milk samples of different geograohic origin: $a=C 1$ Spain; $b=V 6$ South Africa; $c=V 346$ Finland; $d=V 10$ Spain. V= vaginal delivery; $C=C-$ section delivery. 
Table S1. Fungal isolates from breast milk. For confirmation of fungal viability, 3-4 samples were selected from each country to obtain fungal isolates. Data show the tentative taxonomic classification as inferred by sequencing of the 18S rRNA gene, as well as the BLAST parameters against the closest relative in public databases. SA: South Africa, C: China, SP: Spain

\begin{tabular}{|c|c|c|c|c|c|c|c|}
\hline $\begin{array}{l}\text { Isolate } \\
\text { Code }\end{array}$ & Country & Species & $\begin{array}{l}\text { Max } \\
\text { score }^{\mathrm{a}}\end{array}$ & $\begin{array}{l}\text { query } \\
\text { cover }^{b}\end{array}$ & $\begin{array}{l}\text { BLAST } \\
\text { e-value }\end{array}$ & $\begin{array}{l}\text { Max } \\
\text { Identity }^{c}\end{array}$ & $\begin{array}{l}\text { Accession } \\
\text { № }\end{array}$ \\
\hline IHMP29 & $\mathrm{CH}$ & Candida albicans & 527 & $99 \%$ & $8 e-146$ & $98 \%$ & CP032012.1 \\
\hline IHMP110 & $\mathrm{CH}$ & $\begin{array}{l}\text { Uncultured fungus clone YL_OTUO } 18 \mathrm{~S} \\
\text { ribosomal RNA gene, partial sequence }\end{array}$ & 551 & $96 \%$ & $5 e-153$ & $99 \%$ & KT285760.1 \\
\hline IHMP111 & $\mathrm{CH}$ & $\begin{array}{l}\text { Candida albicans strain SC5314-PO } \\
\text { chromosome RB }\end{array}$ & 538 & $97 \%$ & $4 e-149$ & $97 \%$ & CP025165.1 \\
\hline IHMP58 & SA & Candida albicans strain TIMM 1768 & 555 & $99 \%$ & $4 e-154$ & $99 \%$ & СР032012.1 \\
\hline IHMP06R & SA & $\begin{array}{l}\text { Candida albicans strain SC5314-PO } \\
\text { chromosome RB }\end{array}$ & 569 & $96 \%$ & $1 e-158$ & $99 \%$ & СР025165.1 \\
\hline IHMP60 & SP & Candida parapsilosis strain CDC317 & 525 & $98 \%$ & $6 e-147$ & $100 \%$ & HE605209.1 \\
\hline IHMP59 & SP & $\begin{array}{l}\text { Uncultured fungus clone nco88e11c1 } \\
18 \text { ribosomal RNA gene, partial } \\
\text { sequence }\end{array}$ & 568 & $96 \%$ & 5e-158 & $99 \%$ & KC674774.1 \\
\hline IHMP24 & SP & $\begin{array}{l}\text { Candida orthopsilosis Co 90-125, } \\
\text { chromosome } 7 \text { draft sequence }\end{array}$ & 571 & $96 \%$ & $4 e-159$ & $99 \%$ & HE681725.1 \\
\hline
\end{tabular}

A)

Shannon index

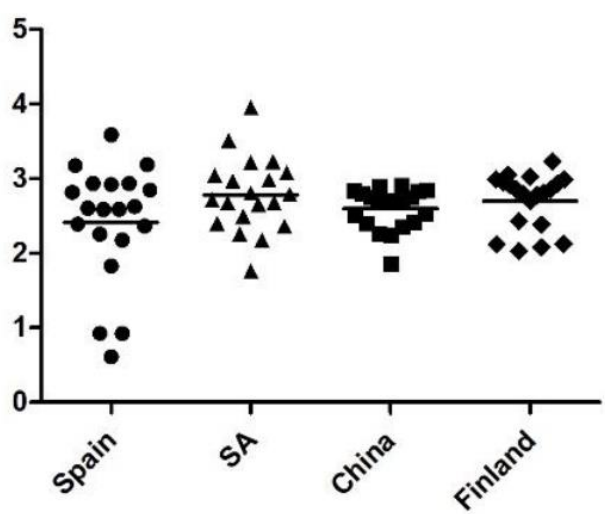

C)

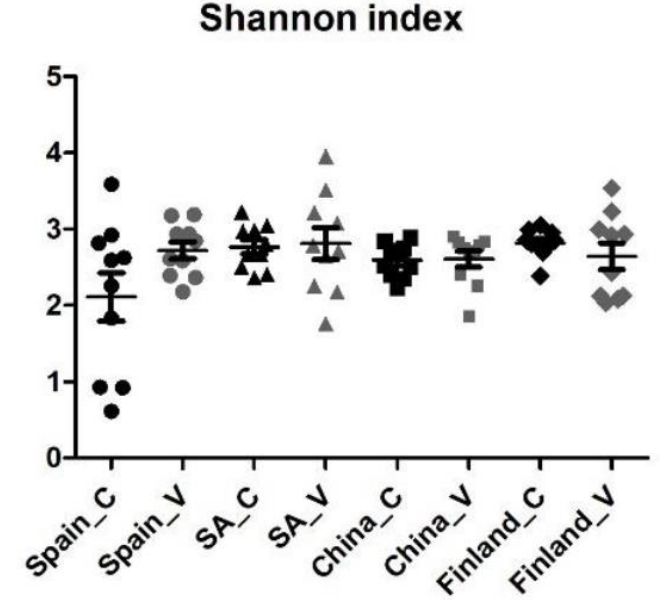

B)

Chao1 index

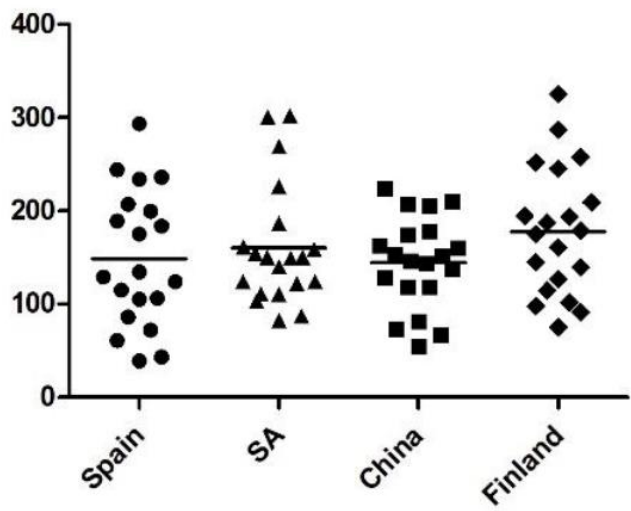

D)

Chao1 index

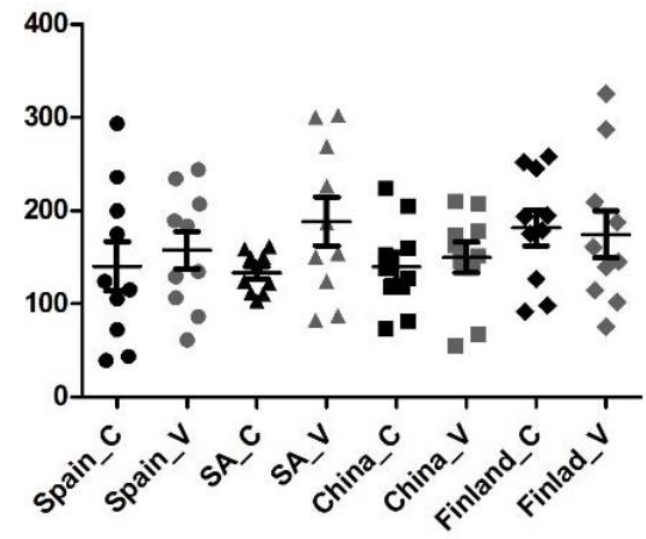

Figure S3. Diversity and richness in breast milk samples. Data show Shannon and Chao1 indices, respectively, per country (Panel A and B) and taking into account mode of delivery (Panel $C$ and D). C=C-section, V=Vaginal. 


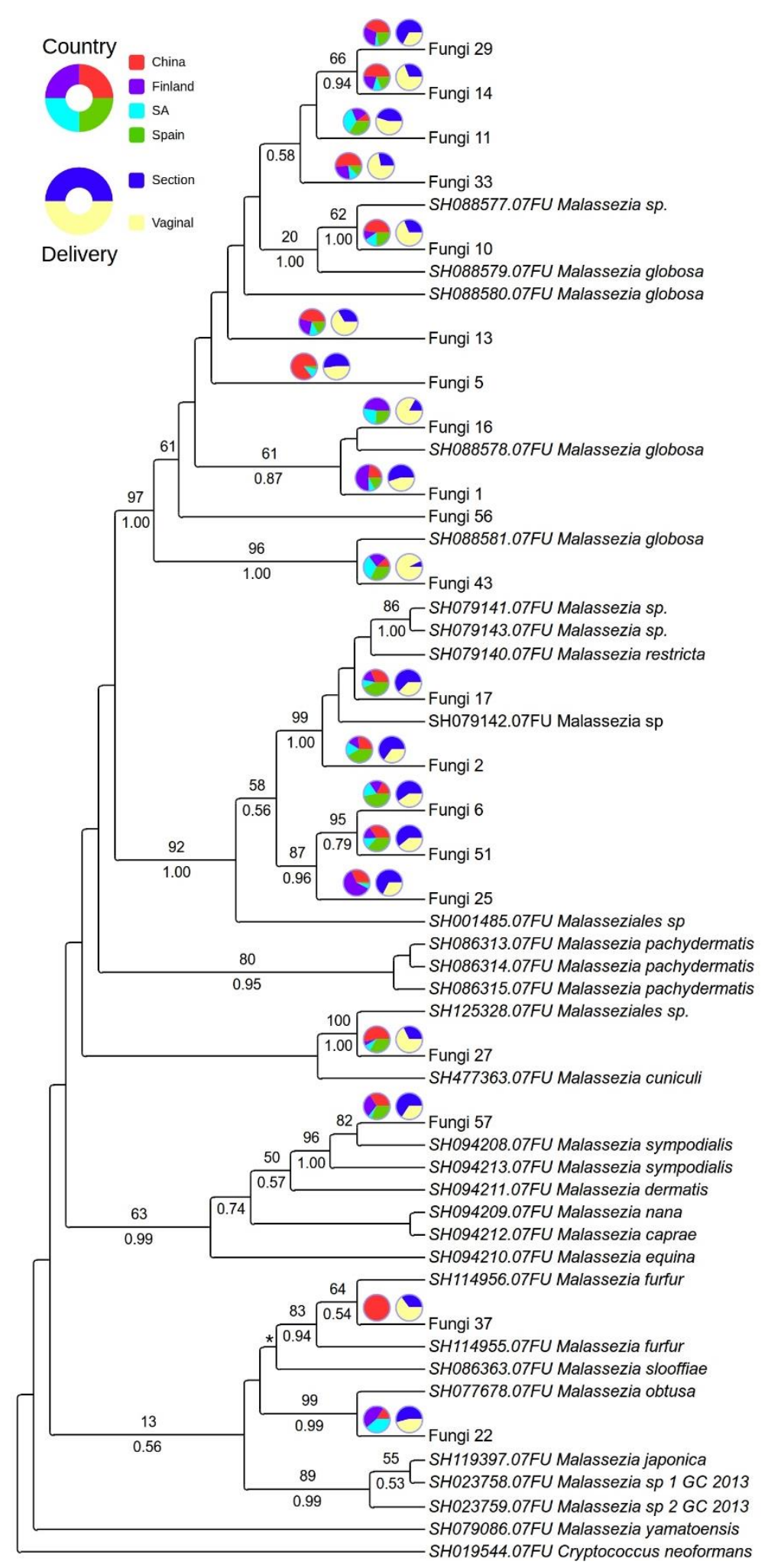

Figure S4. Molecular phylogenetic tree inferred from a maximum likelihood analysis of ITS sequences of the Malassezia OTUs obtained in this work and known members of the genus Malassezia. ML support values $>50 \%$ over 10,000 replicates are shown above the branches. For branches that were also supported by Bayesian inference, the posterior probability is shown below the branches. Brackets surrounding posterior probability values show a conflict between the Bayesian inference and maximum likelihood analysis, in which M. nana clustered in the $M$. restricta branch in maximum likelihood analysis, but outside it in bayesian inference. The tree is rooted with Cryptococcus neoformans. Pie charts indicate prevalence of each OTU per country and delivery mode. The 20 most prevalent Malassezia OTUs from this work are included in the tree. 


\section{Chapter 4}

\section{Etiology of Sub-acute Lactational Mastitis as Inferred by Human Milk Bacterial Composition and Activity.}

Alba Boix-Amoros ${ }^{1,2}$, Maria Teresa HernándezAguilar ${ }^{3}$, Alejandro Artacho², Maria Carmen Collado ${ }^{1}$, Alex Mira ${ }^{2}$

In preparation

${ }^{1}$ Institute of Agrochemistry and Food Technology, Spanish National Research Council (IATA-CSIC), Department of Biotechnology, Paterna, Spain.

2Department of Health and Genomics, Center for Advanced Research in Public Health, FISABIO Foundation, Valencia, Spain.

${ }^{3}$ Breastfeeding Clinical Unit Dr. Peset, University Hospital Dr. Peset, National Health Service, Valencia, Spain. 


\begin{abstract}
Infections by opportunistic pathogens can lead to lactational mastitis, characterized by painful inflammation and duct obstruction in the mammary gland. In particular, subacute mastitis (SAM) is a less acute state of the disease, but it is extremely prevalent among lactating women, being one of the main reasons for early weaning. Although the etiology and diagnose of acute mastitis is well established, very little is known about bacteria causing the sub-acute state. Milk samples from healthy and SAM-suffering mothers was extracted at two time points (during the mastitis and when the symptoms disappeared). Total (DNA-based) and active (RNA-based) bacterial composition were analysed by $16 \mathrm{~S}$ rRNA Illumina sequencing and bacterial load was estimated by qPCR. Bacterial load was significantly higher in mastitis samples compared to healthy mothers and decreased after the clinical symptoms disappeared. Bacterial diversity significantly decreased in milk from SAM samples. Significant differences in bacterial composition and activity were found in milk samples from healthy and SAM mothers, and possible causing agents included not only Staphylococci but also several Streptococci and oral bacteria. Contrary to acute mastitis, the same bacterial species were found in samples from healthy and diseased mothers, although at different proportions. Finally, mammary epithelial cell lines were exposed to human milk from healthy and SAM mothers, showing an over-production of the inflammatory marker IL8 in the presence of SAM bacteria. Our work therefore supports that SAM has a bacterial origin, with increased bacterial loads, reduced diversity and altered composition, which were partly recovered after treatment. Taken together, the data suggest a polymicrobial and varying etiology, which appears to be the outcome of a bacterial dysbiosis.
\end{abstract}




\section{Introduction}

Human milk is a complex and live fluid, containing a relatively diverse and potential beneficial microbiota under healthy conditions (Fitzstevens et al. 2016). Therefore, human milk participates in the microbial supply to the infant, and together with other milk compounds, enhance gut microbiota colonization, likely stimulates commensal tolerance and supports the maturation of the immune system (Fernández et al. 2013; Jost et al. 2014; Marcobal et al. 2010; Toscano et al. 2017a). Occasionally, lactation is afflicted with the development of mastitis, which frequently arises during the first 6 weeks postpartum and is one of the main causes of early weaning (Amir \& Academy of Breastfeeding Medicine Protocol Committee 2014; Berens 2015; Odom et al. 2013). According to the World Health Organization (WHO), mastitis affects up to $33 \%$ of lactating women (World Health Organization 2011), but this is likely biased by the difficulties for defining the disease. Classically, mastitis is defined as an inflammation of the breast, accompanied of infection or not (Amir \& Academy of Breastfeeding Medicine Protocol Committee 2014; Berens et al. 2016; World Health Organization 2011). This definition includes a broad range of conditions that go from local inflammation with minimal systemic response, to inflammation associated to other diseases (such as breast cancer or Raynaud's disease) and infectious processes. However, most researchers consider that lactational mastitis has an infectious origin. Symptoms appear when a blockage of the milk ducts occur, presumably due to the overgrowth of some bacterial species which form biofilms and trigger inflammation (Angelopoulou et al. 2018; Contreras \& Rodríguez 2011; Fernández et al. 2014; Marín et al. 2017). According to its course, lactational mastitis can be classified into different types, being acute (AM) and sub-acute mastitis (SAM) the most prevalent among breastfeeding women. AM can be easily identified, due to the intensity of its symptoms, namely erythema, pain, swelling, fever and other general symptoms. Staphylococcus aureus is considered the main causative agent in AM, producing toxins responsible of the systemic symptoms (Contreras \& Rodríguez 2011; Delgado et al. 2011; Osterman \& Rahm 2000). SAM, albeit courses with milder symptoms, is most prevalent among lactating women, and therefore represents one of the principal causes of undesired weaning. Based on bacterial cultures from human milk samples, Staphylococcus epidermidis has been proposed as the predominant species responsible of sub-acute mastitis (Delgado et al. 2008; Jiménez et al. 2015; Patel et al. 2017), as well as, in lower abundances, other coagulase negative staphylococci (CNS) and viridans streptococci such as Strep. mitis and Strep. salivarius (Contreras \& Rodríguez 2011; Martín et al. 2016). These are frequently encountered in healthy skin microbiota and human milk, and can occasionally overgrow and form thick biofilms in the milk ducts, leading to milk stasis and opportunistic infections, which result in the symptoms of SAM previously described (Fernández et al. 2014; Otto 2014). Identifying SAM can be challenging, and a poor diagnosis and/or treatment can lead to recurrent or chronic infections. Microbial culture is applied as standard diagnose procedure, but this technique is time-consuming, and implies false negatives (as many 
microbial species cannot be grown under standard laboratory conditions). In addition, most bacteria associated with lactational mastitis can be frequently detected in human milk from healthy mothers, which further complicates the diagnosis (Kvist et al. 2008), and thus, their sole presence in the sample does not necessarily imply an infectious process. Studies addressing the microbiology of SAM are limited, and information about bacterial load of human lactational mastitis is scarce. In addition, most human milk microbiota studies based on molecular techniques focus on the total bacterial composition, not considering that part of its DNA may correspond to dead or inactive bacteria, as well as free bacterial DNA. For this reason, RNA-based sequencing of human samples is being used to clarify the elusive aetiology of some diseases with complex microbial origin (Simón-Soro \& Mira 2015; Yost et al. 2015).

The aim of the current work was to describe the human milk bacterial composition and loads in mothers suffering SAM, taking into account total and active bacteria (as inferred by DNA and RNA 165 rRNA gene sequencing, respectively), in order to define the etiology of the disease and find potential bacterial biomarkers. In addition, bacterial pellets from human milk were exposed to a mammary epithelia cell line, in order to investigate their potential role in inflammatory processes. Results could provide insights on the SAM etiology, and facilitate its diagnosis and the development of efficient therapies.

\section{Material and Methods}

\section{Subjects and Sampling}

A total of 51 mothers participated in the study. Among them, 24 presented symptoms of sub-acute mastitis, 3 presented symptoms of acute mastitis and were included for comparison, and the remaining 24 were completely healthy. Human milk samples were collected between 9 and 90 days after delivery, at two time points: during the course of the symptoms (time 0 ) and after the symptoms cessation (time 1) in the mastitis group; and during a medical consultation to the doctor (time 0 ), and a second visit a week after (time 1) in the control group. Details of pregnancy and delivery, mother and infant health status, medicines consumption, lactation, and clinical symptoms during mastitis were collected at recruitment through a detailed questionnaire. Mothers were recruited at the Breastfeeding Unit of Dr. Peset Hospital (Valencia, Spain), and at the Alfafar Health Center (Valencia, Spain). Inclusion criteria for all mothers were: to be 18 years old or older, to reside in the same geographical area (Valencia, Spain), to breastfeed their children and to have signed the informed consent handed by the doctor, nurse or midwife. Women were considered to have sub-acute mastitis when presenting breast pain (usually described as profound, needle-like and/or burning pain) accompanied or not by lumps in the breast tissue; without general symptoms (Jiménez et al. 2015). Women were considered to have acute mastitis when presenting profound pain in the breast accompanied by at least two of the following symptoms: local inflammation signs 
(breast redness, local hyperthermia, or sensitive lump), fever and general discomfort (Jiménez et al. 2015). Controls were healthy breastfeeding woman who did not present any of the previous symptoms. Exclusion criteria were: suffering from an immunological, metabolic or other severe diseases; or having received antibiotics or probiotics 15 days prior to first sample donation. Breastfeeding counselling was offered to all mothers suffering from breast pain. After any other cause of breast pain was discarded and the diagnosis of sub-acute mastitis confirmed, mothers were instructed on breastfeeding massage techniques and optimal lactation positioning. Mothers were advised to breastfeed frequently, apply massages on the breast and pump to empty their breasts frequently and drain any possible lump. Treatment with anti-inflammatory drugs and/or probiotics were prescribed. In three cases, where symptoms persisted after 7 days, antibiotics were prescribed. Mothers suffering acute mastitis received antibiotics and anti-inflammatory drugs, following the recommended standards. Most mothers presenting mastitis symptoms had taken analgesic drugs (NSAIDS or paracetamol) before visiting the doctor. Before sample collection, mothers received oral and written instructions for the standardized collection of samples. Prior to sampling, nipples and mammary areola were cleaned with chlorhexidine soap and sterile water and rinsed with sterile saline solution. After manually discarding the first milk drops, samples were collected with a Medela Symphony breast pump (Medela, Baar, Switzerland) in sterile collection units. Samples were collected in the morning, and at least 1 hour after the last feeding. All samples were encoded, and frozen at $-80^{\circ} \mathrm{C}$ until further processing. All volunteers gave written consent for the protocol, approved by the Ethical Committee of Clinical Research from the Dr. Peset Hospital (Valencia, Spain), with reference number CEIC 19/16.

\section{Sample processing and DNA/RNA isolation}

Human milk samples $(4 \mathrm{ml})$ were centrifuged at 13,000 $\mathrm{g}$ for 10 minutes, discarding fat and whey. Total DNA and RNA were isolated from pellets by using the MasterPure Complete DNA \& RNA Purification Kit (Epicentre, Madison WI, USA) as previously described, following the manufacturer's instructions with some modifications (BoixAmorós et al. 2019b). An enzymatic lysis step was performed with lysozyme (20 mg/ml; Thermomixer comfort, Eppendorf, Hamburg, Germany), mutanolysin (4000 units/mg protein; Sigma-Aldrich, Madrid, Spain), and zymolyase $(0.25 \mathrm{mg} / \mathrm{ml}$; MP Biomedicals, Santa Ana, CA, USA), incubating $1 \mathrm{~h}$ at $37^{\circ} \mathrm{C} .2 \mu \mathrm{l}$ of proteinase $\mathrm{K}$ were added and the tubes were incubated for 15 minutes at $65^{\circ} \mathrm{C}$. To enhance the disruption of microbial cell walls, a mix of 150-212 $\mu \mathrm{m}$ and 425-600 $\mu \mathrm{m}$, acid washed glass beads (Sigma-Aldrich, San Luis, MI, USA) were added to the tubes and samples were put through two cycles of vigorous mixing in a FastPrep-24 ${ }^{\mathrm{TM}} 5 \mathrm{G}$ Instrument (MP Biomedicals, Santa Ana, CA, USA) during 1 minute. Proteins were precipitated using $350 \mu \mathrm{l}$ of protein precipitation agent, centrifuging 10 minutes at $13,000 \mathrm{~g}$ and $4^{\circ} \mathrm{C}$, transferring supernatants to a new tube. Nucleic acids were precipitated using isopropanol, washed with $70 \%$ and $96 \%$ ethanol and resuspended in $30 \mu \mathrm{TE}$ buffer. $10 \mu \mathrm{l}$ of each nucleic acids suspension were 
transferred to a new nuclease-free tube, and treated with the DNA-free DNA Removal Kit (Invitrogen, Carlsbad, CA, USA) to remove DNA and keep only RNA. 0.1 volume of the 10X DNase I Buffer and $1 \mu \mathrm{L}$ of rDNase I were added to the tubes, and incubated at $37^{\circ} \mathrm{C}$ for 30 minutes, three times. 0.1 volume of the DNAse Inactivation Reagent was added, incubated for 2 minutes at RT and centrifuged at $10,000 \mathrm{~g}$ and $4^{\circ} \mathrm{C}$ for 2 minutes. Supernatants containing clean RNA were transferred to new Eppendorf tubes. To confirm the complete removal of the DNA in the RNA samples, an electrophoresis in a $1.4 \%$ agarose gel was carried out. DNA and RNA concentrations were measured in a Nanodrop Spectrophotometer (ThermoScientific, Waltham, MA, USA).

\section{cDNA synthesis}

cDNA was synthesized from RNA by using the Transcriptor First Strand cDNA Synthesis Kit (Roche Life Science, Basel, Switzerland). A mix of: $1 \mu \mathrm{g}$ of each RNA sample, $1 \mu \mathrm{l}$ of Anchored-oligo (dT) primer, $(2.5 \mu \mathrm{M}) ; 2 \mu \mathrm{L}$ of Random Hexamer Primer $(60 \mu \mathrm{M})$ in a final volume of $13 \mu \mathrm{l}$ per sample was prepared. The primer-template mix was heated at $65^{\circ} \mathrm{C}$ for 10 minutes. Then, the following components were added to each reaction tube: $4 \mu \mathrm{l}$ of Transcriptor Reverse Transcriptase Reaction Buffer (1x $8 \mathrm{mM}$ $\mathrm{MgCl}$ ); $0.5 \mu \mathrm{l}$ of Protector RNase Inhibitor (20U), $2 \mu \mathrm{l}$ of Deoxynucleotide Mix (1 mM each) and $0.5 \mu \mathrm{l}(10 \mathrm{U})$ of the Transcriptor Reverse Transcriptase (final volume: $20 \mu \mathrm{l}$ ). Tubes were gently mixed and incubated in a T100 ${ }^{\mathrm{TM}}$ Thermal Cycler (Bio-Rad, Hercules, CA, USA) for 10 minutes at $25^{\circ} \mathrm{C}$, followed by 30 minutes at $55^{\circ} \mathrm{C}$, and 5 minutes at $85^{\circ} \mathrm{C}$.

\section{Detection of $16 S$ rRNA gene by qPCR}

Both total bacterial load (DNA based) and active bacterial load (cDNA-based) of the samples were analysed through quantitative PCR (qPCR) amplification and detection of the $16 \mathrm{~S}$ ribosomal RNA (rRNA) gene. Each reaction mixture of $10 \mu \mathrm{l}$ was composed of: $5 \mu \mathrm{l}$ of Light Cycler 480 SYBR Green I Master mix (Roche Life Science, Basel, Switzerland), $0.25 \mu \mathrm{l}$ of each specific primer (concentration $10 \mu \mathrm{M}$ ) and $1 \mu \mathrm{l}$ of template DNA or cDNA. Amplifications were performed in a Light Cycler 480 Real-Time PCR System (Roche Life Science, Basel, Switzerland), using an annealing temperature of 60 ${ }^{\circ} \mathrm{C}$. All amplifications were performed in duplicates and negative controls were included in each qPCR plate. In all, 5 qPCR plates were used for the analyses of all the samples. Primers sequences were F-5'-CGTGCCAGCAGCCGCGG-3' and R-5'TGGACTACCAGGGTATCTAATCCTG-3'. Ct values in each sample were transformed in bacterial cell numbers per $\mathrm{ml}$ of milk by comparison with a standard curve obtained with flow cytometry. This standard was generated by using DNA extracted from 10 million bacterial cells from 10 pure cultures of different species, commonly found in human milk (Streptococcus epidermidis CECT 231, Bifidobacterium dentium DSM 20436, Acinetobacter lwoffii CECT 453, Corynebacterium matruchotii DSMZ 20635, Lactobacillus casei (lab's isolate), Lactobacillus acidophilus CECT 4179, Staphylococcus aureus strain 240, Pseudomonas aeruginosa ATCC 15442, Rothia mucilaginosa (lab's isolate) and Streptococcus 
mitis DSMZ 12643). DNA from all species were extracted, pooled and diluted in serial ten-fold dilutions to create a single standard curve. Bacterial cells were quantified and sorted using a BD FACSAria II cytometer (East Rutherford, NJ, USA). Samples that showed $\mathrm{C}$ t values higher than the negative control were considered to be negative for bacterial detection. Differences in bacterial loads between groups were estimated with non-parametric Kruskal Wallis test in GraphPad Prism 5 (GraphPad Software, San Diego, CA, USA, Version 5.04)

\section{Bacterial composition and active bacterial composition of human milk samples}

A total of 75 human milk samples were analysed through next generation sequencing of the 16S rRNA gene. Controls, time $0(n=24)$; Mastitis, time $0(n=25 ; 22$ SAM and 3 AM); Mastitis, time 1 ( $n=23 ; 20$ SAM, 3 AM). Controls at time 1 were not included in further steps. Prior to sequencing, DNA and cDNA were pre-amplified by using universal bacterial degenerate primers 27F - 5'-AGAGTTTGATCMTGGCTCAG-3' and 926R - 5'CCGTCAATTCMTTTRAGT3', which comprise the hypervariable regions V1-V5 of the gene. This step was performed by using the high-fidelity ABGene DNA polymerase (Thermo Scientific, Waltham, Mass., USA) with an annealing temperature of $52{ }^{\circ} \mathrm{C}$ and 10 cycles, in order to minimize amplification biases (Sipos et al. 2007). PCR products were purified using Nucleofast 96 PCR filter plates (Macherey-Nagel, Düren, Germany), and concentrations were measured with a QubitTM 3 Fluorometer (ThermoScientific, Waltham, MA, USA). An Illumina amplicon library was performed following the $16 \mathrm{~S}$ rRNA gene Metagenomic Sequencing Library Preparation Illumina protocol (Part \#15044223 Rev. A). The primer sequences used in this protocol target the 16S rRNA gene V3 and V4 regions, resulting in a single amplicon of approximately $460 \mathrm{bp}$. Overhang adapter sequences were used together with the primer pair sequences for compatibility with Illumina index and sequencing adapters. Full length sequences: F-5': TCGTCGGCAGCGTCAGATGTGTATAAGAGACAGCCTACGGGNGGCWGCAG,

and

R-5':

GTCTCGTGGGCTCGGAGATGTGTATAAGAGACAGGACTACHVGGGTATCTAAT CC (Klindworth et al. 2013). After amplification of the 16S rRNA gene, DNA and cDNA were sequenced in an Illumina Miseq platform according to manufacturer's instructions (Illumina) using the $2 \times 300 \mathrm{bp}$ paired-end protocol, at the Foundation for the Promotion of Health and Biomedical Research, FISABIO (Valencia, Spain). No-template controls (NTCs) and negative controls during DNA extraction were included to rule out potential contaminations at the time of DNA extraction or sequencing.

\section{Data Analysis and Statistics}

A quality assessment of the sequences was carried out using the PRINSEQ program (Schmieder \& Edwards 2011). Sequences were end-trimmed in 20 bp sliding windows, and those with average quality value $<30$, and length $<250 \mathrm{bp}$ were not considered for further analyses. Reads were pair-end joined using FLASH program applying default parameters (Magoc \& Salzberg 2011). Only overlapping paired-end reads were used for 
further analysis. Operational taxonomic units (OTUs) were generated by clustering reads at $97 \%$ of similarity by using VSEARCH (Rognes et al. 2016). Centroids (representative OTUs) were taxonomically classified at phylum, class, family, genus and species level using feature-classifier command of QIIME2 (Rognes et al. 2016)version 2017.8 with Greengenes database (version gg_13_5). OTUs with $<10$ total assigned reads were not considered for further analysis. Sequences belonging to Streptococcus and Staphylococcus genera, which $16 \mathrm{~S}$ gene is highly similar, were clustered into OTUs at $100 \%$ similarity and $>400$ bp alignment length by BLAST analysis (Altschul et al. 1990), against a manually curated database for these genera, obtained from RDP Hierarchy Browser (Cole et al. 2009). Streptococcus mitis and Streptococcus oralis appeared to be identical in the sequenced region, and could not be distinguished from each other. $\alpha$ diversity analysis (Shannon and Chao1 indices), were calculated to estimate sample's diversity and richness; and $\beta$-diversity (Bray Curtis dissimilarity index), to quantify the compositional dissimilarity between groups at OTU and genus level, using the Rpackage vegan. Canonical correspondence analysis (CCA), which is a statistic tool used to emphasize community variation, taking into consideration the main features of the distributions of species along environmental variables (here, health status and time), were performed by $\mathrm{R}$ software vegan package. In order to control the potential effects of maternal antibiotics intake, maternal age and days postpartum, MaAsLin multivariate analysis with linear model (Morgan et al. 2012) was applied, which finds associations between metadata and microbial abundances. Then, Adonis statistic for permutational multivariate analysis was used to measure differences in variance between groups, and Wilcoxon test implemented in $\mathrm{R}$ software was applied to determine significantly different bacterial genera between groups (unpaired Wilcoxon test was applied when comparing Control and Mastitis groups; and paired when comparing Mastitis groups, time 0 and time 1). Bacterial-OTUs biomarker discovery was performed by linear discriminant analysis effect size (LEfSe) implemented on Galaxy online platform (http://huttenhower.sph.harvard.edu) (Segata et al. 2011), in order to detect the most differentially abundant OTUs characterizing the populations of healthy and mastitissuffering women. Other statistical analyses and graphs were performed in GraphPad Prism 5 (GraphPad Software, San Diego, CA, USA, Version 5.04).

\section{Exposure of milk bacteria to a mammary gland epithelium cell line.}

The cell line MCF7 (ATCC HTB-22), from mammary epithelium, was seeded onto 96well plates (30000 viable cells per well) in complete growth medium (DMEM high glucose (Gibco) supplemented with 10\% v/v inactivated fetal bovine serum (Sigma), 1 $\mathrm{mM}$ sodium pyruvate (Gibco), $0.1 \mathrm{mM}$ non-essential aminoacids (Gibco), $10 \mathrm{mM}$ HEPES (Gibco), $2 \mathrm{mM}$ L-glutamine (Gibco) and antibiotics (100 U/mL penicillin, $100 \mathrm{~g} / \mathrm{mL}$ streptomycin (Gibco)). The cells were grown at $37^{\circ} \mathrm{C}$ and $5 \% \mathrm{CO} 2$ in an incubator for 2 days, and the integrity of the cell culture was checked with an inverted microscope and the medium was replaced with fresh complete growth medium without antibiotics, containing the bacterial pellet coming from $500 \mathrm{uL}$ of centrifuged human milk samples. 
A total of 18 healthy controls, 21 sub-acute mastitis and 2 acute mastitis milk samples obtained at time 0 ; and 22 controls, 17 sub-acute mastitis and 3 acute mastitis milk samples obtained at time 1, were anaysed in duplicates in the same experiment. Negative controls were included, and consisted of MCF7 cells incubated without bacteria. Coincubation of mammary gland MCF7 epithelial cells with human milk bacteria was maintained for 24 hours at $37^{\circ} \mathrm{C}$ and $5 \% \mathrm{CO} 2$ in an incubator. After the co-incubation period, culture supernatants were aspirated from wells and kept at $4^{\circ} \mathrm{C}$ for measuring human interleukin 8 concentration by ELISA (Invitrogen) using $25 \mathrm{uL}$ of supernatants, following the manufacturer's instructions.

\section{Results}

\section{Study population}

51 women were enrolled in the study, including 24 healthy-controls, 24 sub-acute mastitis and 3 acute mastitis. 4 mothers from the SAM group abandoned the study before collecting the second sample (time 1). Characteristics of mothers and infants are summarized in Table 1.

Table 1. Study population's information

\begin{tabular}{|c|c|c|c|c|}
\hline & Healthy & $\begin{array}{l}\text { Sub-acute } \\
\text { mastitis }\end{array}$ & Acute mastitis & Total \\
\hline Study population, $n$ & 24 & 24 & 3 & 51 \\
\hline Maternal age, years $\pm S D$ & $34.83 \pm 2.85$ & $35.08 \pm 5.32$ & $34.33 \pm 2.08$ & $\begin{array}{l}34.92 \pm \\
4.12\end{array}$ \\
\hline $\begin{array}{l}\text { Weight-gain during } \\
\text { pregnancy } \pm S D\end{array}$ & $14.83 \pm 13.31$ & $13.71 \pm 4.22$ & $11 \pm 3.46$ & $14.08 \pm 9.54$ \\
\hline Vaginal delivery & $19 / 24$ & $17 / 24$ & $2 / 3$ & $38 / 51$ \\
\hline $\begin{array}{l}\text { Maternal antibiotics } \\
\text { during study }\end{array}$ & $0 / 24$ & $3 / 24$ & $3 / 3$ & $6 / 51$ \\
\hline $\begin{array}{l}\text { Infant age } \quad(\text { days }) \pm \\
S D\end{array}$ & $45.66 \pm 2.89$ & $44.83 \pm 25.13$ & $41.66 \pm 43.41$ & $\begin{array}{l}45.04 \pm \\
23.46\end{array}$ \\
\hline $\begin{array}{l}\text { Infant antibiotics during } \\
\text { study }\end{array}$ & $0 / 24$ & $0 / 24$ & $0 / 3$ & $0 / 51$ \\
\hline
\end{tabular}

Total and active bacterial load increase in human milk during mastitis

Quantification of the 16S rRNA gene through qPCR of both DNA (total bacterial load) and RNA (active bacterial load) showed significantly increased bacterial loads in mastitis samples during the course of the symptoms (Figure 1). Mean total bacterial load 
in the control samples was 610,127 cells/ml (SEM=110,218) and 828,850 cells/ml $(\mathrm{SEM}=100,692)$ at first and second time point, respectively. Mean total load in the mastitis samples during the course of the symptoms reached 3,137,000 cells/ml (SEM=956,632), which was significantly higher as compared to controls at the same time point (nonparametric Kruskal Wallis test, $p<0.01$ ). After the symptoms had disappeared, mean total load in the mastitis group decreased to 1,430,000 cells/ml (SEM=259,037), although the values were still significantly higher as compared to controls at time 0 , and thus, bacterial load did not fully returned to healthy levels at this time point (non-parametric Kruskal Wallis test, $p<0.01$ ). Mean active bacterial load was significantly lower as compared to total bacterial load in all groups (non-parametric Kruskal Wallis test, $p<0.001$ ), except in the mastitis group at time 1 . Similar values were observed in the control samples at the two studied time points, time $0=67,064$ cells $/ \mathrm{ml}(\mathrm{SEM}=27,505)$; and time $1=84,808$ cells/ml (SEM=21,117). Mean active bacterial load increased in the mastitis group during the course of symptoms, up to 598,395 cells/ml (SEM=373,253) although this difference was not significant. Mean active load in the mastitis group after symptoms disappeared increased up to 1,601,000 cells/ml (SEM=229,296), and this difference was significant when compared to all the other groups (non-parametric Kruskal Wallis test, $p<0.001)$.

a)

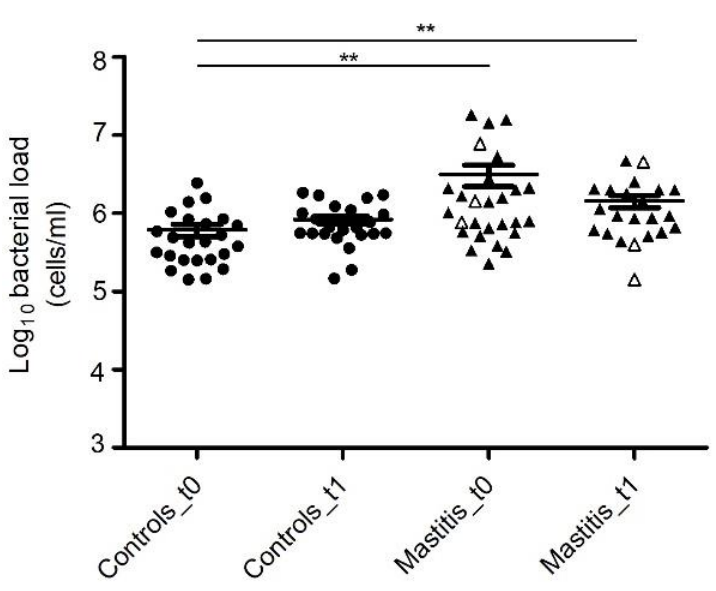

b)

Active bacterial load in breast milk

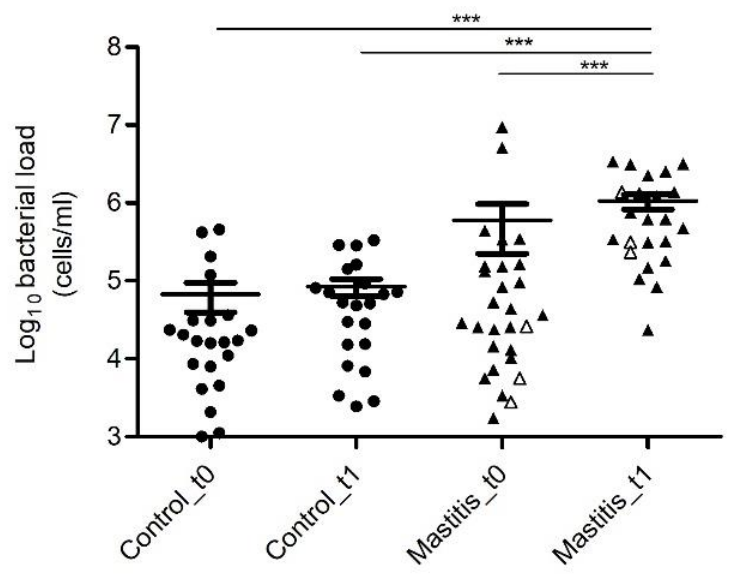

Figure 1. Bacterial load in human milk of healthy mothers and mothers suffering lactational mastitis. Plots show means with standard errors. a) Bacterial load, as inferred from qPCR of the $16 \mathrm{~S}$ rRNA gene of the bacterial DNA. b) Active bacterial load, as inferred from qPCR of the $16 \mathrm{~S}$ rRNA gene of the bacterial RNA (cDNA). Controls_t0, $(\mathrm{n}=24)$; Controls_t1, ( $\mathrm{n}=23)$; Mastitis_t 0 , (SAM, n=24; AM, n=3); Mastitis_t1, (SAM, n=19; AM, n=3). t0, samples collected during the course of mastitis symptoms, or first sample collected in healthy controls; $\mathrm{t} 1$, samples collected after the clinical symptoms disappeared, or samples collected from healthy controls one week after the first sample collection. Acute Mastitis samples are represented with white triangles in the graph. ${ }^{* *}, p<0.01$ and ${ }^{* * *}, p<0.001$, non-parametric Kruskal Wallis test. 


\section{Sequencing summary}

A total of 75 human human milk samples were sequenced in the V1-V2 region of the $16 \mathrm{~S}$ rRNA gene, each of them for the DNA and RNA -cDNA- (total number of sequenced samples $\mathrm{n}=150$ ). One DNA sample and two cDNA samples were not considered for further analyses due to the small number of sequences. After quality filtering, 3,270,552 sequences were obtained from DNA sequencing (average sequences per sample: 45,424 \pm 9,145 SEM), and 3,215,590 sequences from RNA sequencing (average sequences per sample: $44,047 \pm 2,876$ SEM). 3,171,244 DNA sequences could be assigned at phylum level; from which 2,616,633 were further assigned at genus level, and 2,016,688 at species level. Similarly, 3,066,528 RNA sequences were assigned at phylum level; from which 2,704,990 were assigned at genus level, and 2,197,733 at species level.

\section{Bacterial richness and diversity decrease during lactational mastitis}

Total bacterial DNA diversity (as measured by the Shannon Index) and richness (as measured by the Chao1 Index) decreased during the course of mastitis symptoms (Figure 2a; non-parametric Kruskal Wallis test, $p<0.05$ ). Diversity levels were not recovered to control levels after the symptoms had disappeared, although total number of observed OTUs significantly increased (non-parametric Kruskal Wallis test, $p<0.001$ ). A similar pattern was observed at the RNA level: Active bacterial diversity decreased during the mastitis symptoms (Figure 2b; non-parametric Kruskal Wallis test, $p<0.05$ ), and total number of observed OTUs increased after symptoms had disappeared (nonparametric Kruskal Wallis test, $p<0.05)$. Although there was a decreasing trend in richness in the mastitis group during the symptoms, it did not reach statistical significance.

\section{Total and active bacterial composition}

The most abundant phyla, in both DNA and RNA samples were Firmicutes $(80.52 \%$ and $67.19 \%$, respectively) and Proteobacteria (10.50\% and $20.61 \%)$, followed by Actinobacteria (8.01\% and 10.83\%). At genus level, Streptococcus and Staphylococcus were the two most abundant bacterial genera, both in the DNA $(67.12 \%$ and $8.00 \%$, respectively) and RNA sequences (51.23\% and 14.57, respectively) (Figure 3). No statistically significant effect of maternal antibiotics intake, maternal and infant age, delivery mode nor maternal weight gain during pregnancy, was detected on human milk microbial composition ( $p>0.05$, MaAsLin test). Although a high inter-individual variability was observed in bacterial composition between human milk samples, distinct bacterial communities were detected between healthy controls and SAM. 


\section{Diversity and Richness indices}

a)
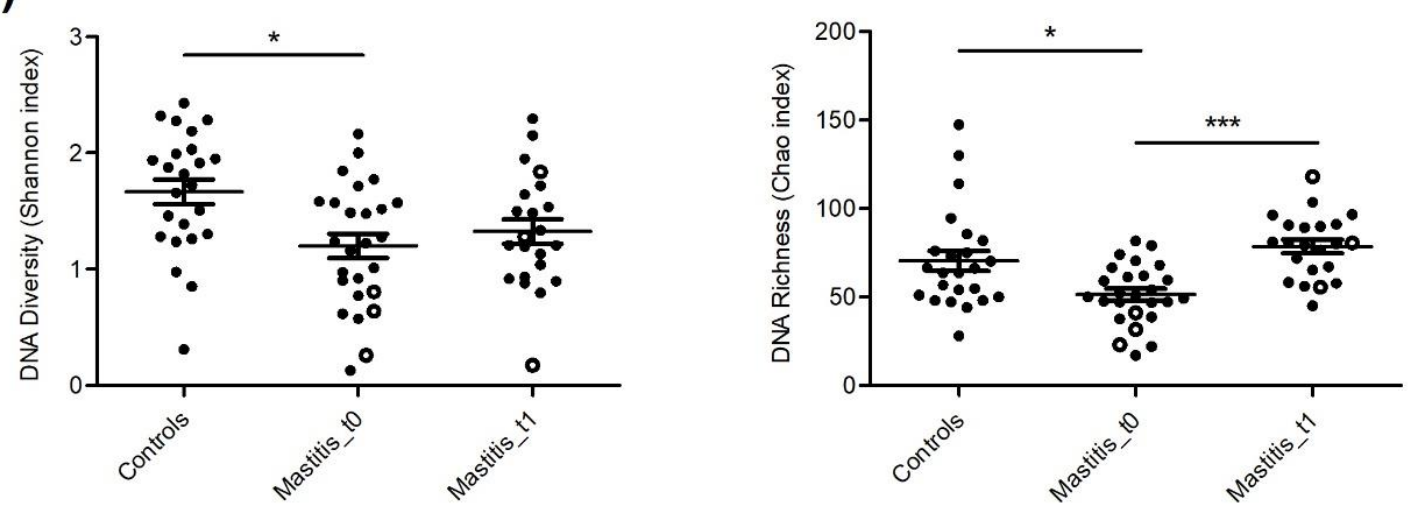

b)
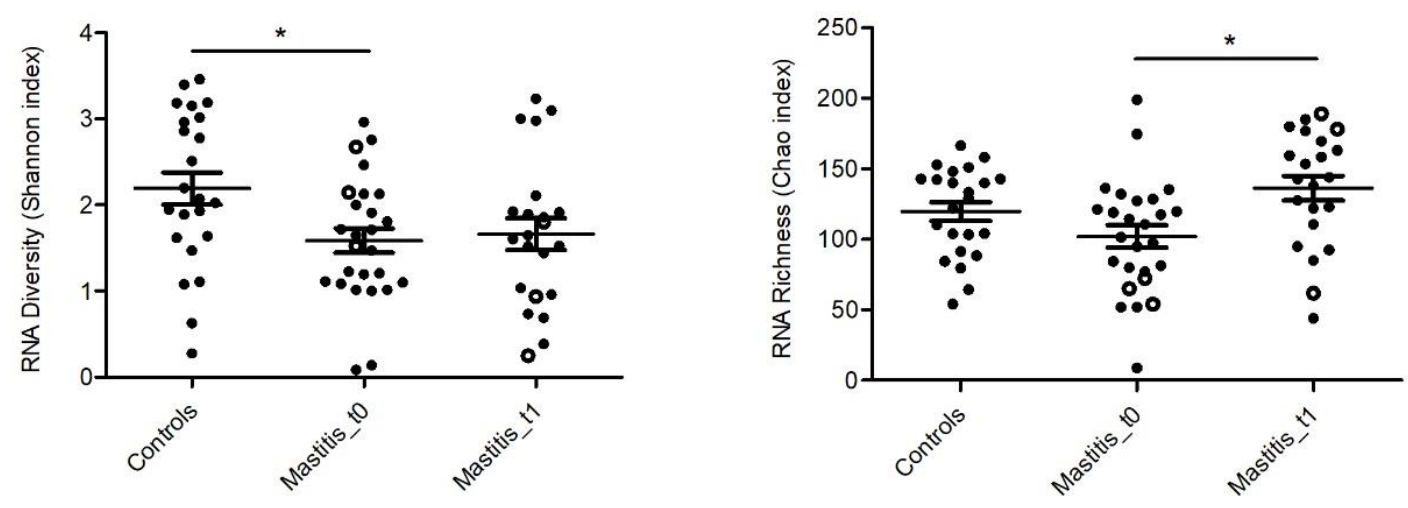

Figure 2. Bacterial diversity and richness in human milk samples from healthy and mastitissuffering women. Plots show human milk microbiota genus-level diversity and richness (here presented with Shannon and Chao1 indices), with means and standard errors. a) Represents microbiota DNA Shannon and Chao1 indices. Controls, n=24; Mastitis_t0, n=26; Mastitis_t1, n=22. b) Shows microbiota RNA Shannon and Chao1 indices. Controls, n=23; Mastitis_t0, n=26; Mastitis_t $1, n=22$. Acute mastitis samples are represented with white circles, $n=3$. $t 0=$ samples during the course of the symptoms; $\mathrm{t} 1=$ samples after symptoms disappeared. ${ }^{*}, p<0.05$ and ${ }^{* * *}$, $p<0.001$, non-parametric Kruskal Wallis test. 


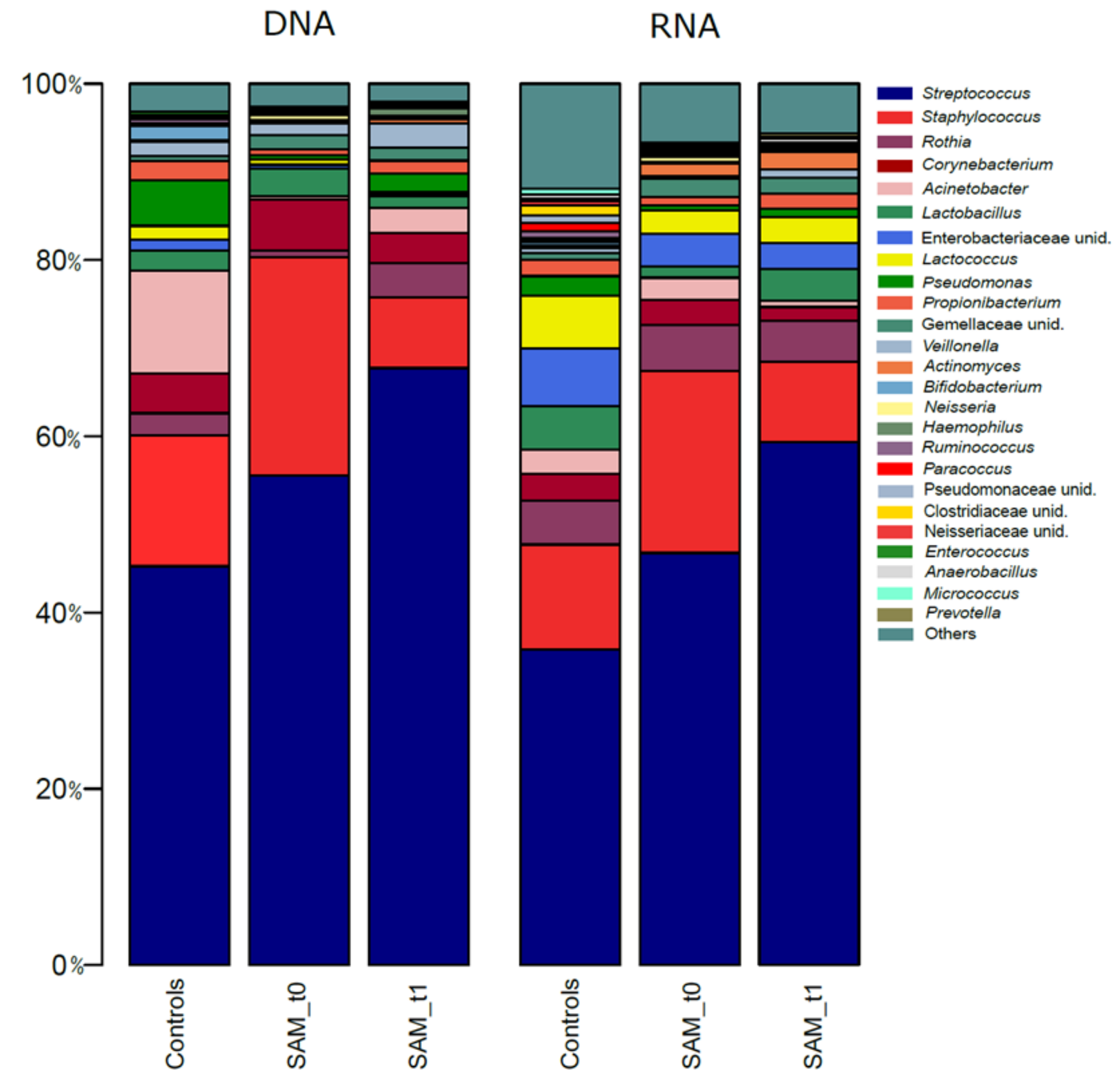

Figure 3. Bacterial composition in human milk samples of healthy mothers and mothers suffering sub-acute mastitis. The barplot shows average percentage of abundance of the genuslevel bacteria (DNA) and active bacteria (RNA) detected in the human milk samples by means of Illumina sequencing of the $16 \mathrm{~S}$ rRNA gene. Controls: DNA, n=24; RNA, n=23; SAM_t0: DNA, $\mathrm{n}=23$; RNA, $\mathrm{n}=23$; SAM_t1; DNA, $\mathrm{n}=19$; RNA, $\mathrm{n}=19$. $\mathrm{t} 0=$ samples during the course of the symptoms; $\mathrm{t} 1=$ samples after symptoms disappeared. Due to the small sample size $(n=3)$, acute mastitis samples were not included in the barplots.

When analysing total bacterial composition, no statistically significant differences were observed at phylum level. At genus level, SAM samples at time 0 had lower levels of Pseudomonas, as compared to healthy controls (unpaired Wilcoxon test, adjusted Pvalue $=0.003$ ), and lower levels of Acinetobacter as compared to SAM at time 1 (paired Wilcoxon test, adjusted P-value= 0.031). When looking at the active (RNA-based) bacterial composition, Firmicutes phylum was higher in the SAM group at time 0, as compared to controls (Wilcoxon test, P-value=0.01), while Proteobacteria were depleted (Wilcoxon test, P-value=0.001) and to SAM at time 1 (Wilcoxon test, P-value=0.05). Peptoniphilus, Prevotella, and Finegoldia were at higher levels in the active portion of SAM at time 1 as compared to healthy controls (unpaired Wilcoxon test, adjusted P-value= 
0.0087, 0.019 and 0.042, respectively), while healthy controls were enriched in Neisseria (unpaired Wilcoxon test, adjusted P-value $=0.042$ ), suggesting that the bacterial composition was not fully recovered after the clinical symptoms disappeared. At OTU (species) level, the impact of health status on human milk microbiota was also reflected in differences in bacterial composition between healthy controls, mastitis during the course of symptoms (time 0 ) and mastitis after symptoms cessation (time 1), both at DNA level (Adonis P-value=0.015, CCA analysis), and active RNA level (Adonis P-value=0.04, CCA analysis) (Figure 4). As inferred from DNA analysis, controls appeared more diverse in the CCA plot, while mastitis groups showed less diversity and clustered closer to each other. At RNA level, although there was also some overlap, the three groups clustered separately, and the highest divergence was explained by axis 1, which separates controls from mastitis groups. Thus, the CCA plots also support a different bacterial composition at the species level in mastitis and control groups, with a partial recovery after the symptoms disappeared. Streptococcus mitis/oralis, Streptococcus salivarius, Acinetobacter johnsonii, Streptococcus lactarius and Rothia mucilaginosa were the most abundant species detected in the human milk samples at DNA level. Streptococcus mitis/oralis, Streptococcus salivarius, Staphylococcus epidermidis, Rothia mucilaginosa and Streptococcus lactarius were the most abundant active bacteria detected. In order to determine which species where responsible for the divergences observed between the groups, Wilcoxon tests at OTU level were performed. Staphylococcus aureus was more abundantly present in SAM, both at time 0 (unpaired Wilcoxon test, adjusted $P$ value $=0.001$ ), and time 1 (adjusted $P$-value $=0.0003$ ), as compared to healthy controls. Porphyromonas endodontalis (adjusted P-value $=0.003$ ) and Streptococcus peroris (adjusted $P$-value $=0.003$ ) were more prevalent in SAM group at time 1 , as compared to controls. Paired Wilcoxon test showed that Acinetobacter johnsonii was more abundantly present in SAM group at time 1 as compared to SAM at time 0 (adjusted P-value=0.025). Staphylococcus aureus and Streptococcus lactarius were also significantly more active in SAM samples both at time 0 (unpaired Wilxocon test, adjusted $P$-value $=0.023 ; P=0.013$, respectively) and time 1 (unpaired Wilxocon test, adjusted $P$-value $=0.005 ; \mathrm{P}=0.018$, respectively), as compared to controls. Streptococcus peroris was significantly higher in SAM group at time 1, as compared to controls (unpaired Wilxocon test, adjusted $P$ value $=0.006$ ) and to SAM time 0 samples (paired Wilcoxon test, adjusted $P$-value $=0.012$ ).

In addition, LEfSe algorithm was applied in order to further examine potential biomarkers of SAM disease (Figure 5). Several bacterial OTUs appeared to be associated with SAM and to health status. Significantly more abundant bacteria in healthy mother's milk, as compared with mothers suffering SAM were Acinetobacter johnsonii, Pseudomonas viridiflava, Corynebacterium simulans, Paracoccus marcusii, Pseudomonas fragi and Acinetobacter lwoffii. Conversely, Corynebacterium kroppenstedtii, Staphylococcus aureus, and Prevotella nanceiensis were observed in increased abundance in human milk during SAM. In addition, within the SAM group of mothers, Coprococcus eutactus was significantly more abundant during the symptoms; while Acinetobacter johnsonii, Rothia 
mucilaginosa, Propionibacterium acnes, Pseudomonas umsongensis, Lactobacillus helveticus and Lactobacillus zeae were significantly more abundant after symptoms had disappeared.

DNA

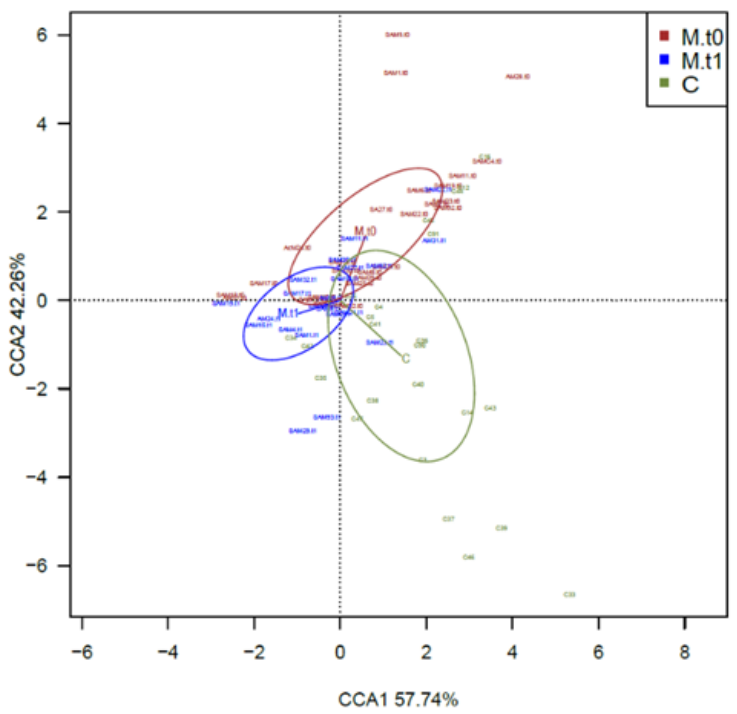

RNA

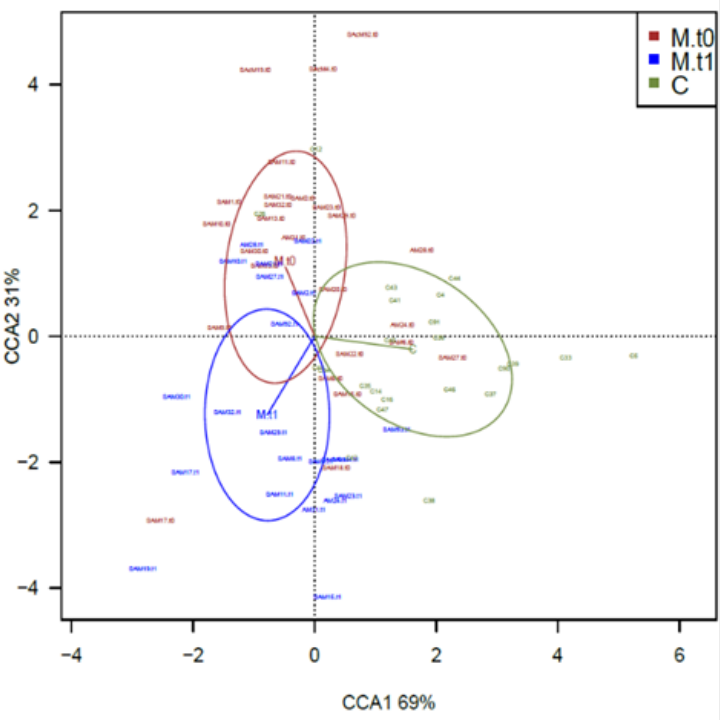

Figure 4. Human milk microbiota patterns in healthy mothers and mothers suffering lactational mastitis. Constrained correspondence analyses (CCA), which here emphasize variations in microbiota OTU-level patterns, show compositional characteristics of total human milk microbiota in control and mastitis samples at two different time points. The percentage of variation explained by constrained correspondence components is indicated on the axes. CCAs show microbial composition differences in human milk from healthy mothers and mothers suffering lactational mastitis at two time points, at DNA-level $(p=0.015)$, and active microbial RNA-level $(p=0.04)$. $\mathrm{t} 0=$ samples during the course of the symptoms; $\mathrm{t} 1=$ samples after symptoms cessation. P-values for CCA plots were determined by Adonis, and indicate if health status and/or time can significantly explain data variability. Controls (C): DNA, $n=24 ; \mathrm{RNA}=23$; Mastitis t0: DNA, $n=26$; RNA= 26; Mastitis t1: DNA, $n=22 ;$ RNA, $n=22$.

Significant differences in bacterial abundance were also observed when analysing the active bacterial fraction of the samples. Active Lactobacillus iners, Neisseria subflava, Streptococcus lactarius, Streptococcus cristatus and Staphylococcus aureus were associated with SAM; while Propionibacterium acnes, Staphylococcus hominis, Acinetobacter lwoffii, Lactobacillus helveticus and Roseomonas mucosa were associated with health. Lactobacillus zeae was significantly more abundant in SAM samples after symptoms disappearance, while Pseudomonas viridiflava, Lactobacillus inners, Eubacterium biforme and Roseomonas mucosa were associated with SAM. 
a)

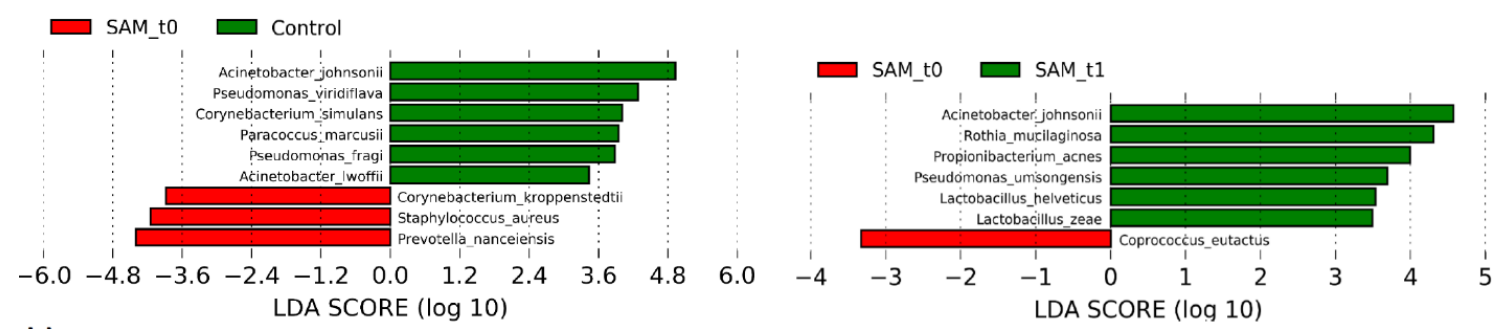

b)
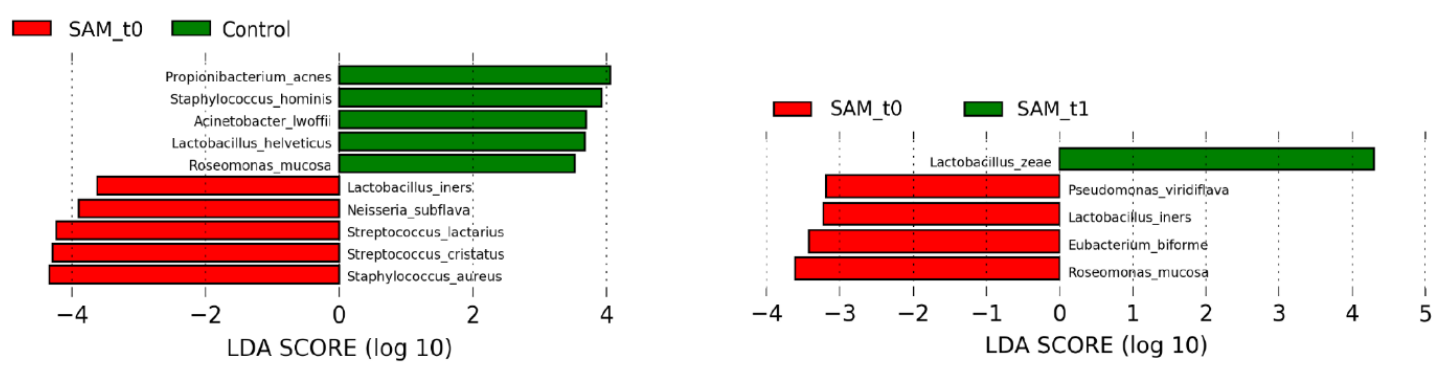

Figure 5. Human milk bacterial OTUs associated with sub-acute mastitis development. The plots show statistically significant bacteria associated with SAM development, as compared to healthy controls and human milk samples after SAM symptoms had disappeared, as inferred from: a) DNA (controls, $\mathrm{n}=24$; SAM_t0, $\mathrm{n}=23$; SAM_t1, $\mathrm{n}=19$ ); and b) RNA (controls, $\mathrm{n}=23$; SAM_t $0=23$; SAM_t $1=19$ ). The LEfSe algorithm was used for biomarker discovery, the threshold for logarithmic discriminant analysis (LDA) score was 2 , and $\mathrm{p}<0.05$.

\section{Human milk bacteria exposure to mammary epithelial cells and release of IL8}

To study the potential pro-inflammatory effect of bacteria associated to SAM, human milk pellets were co-incubated with a mammary epithelial cell line for 24 hours. Results showed higher levels of IL8 in cells exposed to pellets from SAM during the course of the symptoms ( $\mathrm{t} 0$ ), which significantly decreased after symptoms disappeared (Figure 6). As expected, levels of IL8 from cell supernatants exposed to AM pellets were higher during and after the symptoms, as compared to the other groups, although the small sample size did not allow statistical analyses. 


\section{IL-8 concentrations}

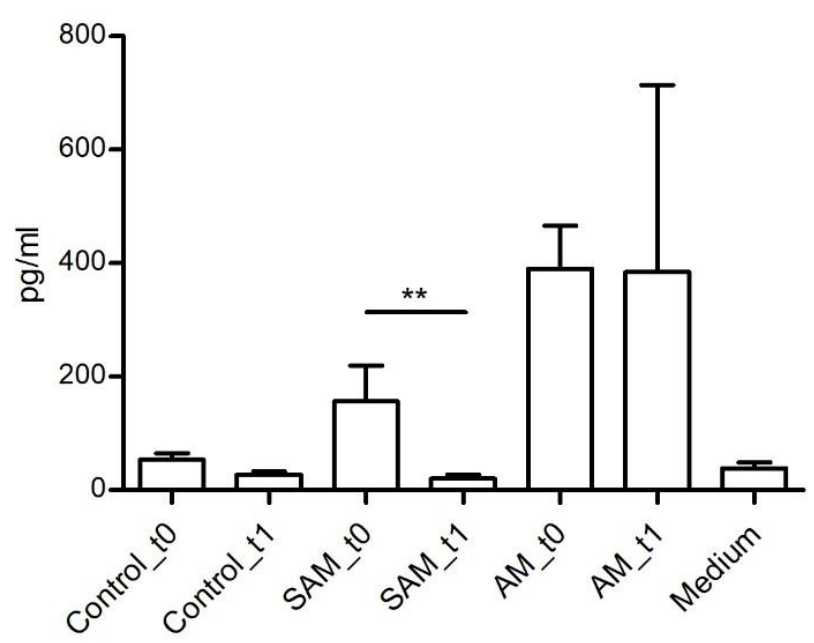

Figure 6. Levels if IL8 produced by mammary cells after exposure to bacteria in human milk. The bar plots show levels of IL8 released by cells from a mammary epithelial line when exposed to bacterial pellet from healthy controls (Controls_t $0, \mathrm{n}=18$; Controls_t $1, \mathrm{n}=22$ ); sub-acute mastitis (SAM_t0, $\mathrm{n}=21$; SAM_t1, $\mathrm{n}=17$ ); and acute mastitis (AM_t0, $\mathrm{n}=2$; $\mathrm{AM} \_\mathrm{t} 1, \mathrm{n}=3$ ). Supernatants from mammary cells exposed only to culture medium were used as negative controls $(\mathrm{n}=8) .{ }^{* *}, p<0.01$, non-parametric Kruskal Wallis test.

\section{Discussion}

Sub-acute mastitis is a fastidious and common disease among lactating mothers, representing one of the main causes of undesired weaning. Although SAM causes with milder symptoms, as compared to its acute version, lactating mothers have to deal with intense pain and discomfort and are very often afflicted by distress and emotional concern. Despite its high prevalence and impact on maternal-infant health, SAM is undervalued and under-diagnosed (Contreras \& Rodríguez 2011). Studies performed on human milk during lactational mastitis up to date point to an altered bacterial profile, increased abundance in opportunistic pathogens and decreased total bacterial diversity (Delgado et al. 2011; Jiménez et al. 2015; Marín et al. 2017; Patel et al. 2017). Classically, AM has been associated to Staphylococcus aureus infections (Contreras \& Rodríguez 2011; Delgado et al. 2011; Osterman \& Rahm 2000). SAM, on the other hand, has been associated with increased Staphylococcus epidermidis presence (Delgado et al. 2008; Jiménez et al. 2015; Patel et al. 2017), and in lower abundances with other coagulase negative staphylococci (CNS), and viridans streptococci such as Strep. mitis and Strep. salivarius (Martín et al. 2016). Most of these results, however, were derived from culturedependent analyses, which are known to be biased by false negative rates, as many potentially pathogenic bacterial strains are difficult to grow under laboratory conditions. Only two studies, up to date, used culture-independent methods to analyse human milk microbial profiles during mastitis. One of them is a metagenomics study of 10 healthy controls, 5 SAM and 5 AM human milk samples (Jiménez et al. 2015); the other one used 
16S rRNA gene amplicon sequencing (Patel et al. 2017) in milk samples from 18 healthy mothers, 16 SAM and 16 AM patients. In both studies, a decreased bacterial diversity in mastitis samples was reported, in addition to an enrichment in opportunistic pathogens.

In the present study, we focused on SAM human milk bacterial composition and abundances. Samples were analysed by means of next generation Illumina sequencing and qPCR of the 16S rRNA gene. For the first time, both total (DNA-based) and active (RNA-based) bacterial composition and load of the SAM and healthy human milk samples have been studied. Results showed that total bacterial load significantly increased during the course of mastitis, as compared to healthy controls, and decreased after the symptoms cessation, although loads remained significantly higher as compared to healthy controls. Interestingly, active load after the symptoms' cessation was significantly higher as compared to healthy controls and mastitis during the symptoms. This could indicate increased bacterial activity levels during the process of re-balancing in the bacterial community. After sequencing the $16 \mathrm{~S}$ rRNA gene amplicons, we observed a decreased bacterial diversity both at DNA and RNA level during the course of mastitis, in agreement with previously reported data (Jiménez et al. 2015; Patel et al. 2017). Richness also decreased during the disease, although it did not reach statistical significance at RNA level. Interestingly, richness significantly increased after symptoms had disappeared, both at DNA and RNA level. However, diversity was not recovered to control levels after the symptoms had disappeared. It should be taken into account that samples were collected right after the symptoms had disappeared, and the data suggest that the full recovery of bacterial communities takes longer than the remission of clinical symptoms. Decreased microbial diversity and/or richness associated to microbial dysbiosis have been previously described in several disease conditions, such as inflammatory bowel disease (Chehoud et al. 2015; Sokol et al. 2016), colorectal cancer (Ahn et al. 2013), tooth decay (Simón-Soro et al. 2013) or celiac disease (Schippa et al. 2010), among others. Our data support a dysbiotic state in human milk during SAM.

A high inter-individual variability was observed in human milk's bacterial composition among samples. However, significant differences between groups were observed, both at DNA and RNA level. During SAM, Pseudomonas and Acinetobacter were diminished, as compared to healthy controls and after symptoms disappeared (SAM, time 1), respectively. Interestingly, after cessation of the symptoms, SAM (time 1) samples were enriched in typical oral inhabitants, such as Streptococcus and Porphyromonas (DNA); and Prevotella (RNA). In addition, potential opportunistic pathogenic Finegoldia and Peptoniphilus genera were also increased in SAM at time 1, which could reflect an imbalance occurred in human milk after the mastitis episode. At OTU level, results showed that milk from mothers suffering SAM were enriched in Staphylococcus aureus, even after the symptoms had disappeared, and were also significantly more active as compared to healthy controls. Given that S. aureus was detected in only 1 out of 24 healthy mothers, its higher proportion and prevalence could have been due to an infection from an outside source. In most other cases, however, the disease-associated 
bacteria were also found in human milk from healthy mothers. Streptococcus lactarius, for instance, was also found to be significantly more active in SAM during and after the symptoms cessation, but it was also found at high prevalence in healthy mothers (13 out of 23 samples). In those cases, it is therefore possible that a change in the proportion of pre-existing microorganisms could trigger the inflammatory process. Alternatively, future studies should determine if specific strains could be associated to the disease, and whether those virulent strains are acquired from the skin or from other human niches. For example, after symptoms disappeared, samples were enriched in typical oral inhabitants such as Porphyromonas endodontalis and Streptococcus peroris. Given that oral health, especially gingivitis and periodontitis is very frequent in mothers during pregnancy and lactation (Tettamanti et al. 2017; Wu et al. 2015), the potential role of oral bacteria in triggering inflammation in the mammary tissue should be considered and tested in future studies.

LEfSe biomarker discovery analyses showed several OTUs associated to health, and included Acinetobacter johnsonii, Pseudomonas viridiflava, Corynebacterium simulans, Paracoccus marcusii, Pseudomonas fragi and Acinetobacter lwoffiii. Corynebacterium kroppenstedtii, Staphylococcus aureus and the oral species such as Prevotella nanceiensis were among the identified SAM biomarkers. Corynebacterium kroppenstedtii has been previously isolated from granulomatous mastitis and breast abscesses samples (Paviour et al. 2002; Wong et al. 2017). Acinetobacter johnsonii, Rothia mucilaginosa, Propionibacterium acnes, Pseudomonas umsongensis, Lactobacillus helveticus and Lactobacillus zeae were significantly more abundant after symptoms had disappeared. Interestingly, P. acnes is a predominant bacterium in the skin microbiome, which has shown anti-S.aureus activity in vitro (Grice \& Segre 2011; Shu et al. 2013). Thus, future studies should focus not only on potentially pathogenic organisms, but also on bacteria which could potentially contribute to health conditions, as promoting their growth with pre- or probiotics could prove to be a strategy to prevent or treat SAM (Espinosa-Martos et al. 2016; Fernández et al. 2014).

RNA analysis showed that active Lactobacillus iners, Neisseria subflava, Streptococcus lactarius, Streptococcus cristatus and Staphylococcus aureus were associated with SAM during the symtoms; while Propionibacterium acnes, Staphylococcus hominis, Acinetobacter lwoffii, Lactobacillus helveticus and Roseomonas mucosa were associated with health. Some of the potential pathogens deserve further study. Lactobacillus inners, for instance, is a member of the vaginal normal microbiota (Shi et al. 2009; Zhou 2004), although it has been associated to vaginal dysbiosis (Petrova et al. 2017). This species can produce a toxin, named as innerlysin, which is dependent upon the availability of cholesterol and cause cell damage (Rampersaud et al. 2011). Thus, its potential role in SAM should be tested in the future. Analysing human milk active bacteria, our study may offer a more precise insight into the bacterial origin of the SAM process. Most microbiota studies only consider the total bacterial DNA present in the samples, not considering that part of this DNA may belong to dead/inactive bacteria, and to free DNA. RNA analyses offer a 
complementary vision to human microbiota studies, allowing us to identify which bacteria are actively present in the samples. In this work, differences observed between human milk microbial DNA and RNA composition make clear that, by only analyzing total DNA, we could miss an important piece of the picture. Detecting bacterial DNA in any human sample does not imply that the corresponding bacteria are actually viable and exerting an effect on the human body, and therefore, results inferred from those observations could be biased. Thus, we propose that those organisms that appear to be enriched during SAM in both the DNA and RNA material would be the first candidates to clarify the complex aetiology of this disease. In addition, our results show that pellets from SAM milk samples, containing bacteria, induce pro-inflammatory IL8 release by mammary epithelial cells, supporting an infectious origin of SAM. IL8 was also increased in AM, although the small sample size of this group in our project prevents us to make any speculations of its immune implications. Thus, this in vitro work, together with the increase in bacterial load, the decrease in diversity and the change in composition during the symptoms, clearly support that SAM should be considered a disease of bacterial origin, with a polymicrobial aetiology.

Thus, the understanding of SAM's complex aetiology, and lactational mastitis in general, can be an arduous task. In addition, a major complications arises from a lack of agreement between the studies performed. While some researchers classify lactational mastitis into different groups according to the symptomatology, others make no distinction, or misclassify them, or in some cases, do not include a description of the symptomatology in their studies. Furthermore, some of the available publications do not include healthy controls in their analyses, and therefore, assumptions and statements derived from those results could be misleading. A possible drawback of this work relies in the fact that we lack a baseline milk sample from women suffering AM and SAM. Although we collected samples after the disappearance of the symptoms, and used them as an internal control, these samples are probably not representative of the initial healthy status of those mothers. Therefore, future prospective studies where samples are collected longitudinally are needed, so samples can be compared between the disease and the previous healthy status. The current work highlights the clinical relevance of understanding microbial populations associated to SAM, and we recommend to study the microbiology of SAM and its interaction with the host in a deeper manner and with larger cohorts, in order to establish the potential basis and mechanisms for SAM aetiology. 


\section{General Discussion}


In the present thesis, we extended the knowledge of breast milk microbiota by performing an in-depth analysis of the microbial communities present in human milk, by using high throughput sequencing techniques. We also studied factors that shape breast milk microbiota composition and diversity, and provided insights on its complex interactions with milk macronutrients and other bioactive compounds. These techniques, supported by classic microbiological analyses and other cultureindependent methodologies, allowed us to accurately describe milk microbiota composition and their interactions with other milk components. We first analyzed the bacterial composition of milk samples from healthy Spanish mothers throughout lactation, their distribution in the fluid and interactions with other milk macronutrients and cells. In addition, we quantified bacterial loads in milk, through qPCR calibrated with an optimized flow cytometry protocol (Chapter 1). Using these optimized protocols, we subsequently explored the presence of yeasts and fungi in breast milk from healthy Spanish donors (Chapter 2). We applied, for the first time, next-generation sequencing of the 28S ribosomal RNA gene to study the composition of fungi in human milk. Our results revealed the existence of a certain diversity of fungi in human milk, previously undescribed. This was further confirmed by culture and microscopy. Results from Chapter 2 motivated an expanded research on breast milk "mycobiota" in samples from different and distant geographic locations, with a look at the potential influence of mode of delivery on its composition (Chapter 3). Co-occurrence of milk fungi and bacteria were analyzed, and revealed that maternal factors and mode of delivery had a potential influence on milk microbial communities. After describing the human milk microbiota under healthy conditions, we set up an observational, prospective casecontrol study to analyse milk from healthy mothers and mothers suffering sub-acute mastitis, before and after the treatment. Here, we looked at the total and active bacterial composition by means of Next Generation Sequencing (NGS) of the 16S rRNA gene (Chapter 4). We analyzed, for the first time in breast milk microbial studies, both bacterial DNA and RNA of the 16S rRNA gene, in order to further unravel differences between total and active bacteria in the samples. Although initially considered sterile, it is now known that breast milk contains a complex community of bacteria and other microorganisms under normal, healthy conditions. In the last decade, there has been a shift from culture-dependent methodologies, to culture-independent, DNA-based methodologies that have been applied to study breast milk microbiota and its potential influence in maternal and infant health. However, these powerful new technologies have important pitfalls that are also worth discussing.

\section{Comparison of Methodologies for Assaying the Human Milk Microbiota}

\section{Classic culture-dependent methods}

Early descriptions of breast milk microbiota were based on microbiological isolation after spreading milk on culture media, which allowed for the detection of specific 
facultative anaerobes, lactic acid bacteria and other gram positives in asepticallycollected samples (Heikkila \& Saris 2003; Martín et al. 2003). The main advantage of classic culture methods is that they allow the growth of live bacteria present in a sample of interest, at low cost, whereas molecular methods may identify DNA from dead organisms which may not be natural inhabitants of the sample. If combined with other techniques, including tests based on staining and microscopy, PCR and Restriction Fragment Length Polymorphism (RFLPs), Sanger sequencing, etc. the isolated organisms can be taxonomically identified. However, this can be very time-consuming, and, importantly, excludes a great number of microorganisms not cultivable under laboratory conditions. Therefore, results from applying culture methods to estimate bacterial composition and loads in human milk are likely biased, as some uncultivable taxon and strict anaerobes (fastidious to grow) present in the samples would be overlooked and bacterial counts would be underestimated (Jost et al. 2013). However, culture methods are important to support other culture-independent techniques that do not discriminate DNA from live and dead microorganisms. In the present thesis, we were able to isolate several yeasts and other fungi from healthy breast milk samples (Chapters 2 and 3), which supported the finding of fungal DNA that we observed by means of NGS, proving that their presence in the samples belonged (at least partially) to live organisms. Bacterial and fungal culture was also a crucial step before counting and sorting individual microorganisms by flow cytometry, that were later used to construct standard curves for calibration for real-time polymerase chain reaction (Real-Time PCR, or qPCR) analysis.

\section{Culture-independent methods}

During the last decade there has been a shift in microbial analyses that moved from classic culture-dependent, to culture-independent techniques based on molecular analyses of the DNA and RNA (Nyvad et al. 2013; Su et al. 2012). 16S ribosomal RNA gene is the most studied bacterial gene in complex bacterial consortia, including environmental and human samples. It has highly conserved regions across all bacteria, and thus it's susceptible to amplification with "universal" primers, while it also contains highly variable regions that allow discrimination of individual bacterial taxa. Similarly, other ribosomal genes, including $18 \mathrm{~S}$ rRNA, $28 \mathrm{~S}$ rRNA, and the hypervariable Internal Transcribed Spacer regions (ITS), are commonly used for fungal community studies. Several methodologies, based on the analysis of those genes, can be applied to study microbial communities. Polymerase chain reaction (PCR) is used to detect the presence of microbial taxa in a sample by using universal or specific primers targeting a particular genera or species (Gueimonde et al. 2007). Denaturing gradient gel electrophoresis (DGGE) and temperature gradient gel electrophoresis (TGGE), are DNA-based techniques for comparison of microbial molecular fingerprints. Human milk bacteria can be analyzed by putting microbial DNA fragments through a denaturing or temperature gradient gel, respectively, which results in differential patterns depending on their DNA sequence (Martín et al. 2007; Perez et al. 2007). However, there are a number of 
disadvantages to these techniques: chemical gradients such as those used in DGGE are difficult to establish and are not so reproducible, and both methods are time-consuming, and require gel staining and further elution of DNA fragments for PCR or other techniques that allow identification.

Real-time polymerase chain reaction (qPCR) represents a fast and reliable method to monitor the amplification of a targeted microbial DNA fragment during a PCR, in realtime, and can be used for quantification. Most estimates of bacterial loads in breast milk have been made based on culture techniques. However, qPCR has demonstrated to be a very suitable tool for microbiota studies, and a promising methodology for the detection and quantification of bacteria in human milk (Collado et al. 2009; Khodayar-Pardo et al. 2014). For a quantitative application of this method, every analyzed plate requires a standard curve with known DNA concentrations. For microbiological studies, calibration based on pure cultures is the standard, which is acceptable when targeting a specific microorganism. However, for the analysis of total bacteria (i.e different species in a sample), calibration with single-bacterial species may not be representative of the whole community. For this reason, standard curves in the current thesis were performed with multiple bacterial species that are commonly found in the corresponding sample. Although "universal" primers, such as those targeting the 16S rRNA gene, are capable of detecting most bacteria present in clinical samples, small differences in sequence composition leads to amplification biases, i.e. not very bacteria is equally amplified, leading to over- or underestimations of the real composition or numbers. Furthermore, $16 \mathrm{~S}$ rRNA gene is present in variable number of copies in each bacterial species, which further difficult an accurate estimation of a communities' bacterial load. This problem could be solved by targeting other universal, yet single-copy genes that could be used for estimations "one gene copy, one cell". In the present thesis, we have quantified bacterial loads (Chapters 1 and 4 ) and fungal loads (Chapters 2 and 3) by applying qPCR with primers designated to be detect "universal" bacterial and fungal genes (16S rRNA, fusA, 28S rRNA and ITS1 genes). With an attempt to improve qPCR calibration methods, we applied flow cytometry with sorting to quantify and separate bacterial and fungal single-cells, previously isolated in the lab. In particular, several bacteria commonly present in milk were selected and sorted, and their DNA extracted, pooled and seriallydiluted and used for calibration. Similarly, different fungi were selected and subjected to the same protocol. Flow cytometry allows individual cells to be quantified and sorted, so that the can be used for further experiments or analysis. We have applied our improved flow cytometry protocol to circumvent the bias associated to culture-based constructed standard curves. However, flow cytometry may also introduce small errors in the microbial counting and sorting, and thus microbial estimates calibrated with this method may present small variations respect to the real loads in the samples.

But if there is a culture-independent method that has revolutionized the study of complex microbial communities, that is Next-generation sequencing (NGS). NGS are recent technologies that enable the analysis of an entire microbial community within a 
sample, representing an extremely powerful tool for genomics and molecular biology analyses. Unlike the classic Sanger sequencing method, that required previous microbial growth and was time-consuming (only one species could be sequenced at a time) and expensive, with NGS we can sequence multiple DNA samples in a rapid, cost-effective and accurate manner. Sequencing of the bacterial 16S rRNA gene, the fungal $18 \mathrm{~S}$ and $28 \mathrm{~S}$ rRNA genes and the ITS1 region, prior PCR amplification (amplicons), emerged as an optimized and relatively simple method to study the composition of complex microbial communities. NGS facilitated the analysis of thousands of sequences per sample, and increased the capacity to observe less abundant bacterial phylotypes, all in a massiveparallel manner, with hundreds of different samples analyzed at the same time. The second-generation sequencing approaches include different methodologies like 454, Illumina or SOliD, that require an amplification step as part of their procedure, as opposed to the recently developed third-generation sequencing methodologies that are single-molecule approaches (Malla et al. 2018). 454 pyrosequencing platform (Roche, Basel, Switzerland) was the first market-available NGS method applied to study complex microbial communities, including those in human milk (Hunt et al. 2011). In 454 pyrosequencing, generic adaptors with barcodes are added to the ends of each DNA amplicon, which are denatured into single strands and annealed to beads, and are later amplified by emulsion PCR. DNA fragments are exposed, in four successive cycles, to each of the four dNTPs. Every time a nucleotide is incorporated to the sequence, a light signal is released, and detected "on the fly". This technology is capable of generating large read lengths, up to $700 \mathrm{bp}$, in a short time (less than $10 \mathrm{~h}$ ). However, it presents some disadvantages: coverage is lower as compared to other sequencing platforms $(<1$ million reads/run), reagents costs are high, presents relatively high error rate over strings of homopolymers ( 3 or more consecutive identical DNA bases) caused by accumulated light intensity variance, and $3^{\prime}$ ends of sequences tend to have higher sequencing error rates compared to the $5^{\prime}$ ends. In the current thesis, we used 454 technology to determine bacterial and fungal composition in healthy breast milk samples, in Chapters 1 and 2. Illumina (San Diego, CA, USA), with different available platforms, adopted the technology of sequencing by synthesis (SBS). Amplicons with adaptors are denatured to single strands and transferred to a flowcell (with billions of micro-wells) were bridge amplification form clusters containing clonal DNA fragments. Then, nucleotides labelled with different fluorophores and removable terminator groups are incorporated, and the fluorescent signal is captured. SBS overcomes homopolymers issue by incorporating terminated nucleotides, adding one single base at a time. It represents the cheapest sequencing method, and offers the greatest coverage, which leads to a more accurate and reliable sequences. In particular, Illumina MiSeq is a bench top sequencer especially convenient for amplicon and bacterial/fungal sample sequencing. It can sequence up to 25 million sequencing reads per run, and $2 \times 300$ bp maximum read lengths. However, this platform also presents some disadvantages: longer times (up to 55 hours), substitution type miscalls, as $A$ and $C$ as well as $G$ and $T$ have a similar emission spectra 
of the fluorophores, and there are limitations of the filters that are used to separate the signals, incomplete removal of the $3^{\prime}$ terminators or the fluorophores, etc. (Schirmer et al. 2015).

In addition, amplicon-based sequencing is a rapid and powerful method to study microbial communities in breast milk, but it also bears some limitations. It requires one or several PCR steps, which may add products of artificial (in vitro) amplification to the sequences of interest. Also, higher abundant sequences tend to be over-amplified, while sequences present in low abundances can be disregarded. Similarly, species with higher copy numbers of the target genes could be overestimated. Furthermore, amplicon-based sequencing provides low confidence for taxonomic assignment at species level, as sequence lengths are not always sufficient for confidence identification at that taxonomical level. In the current thesis, we used Illumina MiSeq sequencing technology to determine bacterial and fungal compositon in human milk samples, in Chapters 3 and 4. As previously mentioned, it should be taken into account that culture-independent DNA/RNA-based methodologies cannot distinguish between nucleic acids belonging to live or dead microorganisms. In addition, amplicon-based sequencing does not provide functional annotation. To overcome this problem, other NGS methods can be applied, including Shotgun metagenomic sequencing, that enables sequencing of all genes in all organisms in a given sample, and thus, reliable taxonomic assignment at species level and the detection of other microorganisms such as fungi, archaea, protozoa and viruses; and metatranscriptomics, which analyses all RNAs encoded by all the microorganisms within a complex sample, and provides functional annotations. Up to date, two works analysing the human milk metagenome have been published, which shed more light on the global microbial composition of breast milk, and their metabolic functions (Jiménez et al. 2015; Ward et al. 2013) However, those methods are expensive and generate big amounts of data that require arduous informatics analyses, including human DNA that is not considered in microbiota studies.

In this thesis, we have observed slightly differences in microbial composition when using 454-pyrosequencing (Chapter 1 and 2) and Illumina MiSeq (Chapters 3 and 4), which reflects one of the drawbacks associated to NGS (Clooney et al. 2016). An additional potential bias introduced in the present work relies in the volume of milk used for the DNA extractions that varied between Chapters. For example, in Chapters 1 and 2, we used 5-10 $\mathrm{ml}$ and $5 \mathrm{ml}$, respectively. In Chapter 3, $1.5 \mathrm{ml}$ of milk were used for the DNA extraction, while $4 \mathrm{ml}$ were used in Chapter 4 for the DNA and RNA extractions. Although microbial DNA was always normalised before NGS, human milk microbial concentrations are relatively low, and when possible, using higher sample volumes reduce the possible biases introduced during the extraction and preamplification steps. These variations are in part due to the lack of a standardised protocol for the DNA and RNA extraction of human milk. In the present thesis, we have developed an improved protocol for the extraction of human milk microbial DNA and RNA, combining physical and chemical disruption to maximise the nucleic acids yields 
from bacterial and fungal cells. The complete protocol can be found in Annex A, at the end of this manuscript. In the present thesis, NGS provided valuable additional insight into the bacteriology of milk. We have combined this methodology with classic culturedependent and other culture-independent methods in order to overcome NGS drawbacks and get the whole picture of the real composition of human milk.

\section{Human Milk is a Live Fluid}

In the present work, we have confirmed the presence of a diverse microbiota in human milk under healthy conditions. In Chapter 1, we analyzed bacterial communities throughout lactation stages (colostrum, transitional and mature milk). Results showed that human milk from healthy Spanish mothers harbor a complex bacterial population, as previously reported in samples from Finnish or American origin (Cabrera-Rubio et al. 2012a; Hunt et al. 2011). Using molecular methods, we found that milk bacteria were present in higher abundances (between one and two orders of magnitude higher load per $\mathrm{ml}$ ) than previously estimated by culture approaches, and that they correlated with other milk components, such as macronutrients or human cells. Confirming previously published findings in samples with other geographic origin, we identified a diversity of bacteria in every sample. The major phylotypes observed in our Spanish samples were Staphylococcus, Acinetobacter, Pseudomonas and Streptococcus, among others. Conversely, while previous works had reported the common presence, yet in low proportions, of Lactobacillus spp. and Bifidobacterium spp. in human milk, by 454-pyrosequencing of the $16 \mathrm{~S}$ rRNA gene we could only detect a few sequences corresponding to those taxa. This could be explained by the low efficiency of "universal" primers in amplifying high G+Ccontent taxa (Sim et al. 2012), and confirm that those genera account for only a small proportion of the total bacterial communities in human milk. A higher number of Lactobacillus and Bifidobacterium sequences were obtained when sequencing the $16 \mathrm{~S}$ rRNA gene by Illumina MiSeq (Chapter 4), which suggest that this platform and/or the primers (gene region) used do not fail to amplify those genera, as observed in Chapter 1. Also, some of the previous works were based on culture methods, or PCR-based methods, which may have overestimated the real abundances of these genera in the samples (Heikkila \& Saris 2003; Martín et al. 2003, 2009; Solís et al. 2010).

\section{Human Milk Microbiome: Beyond Bacteria}

Despite big efforts have been made in order to describe the bacterial composition of the human microbiota, and in particular that of human milk, other fractions including the mycobiota or the virome have been widely overlooked. In Chapter 2 we reported for first time the presence in human milk of yeasts and other fungi in samples from healthy Spanish mothers, over lactation stages by use of a multiple-approach including culture techniques, microscopy and NGS. Although one metagenomic study had previously revealed the presence of fungal DNA in human milk (Jiménez et al. 2015) and others had 
detected the presence of Candida spp. in the fluid associated to nipple pain (Amir et al. 1996, 2013), we were the first to report a detailed analysis of fungi in human milk under healthy conditions. In Chapter 3 we further identified fungal DNA, as well as live organisms, in milk samples from a bigger cohort of healthy mothers living in distant geographic locations. In addition, we observed co-occurrence and correlations of several fungi and bacteria (and within the same domain) in the samples, with an influence of perinatal and maternal factors. In both studies, we confirmed that the genus Malassezia predominated in all the samples. Interestingly, in Chapter 2 we observed a positive correlation between Malassezia and the bacterial load in human milk; and in Chapter 3, we showed positive correlations between several Malassezia and Streptococcus OTUs, the latest representing one of the most predominant bacterial genera in human milk. Although we were not able to isolate Malassezia from the analyzed samples, we did confirm the presence of high abundances of Malassezia RNA in breast milk under healthy conditions (data not published), which confirms their active presence in the fluid. Our results showed that fungi are ubiquitously present in human milk, and suggest that fungal and bacterial populations may interact. Further studies should address those interactions, and their potential role on the infant microbiota development and maternal health. It should be taken into consideration that differences in sequencing platforms, sequencing of different gene regions, informatics pipelines for analysis or use of different genetic databases compromises the heterogeneity of microbiome studies. For example, in Chapter 1 we sequenced the V1-V4 region of the bacterial 16S rRNA gene by means of 454-pyrosequencing, while in Chapter 4 we sequenced the V3-V4 region of the same gene by Illumina MiSeq. In Chapter 2 we sequenced the fungal 28S rRNA gene by means of 454-pyrosequencing, while in Chapter 3 we sequenced the fungal ITS1 region with MiSeq. However, we did not observe great differences in results between our studies.

\section{Microbial Loads in Human Milk and Importance for Human Microbiome Studies}

Early reports of human milk bacterial loads came from utilizing culture-dependent techniques involving plate counting. In 2003, Heikkila and colleagues estimated that an infant feeding $800 \mathrm{ml}$ of milk would ingest $10^{4}-10^{6}$ bacteria daily (Heikkila \& Saris 2003). Later, other studies reported total bacterial loads of $<10^{3} \mathrm{CFU} / \mathrm{ml}$ (Perez et al. 2007) and $10^{5} \mathrm{CFU} / \mathrm{ml}$ in colostrum that decreased down to $10^{4} \mathrm{CFU} / \mathrm{ml}$ in mature milk (Solís et al. 2010). Differences on the results observed by culture methods are likely due to the different culture conditions used (media, temperature, aerobic or anaerobic conditions, etc.). As previously mentioned, culture methods may underestimate the real bacterial diversity of a sample. More recently the application of qPCR, a more accurate and sensitive method, displaced culture techniques for the quantification of specific bacterial groups, as well as total bacteria in complex samples. With this method, total bacterial loads from healthy mother's milk was estimated at approximately $10^{6} 16 \mathrm{~S}$ gene copies $/ \mathrm{ml}$ 
(Collado et al. 2009; Martín et al. 2009); and 104-105 $16 \mathrm{~S}$ gene copies/ml (Khodayar-Pardo et al. 2014). Khodayar-Pardo et al, compared bacterial loads throughout lactation, and observed significant higher bacterial counts in transitional and mature milk, as compared to colostrum. However, these studies used pure bacterial cultures to obtain standard curves for calibration, which ultimately drag biases associated to culture techniques. In Chapter 1, we estimated bacterial loads at the three lactation stages by qPCR targeting the singe-copy bacterial gene fusA. We calibrated the method by using an optimised protocol based on sorting bacteria from a pool of different human milk samples with flow cytometry. Bacterial DNA was later extracted, pooled and diluted, to construct standard curves. This allowed us to interpolate the resulting Cps in the standard curve, and to calculate bacterial counts as "one gene copy, one cell". Results showed that bacterial loads were approximately $10^{6} \mathrm{cells} / \mathrm{ml}$ (median values), with high variability between mothers and also over time, ranging between $10^{4}-10^{8}$ cells $/ \mathrm{ml}$. We observed a tendency towards higher counts in transitional and mature milk, as reported by Khodayar-Pardo et al, although differences were not significant likely due to the high bacterial load variability in the samples. Thus, establishing a range of "normal" bacterial loads in healthy conditions seems complicated. Some researchers consider that human milk samples with more than $10^{4}$ bacterial CFU/ml (culture estimates) would reflect an infection in the mammary gland (Arroyo et al. 2010; Fernández et al. 2016). However, those values are below our estimates for the human milk samples (qPCR estimates) from healthy mothers that we analyzed in Chapter 1 . This difference is probably due to the culture basis of those experiments that would overlook part of the microorganisms present in the samples. However, and as we have mentioned previously, our estimates do not consider that part of the measured DNA likely belongs to dead microorganisms, and the real value must be in between culture-based and our qPCR-based bacterial loads estimates. In Chapter 2, we proved this methodology was also suitable for the detection and quantification of fungi in healthy human milk samples throughout lactation, by using primers against the ITS1-5.8S fungal region. With qPCR and our optimised calibration method (this time, sorting several fungal species obtained from pure cultures), we were able to detect fungal DNA in $90 \%$ of the analyzed samples, with estimated median values of $3.5 \times 10^{5}$ cells $/ \mathrm{ml}$, with no statistical significant differences between lactation stages. In Chapter 3, median fungal load in human milk was estimated at $2.5 \times 10^{5}$ cells $/ \mathrm{ml}$, similar results to those obtained in Chapter 2. More than $70 \%$ of Spanish and South African samples had detectable levels of fungal DNA, while less than $45 \%$ of the Chinese and Finish samples had detectable fungal levels. South African samples had the highest fungal loads, although we did not observe significant differences between countries. Differences in climate, diet, and genetics associated to each country may be responsible for the variable fungal levels and prevalence observed in the samples, as well as the natural variability within each mother.

In the last decade, since the launching of the Human Microbiome Project, and with the fast evolution of DNA sequencing techniques, there has been an exponential growth in 
our knowledge of the microbial communities living on and within us. Despite NGS represents a powerful method for describing microbial diversities in almost any human sample, it does not provide information about microbial quantities, but only relative abundances of specific taxa with respect to the total sequences obtained from a sample of interest. In fact, some authors have criticized microbiome analyses based on bacterial frequencies. For example, a change in the levels of one bacteria would influence the proportion of others even if they do not change, and therefore microbiome data are compositional (Gloor et al. 2017). Most microbiome studies do not take into consideration bacterial or fungal loads, but this can be important under certain situations. For example, a specific taxon could represent $80 \%$ of the total sequences in two similar samples, but we could not detect if microbial loads were higher in one of them. This could be crucial if, for example, one of those samples belonged to a healthy individual, while the second one (with higher bacterial load) belonged to a diseased individual. By only looking at the sequencing data we would miss valuable information that could be key in the diagnosis or treatment of the disease. Thus, we propose including microbial load analyses in microbiome studies, and provide an easy approach to implement it in different human samples. If the sample is a fluid (milk, saliva), normalization can be performed per ml; if not, it could be performed by net weight or by the number of human cells in the sample (Boix-Amorós et al. 2016, 2017, 2019b; López-López et al. 2017). An example of this approach can be seen in Chapter 4, where we applied NGS together with qPCR in order to study bacterial composition and bacterial counts in milk from mothers suffering sub-acute mastitis, and from healthy controls. We observed that, during the course of the symptoms total bacterial loads increased significantly. After symptoms had disappeared, bacterial loads decreased, although did not reach control levels. We also estimated active bacterial load, by analysing bacterial RNA (after retro-transcription into cDNA), and observed increased active bacterial loads during and after the symptoms in the mastitis group.

According to our results, under healthy conditions, human milk microbiota contains approximately $10^{6}$ cells $/ \mathrm{ml}$, considering both bacterial and fungal cells. Those concentrations would depend on the health status of the mother (e.g. increased levels during locational mastitis) and on the milk collection method. It has been reported that the use of milk pumps may result in higher concentrations of contaminating Gramnegative bacteria (such as Pseudomonas, Stenotrophomonas and enterobacteria) and yeasts arising from rinsing water and/or poor hygienic manipulation practices (Arroyo et al. 2010). Quantifying bacterial loads in human milk (and other human samples) offer an ideal support for NGS studies, where microbial quantities cannot be inferred from sequencing data. Throughout the present thesis, we have analyzed bacterial and fungal loads in human milk, by applying our optimised protocols. Our results reinforce the importance of quantifying microbial loads in microbiota studies, and how qPCR represents an accurate and reliable technique for this purpose. In particular, we demonstrate that knowing bacterial or fungal loads can be crucial in the diagnosis of 
infectious or dysbiotic conditions. We reinforce the importance of measuring microbial counts in human microbiota studies, and the methodologies presented in this thesis can be transversally applied to study any other human samples.

\section{Human Milk Microbiota and Interactions with Milk Macronutrients and Cells}

In this thesis, we have studied interactions between human milk microbiota and other milk components as we hypothesize that those interactions could affect the neonatal microbiota and immune system development. We observed correlations between bacterial (Chapter 1) and fungal (Chapter 2) taxa, milk macronutrients, bacterial and fungal loads, and somatic cell counts. Our results suggest that microbial communities in milk are influenced by milk macronutrient composition. For example, we observed that Staphylococcus, a potential opportunistic and pathogenic bacteria, correlated negatively with fat content. Thus, having higher amounts of fat in human milk may be protective of Staphylococcus infections. We also observed a positive significant correlation between Malassezia, the most abundantly detected yeast in human milk by NGS, and lactose. This interaction should be further evaluated, as Malassezia genus is not able to metabolize lactose. The observed correlation could be the result of microbial interactions (for example, synergistic relationships between this genus and other lactose-utilizing bacteria or fungi). Maternal diet has been shown to modulate several nutritional and bioactive elements, including protein content, lipidic profiles, immune compounds, etc. (Linnamaa et al. 2013; Palmer et al. 2008; Urwin et al. 2012). In addition, dietary habits modulate the adult and infant gut microbiota (David et al. 2014; De Filippo et al. 2010). Whether diet affects human milk microbiome populations is unknown. In a recent study, diet directly influenced the mammary tissue microbiota in primates (Shively et al. 2018). In particular, Mediterranean diet was associated with higher levels of Lactobacillus in the mammary gland, and modulation of dietary metabolites and bacterial products, with implications for breast cancer prevention. In Chapter 2, we identified fungal strains presumably from a dietary origin. In particular, Saccharomyces cerevisiae sequences were obtained with NGS, and one S.cerevisiae isolate was identified as a bakery strain. Results support a dietary effect outside the intestinal tract in distal sites such as the mammary gland, and future studies should address if human milk microbiota may depend on maternal diet.

In addition to milk macronutrients, we also measured somatic cells numbers in human milk and studied potential correlations with milk microorganisms. In dairy cattle, the number of somatic cells is routinely used as a biomarker of udder infections, and its constituted mainly of leukocytes (Li et al. 2014; Olechnowicz \& Jaśkowski 2012). In Chapter 1 we observed an absence of somatic cell increase with higher bacterial load (but rather a tendency towards a negative correlation), and in Chapter 2, we reported a weak negative correlation between fungal load and somatic cells, and a significant negative correlation between bacterial load and somatic cells. The absence of a somatic cell 
increase under healthy conditions, suggests that microorganisms in milk are not sensed as a "threat" by the maternal immune system, and rather coexist with the host. However, we only analyzed breast milk from healthy donors and did not measure other antiinflammatory compounds in milk that could hamper an immune reaction.

\section{Effect of Maternal and Environmental Factors on the Human Milk Microbiota}

\section{Lactation stage}

Human milk components, including fat, protein or immunoglobulins, change their composition throughout lactation. Up to date, there were only a few reports regarding milk bacterial composition and loads over the lactation stages. In a study, total bacteria, Bifidobacterium and Enterococcus spp. counts increased throughout lactation, as observed by qPCR analysis of the $16 S$ rRNA gene (Khodayar-Pardo et al. 2014). 454pyrosequencing of human milk at three time points, separated by 1-2 weeks, showed that bacterial communities were often, yet not always, stable over time within an individual, and relatively heterogeneous between them (Hunt et al. 2011). However, researchers did not specify which lactation stages were analyzed, nor if all samples were collected within the same period of time. Cabrera-Rubio and colleagues compared colostrum samples with 1 and 6 months samples (mature milk) by 454-pyrosequencing. They observed a higher bacterial diversity in colostrum, as compared to mature milk, and an increase in typical oral inhabitants (Veillonella, Leptotrichia, and Prevotella) in mature milk. In Chapter 2, we applied 454-pyrosequencing of the 16S rRNA gene, and qPCR targeting the single-copy gen fusA to study human milk bacteria over the three lactation stages. We observed that bacterial abundances varied between mothers, and sometimes, over time within the same mother. In contrast to previous results, we observed a higher bacterial diversity and richness in transitional milk, which was consistent among most mothers, followed by colostrum and mature milk, although we could not identify any statistically significant differences between bacterial taxa. Median bacterial loads increased as the lactation stage progressed, although, again, there was high variability. Interestingly, we also observed that bacteria distributed in a different manner depending on the lactation stage. Bacteria in colostrum were more frequently found aggregated to other bacteria and human cells, while in mature milk, bacteria were more frequently found in a planktonic state. This fact could be a reflect of the higher number of immune cells in colostrum under healthy conditions (Hassiotou et al. 2013a), although further studies where somatic cells subtypes are measured are needed in order to understand the nature of bacterial-human cells associations. In Chapter 2, we compared fungal loads in healthy mothers' milk throughout lactation, and observed similar counts over time, with slightly lower counts in mature milk. Thus, bacteria appear to be more sensitive to the temporal variations during lactation than fungal communities. However, we could not compare fungal diversities between lactation stages, as we only sequenced a subgroup of 10 samples that corresponded mostly to the 
mature stage. Further studies are needed in order to understand a potential influence of lactation time on the composition of breast milk fungal communities.

\section{Geographic location}

Geographic location can influence the composition of human microbial communities (Gaulke \& Sharpton 2018; Yatsunenko et al. 2012). In the current thesis, we studied bacterial communities from healthy Spanish human milk samples. We identified a "core" of bacterial taxa shared in all mothers at the three time points, which was composed by: Streptococcus, Staphylococcus, Acinetobacter, Pseudomonas, Finegoldia, Corynebacterium and Peptoniphilus. Interestingly, the composition observed in these Spanish samples differed from that observed in other high-throughput sequencing studies on samples from other countries. Hunt et al (Hunt et al. 2011) were the first to apply NGS of the 16S rRNA gene to study human milk microbiota in American women. They found a core of 9 bacterial taxa: Staphylococcus, Streptococcus, Serratia, Pseudomonas, Corynebacterium, Ralstonia, Propionibacterium, Sphingomonas and Bradyrhizobiaccae that were present in all the samples. However, some of those bacteria likely correspond to environmental contaminants arising from extraction/sequencing kits, as initial microbiota studies did not include negative controls in their sequencing plates. Later, Cabrera-Rubio and colleagues (Cabrera-Rubio et al. 2012a) applied the same methodology to analyse Finnish human milk samples over the course of lactation. They found that Leuconostoc, Weissella, Lactococcus, Staphylococcus and Streptococcus were the most abundant genera in the samples while other authors (Jost et al. 2013) reported that Pseudomonas, Streptococcus, Staphylococcus and Ralstonia dominated Swiss human milk samples. Similar bacterial diversity patterns were observed in other studies by using Illumina MiSeq sequencing (Urbaniak et al. 2016a), and in two metagenomics approaches (Jiménez et al. 2015; Ward et al. 2013). Very recently, the influence of the geographic location on bacterial profiles was reinforced in a study comprising more than 300 milk and fecal samples from 8 different countries (Lackey et al. 2019). In our last study (Chapter 4), specific differences on bacterial abundances were observed between healthy and mastitis-suffering women. However, we observed that Streptococcus, Staphylococcus, Rothia, Corynebacterium and Acinetobacter were most prevalent in the Spanish samples that were analyzed by Illumina MiSeq of the 16S rRNA gene. Putting all evidence together, results suggest that at least, Streptococcus and Staphylococcus are ubiquitously present in the human milk of healthy lactating woman. In Chapter 2, results from applying 454-pyrosequencing of the fungal $28 S$ rRNA gene revealed that Malassezia, Saccharomyces and Candida were prevalent in Spanish human milk samples. In Chapter 3, we observed a strong influence of the geographic location on human milk fungal composition, as inferred by Illumina sequencing of the ITS1 fungal ribosomal gene region of samples from Spain, Finland, China and South Africa. South African samples had the most different composition, with significantly higher abundances of Ascomycota, and lower levels of Basidiomicota, as compared to the other countries. Differences at genus, and sometimes at species level, were observed in all the countries, although no significant differences were observed in 
the fungal loads nor alpha diversities of the different geographic locations. As for the bacterial fraction, we identified a fungal core comprised by Malassezia, Davidiella, Sistotrema and Penicillium, shared in all the samples.

Differences observed between countries may be explained, at least partially, by geography-associated factors, such as genetics, diet, climate or cultural habits. For example, Finnish human milk samples were dominated by lactic acid bacteria, such as Lactococcus, Leuconostoc and Weissella (Cabrera-Rubio et al. 2012a). It is widely known that Nordic countries consume high quantities of dairy in their diet, and we could speculate that some microorganisms present in those products would reach the mammary gland and milk. Another potential factor associated to differences in milk microbiota profiles between countries could be the different use of antibiotics during birth. In Nordic countries the usage of antibiotics (including during pregnancy and delivery) is low compared with most other countries (Bergan 2001), and it is known that antibiotics can disrupt human microbial communities (Ubeda \& Pamer 2012). Overall, our results and those from other researchers suggest that geographic location, and possibly other genetic and dietary factors, could be influencing microbial diversity in human milk, both directly and also by modifying mucosal-associated communities in different parts of the body, which would ultimately be translocated to the human milk.

\section{Mode of delivery}

Some studies had suggested a potential influence of mode of delivery on human milk microbiota (Cabrera-Rubio et al. 2012a, 2016; Hoashi et al. 2016; Khodayar-Pardo et al. 2014; Toscano et al. 2017b), presumably due to differences in hormonal changes and physiological stress associated to the initiation of labor that may facilitate mucosal permeability and microbial translocation to the mammary gland. Previous qPCR estimates showed that woman delivering via $C$-section had higher total bacterial counts in colostrum and transition milk, but lower abundances of Bifidobacterium spp (Khodayar-Pardo et al. 2014). Cabrera-Rubio et al showed that milk from mothers delivering by elective C-section had a significant decreased abundance of Leuconostocaceae and increased Carnobacteriaceae, as compared to the milk of mothers who delivered vaginally. Interestingly, bacterial profiles in mothers' milk delivering by non-elective C-section were more similar to those from mothers delivering vaginally, than to milk from elective C-section (Cabrera-Rubio et al. 2012a). This could be the result of the lack of physiological stress in elective C-section deliveries. In Chapter 3, we observed a significant effect of mode of delivery on the fungal profiles of human milk, although this effect was weaker as compared to the effect of geographic location. We observed that Cryptococcus genera was associated to vaginal deliveries, and other specific differences associated to delivery mode within every country. However, other studies have not observed differences in milk bacterial profiles depending on mode of delivery (Urbaniak et al. 2016a). In our study, we did not observe either significant differences on fungal loads nor alpha diversities associated to mode of delivery in any of the countries 
of study. It should be taken into account that C-section deliveries are usually accompanied by antibiotics use, while in vaginal deliveries, antibiotics are usually applied under particular cases. For example, pre-partum antibiotics are recommended when the mother is carrier of group B streptococci bacteria (World Health Organization 2015). However, some countries use antibiotics at delivery in a routinely manner.

Our results and other researchers' suggest a potential effect of environmental factors on human milk bacteriology. Recently, a research work comprising almost 400 mother/infant pairs reported a significant effect of maternal BMI, parity, mode of delivery and breastfeeding practices on the human milk bacterial composition, in a sexspecific manner (Moossavi et al. 2019). Results should be taken with caution, as some differences could be partly explained due to differences in studies methodologies, such as sample collection methods (manual or pump expression, skin cleaning procedure), use of different DNA extraction kits, and sequencing technologies. In addition, it should be taken into account that human milk contains relatively low amount of microbial DNA, as compared to other human niches, and amplification of extraction kits contaminants can occur, which could be over amplified during PCR steps (Salter et al. 2014). For this reason, as it has been suggested for low-DNA yield samples, all studies should include careful negative controls at the moment of sampling, DNA extraction and sequencing (Biesbroek et al. 2012).

\section{Nature of Sub-acute Mastitis Aetiology}

In Chapters 1-3, we described bacteria and fungi in human milk during healthy conditions. In Chapter 4, on the other hand, we analyzed milk samples from mothers suffering lactational mastitis, and healthy controls, with the main objective of investigating the aetiology of sub-acute mastitis. In the last decade, the definition of subacute mastitis as a sub-type of lactational mastitis was introduced, as the general term of "mastitis" failed to cover the wide symptomatology of the disease (Arroyo et al. 2010; Jiménez et al. 2015). Nowadays, sub-acute mastitis is generally recognised as a sub-type of mastitis that differs from acute mastitis or other sub-types (such as subclinical or chronic mastitis). However, the aetiology of this disease is still poorly understood and there are even many medical doctors that do not consider this condition has a microbial origin. We analyzed both total and active bacterial composition, by sequencing and quantifying the 16S rRNA gene from the DNA and RNA in the samples. Our results revealed that sub-acute mastitis, rather than being caused by a single or a few species, represents a dysbiotic process. We observed higher bacterial loads, decreased bacterial diversity and richness, in addition to altered bacterial patterns as compared to healthy controls' milk. In support of this result, in vitro incubation of bacteria from sub-acute mastitis human milk on a breast tissue cell line, triggered the production of the proinflammatory interleukin-8. We observed that total and active bacterial composition differed considerably between mothers suffering the disease. However, we identified a 
few bacteria that were more prevalent and abundant during sub-acute mastitis. Those included S.aureus and Corynebacterium kroppenstedtii in the total DNA, and S.aureus and S.lactarius in the RNA fraction (and thus, live and active in the samples). S.aureus is considered the main etiological agent in acute mastitis (Jiménez et al. 2015; Osterman \& Rahm 2000), and as we reported, it can also be involved in the sub-acute version. $C$. kroppenstedtii is commonly associated with granulomatous mastitis (Paviour et al. 2002), while S.lactarius, which had been previously isolated from healthy mothers' milk (Martin et al. 2011), was reported to be the causing agent of a fastidious case of mastitis, in a single study (Tena et al. 2016). It should be noted that, contrary the observations in Chapter 1, in Chapter 4 we were able to detect Lactobacillus and Bifidobacterium genera in the human milk samples from healthy and mastitis-suffering women. In this case, we applied Illumina MiSeq sequencing of the 16S rRNA gene, which shows that this platform and the primers used overcome the low amplification efficiency in high $\mathrm{G}+\mathrm{C}$ content taxa. Our results have shed some light on the understanding of the etiology of sub-acute mastitis. However, further extensive research is needed to uncover the potential causality of the observed dysbiosis on the onset of the disease. Future studies should target other milk components, including immune cells, cytokines, macronutrients or metabolomics analyses to fill in the gaps remaining in the current knowledge of sub-acute mastitis. This could permit the discovery of biomarkers that could be used for a correct diagnose and/or treatment of this fastidious condition, which we believe this thesis shows it has a microbial etiology.

\section{Total vs Active Bacteria in Human Milk: Viability Matters}

A special mention deserves the fact that for the first time we analyzed the 16S rRNA gene from the RNA fraction of human milk, by means of NGS. The majority of human microbiota studies are based on the sequencing of a genetic DNA region of the universal bacterial or fungal genes (amplicon-based NGS). However, most studies and the results inferred from them do not take into consideration that microbial DNA does not necessarily come from live or active microbes in the sample. In fact, part of that DNA likely belongs to dead or transient organisms, as well as to free DNA. Transcriptomic analyses surpass this problem by sequencing the total RNA molecules within a sample (Lowe et al. 2017). However, the big data amount generated by this method makes it hard to analyze, and the low RNA yield in human milk samples may prevent direct cDNA sequencing. In the present thesis, we have applied the amplicon-based NGS methodology to sequence the RNA of the bacterial 16S rRNA gene, which by definition would need to be transcribed in live or viable cells, and thus approximates to the real "active" bacterial composition of a sample. Analyzing human milk active bacteria, our study offers a more precise insight into the bacterial etiology of the SAM process, only considering live organisms that could interact with the host and contribute to the disease. The methodologies applied in Chapter 4 open the possibility to calculate an 
"activity ratio", as the logarithm of the difference between reads of the 16S rRNA gene in the cDNA and DNA sequences, that could be used in future worsk to better identify infectious diseases' etiology. This ratio would permit to stand out those bacteria that are not only present, but also active in human milk. On the other hand, RNA-based studies have some disadvantages, as RNA is more unstable and degrades more easily than DNA. In addition, RNA yields are lower than DNA, which makes it more prone to contamination. In our study, we retro-transcribed RNA into cDNA, to maintain its stability and facilitate its manipulation and amplification.

Thus, RNA analyses offer a complementary vision to human microbiota studies. In this work, differences observed between human milk microbial DNA and RNA composition make clear that, by only analyzing total DNA, we would miss an important piece of the whole microbial picture. Detecting bacterial DNA in any human sample does not imply that the corresponding bacteria are actually live and exerting an effect on the human body, and therefore, results inferred from those observations could be incomplete. Taking into account the active fraction of human milk microbiota, our study offers a more precise insight into the bacterial origin in the SAM process and we recommend its use in other pathologies.

\section{Potential Origin and Roles of the Human Milk Microbiota}

Investigating the origin of human milk microbiota was not an objective of the present work. However, our results may shed some light on the debate of how bacteria and other microorganisms reach the mammary gland. Throughout this thesis, we have identified several organisms commonly found in other human body niches. For example, Streptococcus, one of the most commonly detected in human milk, is also a typical inhabitant of the oral cavity (including several species, such as S. mitis, S.salivarius or S.mutans that we also detected in human milk). Other oral bacteria, such as Veionella, Rothia, or Gemella, were detected in our milk samples. We also detected several fungi and yeasts, including Candida, Cladosporium, Fusarium, Saccharomycetales, or Cryptococcus, which have also been detected in the oral cavity. Similarly, we have detected two of the most prevalent bacterial and fungal inhabitants of the human skin, Staphylococcus and Malassezia. Among Staphylococcus sequences, S.epidermidis was the most frequently assigned at species level, and despite S.aureus was not detected (or detected in very low abundances) in healthy conditions, it was identified as one of the species associated to mastitis. Other common skin organisms detected in milk included Corynebacterium, Propionibacterium, Candida, Aspergillus or Penicillium. Our results support a potential microbial exchange between the infant oral cavity and the mammary gland, and further studies should address if there is a potential seeding of oral colonizers from the mammary gland, or vice-versa. This colonization from the oral cavity may also be responsible for the increase in diversity in transition milk observed in Chapter 2. As previously reported, a retrograde flux of milk from the infant's oral cavity to the 
mammary gland occurs during breastfeeding, which likely drags some microorganisms from the skin of the breast. However, although some bacteria are shared between oral cavity and skin with human milk, the overall composition and relative abundances are different, and specific bacterial DNA profiles also differ between milk and breast skin and areola (Cabrera-Rubio et al. 2012a; Martín et al. 2003). Future studies should compare fungi from those niches, and confirm that populations differ from each other. However, recent work has examined by both culture and high-throughput sequencing the bacterial composition of precolostrum, i.e. the milk produced by mothers before delivery (Ruiz et al. 2019). This work confirms the presence of oral bacteria in this fluid, which has obviously not been exposed to the baby's oral cavity. In addition, several bacterial strains isolated from precolostrum and the oral cavity of the corresponding baby a week after delivery were fully sequenced and showed a $99.9-100 \%$ sequence identity at the genomic scale, supporting transfer of the same strains from precolostrum to the baby's oral cavity.

It is also important to underline that obligate anaerobes that are unlikely to survive to the aerobic conditions of the breast skin had been previously identified and isolated from human milk (Gueimonde et al. 2007; Jost et al. 2013, 2014). In the present thesis, we identified several strict anaerobes in human milk, including Bifidobacterium, Finegoldia, Anaerococcus and Veillonella, which colonize human mucous membranes, including that of the intestinal tract. Some fungi, such as Candida, Malassezia, Debaromyces, or S.cerevisiae detected in our samples, have also been found in the human adult and infant gut. Some microorganisms in human milk may have a dietary origin, as they can be found in the human gut and in several foods, including the bakery strain S. cerevisiae that we isolated from a milk sample in Chapter 2. As has previously been suggested, and in light of our observations, human milk likely seeds some colonizers to the infant gut (Delgado et al. 2008; Jost et al. 2014; Martín et al. 2009). Interestingly, in Chapter 1 we observed bacteria in human milk adhered to the surface of milk cells. Although we did not characterize those cells types, they likely correspond to immune cells. Previously, Perez et al, observed that human milk and peripheral blood mononuclear cells in mothers after giving birth contained a number of viable bacteria and bacterial DNA (Perez et al. 2007). They also observed bacterial translocation from the maternal gut to mesenteric lymph nodes and mammary gland in a mice model. Although we have not studied the infant microbiome, the presence of bacteria and fungi in human milk potentially shared with the maternal gut, in addition to the fact that they can be associated to human cells, would be in accordance with the entero-mammary pathway and with the transmission of milk microorganisms to the baby.

In addition, we have observed that bacterial communities in human milk can play a role on maternal health. Previously, imbalances in milk bacteriome have been linked to several health disorders, including allergies (Grönlund et al. 2007), HIV (González et al. 2013), celiac disease (Olivares et al. 2015) and breast cancer (Xuan et al. 2014). Lactational mastitis represents one of the main problems during lactation, that affects up to $30 \%$ of lactating women, being one of the main causes of undesired weaning. Despite the 
etiology of acute mastitis is better understood, information about sub-acute mastitis and its aetiology is scarce (Arroyo et al. 2010; Jiménez et al. 2015). Our results showed that sub-acute mastitis is a dysbiotic process, with higher bacterial loads, lower diversity and altered bacterial patterns as compared to healthy controls. In addition, in vitro studies showed that exposure of bacteria from sub-acute mastitis human milk on a breast tissue cell line triggered an inflammatory response. Thus, bacterial imbalances in the mammary gland can have a direct effect on maternal health, and future studies should analyze cytokines in human milk during sub-acute mastitis, as well as potential influences on infant health. Interestingly, some bacteria which appeared to be associated to mastitis in our samples, like Gemella, were typical oral inhabitants, underlining again the importance of the oral cavity as a potential source of microbes (both beneficial and potentially pathogenic) which could reach the mammary gland. We believe that clarifying the complex, polymicrobial etiology of sub-acute mastitis will help in the diagnosis and treatment of this condition, and hope that the present thesis can be a step towards that end.

Thus, the data would support both an endogenous route of transmission from different mucosal surfaces (including the maternal gut and oral cavity), together with colonization from the mother's skin and the baby's mouth (Mira \& Rodriguez 2016). Independently from their origin, bacteria in human milk are transferred to the infant during breastfeeding, representing a microbial supply to the infant microbiota and health. In the present thesis, we have applied a cleaning protocol to avoid contamination from the breast's skin prior sample collection. However, bacteria and fungi residing in the skin may also play important roles in the infant (Chen et al. 2018) and future works may consider them as part of the normal human milk microbiota.

\section{Conclusions and Future Prospects}

In this thesis, we have attempted to build on our understanding of the composition of the human milk microbiota under healthy conditions, and how microbial imbalances can influence the lactating mother's health and lead to disorders such as lactational mastitis. Our investigations have contributed to human milk microbiota research with novel and valuable information. For instance, we have defined bacterial communities in healthy conditions by applying up-to-date NGS methodologies, how bacteria distribute in the samples, and showed that they are sometimes associated to human cells and correlate with several milk compounds. The results of this study, presented in Chapter 1, therefore, provided a more comprehensive view of the ecology of milk bacterial communities. We also identified fungi in milk under healthy conditions (Chapters 2 and 3), although in lower frequencies than bacteria, and reported that Malassezia and Candida were the most abundant genera, that seemed to be ubiquitously present in human milk regardless of the geographic location. Our results, based on a broad range of methodological approaches, identified a much greater diversity of bacteria (and for the 
first time, of fungi) in milk than what had previously been reported in culture-dependent and culture-independent studies that relied on less open-ended or accurate methods, such as qPCR, PCR, or DGGE, among others. NGS methodologies also allowed us to describe total DNA and active RNA 16S rRNA gene in milk samples from mothers suffering sub-acute mastitis, as compared to controls. Despite the fact that the application of NGS has revolutionized the study of complex microbial communities, including milk, these methods also present significant biases. For example, we have observed slightly differences when sequencing the $16 \mathrm{~S}$ rRNA gene by 454pyrosequencing (Chapter 1 ) and by Illumina MiSeq (Chapter 4 ), which reflects that the drawbacks associated to NGS call for the need of a holistic approach to study the human milk microbiota (and that of any other human niches), combining those novel techniques with other classic or more restricted methodologies that complement them.

In light of the findings presented in Chapters 2 and 3 on the presence of fungi in human milk under healthy conditions, it would be interesting to further determine potential influences of human milk fungal species on the infant mycobiota development and maternal-infant health. Although almost all the probiotics available in the market are composed of bacterial strains, some yeasts have demonstrated probiotic activities, such as Saccharomyces boulardii, which is commonly used to treat diarrhea and gastrointestinal diseases in adults and infants (Zanello et al. 2009). Several bacterial isolates from human milk are currently available for consumption, and it would be of interest to investigate whether fungal isolates from milk could also have probiotic properties.

The provision of beneficial bacteria from human milk to the infant may not be limited to the gut or the oral cavity. In another study, for example, an association between the presence of Dolosigranulum and resistance to pneumococcal disease was detected in children (Chen et al. 2018), and a potential antagonistic effect between this bacterium and Streptococcus pneumoniae has been proposed. Dolosigraniulum is a very little studied lactic acid bacterium that is frequently found in the respiratory tract and nasopharynx of infants, but it has not been cultured to date. Given that it has been detected in the respiratory tract of breastfed infants (Biesbroek et al. 2014) and in human milk DNA studies (Drago et al. 2017), and that children breastfed for longer periods had lower rates of pneumonia and other respiratory tract infections future studies should aim to isolate Dolosigranulum from human milk or from aspirates in breast-fed children and test it as a probiotic. In fact, the use of milk from healthy mothers as a source of efficient probiotics has been demonstrated before, with different applications (Arroyo et al. 2010; Maldonado et al. 2012). Similarly, other yeasts and fungi present in human milk could have probiotic properties that are worth further studying. For example, Debaryomyces hansenii, that has been recognized as one of the most prevalent yeasts in the infant gut during breastfeeding (Schei et al. 2017), can produce a killer toxin that has stable activity against pathogenic yeasts at $37^{\circ} \mathrm{C}$ (Breuer \& Harms 2006). Although we were not able to isolate any D. hansenii strains in the current thesis, we did detect its DNA (by NGS) in milk from healthy mothers (Chapter 2), and other Debaryomyces sequences that could not 
be assigned at species level (Chapter 3), but that could partially correspond to that species. D. hansenii is also a common yeast detected in cheese, meat and other foods (Breuer \& Harms 2006). Some S.cerevisiae have also shown anti-fungal and antiinflammatory properties (Gabrielli et al. 2018; Zhu \& Bussey 1989). Future studies should aim to isolate D.hansenii from breast milk, and address its potential dietary origin, and if it (and other yeasts, such as S.cerevisiae) exert any beneficial properties in the infant gut.

Microorganisms living in human communities may have complex relationships, and these, ranging from cooperative to antagonistic, have been little explored, especially in human milk. In the light of our results from Chapter 3, where bacterial-fungal relationships in milk were observed, further studies should aim to understand interkingdom interactions and their potential effect on human health. Results may, for instance, lead to the development of combined, bacterial-fungal probiotics of human milk origin. In fact, new probiotic strategies are directed towards multiple-species probiotics, as opposed to single isolates, in order to maximize colonization and beneficial effects, especially after the success of microbial fecal transplants to treat certain inflammatory disorders (Friedman-Korn et al. 2018; Kao et al. 2017).

Finally, we have contributed to the understanding of the etiology of sub-acute mastitis, by analyzing human milk samples during the course of the symptoms and after the clearance of the disease, as compared to healthy controls. By applying NGS and novel protocols (studying not only the bacterial DNA, but also the RNA belonging to live, active bacteria), we have in Chapter 4 observed that sub-acute mastitis appears to be a real disease reflected on a microbial dysbiosis. This is opposed to acute mastitis, where S. aureus has been shown to be strongly associated to the disease, and has been proposed to infect the mammary gland, which is supported by our data in Chapter 1, where this species was not detected in healthy mothers. In addition, there is a vital need for finding biomarkers that could be used to diagnose and/or treatment of the disease. Some studies have observed an increased permeability of the blood/milk barrier during mastitis, which could result in the detection of milk components in the maternal blood and urine (Nguyen \& Neville 1998). Within this context, we are currently analyzing human milk and urine samples from our cohort of mastitis-suffering women, as well as the healthy controls, in order to try to identify biomarkers of the disease. To do so, we will investigate cells populations, immunoglobulins, hormones, macronutrients and metabolomics profiles that could result in a diagnostic test, which could prove of great value for a correct diagnosis and/or treatment of sub-acute mastitis in the lactating mother. 


\section{Main conclusions}

In the light of the results obtained in the present thesis, we can conclude that:

1) Several culture-independent methodologies indicate that there is a specific bacterial composition of human milk samples from Spanish healthy mothers throughout lactation, dominated mainly by Staphylococcus, Pseudomonas, Streptococcus, and Acinetobacter.

2) The total bacterial load in human milk samples from healthy Spanish mothers is around $10^{6}$ bacterial cells $/ \mathrm{ml}$, as estimated by qPCR analysis using universal primers for the single-copy gene fus $A$. Thus, a lactating infant feeding $800 \mathrm{ml}$ of human milk would ingest $10^{7}-10^{8}$ bacterial cells daily.

3) Human milk bacteria can be detected both in a free-living, "planktonic" state and associated to human immune cells. Future studies should evaluate if this association to human cells could represent a transport method to the mammary gland from other maternal body sites.

4) Specific bacteria in human milk were associated to some milk macronutrients while no association was found with somatic cells, supporting the idea that milk bacteria are not sensed as an infection by the maternal immune system.

5) Yeasts and other fungi were detected in human milk from healthy donors throughout lactation, by culture-dependent and independent methods. Using qPCR targeted at the ITS1 region, the total fungal load was estimated in approximately $10^{5}$ cells $/ \mathrm{ml}$. Malassezia, Candida and Saccharomyces were the most prevalent genera detected by NGS, while Candida parapsilosis and Rhodotorula mucilaginosa were the most frequently isolated species.

6) As described in milk bacteria, we demonstrated that the presence of a "milk mycobiota" is ubiquitous around the globe in healthy mothers, and factors such as mode of delivery and geographic location shape its composition.

7) Total bacterial load significantly increases during the course of sub-acute mastitis and decreases to normal levels after cessation of the symptoms. Active load after symptoms' cessation is higher than that of healthy controls and subacute mastitis during the course of the symptoms. Bacterial diversity decreased at the DNA and RNA level during the course of mastitis, and was not recovered to control levels after the symptoms had disappeared. Richness also decreased significantly during the disease, but only at the DNA level, and increased after symptoms had disappeared, both at DNA and RNA level. This reduction in bacterial diversity and richness could reflect a dysbiosis in the milk environment during sub-acute mastitis. The incomplete recovery in bacterial 
diversity, composition and activity after cessation of clinical symptoms indicate that SAM remission precedes full re-balance of the bacterial community.

8) There was a high variability in bacterial composition between healthy mothers and mothers suffering lactational mastitis. This suggests that mastitis, and especially the sub-acute version, is a complex and polymicrobial disease, which appears to be caused by a microbial dysbiosis rather than by one or a few specific infectious bacteria. 


\section{References}

Aagaard K, Ma J, Antony KM, Ganu R, Petrosino J, Versalovic J. 2014. The placenta harbors a unique microbiome. Sci. Transl. Med. 6(237):237ra65

Ahn J, Sinha R, Pei Z, Dominianni C, Wu J, et al. 2013. Human Gut Microbiome and Risk for Colorectal Cancer. JNCI J. Natl. Cancer Inst. 105(24):1907-11

Akkerman R, Faas MM, de Vos P. 2018. Non-digestible carbohydrates in infant formula as substitution for human milk oligosaccharide functions: Effects on microbiota and gut maturation. Crit. Rev. Food Sci. Nutr. $1-12$

Akobeng AK, Ramanan A V, Buchan I, Heller RF. 2005. Effect of breast feeding on risk of coeliac disease: a systematic review and meta-analysis of observational studies. Arch. Dis. Child. 91(1):39-43

Al-Kerwi EAA, Al-Hashimi AH, Salman AM. 2005. Mother's milk and hydrogen peroxide. Asia Pac. J. Clin. Nutr. 14(4):428-31

Albanese D, Riccadonna S, Donati C, Franceschi P. 2017. A practical tool for Maximal Information Coefficient analysis. bioRxiv. 215855

Allali I, Arnold JW, Roach J, Cadenas MB, Butz N, et al. 2017. A comparison of sequencing platforms and bioinformatics pipelines for compositional analysis of the gut microbiome. BMC Microbiol. 17(1):194

Allan Walker W, Shuba Iyengar R. 2014. Breast milk, microbiota, and intestinal immune homeostasis. Pediatr. Res. 77(1):220-28

Altschul SF, Gish W, Miller W, Myers EW, Lipman DJ. 1990. Basic local alignment search tool. J. Mol. Biol. 215(3):403-10

Amann RI, Binder BJ, Olson RJ, Chisholm SW, Devereux R, Stahl DA. 1990. Combination of 16S rRNAtargeted oligonucleotide probes with flow cytometry for analyzing mixed microbial populations. Appl. Environ. Microbiol. 56(6):1919-25

American Academy of Pediatrics. 2012. Breastfeeding and the Use of Human Milk. Pediatrics. 129(3):e82741

Amir LH, Academy of Breastfeeding Medicine Protocol Committee. 2014. ABM Clinical Protocol \#4: Mastitis, Revised March 2014. Breastfeed. Med. 9(5):239-43

Amir LH, Donath SM, Garland SM, Tabrizi SN, Bennett CM, et al. 2013. Does Candida and/or Staphylococcus play a role in nipple and breast pain in lactation? A cohort study in Melbourne, Australia. BMJ Open. 3(3):e002351

Amir LH, Garland SM, Dennerstein L, Farish SJ. 1996. Candida albicans: is it associated with nipple pain in lactating women? Gynecol. Obstet. Invest. 41(1):30-34

Amir LH, Griffin L, Cullinane M, Garland SM. 2016. Probiotics and mastitis: evidence-based marketing? Int. Breastfeed. J. 11:19

Angelopoulou A, Field D, Ryan CA, Stanton C, Hill C, Ross RP. 2018. The microbiology and treatment of human mastitis. Med. Microbiol. Immunol. 207(2):83-94

Arrieta M-C, Arévalo A, Stiemsma L, Dimitriu P, Chico ME, et al. 2017. Associations between infant fungal and bacterial dysbiosis and childhood atopic wheeze in a nonindustrialized setting. J. Allergy Clin. Immunol.

Arroyo R, Martín V, Maldonado A, Jiménez E, Fernández L, Rodríguez JM. 2010. Treatment of Infectious Mastitis during Lactation: Antibiotics versus Oral Administration of Lactobacilli Isolated from Breast Milk. 
Clin. Infect. Dis. 50(12):1551-58

Baeza C. 2016. Acute, Subclinical, and Subacute Mastitis. Clin. Lact. 7(1):7-10

Ballard O, Morrow AL. 2013. Human milk composition: nutrients and bioactive factors. Pediatr. Clin. North Am. 60(1):49-74

Barbosa JO, Rossoni RD, Vilela SFG, de Alvarenga JA, Velloso M dos S, et al. 2016. Streptococcus mutans Can Modulate Biofilm Formation and Attenuate the Virulence of Candida albicans. PLoS One. 11(3):e0150457

Bates CJ, Prentice A. 1994. Breast milk as a source of vitamins, essential minerals and trace elements. Pharmacol. Ther. 62(1-2):193-220

Bearfield C, Davenport ES, Sivapathasundaram V, Allaker RP. 2002. Possible association between amniotic fluid micro-organism infection and microflora in the mouth. BJOG An Int. J. Obstet. Gynaecol. 109(5):527-33

Beasley SS, Saris PEJ. 2004. Nisin-producing Lactococcus lactis strains isolated from human milk. Appl. Environ. Microbiol. 70(8):5051-53

Beaudry M, Dufour R, Marcoux S. 1995. Relation between infant feeding and infections during the first six months of life. J. Pediatr. 126(2):191-97

Benítez-Páez A, Álvarez M, Belda-Ferre P, Rubido S, Mira A, Tomás I. 2013. Detection of transient bacteraemia following dental extractions by $16 \mathrm{~S}$ rDNA pyrosequencing: a pilot study. PLoS One. 8(3):e57782

Berens P, Eglash A, Malloy M, Steube AM. 2016. ABM Clinical Protocol \#26: Persistent Pain with Breastfeeding. Breastfeed. Med. 11(2):46-53

Berens PD. 2015. Breast Pain: Engorgement, Nipple Pain, and Mastitis. Clin. Obstet. Gynecol. 58(4):902-14

Bergan T. 2001. Antibiotic usage in Nordic countries. Int. J. Antimicrob. Agents. 18(3):279-82

Biesbroek G, Bosch AATM, Wang X, Keijser BJF, Veenhoven RH, et al. 2014. The Impact of Breastfeeding on Nasopharyngeal Microbial Communities in Infants. Am. J. Respir. Crit. Care Med. 190(3):140612135546007

Biesbroek G, Sanders EAM, Roeselers G, Wang X, Caspers MPM, et al. 2012. Deep Sequencing Analyses of Low Density Microbial Communities: Working at the Boundary of Accurate Microbiota Detection. PLoS One. 7(3):e32942

Bliss JM, Basavegowda KP, Watson WJ, Sheikh AU, Ryan RM. 2008. Vertical and Horizontal Transmission of Candida albicans in Very Low Birth Weight Infants Using DNA Fingerprinting Techniques. Pediatr. Infect. Dis. J. 27(3):231-35

Bode L. 2012. Human milk oligosaccharides: Every baby needs a sugar mama. Glycobiology. 22(9):1147-62

Boix-Amorós A, Collado MC, Mira A. 2016. Relationship between Milk Microbiota, Bacterial Load, Macronutrients, and Human Cells during Lactation. Front. Microbiol. 7:492

Boix-Amorós A, Collado MC, Van't Land B, Calvert A, Le Doare K, et al. 2019a. Reviewing the evidence on breast milk composition and immunological outcomes. Nutr. Rev.

Boix-Amorós A, Martinez-Costa C, Querol A, Collado MC, Mira A. 2017. Multiple Approaches Detect the Presence of Fungi in Human Breastmilk Samples from Healthy Mothers. Sci. Rep. 7(1):13016

Boix-Amorós A, Puente-Sánchez F, du Toit E, Linderborg KM, Zhang Y, et al. 2019b. Mycobiome Profiles in Breast Milk from Healthy Women Depend on Mode of Delivery, Geographic Location, and Interaction with Bacteria. Appl. Environ. Microbiol. 85(9):

Braun-Fahrländer C, Von Mutius E. 2011. Can farm milk consumption prevent allergic diseases? Clin. Exp. 
Allergy. 41(1):29-35

Breuer U, Harms H. 2006. Debaryomyces hansenii - an extremophilic yeast with biotechnological potential. Yeast. 23(6):415-37

Bryan D-L, Hart PH, Forsyth KD, Gibson RA. 2007. Immunomodulatory constituents of human milk change in response to infant bronchiolitis. Pediatr. Allergy Immunol. 18(6):495-502

Cabrera-Rubio R, Collado MC, Laitinen K, Salminen S, Isolauri E, Mira A. 2012a. The human milk microbiome changes over lactation and is shaped by maternal weight and mode of delivery. Am J Clin Nutr. 96:544-51

Cabrera-Rubio R, Garcia-Nunez M, Seto L, Anto JM, Moya A, et al. 2012b. Microbiome Diversity in the Bronchial Tracts of Patients with Chronic Obstructive Pulmonary Disease. J. Clin. Microbiol. 50(11):3562-68

Cabrera-Rubio R, Mira-Pascual L, Mira A, Collado MC. 2016. Impact of mode of delivery on the milk microbiota composition of healthy women. J. Dev. Orig. Health Dis. 7(01):54-60

Callon C, Delbès C, Duthoit F, Montel M-C. 2006. Application of SSCP-PCR fingerprinting to profile the yeast community in raw milk Salers cheeses. Syst. Appl. Microbiol. 29(2):172-80

Callon C, Duthoit F, Delbès C, Ferrand M, Le Frileux Y, et al. 2007. Stability of microbial communities in goat milk during a lactation year: Molecular approaches. Syst. Appl. Microbiol. 30(7):547-60

Carroll L, Osman M, Davies DP, McNeish AS. 1979. Bacteriology of raw breast milk. Lancet (London, England). 2(8153):1186

Cephas KD, Kim J, Mathai RA, Barry KA, Dowd SE, et al. 2011. Comparative Analysis of Salivary Bacterial Microbiome Diversity in Edentulous Infants and Their Mothers or Primary Care Givers Using Pyrosequencing. PLoS One. 6(8):e23503

Chan D, Goruk S, Becker AB, Subbarao P, Mandhane PJ, et al. 2018. Adiponectin, leptin and insulin in breast milk: associations with maternal characteristics and infant body composition in the first year of life. Int. J. Obes. 42(1):36-43

Chehoud C, Albenberg LG, Judge C, Hoffmann C, Grunberg S, et al. 2015. Fungal Signature in the Gut Microbiota of Pediatric Patients With Inflammatory Bowel Disease. Inflamm. Bowel Dis. 21(8):1948-56

Chen YE, Fischbach MA, Belkaid Y. 2018. Skin microbiota-host interactions. Nature. 553(7689):427-36

Chervonsky A V. 2010. Influence of microbial environment on autoimmunity. Nat. Immunol. 11(1):28-35

Cieslak M, Ferreira CHF, Shifrin Y, Pan J, Belik J. 2018. Human milk H2O2 content: does it benefit preterm infants? Pediatr. Res. 83(3):687-92

Clooney AG, Fouhy F, Sleator RD, O' Driscoll A, Stanton C, et al. 2016. Comparing Apples and Oranges?: Next Generation Sequencing and Its Impact on Microbiome Analysis. PLoS One. 11(2):e0148028

Cocolin L, Aggio D, Manzano M, Cantoni C, Comi G. 2002. An application of PCR-DGGE analysis to profile the yeast populations in raw milk. Int. Dairy J. 12(5):407-11

Cole JR, Wang Q, Cardenas E, Fish J, Chai B, et al. 2009. The Ribosomal Database Project: improved alignments and new tools for rRNA analysis. Nucleic Acids Res. 37(Database):D141-45

Cole JR, Wang Q, Fish JA, Chai B, McGarrell DM, et al. 2014. Ribosomal Database Project: data and tools for high throughput rRNA analysis. Nucleic Acids Res. 42(D1):D633-42

Collado MC, Delgado S, Maldonado A, Rodríguez JM. 2009. Assessment of the bacterial diversity of breast milk of healthy women by quantitative real-time PCR. Lett. Appl. Microbiol. 48(5):523-28 
Contreras GA, Rodríguez JM. 2011. Mastitis: Comparative etiology and epidemiology. J. Mammary Gland Biol. Neoplasia. 16(4):339-56

Coppa G V, Gabrielli O, Pierani P, Catassi C, Carlucci A, Giorgi PL. 1993. Changes in carbohydrate composition in human milk over 4 months of lactation. Pediatrics. 91(3):637-41

Coppa G V, Zampini L, Galeazzi T, Facinelli B, Ferrante L, et al. 2006. Human Milk Oligosaccharides Inhibit the Adhesion to Caco-2 Cells of Diarrheal Pathogens: Escherichia coli, Vibrio cholerae, and Salmonella fyris. Pediatr. Res. 59(3):377-82

Corbo MR, Lanciotti R, Albenzio M, Sinigaglia M. 2001. Occurrence and characterization of yeasts isolated from milks and dairy products of Apulia region. Int. J. Food Microbiol. 69(1-2):147-52

Costantini L, Magno S, Albanese D, Donati C, Molinari R, et al. 2018. Characterization of human breast tissue microbiota from core needle biopsies through the analysis of multi hypervariable 16S-rRNA gene regions. Sci. Rep. 8(1):16893

Cregan MD, Fan Y, Appelbee A, Brown ML, Klopcic B, et al. 2007. Identification of nestin-positive putative mammary stem cells in human breastmilk. Cell Tissue Res. 329(1):129-36

Cui L, Morris A, Ghedin E. 2013. The human mycobiome in health and disease. Genome Med. 5(7):63

Das UN. 2007. Breastfeeding prevents type 2 diabetes mellitus: but, how and why? Am. J. Clin. Nutr. 85(5):1436-37

David LA, Maurice CF, Carmody RN, Gootenberg DB, Button JE, et al. 2014. Diet rapidly and reproducibly alters the human gut microbiome. Nature. 505(7484):559-63

de Andrés J, Jiménez E, Chico-Calero I, Fresno M, Fernández L, Rodríguez JM. 2017. Physiological Translocation of Lactic Acid Bacteria during Pregnancy Contributes to the Composition of the Milk Microbiota in Mice. Nutrients. 10(1):

De Filippo C, Cavalieri D, Di Paola M, Ramazzotti M, Poullet JB, et al. 2010. Impact of diet in shaping gut microbiota revealed by a comparative study in children from Europe and rural Africa. Proc. Natl. Acad. Sci. U. S. A. 107(33):14691-96

de Llanos R, Querol A, Pemán J, Gobernado M, Fernandez-Espinar MT. 2006. Food and probiotic strains from the Saccharomyces cerevisiae species as a possible origin of human systemic infections. Int. J. Food Microbiol. 110(3):286-90

de Llanos R, Querol A, Planes AM, Fernandez-Espinar MT. 2004. Molecular Characterization of Clinical Saccharomyces cerevisiae Isolates and their Association with Non-Clinical Strains. Syst. Appl. Microbiol. 27(4):427-35

De Llanos R, Llopis S, Molero G, Querol A, Gil C, Fernandez-Espinar MT. 2011. In vivo virulence of commercial Saccharomyces cerevisiae strains with pathogenicity-associated phenotypical traits. Int. J. Food Microbiol. 144(3):393-99

Delavenne E, Mounier J, Asmani K, Jany J-L, Barbier G, Le Blay G. 2011. Fungal diversity in cow, goat and ewe milk. Int. J. Food Microbiol. 151:247-51

Delgado S, Arroyo R, Martín R, Rodríguez JM. 2008. PCR-DGGE assessment of the bacterial diversity of breast milk in women with lactational infectious mastitis. BMC Infect. Dis. 8(1):51

Delgado S, García P, Fernández L, Jiménez E, Rodríguez-Baños M, et al. 2011. Characterization of Staphylococcus aureus strains involved in human and bovine mastitis. FEMS Immunol. Med. Microbiol. 62(2):225-35

Demirel G, Erdeve O, Celik IH, Dilmen U. 2013. Saccharomyces boulardii for prevention of necrotizing 
enterocolitis in preterm infants: a randomized, controlled study. Acta Paediatr. 102(12):e560-65

Díaz-Ropero MP, Martín R, Sierra S, Lara-Villoslada F, Rodríguez JM, et al. 2007. Two Lactobacillus strains, isolated from breast milk, differently modulate the immune response. J. Appl. Microbiol. 102(2):337-43

Diezmann S, Dietrich FS. 2011. Oxidative stress survival in a clinical Saccharomyces cerevisiae isolate is influenced by a major quantitative trait nucleotide. Genetics. 188(3):709-22

Doherty AM, Lodge CJ, Dharmage SC, Dai X, Bode L, Lowe AJ. 2018. Human Milk Oligosaccharides and Associations With Immune-Mediated Disease and Infection in Childhood: A Systematic Review. Front. Pediatr. 6:91

Donnet-Hughes A, Perez PF, Doré J, Leclerc M, Levenez F, et al. 2010. Potential role of the intestinal microbiota of the mother in neonatal immune education. Proc. Nutr. Soc. 69(03):407-15

Drago L, Toscano M, De Grandi R, Grossi E, Padovani EM, Peroni DG. 2017. Microbiota network and mathematic microbe mutualism in colostrum and mature milk collected in two different geographic areas: Italy versus Burundi. ISME J. 11(4):875-84

Drell T, Lillsaar T, Tummeleht L, Simm J, Aaspõllu A, et al. 2013. Characterization of the Vaginal Micro- and Mycobiome in Asymptomatic Reproductive-Age Estonian Women. PLoS One. 8(1):e54379

Drell T, Štšepetova J, Simm J, Rull K, Aleksejeva A, et al. 2017. The Influence of Different Maternal Microbial Communities on the Development of Infant Gut and Oral Microbiota. Sci. Rep. 7(1):9940

Dundar NO, Anal O, Dundar B, Ozkan H, Caliskan S, Büyükgebiz A. 2005. Longitudinal investigation of the relationship between breast milk leptin levels and growth in breast-fed infants. J. Pediatr. Endocrinol. Metab. 18(2):181-87

Dupuy AK, David MS, Li L, Heider TN, Peterson JD, et al. 2014. Redefining the human oral mycobiome with improved practices in amplicon-based taxonomy: discovery of Malassezia as a prominent commensal. PLoS One. 9(3):e90899

Dvorak B, Fituch CC, Williams CS, Hurst NM, Schanler RJ. 2003. Increased Epidermal Growth Factor Levels in Human Milk of Mothers with Extremely Premature Infants. Pediatr. Res. 54(1):15-19

Dvorak B, Halpern MD, Holubec H, Williams CS, McWilliam DL, et al. 2002. Epidermal growth factor reduces the development of necrotizing enterocolitis in a neonatal rat model. Am. J. Physiol. Liver Physiol. 282(1):G156-64

Dzidic M, Boix-Amorós A, Selma-Royo M, Mira A, Collado M. 2018a. Gut Microbiota and Mucosal Immunity in the Neonate. Med. Sci. 6(3):56

Dzidic M, Collado MC, Abrahamsson T, Artacho A, Stensson M, et al. 2018b. Oral microbiome development during childhood: an ecological succession influenced by postnatal factors and associated with tooth decay. ISME J. 12(9):2292-2306

Edgar RC. 2004. MUSCLE: multiple sequence alignment with high accuracy and high throughput. Nucleic Acids Res. 32(5):1792-97

Edgar RC, Haas BJ, Clemente JC, Quince C, Knight R. 2011. UCHIME improves sensitivity and speed of chimera detection. Bioinformatics. 27(16):2194-2200

Eidelman AI, Szilagyi G. 1979. Patterns of bacterial colonization of human milk. Obstet. Gynecol. 53(5):55052

Ellison RT, Giehl TJ, Giehl TJ. 1991. Killing of gram-negative bacteria by lactoferrin and lysozyme. J. Clin. Invest. 88(4):1080-91 
Espinosa-Martos I, Jiménez E, de Andrés J, Rodríguez-Alcalá LM, Tavárez S, et al. 2016. Milk and blood biomarkers associated to the clinical efficacy of a probiotic for the treatment of infectious mastitis. Benef. Microbes. 7(3):305-18

Faria AMC, Weiner HL. 2006. Oral tolerance and TGF-beta-producing cells. Inflamm. Allergy Drug Targets. 5(3):179-90

Fernandes KE, Carter DA. 2017. The Antifungal Activity of Lactoferrin and Its Derived Peptides: Mechanisms of Action and Synergy with Drugs against Fungal Pathogens. Front. Microbiol. 8:2

Fernández L, Arroyo R, Espinosa I, Marín M, Jiménez E, Rodríguez JM. 2014. Probiotics for human lactational mastitis. Benef. Microbes. 5(2):169-83

Fernández L, Cárdenas N, Arroyo R, Manzano S, Jiménez E, et al. 2016. Prevention of Infectious Mastitis by Oral Administration of Lactobacillus salivarius PS2 During Late Pregnancy. Clin. Infect. Dis. 62(5):568-73

Fernández L, Langa S, Martín V, Maldonado A, Jiménez E, et al. 2013. The human milk microbiota: Origin and potential roles in health and disease. Pharmacol. Res. 69:1-10

Findley K, Oh J, Yang J, Conlan S, Deming C, et al. 2013. Topographic diversity of fungal and bacterial communities in human skin. Nature. 498(7454):367-70

Fish JA, Chai B, Wang Q, Sun Y, Brown CT, et al. 2013. FunGene: the functional gene pipeline and repository. Front. Microbiol. 4:291

Fishaut M, Murphy D, Neifert M, McIntosh K, Ogra PL. 1981. Bronchomammary axis in the immune response to respiratory syncytial virus. J. Pediatr. 99(2):186-91

Fitzstevens JL, Smith KC, Hagadorn JI, Caimano MJ, Matson AP, Brownell EA. 2016. Systematic Review of the Human Milk Microbiota. Nutr. Clin. Pract.

Francino MP. 2018. Birth Mode-Related Differences in Gut Microbiota Colonization and Immune System Development. Ann. Nutr. Metab. 73(3):12-16

Friedman-Korn T, Livovsky DM, Maharshak N, Aviv Cohen N, Paz K, et al. 2018. Fecal Transplantation for Treatment of Clostridium Difficile Infection in Elderly and Debilitated Patients. Dig. Dis. Sci. 63(1):198-203

Fujimura KE, Sitarik AR, Havstad S, Lin DL, Levan S, et al. 2016. Neonatal gut microbiota associates with childhood multisensitized atopy and T cell differentiation. Nat. Med. 22(10):1187-91

Gabrielli E, Pericolini E, Ballet N, Roselletti E, Sabbatini S, et al. 2018. Saccharomyces cerevisiae -based probiotic as novel anti-fungal and anti-inflammatory agent for therapy of vaginal candidiasis. Benef. Microbes. 9(2):219-30

García-Tejedor A, Gimeno-Alcañíz J V., Tavárez S, Alonso E, Salom JB, Manzanares P. 2015. An antihypertensive lactoferrin hydrolysate inhibits angiotensin I-converting enzyme, modifies expression of hypertension-related genes and enhances nitric oxide production in cultured human endothelial cells. J. Funct. Foods. 12:45-54

Garofalo R. 2010. Cytokines in Human Milk. J. Pediatr. 156(2):S36-40

Garwolińska D, Namieśnik J, Kot-Wasik A, Hewelt-Belka W. 2018. Chemistry of Human Breast Milk-A Comprehensive Review of the Composition and Role of Milk Metabolites in Child Development. J. Agric. Food Chem. 66(45):11881-96

Gaulke CA, Sharpton TJ. 2018. The influence of ethnicity and geography on human gut microbiome composition. Nat. Med. 24(10):1495-96

Gay M, Koleva P, Slupsky C, Toit E, Eggesbo M, et al. 2018. Worldwide Variation in Human Milk 
Metabolome: Indicators of Breast Physiology and Maternal Lifestyle? Nutrients. 10(9):1151

Geirnaert A, Calatayud M, Grootaert C, Laukens D, Devriese S, et al. 2017. Butyrate-producing bacteria supplemented in vitro to Crohn's disease patient microbiota increased butyrate production and enhanced intestinal epithelial barrier integrity. Sci. Rep. 7(1):1-14

Ghannoum MA, Mukherjee PK. 2013. The human mycobiome and its impact on health and disease. Curr. Fungal Infect. Rep. 7(4):345-50

Gloor GB, Macklaim JM, Pawlowsky-Glahn V, Egozcue JJ. 2017. Microbiome Datasets Are Compositional: And This Is Not Optional. Front. Microbiol. 8:2224

Goldman AS. 1993. The immune system of human milk: antimicrobial, antiinflammatory and immunomodulating properties. Pediatr. Infect. Dis. J. 12(8):664-71

Goldman AS, Garza C, Nichols BL, Goldblum RM. 1982. Immunologic factors in human milk during the first year of lactation. J. Pediatr. 100(4):563-67

Gómez-Gallego C, Morales JM, Monleón D, du Toit E, Kumar H, et al. 2018. Human Breast Milk NMR Metabolomic Profile across Specific Geographical Locations and Its Association with the Milk Microbiota. Nutrients. 10(10):

González R, Mandomando I, Fumadó V, Sacoor C, Macete E, et al. 2013. Breast Milk and Gut Microbiota in African Mothers and Infants from an Area of High HIV Prevalence. PLoS One. 8(11):e80299

Gosalbes MJ, Llop S, Vallès Y, Moya A, Ballester F, Francino MP. 2013. Meconium microbiota types dominated by lactic acid or enteric bacteria are differentially associated with maternal eczema and respiratory problems in infants. Clin. Exp. Allergy. 43(2):198-211

Gouba N, Raoult D, Drancourt M. 2013. Plant and Fungal Diversity in Gut Microbiota as Revealed by Molecular and Culture Investigations. PLoS One. 8(3):e59474

Greenslade L. 2018. Breast Milk, Global Health and Sustainable Development. In Breastfeeding and Breast Milk- from Biochemistry to Impact. Family Larsson-Rosenquist Foundation

Greer FR. 2001. Do breastfed infants need supplemental vitamins? Pediatr. Clin. North Am. 48(2):415-23

Grice EA, Kong HH, Conlan S, Deming CB, Davis J, et al. 2009. Topographical and temporal diversity of the human skin microbiome. Science. 324(5931):1190-92

Grice EA, Segre JA. 2011. The skin microbiome. Nat. Rev. Microbiol. 9(4):244-53

Grönlund M-M, Gueimonde M, Laitinen K, Kociubinski G, Grönroos T, et al. 2007. Maternal breast-milk and intestinal bifidobacteria guide the compositional development of the Bifidobacterium microbiota in infants at risk of allergic disease. Clin. Exp. Allergy. 37(12):1764-72

Gross SJ, Buckley RH, Wakil SS, McAllister DC, David RJ, Faix RG. 1981. Elevated IgA concentration in milk produced by mothers delivered of preterm infants. J. Pediatr. 99(3):389-93

Grulee CG, Sanford HN, Herron PH. 1934. Breast and artificial feeding: influence on morbidity and mortality of twenty thousand infants. J. Am. Med. Assoc. 103(10):735

Guého E, Midgley G, Guillot J. 1996. The genus Malassezia with description of four new species. Antonie Van Leeuwenhoek. 69(4):337-55

Gueimonde M, Laitinen K, Salminen S, Isolauri E. 2007. Breast Milk: A Source of Bifidobacteria for Infant Gut Development and Maturation? Neonatology. 92(1):64-66

Hagi T, Sasaki K, Aso H, Nomura M. 2013. Adhesive properties of predominant bacteria in raw cow's milk 
to bovine mammary gland epithelial cells. Folia Microbiol. (Praha). 58(6):515-22

Halpern MD, Dominguez JA, Dvorakova K, Holubec H, Williams CS, et al. 2003. Ileal cytokine dysregulation in experimental necrotizing enterocolitis is reduced by epidermal growth factor. J. Pediatr. Gastroenterol. Nutr. 36(1):126-33

Hanson LA. 1961. Comparative immunological studies of the immune globulins of human milk and of blood serum. Int. Arch. Allergy Appl. Immunol. 18:241-67

Harriott MM, Noverr MC. 2009. Candida albicans and Staphylococcus aureus form polymicrobial biofilms: Effects on antimicrobial resistance. Antimicrob. Agents Chemother. 53(9):3914-22

Hassiotou F, Beltran A, Chetwynd E, Stuebe AM, Twigger A-J, et al. 2012. Breastmilk Is a Novel Source of Stem Cells with Multilineage Differentiation Potential. Stem Cells. 30(10):2164-74

Hassiotou F, Geddes DT, Hartmann PE. 2013a. Cells in Human Milk. J. Hum. Lact. 29(2):171-82

Hassiotou F, Hepworth AR, Metzger P, Tat Lai C, Trengove N, et al. 2013b. Maternal and infant infections stimulate a rapid leukocyte response in breastmilk. Clin. Transl. Immunol. 2(4):e3

Hatoum R, Labrie S, Fliss I. 2012. Antimicrobial and Probiotic Properties of Yeasts: From Fundamental to Novel Applications. Front. Microbiol. 3:421

Håversen L, Ohlsson BG, Hahn-Zoric M, Hanson LA, Mattsby-Baltzer I. 2002. Lactoferrin down-regulates the LPS-induced cytokine production in monocytic cells via NF-kappa B. Cell. Immunol. 220(2):83-95

He Y, Lawlor NT, Newburg DS. 2016. Human Milk Components Modulate Toll-Like Receptor-Mediated Inflammation. Adv. Nutr. 7(1):102

Heikkila MP, Saris PEJ. 2003. Inhibition of Staphylococcus aureus by the commensal bacteria of human milk. J. Appl. Microbiol. 95(3):471-78

Heisel T, Podgorski H, Staley CM, Knights D, Sadowsky MJ, Gale CA. 2015. Complementary AmpliconBased Genomic Approaches for the Study of Fungal Communities in Humans. PLoS One. 10(2):e0116705

Hernell O, Ward H, Bläckberg L, Pereira ME. 1986. Killing of Giardia lamblia by human milk lipases: an effect mediated by lipolysis of milk lipids. J. Infect. Dis. 153(4):715-20

Hieken TJ, Chen J, Hoskin TL, Walther-Antonio M, Johnson S, et al. 2016. The Microbiome of Aseptically Collected Human Breast Tissue in Benign and Malignant Disease. Sci. Rep. 6(1):30751

Ho JCS, Nadeem A, Svanborg C. 2017. HAMLET - A protein-lipid complex with broad tumoricidal activity. Biochem. Biophys. Res. Commun. 482(3):454-58

Hoashi M, Meche L, Mahal LK, Bakacs E, Nardella D, et al. 2016. Human Milk Bacterial and Glycosylation Patterns Differ by Delivery Mode. Reprod. Sci. 23(7):902-7

Hoffmann C, Dollive S, Grunberg S, Chen J, Li H, et al. 2013. Archaea and fungi of the human gut microbiome: correlations with diet and bacterial residents. PLoS One. 8(6):e66019

Houghteling PD, Walker WA. 2015. Why is initial bacterial colonization of the intestine important to infants' and children's health? J. Pediatr. Gastroenterol. Nutr. 60(3):294-307

Human Microbiome Project Consortium. 2012. Structure, function and diversity of the healthy human microbiome. Nature. 486(7402):207-14

Hunt KM, Foster JA, Forney LJ, Schütte UME, Beck DL, et al. 2011. Characterization of the Diversity and Temporal Stability of Bacterial Communities in Human Milk. PLoS One. 6(6):e21313 
International Food Policy Research Institute. 2015. Global Nutrition Report 2015: Actions and accountability to advance nutrition and sustainable development. Washington DC

Isaacs EB, Fischl BR, Quinn BT, Chong WK, Gadian DG, Lucas A. 2010. Impact of breast milk on intelligence quotient, brain size, and white matter development. Pediatr. Res. 67(4):357-62

Jabra-Rizk MA, Ferreira SMS, Sabet M, Falkler WA, Merz WG, Meiller TF. 2001. Recovery of Candida dubliniensis and Other Yeasts from Human Immunodeficiency Virus-Associated Periodontal Lesions. J. Clin. Microbiol. 39(12):4520-22

Jeurink PV, van Bergenhenegouwen J, Jiménez E, Knippels LMJ, Fernández L, et al. 2013. Human milk: a source of more life than we imagine. Benef. Microbes. 4(1):17-30

Jiménez E, de Andrés J, Manrique M, Pareja-Tobes P, Tobes R, et al. 2015. Metagenomic Analysis of Milk of Healthy and Mastitis-Suffering Women. J. Hum. Lact. 31(3):406-15

Jiménez E, Fernández L, Maldonado A, Martín R, Olivares M, et al. 2008. Oral administration of Lactobacillus strains isolated from breast milk as an alternative for the treatment of infectious mastitis during lactation. Appl. Environ. Microbiol. 74(15):4650-55

Jiménez E, Fernández L, Marín ML, Martín R, Odriozola JM, et al. 2005. Isolation of Commensal Bacteria from Umbilical Cord Blood of Healthy Neonates Born by Cesarean Section. Curr. Microbiol. 51(4):270-74

Jo J-H, Deming C, Kennedy EA, Conlan S, Polley EC, et al. 2016. Diverse Human Skin Fungal Communities in Children Converge in Adulthood. J. Invest. Dermatol. 136(12):2356-63

Jones G, Steketee RW, Black RE, Bhutta ZA, Morris SS. 2003. How many child deaths can we prevent this year? Lancet. 362(9377):65-71

Jost T, Lacroix C, Braegger C, Chassard C. 2013. Assessment of bacterial diversity in breast milk using culture-dependent and culture-independent approaches. Br. J. Nutr. 110(07):1253-62

Jost T, Lacroix C, Braegger CP, Rochat F, Chassard C. 2014. Vertical mother-neonate transfer of maternal gut bacteria via breastfeeding. Environ. Microbiol. 16(9):2891-2904

Kamada N, Chen GY, Inohara N, Núñez G. 2013. Control of pathogens and pathobionts by the gut microbiota. Nat. Immunol. 14(7):685-90

Kao D, Roach B, Silva M, Beck P, Rioux K, et al. 2017. Effect of Oral Capsule- vs Colonoscopy-Delivered Fecal Microbiota Transplantation on Recurrent Clostridium difficile Infection. JAMA. 318(20):1985

Katoh, K. \& Standley DM. 2013. MAFFT multiple sequence alignment software version 7: improvements in performance and usability. Mol. Biol. Evol. 30(4):772-80

Khodayar-Pardo P, Mira-Pascual L, Collado MC, Martínez-Costa C. 2014. Impact of lactation stage, gestational age and mode of delivery on breast milk microbiota. J. Perinatol. 34(8):599-605

Kirjavainen P V, Apostolou E, Arvola T, Salminen SJ, Gibson GR, Isolauri E. 2001. Characterizing the composition of intestinal microflora as a prospective treatment target in infant allergic disease. FEMS Immunol. Med. Microbiol. 32(1):1-7

Kleinegger CL, Lockhart SR, Vargas K, Soll DR. 1996. Frequency, intensity, species, and strains of oral Candida vary as a function of host age. J. Clin. Microbiol. 34(9):2246-54

Kleinman RE, Walker WA. 1979. The enteromammary immune system: an important new concept in breast milk host defense. Dig. Dis. Sci. 24(11):876-82

Klindworth A, Pruesse E, Schweer T, Peplies J, Quast C, et al. 2013. Evaluation of general 16S ribosomal RNA gene PCR primers for classical and next-generation sequencing-based diversity studies. Nucleic Acids 
Res. 41(1):e1-e1

Kõljalg U, Nilsson RH, Abarenkov K, Tedersoo L, Taylor AFS, et al. 2013. Towards a unified paradigm for sequence-based identification of fungi. Mol. Ecol. 22(21):5271-77

Kramer MS, Aboud F, Mironova E, Vanilovich I, Platt RW, et al. 2008. Breastfeeding and Child Cognitive Development. Arch. Gen. Psychiatry. 65(5):578

Kraneveld EA, Buijs MJ, Bonder MJ, Visser M, Keijser BJF, et al. 2012. The Relation between Oral Candida Load and Bacterial Microbiome Profiles in Dutch Older Adults. PLoS One. 7(8):e42770

Kumar H, du Toit E, Kulkarni A, Aakko J, Linderborg KM, et al. 2016. Distinct Patterns in Human Milk Microbiota and Fatty Acid Profiles Across Specific Geographic Locations. Front. Microbiol. 7:1619

Kvist LJ, Larsson BW, Hall-Lord ML, Steen A, Schalén C. 2008. The role of bacteria in lactational mastitis and some considerations of the use of antibiotic treatment. Int. Breastfeed. J. 3:6

Kwon-Chung, K.J. Bennett JE. 1992. Saccharomyces Meyen Ex Reess. Philadelphia. Lea and Fe ed.

Labbok MH, Clark D, Goldman AS. 2004. Breastfeeding: maintaining an irreplaceable immunological resource. Nat. Rev. Immunol. 4(7):565-72

Lackey KA, Williams JE, Meehan CL, Zachek JA, Benda ED, et al. 2019. What's Normal? Microbiomes in Human Milk and Infant Feces Are Related to Each Other but Vary Geographically: The INSPIRE Study. Front. Nutr. 6:45

Laforest-Lapointe I, Arrieta M-C. 2018. Microbial Eukaryotes: a Missing Link in Gut Microbiome Studies. mSystems. 3(2):e00201-17

Langa S. 2006. Interactions Between Lactic Acid Bacteria, Intestinal Epithelial Cells and Immune Cells. Development of in vitro Models. Complutense University of Madrid

Lara-Villoslada F, Olivares M, Sierra S, Miguel Rodríguez J, Boza J, Xaus J. 2007. Beneficial effects of probiotic bacteria isolated from breast milk. Br. J. Nutr. 98(S1):S96-100

LaTuga MS, Ellis JC, Cotton CM, Goldberg RN, Wynn JL, et al. 2011. Beyond Bacteria: A Study of the Enteric Microbial Consortium in Extremely Low Birth Weight Infants. PLoS One. 6(12):e27858

Lauder AP, Roche AM, Sherrill-Mix S, Bailey A, Laughlin AL, et al. 2016. Comparison of placenta samples with contamination controls does not provide evidence for a distinct placenta microbiota. Microbiome. 4(1):29

Lawley TD, Walker AW. 2013. Intestinal colonization resistance. Immunology. 138(1):1-11

Layeghifard M, Hwang DM, Guttman DS. 2017. Disentangling Interactions in the Microbiome: A Network Perspective. Trends Microbiol. 25(3):217-28

Li N, Richoux R, Boutinaud M, Martin P, Gagnaire V. 2014. Role of somatic cells on dairy processes and products: a review. Dairy Sci. Technol. 94(6):517-38

Li Q, Wang C, Tang C, He Q, Li N, Li J. 2013. Dysbiosis of Gut Fungal Microbiota is Associated With Mucosal Inflammation in Crohn's Disease. J. Clin. Gastroenterol. 48(6):1

Li S-W, Watanabe K, Hsu C-C, Chao S-H, Yang Z-H, et al. 2017. Bacterial Composition and Diversity in Breast Milk Samples from Mothers Living in Taiwan and Mainland China. Front. Microbiol. 8:965

Li W, Godzik A. 2006. Cd-hit: A fast program for clustering and comparing large sets of protein or nucleotide sequences. Bioinformatics. 22(13):1658-59

Lim ES, Rodriguez C, Holtz LR. 2018. Amniotic fluid from healthy term pregnancies does not harbor a 
detectable microbial community. Microbiome. 6(1):87

Lima MF, Kierszenbaum F. 1985. Lactoferrin effects on phagocytic cell function. I. Increased uptake and killing of an intracellular parasite by murine macrophages and human monocytes. J. Immunol. 134(6):417683

Lin AE, Autran CA, Szyszka A, Escajadillo T, Huang M, et al. 2017. Human milk oligosaccharides inhibit growth of group B Streptococcus. J. Biol. Chem. 292(27):11243-49

Linnamaa P, Nieminen K, Koulu L, Tuomasjukka S, Kallio H, et al. 2013. Black currant seed oil supplementation of mothers enhances IFN- $\gamma$ and suppresses IL-4 production in breast milk. Pediatr. Allergy Immunol. 24(6):562-66

Liu K-L, Porras-Alfaro A, Kuske CR, Eichorst SA, Xie G. 2012. Accurate, Rapid Taxonomic Classification of Fungal Large-Subunit rRNA Genes. Appl. Environ. Microbiol. 78(5):1523-33

Lodge C, Tan D, Lau M, Dai X, Tham R, et al. 2015. Breastfeeding and asthma and allergies: a systematic review and meta-analysis. Acta Paediatr. 104(467):38-53

Lönnerdal B. 2003. Nutritional and physiologic significance of human milk proteins. Am. J. Clin. Nutr. 77(6):1537S-1543S

Lönnerdal B. 2010. Bioactive Proteins in Human Milk: Mechanisms of Action. J. Pediatr. 156(2):S26-30

López-López A, Camelo-Castillo A, Ferrer MD, Simon-Soro Á, Mira A. 2017. Health-Associated Niche Inhabitants as Oral Probiotics: The Case of Streptococcus dentisani. Front. Microbiol. 8:379

Lowe R, Shirley N, Bleackley M, Dolan S, Shafee T. 2017. Transcriptomics technologies. PLOS Comput. Biol. 13(5):e1005457

Lucas A, Cole TJ. 1990. Breast milk and neonatal necrotising enterocolitis. Lancet (London, England). 336(8730):1519-23

Lucas A, Morley R, Cole TJ, Lister G, Leeson-Payne C. 1992. Breast milk and subsequent intelligence quotient in children born preterm. Lancet (London, England). 339(8788):261-64

Lutter CK, Morrow AL. 2013. Protection, Promotion, and Support and Global Trends in Breastfeeding. Adv. Nutr. 4(2):213-19

Ma Z, Guan Q, Ye C, Zhang C, Foster JA, Forney LJ. 2015. Network analysis suggests a potentially "evil" alliance of opportunistic pathogens inhibited by a cooperative network in human milk bacterial communities. Sci. Rep. 5(2011):1-6

Macpherson AJ, Uhr T. 2004. Induction of Protective IgA by Intestinal Dendritic Cells Carrying Commensal Bacteria. Science (80-. ). 303(5664):1662-65

Magoc T, Salzberg SL. 2011. FLASH: fast length adjustment of short reads to improve genome assemblies. Bioinformatics. 27(21):2957-63

Maldonado J, Cañabate F, Sempere L, Vela F, Sánchez AR, et al. 2012. Human Milk Probiotic Lactobacillus fermentum CECT5716 Reduces the Incidence of Gastrointestinal and Upper Respiratory Tract Infections in Infants. J. Pediatr. Gastroenterol. Nutr. 54(1):55-61

Malla MA, Dubey A, Kumar A, Yadav S, Hashem A, Abd Allah EF. 2018. Exploring the Human Microbiome: The Potential Future Role of Next-Generation Sequencing in Disease Diagnosis and Treatment. Front. Immunol. 9:2868

Marcobal A, Barboza M, Froehlich JW, Block DE, German JB, et al. 2010. Consumption of human milk oligosaccharides by gut-related microbes. J. Agric. Food Chem. 58(9):5334-40 
Marín M, Arroyo R, Espinosa-Martos I, Fernández L, Rodríguez JM. 2017. Identification of Emerging Human Mastitis Pathogens by MALDI-TOF and Assessment of Their Antibiotic Resistance Patterns. Front. Microbiol. 8:1258

Martín R, Heilig HGHJ, Zoetendal EG, Jiménez E, Fernández L, et al. 2007. Cultivation-independent assessment of the bacterial diversity of breast milk among healthy women. Res. Microbiol. 158(1):31-37

Martín R, Jiménez E, Heilig H, Fernández L, Marín ML, et al. 2009. Isolation of bifidobacteria from breast milk and assessment of the bifidobacterial population by PCR-denaturing gradient gel electrophoresis and quantitative real-time PCR. Appl. Environ. Microbiol. 75(4):965-69

Martín R, Langa S, Reviriego C, Jiménez E, Marín ML, et al. 2004. The commensal microflora of human milk: New perspectives for food bacteriotherapy and probiotics. Trends Food Sci. Technol. 15(3-4):121-27

Martín R, Langa S, Reviriego C, Jimínez E, Marín ML, et al. 2003. Human milk is a source of lactic acid bacteria for the infant gut. J. Pediatr. 143(6):754-58

Martin V, Manes-Lazaro R, Rodriguez JM, Maldonado-Barragan A. 2011. Streptococcus lactarius sp. nov., isolated from breast milk of healthy women. Int. J. Syst. Evol. Microbiol. 61(5):1048-52

Martín V, Maldonado-Barragán A, Moles L, Rodriguez-Baños M, Campo R del, et al. 2012. Sharing of Bacterial Strains Between Breast Milk and Infant Feces. J. Hum. Lact. 28(1):36-44

Martín V, Maldonado A, Fernández L, Rodríguez JM, Connor RI. 2010. Inhibition of human immunodeficiency virus type 1 by lactic acid bacteria from human breastmilk. Breastfeed. Med. 5(4):153-58

Martín V, Mediano P, del Campo R, Rodríguez JM, Marín M. 2016. Streptococcal Diversity of Human Milk and Comparison of Different Methods for the Taxonomic Identification of Streptococci. J. Hum. Lact. 32(4):NP84-94

Mason KL, Erb Downward JR, Mason KD, Falkowski NR, Eaton KA, et al. 2012. Candida albicans and Bacterial Microbiota Interactions in the Cecum during Recolonization following Broad-Spectrum Antibiotic Therapy. Infect. Immun. 80(10):3371-80

Mastromarino P, Capobianco D, Campagna G, Laforgia N, Drimaco P, et al. 2014. Correlation between lactoferrin and beneficial microbiota in breast milk and infant's feces. BioMetals. 27(5):1077-86

McGuire MK, Meehan CL, McGuire MA, Williams JE, Foster J, et al. 2017. What's normal? Oligosaccharide concentrations and profiles in milk produced by healthy women vary geographically. Am. J. Clin. Nutr. 105(5):1086-1100

Milani C, Mancabelli L, Lugli GA, Duranti S, Turroni F, et al. 2015. Exploring Vertical Transmission of Bifidobacteria from Mother to Child. Appl. Environ. Microbiol. 81(20):7078-87

Mira A, Rodriguez J. 2016. The Origin of Human Milk Bacteria. In Prebiotics and Probiotics in Human Milk, eds. M McGuire, MA McGuire, L Bode. Academic Press

Mitoulas L.R. LR, Kent JC, Cox DB, Owens RA, Sherriff JL, Hartmann PE. 2002. Variation in fat, lactose and protein in human milk over $24 \mathrm{~h}$ and throughout the first year of lactation. Br. J. Nutr. 88(1):29-37

Moles L, Gómez M, Heilig H, Bustos G, Fuentes S, et al. 2013. Bacterial Diversity in Meconium of Preterm Neonates and Evolution of Their Fecal Microbiota during the First Month of Life. PLoS One. 8(6):e66986

Moossavi S, Sepehri S, Robertson B, Bode L, Goruk S, et al. 2019. Composition and Variation of the Human Milk Microbiota Are Influenced by Maternal and Early-Life Factors. Cell Host Microbe. 25(2):324-335.e4

Moré MI, Swidsinski A. 2015. Saccharomyces boulardii CNCM I-745 supports regeneration of the intestinal microbiota after diarrheic dysbiosis - a review. Clin. Exp. Gastroenterol. 8:237 
Morgan XC, Tickle TL, Sokol H, Gevers D, Devaney KL, et al. 2012. Dysfunction of the intestinal microbiome in inflammatory bowel disease and treatment. Genome Biol. 13(9):R79

Morrow AL, Ruiz-Palacios GM, Altaye M, Jiang X, Lourdes Guerrero M, et al. 2004. Human milk oligosaccharides are associated with protection against diarrhea in breast-fed infants. J. Pediatr. 145(3):297303

Munblit D, Peroni D, Boix-Amorós A, Hsu P, Land B, et al. 2017. Human Milk and Allergic Diseases: An Unsolved Puzzle. Nutrients. 9(8):894

Nash AK, Auchtung TA, Wong MC, Smith DP, Gesell JR, et al. 2017. The gut mycobiome of the Human Microbiome Project healthy cohort. Microbiome. 5(1):153

Newburg DS, Walker WA. 2007. Protection of the Neonate by the Innate Immune System of Developing Gut and of Human Milk. Pediatr. Res. 61(1):2-8

Newburg DS, Woo JG, Morrow AL. 2010. Characteristics and Potential Functions of Human Milk Adiponectin. J. Pediatr. 156(2):S41-46

Nguyen DA, Neville MC. 1998. Tight junction regulation in the mammary gland. J. Mammary Gland Biol. Neoplasia. 3(3):233-46

Nyvad B, Crielaard W, Mira A, Takahashi N, Beighton D. 2013. Dental Caries from a Molecular Microbiological Perspective. Caries Res. 47(2):89-102

Odom EC, Li R, Scanlon KS, Perrine CG, Grummer-Strawn L. 2013. Reasons for Earlier Than Desired Cessation of Breastfeeding. Pediatrics. 131(3):e726-32

Oever J ten, Netea MG. 2014. The bacteriome-mycobiome interaction and antifungal host defense. Eur. J. Immunol. 44(11):3182-91

Okada H, Kuhn C, Feillet H, Bach J-F. 2010. The "hygiene hypothesis" for autoimmune and allergic diseases: an update. Clin. Exp. Immunol. 160(1):1-9

Olechnowicz J, Jaśkowski JM. 2012. Somatic Cells Count in Cow's Bulk Tank Milk. J. Vet. Med. Sci. 74(6):68186

Olivares M, Albrecht S, De Palma G, Ferrer MD, Castillejo G, et al. 2015. Human milk composition differs in healthy mothers and mothers with celiac disease. Eur. J. Nutr. 54(1):119-28

Olivares M, Diaz-Ropero MP, Martin R, Rodriguez JM, Xaus J. 2006. Antimicrobial potential of four Lactobacillus strains isolated from breast milk. J. Appl. Microbiol. 101(1):72-79

Osterman KL, Rahm V-A. 2000. Lactation Mastitis: Bacterial Cultivation of Breast Milk, Symptoms, Treatment, and Outcome. J. Hum. Lact. 16(4):297-302

Otto M. 2014. Staphylococcus epidermidis Pathogenesis. In Methods in Molecular Biology (Clifton, N.J.), Vol. 1106, pp. 17-31

Palmer DJ, Gold MS, Makrides M. 2008. Effect of maternal egg consumption on breast milk ovalbumin concentration. Clin. Exp. Allergy. 38(7):1186-91

Parolin C, Marangoni A, Laghi L, Foschi C, Nahui Palomino RA, et al. 2015. Isolation of Vaginal Lactobacilli and Characterization of Anti-Candida Activity. PLoS One. 10(6):e0131220

Patel SH, Vaidya YH, Patel RJ, Pandit RJ, Joshi CG, Kunjadiya AP. 2017. Culture independent assessment of human milk microbial community in lactational mastitis. Sci. Rep. 7(1):7804

Paviour S, Musaad S, Roberts S, Taylor G, Taylor S, et al. 2002. Corynebacterium Species Isolated from Patients 
with Mastitis. Clin. Infect. Dis. 35(11):1434-40

Peleg AY, Hogan DA, Mylonakis E. 2010. Medically important bacterial-fungal interactions. Nat. Rev. Microbiol. 8(5):340-49

Pérez-Cano FJ, Dong H, Yaqoob P. 2010. In vitro immunomodulatory activity of Lactobacillus fermentum CECT5716 and Lactobacillus salivarius CECT5713: two probiotic strains isolated from human breast milk. Immunobiology. 215(12):996-1004

Perez PF, Dore J, Leclerc M, Levenez F, Benyacoub J, et al. 2007. Bacterial Imprinting of the Neonatal Immune System: Lessons From Maternal Cells? Pediatrics. 119(3):e724-32

Petherick A. 2010. Development: Mother's milk: A rich opportunity. Nature. 468(7327):S5-7

Petrova MI, Reid G, Vaneechoutte M, Lebeer S. 2017. Lactobacillus iners : Friend or Foe? Trends Microbiol. 25(3):182-91

Plaza-Zamora J, Sabater-Molina M, Rodríguez-Palmero M, Rivero M, Bosch V, et al. 2013. Polyamines in human breast milk for preterm and term infants. Br. J. Nutr. 110(03):524-28

Querol A, Barrio E, Huerta T, Ramón D. 1992. Molecular monitoring of wine fermentations conducted by active dry yeast strains. Appl. Environ. Microbiol. 58(9):2948-53

R Development Core Team. 2011. R: A Language and Environment for Statistical Computing.

Rampersaud R, Planet PJ, Randis TM, Kulkarni R, Aguilar JL, et al. 2011. Inerolysin, a CholesterolDependent Cytolysin Produced by Lactobacillus iners. J. Bacteriol. 193(5):1034-41

Ramsay DT, Kent JC, Owens RA, Hartmann PE. 2004. Ultrasound imaging of milk ejection in the breast of lactating women. Pediatrics. 113(2):361-67

Riskin A, Almog M, Peri R, Halasz K, Srugo I, Kessel A. 2012. Changes in immunomodulatory constituents of human milk in response to active infection in the nursing infant. Pediatr. Res. 71(2):220-25

Rodriguez JM. 2014. The Origin of Human Milk Bacteria: Is There a Bacterial Entero-Mammary Pathway during Late Pregnancy and Lactation? Adv. Nutr. An Int. Rev. J. 5(6):779-84

Rognes T, Flouri T, Nichols B, Quince C, Mahé F. 2016. VSEARCH: a versatile open source tool for metagenomics. PeerJ. 4:e2584

Ronquist F, Teslenko M, van der Mark P, Ayres DL, Darling A, et al. 2012. MrBayes 3.2: Efficient Bayesian Phylogenetic Inference and Model Choice Across a Large Model Space. Syst. Biol. 61(3):539-42

Rosenbauer J, Herzig P, Giani G. 2008. Early infant feeding and risk of type 1 diabetes mellitus - a nationwide population-based case-control study in pre-school children. Diabetes. Metab. Res. Rev. 24(3):21122

Ruiz L, Bacigalupe R, García-Carral C, Boix-Amoros A, Argüello H, et al. 2019. Microbiota of human precolostrum and its potential role as a source of bacteria to the infant mouth. Sci. Rep. 9(1):8435

Russell C, Lay KM. 1973. Natural history of Candida species and yeasts in the oral cavities of infants. Arch. Oral Biol. 18(8):957-62

Sakwinska O, Moine D, Delley M, Combremont S, Rezzonico E, et al. 2016. Microbiota in Breast Milk of Chinese Lactating Mothers. PLoS One. 11(8):e0160856

Salonen J., Richardson M., Gallacher K, Issakainen J, Helenius H, et al. 2000. Fungal colonization of haematological patients receiving cytotoxic chemotherapy: emergence of azole-resistant Saccharomyces cerevisiae. J. Hosp. Infect. 45(4):293-301 
Salter SJ, Cox MJ, Turek EM, Calus ST, Cookson WO, et al. 2014. Reagent and laboratory contamination can critically impact sequence-based microbiome analyses. BMC Biol. 12(1):87

Sam QH, Chang MW, Chai LYA. 2017. The Fungal Mycobiome and Its Interaction with Gut Bacteria in the Host. Int. J. Mol. Sci. 18(2):

Santos SR, Ochman H. 2004. Identification and phylogenetic sorting of bacterial lineages with universally conserved genes and proteins. Environ. Microbiol. 6(7):754-59

Savino F, Benetti S, Liguori SA, Sorrenti M, Cordero Di Montezemolo L. 2013. Advances on human milk hormones and protection against obesity. Cell. Mol. Biol. (Noisy-le-grand). 59(1):89-98

Savino F, Liguori SA. 2008. Update on breast milk hormones: Leptin, ghrelin and adiponectin. Clin. Nutr. 27(1):42-47

Scariati PD, Grummer-Strawn LM, Fein SB. 1997. A longitudinal analysis of infant morbidity and the extent of breastfeeding in the United States. Pediatrics. 99(6):E5

Schei K, Avershina E, Øien T, Rudi K, Follestad T, et al. 2017. Early gut mycobiota and mother-offspring transfer. Microbiome. 5(1):107

Scheres N, Krom BP. 2016. Staphylococcus-Candida Interaction Models: Antibiotic Resistance Testing and Host Interactions. In Methods in Molecular Biology (Clifton, N.J.), Vol. 1356, pp. 153-61

Schippa S, Iebba V, Barbato M, Di Nardo G, Totino V, et al. 2010. A distinctive "microbial signature" in celiac pediatric patients. BMC Microbiol. 10(1):175

Schirmer M, Ijaz UZ, D’Amore R, Hall N, Sloan WT, Quince C. 2015. Insight into biases and sequencing errors for amplicon sequencing with the Illumina MiSeq platform. Nucleic Acids Res. 43(6):e37

Schmieder R, Edwards R. 2011. Quality control and preprocessing of metagenomic datasets. Bioinformatics. 27(6):863-64

Schorey JS, Cheng Y, Singh PP, Smith VL. 2015. Exosomes and other extracellular vesicles in host-pathogen interactions. EMBO Rep. 16(1):24-43

Schrezenmeir J, Korhonen H, Williams C, Gill HS, Shah N. 2000. Foreword. Br. J. Nutr. 84(S1):1-1

Schubert K, Groenewald JZ, Braun U, Dijksterhuis J, Starink M, et al. 2007. Biodiversity in the Cladosporium herbarum complex (Davidiellaceae, Capnodiales), with standardisation of methods for Cladosporium taxonomy and diagnostics. Stud. Mycol. 58:105-56

Schulze J, Sonnenborn U. 2009. Yeasts in the gut: from commensals to infectious agents. Dtsch. Arztebl. Int. 106(51-52):837-42

Seddik HA, Ceugniez A, Bendali F, Cudennec B, Drider D. 2016. Yeasts isolated from Algerian infants's feces revealed a burden of Candida albicans species, non-albicans Candida species and Saccharomyces cerevisiae. Arch. Microbiol. 198(1):71-81

Segata N, Izard J, Waldron L, Gevers D, Miropolsky L, et al. 2011. Metagenomic biomarker discovery and explanation. Genome Biol. 12(6):R60

Sela DA, Mills DA. 2010. Nursing our microbiota: molecular linkages between bifidobacteria and milk oligosaccharides. Trends Microbiol. 18(7):298-307

Shannon P, Markiel A, Ozier O, Baliga NS, Wang JT, et al. 2003. Cytoscape: A Software Environment for Integrated Models of Biomolecular Interaction Networks. Genome Res. 13(11):2498-2504

Shi Y, Chen L, Tong J, Xu C. 2009. Preliminary characterization of vaginal microbiota in healthy Chinese 
women using cultivation-independent methods. J. Obstet. Gynaecol. Res. 35(3):525-32

Shin CE, Falcone RA, Stuart L, Erwin CR, Warner BW. 2000. Diminished epidermal growth factor levels in infants with necrotizing enterocolitis. J. Pediatr. Surg. 35(2):173-76; discussion 177

Shively CA, Register TC, Appt SE, Clarkson TB, Uberseder B, et al. 2018. Consumption of Mediterranean versus Western Diet Leads to Distinct Mammary Gland Microbiome Populations. Cell Rep. 25(1):47-56.e3

Shu M, Wang Y, Yu J, Kuo S, Coda A, et al. 2013. Fermentation of Propionibacterium acnes, a Commensal Bacterium in the Human Skin Microbiome, as Skin Probiotics against Methicillin-Resistant Staphylococcus aureus. PLoS One. 8(2):e55380

Sim K, Cox MJ, Wopereis H, Martin R, Knol J, et al. 2012. Improved Detection of Bifidobacteria with Optimised 16S rRNA-Gene Based Pyrosequencing. PLoS One. 7(3):e32543

Simón-Soro A, Guillen-Navarro M, Mira A. 2014. Metatranscriptomics reveals overall active bacterial composition in caries lesions. J. Oral Microbiol. 6:25443

Simón-Soro A, Mira A. 2015. Solving the etiology of dental caries. Trends Microbiol. 23(2):76-82

Simón-Soro Á, Belda-Ferre P, Cabrera-Rubio R, Alcaraz LD, Mira A. 2013. A Tissue-Dependent Hypothesis of Dental Caries. Caries Res. 47(6):591-600

Simón-Soro Á, D’Auria G, Collado MC, Džunková M, Culshaw S, Mira A. 2015. Revealing microbial recognition by specific antibodies. BMC Microbiol. 15(1):132

Singhal A, Cole TJ, Lucas A. 2001. Early nutrition in preterm infants and later blood pressure: two cohorts after randomised trials. Lancet (London, England). 357(9254):413-19

Sipos R, Székely AJ, Palatinszky M, Révesz S, Márialigeti K, Nikolausz M. 2007. Effect of primer mismatch, annealing temperature and PCR cycle number on $16 \mathrm{~S}$ rRNA gene-targetting bacterial community analysis. FEMS Microbiol. Ecol. 60(2):341-50

Smilowitz J, Lebrilla C, Mills D, German J, Freeman S. 2014. Breast milk oligosaccharides: structure-function relationships in the neonate. Annu Rev Nutr. 34:143-69

Smith PM, Howitt MR, Panikov N, Michaud M, Gallini CA, et al. 2013. The Microbial Metabolites, ShortChain Fatty Acids, Regulate Colonic Treg Cell Homeostasis. Science (80-. ). 341(6145):569-73

Sokol H, Leducq V, Aschard H, Pham H-P, Jegou S, et al. 2016. Fungal microbiota dysbiosis in IBD. Gut. gutjnl-2015-310746

Solís G, de los Reyes-Gavilan CG, Fernández N, Margolles A, Gueimonde M. 2010. Establishment and development of lactic acid bacteria and bifidobacteria microbiota in breast-milk and the infant gut. Anaerobe. 16(3):307-10

Spanamberg A, Fraga CF, Ferreiro L, Scherer Aguinsky M, Cavallini Sanches EM, et al. 2014. Yeasts in the Raw Ewe's Milk. Acta Sci. Vet. 42:1236

Stamatakis A. 2014. RAxML version 8: a tool for phylogenetic analysis and post-analysis of large phylogenies. Bioinformatics. 30(9):1312-13

Stecksén-Blicks C, Granström E, Silfverdal SA, West CE. 2015. Prevalence of oral Candida in the first year of life. Mycoses. 58(9):550-56

Stöver BC, Müller KF. 2010. TreeGraph 2: Combining and visualizing evidence from different phylogenetic analyses. BMC Bioinforma. 2010 111. 11(1):7

Strati F, Di Paola M, Stefanini I, Albanese D, Rizzetto L, et al. 2016. Age and Gender Affect the Composition 
of Fungal Population of the Human Gastrointestinal Tract. Front. Microbiol. 7:1227

Stuebe A. 2009. The risks of not breastfeeding for mothers and infants. Rev. Obstet. Gynecol. 2(4):222-31

Su C, Lei L, Duan Y, Zhang K-Q, Yang J. 2012. Culture-independent methods for studying environmental microorganisms: methods, application, and perspective. Appl. Microbiol. Biotechnol. 93(3):993-1003

Suhr MJ, Banjara N, Hallen-Adams HE. 2016. Sequence-based methods for detecting and evaluating the human gut mycobiome. Lett. Appl. Microbiol. 62(3):209-15

Sullivan PB, Lewindon PJ, Cheng C, Lenehan PF, Bo-Sheng K, et al. 2007. Intestinal mucosa remodeling by recombinant human epidermal growth factor1-48 in neonates with severe necrotizing enterocolitis. J. Pediatr. Surg. 42(3):462-69

Sundekilde U, Downey E, O'Mahony J, O'Shea C-A, Ryan C, et al. 2016. The Effect of Gestational and Lactational Age on the Human Milk Metabolome. Nutrients. 8(5):304

Szajewska H, Canani RB, Guarino A, Hojsak I, Indrio F, et al. 2016. Probiotics for the Prevention of Antibiotic-Associated Diarrhea in Children. J. Pediatr. Gastroenterol. Nutr. 62(3):495-506

Tamburini S, Shen N, Wu HC, Clemente JC. 2016. The microbiome in early life: implications for health outcomes. Nat. Med. 22(7):713-22

Telemo E, Hanson LA. 1996. Antibodies in milk. J. Mammary Gland Biol. Neoplasia. 1(3):243-49

Ten Oever J, Netea MG. 2014. The bacteriome-mycobiome interaction and antifungal host defense. Netea Eur. J. Immunol. 44:3182-91

Tena D, Fernández C, López-Garrido B, Pérez-Balsalobre M, Losa C, et al. 2016. Lactational mastitis caused by Streptococcus lactarius. Diagn. Microbiol. Infect. Dis. 85(4):490-92

Tettamanti L, Lauritano D, Nardone M, Gargari M, Silvestre-Rangil J, et al. 2017. Pregnancy and periodontal disease: does exist a two-way relationship? Oral Implantol. (Rome). 10(2):112-18

Thomsen AC, Hansen KB, Møller BR. 1983. Leukocyte counts and microbiologic cultivation in the diagnosis of puerperal mastitis. Am. J. Obstet. Gynecol. 146(8):938-41

Thormar H, Isaacs CE, Brown HR, Barshatzky MR, Pessolano T. 1987. Inactivation of enveloped viruses and killing of cells by fatty acids and monoglycerides. Antimicrob. Agents Chemother. 31(1):27-31

Toju H, Tanabe AS, Yamamoto S, Sato H. 2012. High-Coverage ITS Primers for the DNA-Based Identification of Ascomycetes and Basidiomycetes in Environmental Samples

Toscano M, De Grandi R, Grossi E, Drago L. 2017a. Role of the Human Breast Milk-Associated Microbiota on the Newborns' Immune System: A Mini Review. Front. Microbiol. 8:2100

Toscano M, De Grandi R, Peroni DG, Grossi E, Facchin V, et al. 2017b. Impact of delivery mode on the colostrum microbiota composition. BMC Microbiol. 17(1):205

Tourneur E, Chassin C. 2013. Neonatal immune adaptation of the gut and its role during infections. Clin. Dev. Immunol. 2013:270301

Trama JP, Mordechai E, Adelson ME. 2005. Detection and identification of Candida species associated with Candida vaginitis by real-time PCR and pyrosequencing. Mol. Cell. Probes. 19(2):145-52

Ubeda C, Pamer EG. 2012. Antibiotics, microbiota, and immune defense. Trends Immunol. 33(9):459-66

Underhill DM, Iliev ID. 2014. The mycobiota: interactions between commensal fungi and the host immune system. Nat. Rev. Immunol. 14(6):405-16 
Urbaniak C, Angelini M, Gloor GB, Reid G. 2016a. Human milk microbiota profiles in relation to birthing method, gestation and infant gender. Microbiome. 4(1):1

Urbaniak C, Cummins J, Brackstone M, Macklaim JM, Gloor GB, et al. 2014. Microbiota of human breast tissue. Appl. Environ. Microbiol. 80(10):3007-14

Urbaniak C, Gloor GB, Brackstone M, Scott L, Tangney M, Reid G. 2016b. The Microbiota of Breast Tissue and Its Association with Breast Cancer. Appl. Environ. Microbiol. 82(16):5039-48

Urwin HJ, Miles EA, Noakes PS, Kremmyda L-S, Vlachava M, et al. 2012. Salmon Consumption during Pregnancy Alters Fatty Acid Composition and Secretory IgA Concentration in Human Breast Milk. J. Nutr. 142(8):1603-10

Valentine CJ, Wagner CL. 2013. Nutritional Management of the Breastfeeding Dyad. Pediatr. Clin. North Am. 60(1):261-74

Van de Perre P. 2003. Transfer of antibody via mother's milk. Vaccine. 21(24):3374-76

van der Strate BW., Beljaars L, Molema G, Harmsen M., Meijer DK. 2001. Antiviral activities of lactoferrin. Antiviral Res. 52(3):225-39

van Herwijnen MJC, Zonneveld MI, Goerdayal S, Nolte - 't Hoen ENM, Garssen J, et al. 2016. Comprehensive Proteomic Analysis of Human Milk-derived Extracellular Vesicles Unveils a Novel Functional Proteome Distinct from Other Milk Components. Mol. Cell. Proteomics. 15(11):3412-23

Vázquez-Fresno R, Llorach R, Marinic J, Tulipani S, Garcia-Aloy M, et al. 2014. Urinary metabolomic fingerprinting after consumption of a probiotic strain in women with mastitis. Pharmacol. Res. 87:160-65

Vazquez-Torres A, Jones-Carson J, Bäumler AJ, Falkow S, Valdivia R, et al. 1999. Extraintestinal dissemination of Salmonella by CD18-expressing phagocytes. Nature. 401(6755):804-8

Venema K. 2012. Intestinal fermentation of lactose and prebiotic lactose derivatives, including human milk oligosaccharides. Int. Dairy J. 22(2):123-40

Victora CG, Bahl R, Barros AJD, França GVA, Horton S, et al. 2016a. Breastfeeding in the 21st century: epidemiology, mechanisms, and lifelong effect. Lancet (London, England). 387(10017):475-90

Victora CG, Bahl R, Barros AJD, França GVA, Horton S, et al. 2016b. Breastfeeding in the 21st century: epidemiology, mechanisms, and lifelong effect. Lancet (London, England). 387(10017):475-90

Vidal K, Labéta MO, Schiffrin EJ, Donnet-Hughes A. 2001. Soluble CD14 in human breast milk and its role in innate immune responses. Acta Odontol. Scand. 59(5):330-34

Vijayakumar R, Muthukumar C, Kumar T, Saravanamuthu R. 2006. Characterization of Malassezia Furfur and its control by using plant extracts. Indian J. Dermatol. 51(2):145

Vilgalys R, Hester M. 1990. Rapid genetic identification and mapping of enzymatically amplified ribosomal DNA from several Cryptococcus species. J. Bacteriol. 172(8):4238-46

Walker A. 2010. Breast Milk as the Gold Standard for Protective Nutrients. J. Pediatr. 156(2):S3-7

Walker WA, Iyengar RS. 2015. Breast milk, microbiota and intestinal immune homeostasis. Pediatr. Res. 77(12):220-28

Wang Q, Garrity GM, Tiedje JM, Cole JR. 2007. Naive Bayesian Classifier for Rapid Assignment of rRNA Sequences into the New Bacterial Taxonomy. Appl. Environ. Microbiol. 73(16):5261-67

Wang X, Thompson CD, Weidenmaier C, Lee JC. 2018. Release of Staphylococcus aureus extracellular vesicles and their application as a vaccine platform. Nat. Commun. 9(1):1379 
Ward TL, Dominguez-Bello MG, Heisel T, Al-Ghalith G, Knights D, Gale CA. 2018. Development of the Human Mycobiome over the First Month of Life and across Body Sites. mSystems. 3(3):e00140-17

Ward TL, Hosid S, Ioshikhes I, Altosaar I. 2013. Human milk metagenome: a functional capacity analysis. BMC Microbiol. 13:1

Ward TL, Knights D, Gale CA. 2017. Infant fungal communities: current knowledge and research opportunities. BMC Med. 15(1):30

Warnes GR, Bolker B, Bonebakker L, Gentleman R, Liaw WHA, et al. 2015. gplots: Various R Programming Tools for Plotting Data.

Weber JA, Baxter DH, Zhang S, Huang DY, Huang KH, et al. 2010. The microRNA spectrum in 12 body fluids. Clin. Chem. 56(11):1733-41

Weinberg GA. 1994. Iron chelators as therapeutic agents against Pneumocystis carinii. Antimicrob. Agents Chemother. 38(5):997-1003

West PA, Hewitt JH, Murphy OM. 1979. The Influence of Methods of Collection and Storage on the Bacteriology of Human Milk. J. Appl. Bacteriol. 46(2):269-77

White TJ, Bruns T, Lee S TJ. 1990. Amplification and direct sequencing of fungal ribosomal RNA genes for phylogenetics. In PCR Protocols a Guide to Methods and Applications, pp. 315-322. Academic Press, San Diego.

Willems HM, Kos K, Jabra-Rizk MA, Krom BP. 2016. Candida albicans in oral biofilms could prevent caries. Pathog. Dis. 74(5):ftw039

Wirth F, Goldani LZ. 2012. Epidemiology of Rhodotorula: An Emerging Pathogen. Interdiscip. Perspect. Infect. Dis. 1-7

Wong SCY, Poon RWS, Chen JHK, Tse H, Lo JYC, et al. 2017. Corynebacterium kroppenstedtii Is an Emerging Cause of Mastitis Especially in Patients With Psychiatric Illness on Antipsychotic Medication. Open Forum Infect. Dis. 4(2):ofx096

World Health Organization. 2011. Mastitis: causes and management. WHO

World Health Organization. 2015. WHO recommendation on intrapartum antibiotic administration to women with group B Streptococcus (GBS) colonization for prevention of early neonatal GBS infection. WHO Reprod. Heal. Libr.

World Health Organization. 2017. Guideline: protecting, promoting and supporting breastfeeding in facilities providing maternity and newborn services. Licence: CC BY-NC-SA 3.0 IGO. Geneva

World Health Organization, UNICEF. 2003. Global Strategy for Infant and Young Child Feeding. Geneva: WHO

Wu M, Chen S-W, Jiang S-Y. 2015. Relationship between Gingival Inflammation and Pregnancy. Mediators Inflamm. 2015:

Wyatt RG, Mata LJ. 1969. Bacteria in colostrum and milk of Guatemalan Indian women. J. Trop. Pediatr. 15(4):159-62

Xu H, Sobue T, Bertolini M, Thompson A, Dongari-Bagtzoglou A. 2016. Streptococcus oralis and Candida albicans Synergistically Activate $\mu$-Calpain to Degrade E-cadherin From Oral Epithelial Junctions. J. Infect. Dis. 214(6):925-34

Xuan C, Shamonki JM, Chung A, Dinome ML, Chung M, et al. 2014. Microbial dysbiosis is associated with human breast cancer. PLoS One. 9(1):e83744

Yarza P, Richter M, Peplies J, Euzeby J, Amann R, et al. 2008. The All-Species Living Tree project: A $16 \mathrm{~S}$ 
rRNA-based phylogenetic tree of all sequenced type strains. Syst. Appl. Microbiol. 31(4):241-50

Yatsunenko T, Rey FE, Manary MJ, Trehan I, Dominguez-Bello MG, et al. 2012. Human gut microbiome viewed across age and geography. Nature. 486(7402):222-27

Yolken RH, Peterson JA, Vonderfecht SL, Fouts ET, Midthun K, Newburg DS. 1992. Human milk mucin inhibits rotavirus replication and prevents experimental gastroenteritis. J. Clin. Invest. 90(5):1984-91

Yoshioka H, Iseki K, Fujita K. 1983. Development and differences of intestinal flora in the neonatal period in breast-fed and bottle-fed infants. Pediatrics. 72(3):317-21

Yost S, Duran-Pinedo AE, Teles R, Krishnan K, Frias-Lopez J. 2015. Functional signatures of oral dysbiosis during periodontitis progression revealed by microbial metatranscriptome analysis. Genome Med. 7(1):27

Zakrzewski M, Proietti C, Ellis JJ, Hasan S, Brion M-J, et al. 2016. Calypso: a user-friendly web-server for mining and visualizing microbiome-environment interactions. Bioinformatics. 33(5):btw725

Zanello G, Meurens F, Berri M, Salmon H. 2009. Saccharomyces boulardii effects on gastrointestinal diseases. Curr. Issues Mol. Biol. 11(33):47-58

Zhou X. 2004. Characterization of vaginal microbial communities in adult healthy women using cultivationindependent methods. Microbiology. 150(8):2565-73

Zhu H, Bussey H. 1989. The K1 Toxin of Saccharomyces cerevisiae Kills Spheroplasts of Many Yeast Species. Appl. Environ. Microbiol. 55(8):2105-7

Zonneveld MI, Brisson AR, van Herwijnen MJC, Tan S, van de Lest CHA, et al. 2014. Recovery of extracellular vesicles from human breast milk is influenced by sample collection and vesicle isolation procedures. J. Extracell. Vesicles. 3(1):24215 
Annexes 


\section{ANNEX A - Standardised Protocol for the Extraction and Isolation of Bacterial and Fungal DNA and RNA from Human Milk.}

This protocol has been developed with the MasterPure Complete DNA \& RNA Purification Kit (Epicentre, Madison WI, USA).

Bacterial and fungal DNA extraction

1) Thaw $1.5-5 \mathrm{ml}$ of human milk. Centrifuge at 13,000g for 10 minutes, discarding fat and whey from pellets.

2) Add lysozyme $(20 \mathrm{mg} / \mathrm{ml}$; Thermomixer comfort, Eppendorf, Hamburg, Germany), and mutanolysin (4000 units/mg protein; Sigma-Aldrich, Madrid, Spain) for bacterial disruption, and add zymolyase $(0.25 \mathrm{mg} / \mathrm{ml}$; MP Biomedicals, Santa Ana, CA, USA) to the mix for fungal disruption.

3) Incubate $1 \mathrm{~h}$ at $37^{\circ} \mathrm{C}$.

4) Add $2 \mu \mathrm{l}$ of proteinase $\mathrm{K}$ to the tubes were, and incubate for 15 minutes at $65^{\circ} \mathrm{C}$. To enhance the disruption of microbial cell walls, add a mix of 150-212 $\mu \mathrm{m}$ and 425-600 $\mu \mathrm{m}$, acid washed glass beads (Sigma-Aldrich, San Luis, MI, USA) to the tubes. Perform one cycle of vigorous mixing in a FastPrep-24 ${ }^{\mathrm{TM}}$ 5G Instrument (MP Biomedicals, Santa Ana, CA, USA) during 1 minute, wait 1 minute and repeat with a second mixing cycle. Fungal extractions can be improved by freezing the samples in dry ice and incubating 10 minutes at $65^{\circ} \mathrm{C}$ between the mixing cycles.

5) Precipitate proteins with $350 \mu \mathrm{l}$ of protein precipitation agent and centrifuge 10 minutes at $13,000 \mathrm{~g}$ at $4^{\circ} \mathrm{C}$, and transfer supernatants to new tubes.

6) Add isopropanol to precipitate nucleic acids, and incubate at $-20^{\circ} \mathrm{C}$ for at least 2 hours.

7) Centrifuge at 13,000g 10 minutes, and wash pellets with $70 \%$ ethanol. Repeat and wash with and $96 \%$ ethanol.

8) Resuspended in $30 \mu \mathrm{l}$ of TE buffer of purified $\mathrm{H}_{2} 0$.

To continue with microbial RNA extraction

9) Remove DNA from the nucleic acid pellets, to keep only RNA. In the present thesis, we have used the DNA-free DNA Removal Kit (Invitrogen, Carlsbad, CA, USA). Add 0.1 volume of the 10X DNase I Buffer and $1 \mu \mathrm{L}$ of rDNase I to the tubes, and incubate at $37^{\circ} \mathrm{C}$ for 30 minutes. Repeat 2 times.

10) Add 0.1 volume of the DNAse Inactivation Reagent and incubate for 2 minutes at RT.

11) Centrifuge at $10,000 \mathrm{~g}$ and $4^{\circ} \mathrm{C}$ for 2 minutes. Transfer supernatants containing clean RNA to new Eppendorf tubes.

*Note: when performing RNA extractions, use only RNase-free solutions during the extraction, as well as RNase-free pipet tips and glassware. Allways keep aseptical conditions to avoid contaminations. 


\section{ANNEX B - Published version of Chapter 1}

CFrontiers in Microbiology 2016

OPEN ACCESS

Edited by:

Clara G. De Los Reyes-Gavilan, Instituto de Productos Lácteos de

Asturias, Consejo Superior de Investigaciones Cientificas, Spain

Reviewed by: David Andrew Mills, University of Califomia, Davis, USA Douwe Van Sinderen.

University College Cork, Ireland

"Correspondence:

Mania C. Collado mcolam@iata.csic.es;

Alex Mira

mira_aleagva.es

Specialty section: This article was submitted to Microbial Physiology and Metabolism. a section of the joumal Frontiers in Microbiology

Received: 29 December 2015 Accepted: 24 March 2016 Published: 20 April 2016

citation:

Boix-Amoros $A$, Collado $M C$ and Mira A (2016) Relationship between Milk Microbiota, Bacterial Load, Macronutrients, and Human Cells during Lactation. Front. Microbiol. 7:492. dol: $10.3389 / \mathrm{fmicb} .2016 .00492$

\section{Relationship between Milk Microbiota, Bacterial Load, Macronutrients, and Human Cells during Lactation}

\author{
Alba Boix-Amorós ${ }^{1,2}$, Maria C. Collado ${ }^{2 *}$ and Alex Mira ${ }^{1 *}$ \\ ' Department of Health and Genomics, Center for Advanced Research in Public Health, FISABIO Foundation, Valencia, \\ Spain, ${ }^{2}$ Department of Biotechnology, Institute of Agrochemistry and Food Technology, Spanish National Research Council, \\ Valencia, Spain
}

Human breast milk is considered the optimal nutrition for infants, providing essential nutrients and a broad range of bioactive compounds, as well as its own microbiota. However, the interaction among those components and the biological role of milk microorganisms is still uncovered. Thus, our aim was to identify the relationships between milk microbiota composition, bacterial load, macronutrients, and human cells during lactation. Bacterial load was estimated in milk samples from a total of 21 healthy mothers through lactation time by bacteria-specific qPCR targeted to the single-copy gene fusA. Milk microbiome composition and diversity was estimated by 16S-pyrosequencing and the structure of these bacteria in the fluid was studied by flow cytometry, GPCR, and microscopy. Fat, protein, lactose, and dry extract of milk as well as the number of somatic cells were also analyzed. We observed that milk bacterial communities were generally complex, and showed individual-specific profiles. Milk microbiota was dominated by Staphylococcus, Pseudomonas, Streptococcus, and Acinetobacter. Staphylococcus aureus was not detected in any of these samples from healthy mothers. There was high variability in composition and number of bacteria per milliliter among mothers and in some cases even within mothers at different time points. The median bacterial load was $10^{6}$ bacterial cells/ml through time, higher than those numbers reported by $16 \mathrm{~S}$ gene PCR and culture methods. Furthermore, milk bacteria were present in a free-living, "planktonic" state, but also in equal proportion associated to human immune cells. There was no correlation between bacterial load and the amount of immune cells in milk, strengthening the idea that milk bacteria are not sensed as an infection by the immune system.

Keywords: human microbiome, breast milk, lactation, qPCR, flow cytometry, somatic cells, 16S rRNA, bacterial load

\section{INTRODUCTION}

Human milk is a complex fluid adapted to satisfy the nutritional requirements of the infant, and also protective compounds which help to create the right microenvironment for gut development and maturation of the immune system (Petherick, 2010; Walker, 2010). More recently, milk has been recognized to host commensal and potential probiotic bacteria, which together with milk's growth 


\section{ANNEX C - Published version of Chapter 2}

(C) Scientific Reports 2017

Received: 10 May 2017

Accepted: 21 September 2017

Published online: 12 October 2017

\section{Multiple Approaches Detect the Presence of Fungi in Human Breastmilk Samples from Healthy Mothers}

Alba Boix-Amorós $\mathbb{C}^{1,2}{ }^{2}$, Cecilia Martinez-Costa ${ }^{3}$, Amparo Querol ${ }^{1}$, Maria Carmen Collado ${ }^{1}$ \& Alex Mira ${ }^{2}$

Human breastmilk contains a variety of bacteria that are transmitted to the infant and have been suggested to contribute to gut microbiota development and immune maturation. However, the characterization of fungal organisms in milk from healthy mothers is currently unknown although their presence has been reported in the infant gut and also in milk from other mammals. Breastmilk samples from healthy lactating mothers $(n=65)$ within 1 month after birth were analyzed. Fungal presence was assessed by different techniques, including microscopy, growth and identification of cultured isolates, fungal load estimation by qPCR, and fungal composition using $28 \mathrm{~S}$ rRNA gene highthroughput sequencing. In addition, milk macronutrients and human somatic cells were quantified by spectrophotometry and cytometry. qPCR data showed that $89 \%$ of samples had detectable levels of fungal DNA, at an estimated median load of $3,5 \times 10^{5} \mathrm{cell} / \mathrm{s} / \mathrm{ml}$, potentially including both viable and non-viable fungi. Using different culture media, 33 strains were isolated and identified, confirming the presence of viable fungal species. Pyrosequencing results showed that the most common genera were Malassezia (44\%), followed by Candida (19\%) and Saccharomyces (12\%). Yeast cells were observed by fluorescence microscopy. Future work should study the origin of these fungi and their potential contribution to infant health.

Microbiome development in the newborn is a stepwise and crucial process, contributing at the physiological level and influencing the development and maturation of the immune system ${ }^{1,2}$. During delivery, the neonate is exposed to maternal microbes, first from the mother's reproductive system, rapidly after from the maternal skin and the environment, and later influenced by diet, including breastfeeding. Breastmilk plays an important role in the microbial supply as it contains a variety of potential beneficial bacteria, as well as a wide source of nutrients and essential protective substances that makes it the optimal nutrition for the infant ${ }^{1,2}$. Those bacteria residing in breastmilk are transmitted to the infant during breastfeeding, getting to the intestine and contributing to the settlement of the gut microbiota and acquired immunity ${ }^{3}$. Although bacteria in human milk have been widely assessed, information about the natural presence of fungal species is generally lacking, and it is limited to a few studies focused on mammary infections describing breast candidiasis ${ }^{4,5}$ and a recent metagenomic study on human breastmilk from mothers suffering from mastitis, which confirmed the presence of fungal sequences, in addition to the dominant bacterial fraction ${ }^{6}$. However, fungal presence in the milk of other mammals has been widely described in several studies ${ }^{7-12}$, which supports the idea that human breastmilk could also contain fungi under normal, healthy conditions.

Furthermore, there is evidence that fungal species (yeast-like mainly) can be found in the infant gut early in life ${ }^{13-17}$. The importance of the fungal component -mycobiome- in the human gut has received increased attention

IInstitute of Agrochemistry and Food Technology, Spanish National Research Council (IATA-CSIC), Department of Biotechnology, Av. Agustin Escardino 7, 46980, Valencia, Spain. ${ }^{2}$ Department of Health and Genomics, Center for Advanced Research in Public Health, FISABIO Foundation, Valencia, Spain. ${ }^{3}$ Department of Paediatrics. University of Valencia, Paediatric Gastroenterology and Nutrition Section, Hospital Clínico Universitario de Valencia (Spain), Blasco Ibáñez Av., 17, 46010, Valencia, Spain. Maria Carmen Collado and Alex Mira contributed equally to this work. Correspondence and requests for materials should be addressed to M.C.C. (email: mcolam @iata.csic.es) or A.M. (email:mira_ale@gva.es) 


\title{
ANNEX D - Published version of Chapter 3
}

(C) Applied and Environmental Microbiology 2019

\section{Mycobiome Profiles in Breast Milk from Healthy Women Depend on Mode of Delivery, Geographic Location, and Interaction with Bacteria}

\author{
Alba Boix-Amorós, a,b - Fernando Puente-Sánchez, ${ }^{\text {c }}$ Elloise du Toit, ${ }^{d}$ Kaisa M. Linderborg, e Yumei Zhang, ${ }^{\mathrm{f}}$ Baoru Yang, \\ Seppo Salminen, ${ }^{9}$ Erika Isolauri, ${ }^{\text {h }}$ Javier Tamames, ${ }^{c}$ Alex Mira, ${ }^{b}$ - Maria Carmen Collado ${ }^{\mathrm{a}, \mathrm{g}}$ \\ 2Department of Biotechnology, Institute of Agrochemistry and Food Technology-National Research Council (IATA-CSIC), Valencia, Spain \\ bDepartment of Health and Genomics, Center for Advanced Research in Public Health, FISABIO Foundation, Valencia, Spain \\ cSystems Biology Program, Centro Nacional de Biotecnologla, Consejo Superior de Investigaciones Cientificas (CSIC), Madrid, Spain \\ dDivision of Medical Microbiology, Department of Pathology, University of Cape Town, Cape Town, South Africa \\ eFood Chemistry and Food Development, Department of Biochemistry, University of Turku, Turku, Finland \\ fDepartment of Nutrition and Food Hygiene, School of Public Health, Peking University, Beijing, China \\ sFunctional Foods Forum, Faculty of Medicine, University of Turku, Turku, Finland \\ hDepartment of Pediatrics, University of Turku and Turku University Hospital, Turku, Finland
}

\begin{abstract}
Recent studies report the presence of fungal species in breast milk of healthy mothers, suggesting a potential role in infant mycobiome development. In the present work, we aimed to determine whether the healthy human breast milk mycobiota is influenced by geographical location and mode of delivery, as well as to investigate its interaction with bacterial profiles in the same samples. A total of 80 mature breast milk samples from 4 different countries were analyzed by Illumina sequencing of the internal transcribed spacer 1 (ITS1) region, joining the $18 \mathrm{~S}$ and $5.8 \mathrm{~S}$ regions of the fungal rRNA region. Basidiomycota and Ascomycota were found to be the dominant phyla, with Malassezia and Davidiella being the most prevalent genera across countries. A core formed by Malassezia, Davidiella, Sistotrema, and Penicillium was shared in the milk samples from the different origins, although specific shifts in mycobiome composition were associated with geographic location and delivery mode. The presence of fungi in the breast milk samples was further confirmed by culture and isolate characterization, and fungal loads were estimated by quantitative PCR (qPCR) targeting the fungal ITS1 region. Cooccurrence network analysis of bacteria and fungi showed complex interactions that were influenced by geographical location, mode of delivery, maternal age, and pregestational body mass index. The presence of a breast milk mycobiome was confirmed in all samples analyzed, regardless of the geographic origin.
\end{abstract}

IMPORTANCE During recent years, human breast milk has been documented as a potential source of bacteria for the newborn. Recently, we have reported the presence of fungi in breast milk from healthy mothers. It is well known that environmental and perinatal factors can affect milk bacteria; however, the impact on milk fungi is still unknown. The current report describes fungal communities (mycobiota) in breast milk samples across different geographic locations and the influence of the mode of delivery. We also provide novel insights on bacterium-fungus interactions, taking into account environmental and perinatal factors. We identified a core of four genera shared across locations, consisting of Malassezia, Davidiella, Sistotrema, and Penicillium, which have been reported to be present in the infant gut. Our data confirm the presence of fungi in breast milk across continents and support the potential role of breast milk in the initial seeding of fungal species in the infant gut.

KEYWORDS fungi, Illumina sequencing, microbiota, mycobiota, breast milk
Citation Boix-Amorós A, Puente-SánchezF, du Toit E, Linderborg KM, Zhang Y, Yang B, Salminen S, Isolauri E, Tamames J, Mira A, Collado MC 2019. Mycobiome profiles in breast milk from healthy women depend on mode of delivery, geographic location, and inde of de interaction with bacteria Appl Environ Microbiol 85.e02994-18. https $/ /$ doi.org/10 $.1128 /$ AEM. 02994-18 Editor Irina S. Druzhinina, Nanjing Agricultural University

Copyright $\odot 2019$ American Society for Microbiology. All Rights Reserved. Address correspondence to Alex Mira, mira_ale@gva.es, or Maria Carmen Collado, mcolam@iata.csices.

Received 13 December 2018 Accepted 13 February 2019 Accepted manuscript posted online March 2019

Published 18 April 2019 


\title{
ANNEX E - Human Milk and Allergic Diseases: An Unsolved Puzzle (Review article)
}

(C) Nutrients 2017

\section{Human Milk and Allergic Diseases: An Unsolved Puzzle}

Daniel Munblit ${ }^{1,2,3, *,+}$ (D), Diego G. Peroni ${ }^{3,4,+}$, Alba Boix-Amorós ${ }^{3,5,+}$, Peter S. Hsu ${ }^{3,6,+}$, Belinda Van't Land ${ }^{7,8,+}$, Melvin C. L. Gay ${ }^{3,9,+}$ (D), Anastasia Kolotilina ${ }^{2}$ (D), Chrysanthi Skevaki ${ }^{3,10}$, Robert J. Boyle ${ }^{1,3,+}$ (D), Maria Carmen Collado ${ }^{3,5,+}$, Johan Garssen $7,11,+$, Donna T. Geddes ${ }^{3,9,+}$, Ralph Nanan ${ }^{12,+}$, Carolyn Slupsky ${ }^{13,+}$, Ganesa Wegienka ${ }^{3,14,15,+}$, Anita L. Kozyrskyj ${ }^{16,+}$ and John O. Warner $1,3,17,+$

1 Department of Paediatrics, Imperial College London, London W2 1NY, UK; r.boyle@nhs.net (R.J.B.); j.o.warner@imperial.ac.uk (J.O.W.)

2 Faculty of Pediatrics, I.M. Sechenov First Moscow State Medical University, 119991 Moscow, Russia; aikolotilina@yandex.ru

3 The In-FLAME Global Network, an Affiliate of the World Universities Network (WUN), West New York, NJ 07093, USA; diego.peroni@unipi.it (D.G.P.); albaboix90@gmail.com (A.B.-A.); peter.hsu@health.nsw.gov.au (P.S.H.); melvin.gay@uwa.edu.au (M.C.L.G.); Chrysanthi.Skevaki@uk-gm.de (C.S.); mcolam@iata.csic.es (M.C.C.); Donna.Geddes@uwa.edu.au (D.T.G.); gwegien1@hfhs.org (G.W.)

4 Department of Clinical and Experimental Medicine, Section of Paediatrics, University of Pisa, 56126 Pisa, Italy

5 Institute of Agrochemistry and Food Technology, National Research Council (IATA-CSIC), 46980 Valencia, Spain

6 Allergy and Immunology, The Kids Research Institute, The Children's Hospital at Westmead, Sydney, NSW 2145, Australia

7 Nutricia Research, 3584 CT Utrecht, The Netherlands; Belinda.vantland@danone.com (B.V.L.); johan.garssen@danone.com (J.G.)

8 Department of Paediatric Immunology, Wilhelmina Children's Hospital, University Medical Centre Utrecht, 3584 EA Utrecht, The Netherlands

9 School of Molecular Sciences, The University of Western Australia, Perth, WA 6009, Australia

10 Institute of Laboratory Medicine and Pathobiochemistry, Molecular Diagnostics, Philipps University Marburg, University Hospital Giessen and Marburg GmbH Baldingerstr, 35043 Marburg, Germany

11 Utrecht Institute for Pharmaceutical Sciences, Faculty of Science, Utrecht University, 3584 CG Utrecht, The Netherlands

12 Charles Perkins Centre Nepean, University of Sydney, Sydney, NSW 2747, Australia; ralph.nanan@sydney.edu.au

13 Department of Nutrition, University of California, Davis, CA 95616-5270, USA; cslupsky@ucdavis.edu

14 Department of Public Health Sciences, Henry Ford Health System, Detroit, MI 48202, USA

15 Center for Urban Responses to Environmental Stressors, Detroit, MI 48202, USA

16 Department of Pediatrics, University of Alberta, Edmonton, AB T6G 1C9, Canada; kozyrsky@ualberta.ca

17 National Institute for Health Research, Collaboration for Leadership in Applied Health Research and Care for NW London, London SW10 9NH, UK

* Correspondence: daniel.munblit08@imperial.ac.uk; Tel.: +44-07-898-257-151

+ All authors contributed equally to this work.

Received: 3 July 2017; Accepted: 1 August 2017; Published: 17 August 2017

\begin{abstract}
There is conflicting evidence on the protective role of breastfeeding in relation to the development of allergic sensitisation and allergic disease. Studies vary in methodology and definition of outcomes, which lead to considerable heterogeneity. Human milk composition varies both within and between individuals, which may partially explain conflicting data. It is known that human milk composition is very complex and contains variable levels of immune active molecules, oligosaccharides, metabolites, vitamins and other nutrients and microbial content. Existing evidence suggests that modulation of human breast milk composition has potential for preventing allergic
\end{abstract}




\title{
ANNEX F - Gut Microbiota and Mucosal Immunity in the Neonate (Review article)
}

(C) Medical Sciences 2018

\section{Gut Microbiota and Mucosal Immunity in the Neonate}

\author{
Majda Dzidic ${ }^{1,2,+}$, Alba Boix-Amorós ${ }^{1,2,+}$ (D), Marta Selma-Royo ${ }^{1,+}$, Alex Mira ${ }^{2, *}$ and \\ Maria Carmen Collado $1, *$ (D) \\ 1 Department of Biotechnology, Institute of Agrochemistry and Food Technology-Spanish National Research \\ Council (IATA-CSIC), 46980 Valencia, Spain; majda.dzidic@iata.csic.es (M.D.); albaboix@iata.csic.es (A.B.-A.); \\ mselma@iata.csic.es (M.S.-R.) \\ 2 Department of Health and Genomics. Center for Advanced Research in Public Health, FISABIO Foundation, \\ 46020 Valencia, Spain \\ * Correspondence: mira_ale@gva.es (A.M.); mcolam@iata.csic.es (M.C.C.); \\ Tel.: +34-961-925-925 (A.M.); +34-963-900-022 (M.C.C.) \\ + These authors contributed equally in this paper.
}

Received: 8 June 2018; Accepted: 12 July 2018; Published: 17 July 2018

\begin{abstract}
Gut microbiota colonization is a complex, dynamic, and step-wise process that is in constant development during the first years of life. This microbial settlement occurs in parallel with the maturation of the immune system, and alterations during this period, due to environmental and host factors, are considered to be potential determinants of health-outcomes later in life. Given that host-microbe interactions are mediated by the immune system response, it is important to understand the close relationship between immunity and the microbiota during birth, lactation, and early infancy. This work summarizes the evidence to date on early gut microbiota colonization, and how it influences the maturation of the infant immune system and health during the first 1000 days of life. This review will also address the influence of perinatal antibiotic intake and the importance of delivery mode and breastfeeding for an appropriate development of gut immunity.
\end{abstract}

Keywords: gut microbiota; postnatal immune development; gut immunity; breastfeeding; probiotics; antibiotics

\section{Introduction}

Epidemiological studies highlight the relevance of the period from conception to early life in the physiological and structural patterns of infant development, affecting their potential "health programming". The fetus adapts to the intrauterine environment, being able to alter its metabolism in response to external stimuli. The physiological and metabolic adaptations that the fetus undergoes in response to those stimuli could produce permanent changes in the host, which may lead to a higher risk of developing diseases and/or disorders, such as obesity, allergies, diabetes, or cardiovascular diseases, in adult life [1].

The first 1000 days after conception (including the pregnancy period and the first two years of life), which are considered a "window of opportunity", are crucial for the development and health of the future adult, as well as key to the establishment of the intestinal microbiota and immune system maturation. The physiological and immune development of the infant and the establishment of their microbiota occur in parallel throughout this short space of time. This microbiota plays a central role in health, intervening in key host metabolic and immunological functions.

\section{DEFINITIONS}

Microbiota: the microbial community in a specific niche/environment.

Microbiome: the total genomic repertoire of a microbial community (microbiota). 


\title{
ANNEX G - Reviewing the Evidence on Breast Milk Composition and Immunological Outcomes (Review article)
}

(c) Nutrition Reviews 2019

\section{Reviewing the evidence on breast milk composition and immunological outcomes}

Alba Boix-Amorós, ${ }^{*}$ Maria Carmen Collado, ${ }^{*}$ Belinda Van't Land, Anna Calvert, Kirsty Le Doare, Johan Garssen, Heather Hanna, Ekaterina Khaleva, Diego G. Peroni, Donna T. Geddes, Anita L. Kozyrskyj,* John O. Warner, ${ }^{*}$ and Daniel Munblit*

\begin{abstract}
A large number of biologically active components have been found in human milk $(H M)$, and in both human and animal models, studies have provided some evidence suggesting that HM composition can be altered by maternal exposures, subsequently influencing health outcomes for the breastfed child. Evidence varies from the research studies on whether breastfeeding protects the offspring from noncommunicable diseases, including those associated with immunological dysfunction. It has been hypothesized that the conflicting evidence results from HM composition variations, which contain many immune active molecules, oligosaccharides, lactoferrin, and lysozyme in differing concentrations, along with a diverse microbiome. Determining the components that influence infant health outcomes in terms of both short- and long-term sequelae is complicated by a lack of understanding of the environmental factors that modify HM constituents and thereby offspring outcomes. Variations in HM immune and microbial composition (and the differing infantile responses) may in part explain the controversies that are evidenced in studies that aim to evaluate the prevalence of allergy by prolonged and exclusive breastfeeding. HM is a "mixture" of immune active factors, oligosaccharides, and microbes, which all may influence early immunological outcomes. This comprehensive review provides an indepth overview of existing evidence on the studied relationships between maternal exposures, HM composition, vaccine responses, and immunological outcomes.
\end{abstract}

Affiliation: A. Boix-Amorós and M. Carmen Collado are with the Institute of Agrochemistry and Food Technology, National Research Council (IATA-CSIC), Valencia, Spain. A. Boix-Amorós, M. Carmen Collado, E. Khaleva, D.G. Peroni, D.T. Geddes, A.L. Kozyrskyj, J.O. Warner, and D. Munblit are with The In-VIVO Global Network, an affiliate of the World Universities Network (WUN), New York, New York, United States. B. Van't Land and J. Garssen are with the Department of Immunology, Danone Nutricia Research, Utrecht, the Netherlands. B. Van't Land is with Wilhelmina Children's Hospital, University Medical Centre Utrecht, Utrecht, the Netherlands. K. Le Doare and A. Calvert are with the Paediatric Infectious Diseases Research Group, St George's University of London, London, United Kingdom. K. Le Doare, H. Hanna, J.O. Warner, and D. Munblit are with the Imperial College London, London, United Kingdom. K. Le Doare is with Public Health England, Porton Down, United Kingdom, and the MRC Unit, Fajara, Gambia. J. Garssen is with the Utrecht Institute for Pharmaceutical Sciences, Utrecht University, Utrecht, the Netherlands. E. Khaleva is with the University of Southampton, Southampton, UK. D.G. Peroni is with the Department of Clinical and Experimental Medicine, Section of Paediatrics, University of Pisa, Pisa, Italy. D.T. Geddes is with the School of Molecular Sciences, the University of Westem Australia, Perth, Australia. A.L. Kozyrskyj is with the Department of Pediatrics, Department of Obstetrics \& Gynecology, Faculty of Medicine \& Dentistry, School of Public Health, University of Alberta, Alberta, Canada. J.O. Warner is with the National Institute for Health Research, Collaboration for Leadership in Applied Health Research and Care for NW London, London, United Kingdom. D. Munblit is with the Department of Pediatrics, Sechenov University, Moscow, Russia, and the Solov'ev Research and Clinical Center for Neuropsychiatry, Moscow, Russia.

*Authors contributed equally to this work.

Correspondence: D. Munblit, Department of Pediatrics, Sechenov University, 119991 Moscow, Russia. E-mail: danielmunblit08@imperial.ac.uk Key words: antibiotics, breast milk, human milk, immune active molecules, immunological outcomes, microbiome, oligosaccharides, vaccine response. (c) The Author(s) 2019. Published by Oxford University Press on behalf of the International Life Sciences Institute. All rights reserved. For permissions, please e-mail: journals.permissions@oup.com. 
UNIVERSITAT
POLITECNICA
DE VALËNCIA 